\title{
Interplay between tumor angiogenesis and the immune system : towards a new cancer therapy.
}

Citation for published version (APA):

Dirkx, A. E. (2006). Interplay between tumor angiogenesis and the immune system : towards a new cancer therapy. [Doctoral Thesis, Maastricht University]. Universiteit Maastricht. https://doi.org/10.26481/dis.20060323ad

Document status and date:

Published: 01/01/2006

DOI:

10.26481/dis.20060323ad

Document Version:

Publisher's PDF, also known as Version of record

\section{Please check the document version of this publication:}

- A submitted manuscript is the version of the article upon submission and before peer-review. There can be important differences between the submitted version and the official published version of record.

People interested in the research are advised to contact the author for the final version of the publication, or visit the DOI to the publisher's website.

- The final author version and the galley proof are versions of the publication after peer review.

- The final published version features the final layout of the paper including the volume, issue and page numbers.

Link to publication

\footnotetext{
General rights rights.

- You may freely distribute the URL identifying the publication in the public portal. please follow below link for the End User Agreement:

www.umlib.nl/taverne-license

Take down policy

If you believe that this document breaches copyright please contact us at:

repository@maastrichtuniversity.nl

providing details and we will investigate your claim.
}

Copyright and moral rights for the publications made accessible in the public portal are retained by the authors and/or other copyright owners and it is a condition of accessing publications that users recognise and abide by the legal requirements associated with these

- Users may download and print one copy of any publication from the public portal for the purpose of private study or research.

- You may not further distribute the material or use it for any profit-making activity or commercial gain

If the publication is distributed under the terms of Article $25 \mathrm{fa}$ of the Dutch Copyright Act, indicated by the "Taverne" license above, 
INTERPLAY BETWEEN TUMOR ANGIOGENESIS

AND THE IMMUNE SYSTEM towards a new cancer therapy 
Voor ons pap en ons mam

Voor Michel 


\title{
INTERPLAY BETWEEN TUMOR ANGIOGENESIS AND THE IMMUNE SYSTEM towards a new cancer therapy
}

\author{
PROEFSCHRIFT \\ ter verkrijging van de graad van doctor aan de Universiteit Maastricht, \\ op gezag van de Rector Magnificus, Prof. mr. G.P.M.F. Mols \\ wolgens het besluit van het College van Decanen, \\ in het openbaar te verdedigen \\ op donderdag 23 maart 2006 om 14.00 uur
}

door

Anita Elizabeth Maria Dirkx

geboren op 8 februari 1976 te Eindhoven 


\section{Promotores:}

Prof. Dr. J. Wagstaff (South West Wales Cancer Institute, Swansea, United Kingdom) Prof. Dr. A.W. Griffioen

\section{Copromotor:}

Dr. M.G.A. oude Egbrink

\section{Beoordelingscommissie:}

Prof. dr: H.F.P. Hillen (voorzitter)

Dr. W.P.J. Leenders (Universitair Medisch Centrum St Radboud, Nijmegen)

Prof. dr. G. Molema (Rijksuniversiteit Groningen)

Prof. dr. M. Pos:

Prof. dr. D.W. Slaaf

\section{Sponsoring}

"The studies presented in this thesis were supported by grants of the Dutch Cancer Society (grant number UM2001-2529) and the Stichting Vanderes (grant number 42). Printing of this these was financially supported by the Dr.Ir. van der Laar Stichting."

Vormgeving, Layout en illustraties:

D\&L graphics: John Derwall, Eric Lemmens

www.dlgraphics.nl

Druk:

Schrijen-Lippertz-Huntjens

ISBN-10: $90 \cdot 8590 \cdot 010 \cdot 7$

ISBN-13: $978-90-8590-010-8$ 


\section{CONTENTS}

Chapter 1. Interplay between tumor angiogenesis and leukocyte-vessel wall. interactions

Chapter 2. Tumor angiogenesis modulates leukocyte-vessel wall interactions

In vivo by reducing endothelial adhesion molecule expression

Chapter 3. Anti-angiogenesis therapy can overcome endothelial cell anergy and promote leukocyte-endothelium interactions and infiltration in tumors

Chapter 4. HIV-1 Tat increases the adhesion of monocytes

and T-cells to the endothelium in vitro and in vivo:

implications for AlDS-associated vasculopathy

Chapter 5. Monocyte/macrophage infiltration in tumors: modulators of angiogenesis

Chapter 6. General discussion

Chapter 7. Surnmary

Samenvatting

Curriculum Vitae

Dankwoord

List of publications 


\section{Chapter 1}

\section{Interplay between}

tumor angiogenesis and

leukocyte-vessel wall

\section{interactions}


chapter 1 


\section{INTRODUCTION}

The process of angiogenesis is involved in physiological situations such as the femal reproductive cycle, embryonic morphogenesis ${ }^{2}$ and wound healing ${ }^{3,4}$. Its primary function is to reverse tissue ischemia, accumulation of metabolic waste products and to supply tissues with nutrients. Excessive angiogenesis is usually associated with diseases such as diabetic retinopathy ${ }^{5}$, rheumatoid arthritis ${ }^{6}$, cardiovascular disease ${ }^{7,8}$ and cancer ${ }^{4,9}$. Such diseases may benefit from therapeutic inhibition of angiogenesis ${ }^{10}$. It was already in the early 1970 s that Folkman and colleagues launched the idea that tumors -because they are highly vascularized-are most vulnerable at the level of blood supply ${ }^{10}$. Research on angiogenesis inhibition in cancer really expanded in the 1990's after the discovery of the angiostatic compounds TNP-470 (AGM-1470) by Ingber and colleagues" and angiostatin by $O^{\prime}$ Reilly and colleagues ${ }^{12}$. Since then, several potent angiogenesis inhibitors have been discovered, some of which are already being tested in clinical trials. Anti-angiogenesis therapy is now considered to be a promising approach for treatment of cancer and other pro-angiogenic diseases.

Once a tumor is vascularized it is not only accessible for plasma constituents, but also for blood cells. As a result, it can be infiltrated by leukocytes, a phenomenon observed in most solid cancers. The first observation of leukocyte infiltration in tumors was done by Virchow in $1863^{13}$. At that time, it was thought to be the result of a chronic inflammation that was already present before tumor development. Nowadays, however, it is known that the presence of leukocytes is a consequence of a specific immune reaction to the tumor itself, since the immune system is able to recognize various tumor-associated antigens ${ }^{14}$. Although associated with better prognosis, immune responses to a tumor are often weak and not able to completely destroy a tumor ${ }^{14}$, suggesting that tumors have developed mechanisms to escape immune surweillance. One mechanism to escape tumor-directed immunity is inhibition of leukocyte-vessel wall interactions in tumor vessels ${ }^{15-18}$, due to suppressed expression of endothelial adhesion molecules ${ }^{19.22}$ and endothelial cell anergy ${ }^{10}$. As a result, tumors frequently show only limited leukocyte infiltration ${ }^{20}$.

In this thesis, focus will be on the interplay between tumor angiogenesis and the immune system. As an introduction, several aspects of tumor angiogenesis will be discussed in the first part of this chapter, with additional attention for the possible use of angiogenesis inhibition to improve cancer therapy. Subsequently, adhesion moleculles involved in leukocyte-vessel wall interactions are described. In the next section, focus is on the effect of tumor angiogenesis on leukocyte-vessel wall interactions. Understanding behavior of leukocytes in tumor blood vessels may be of major impact for the improvement of immunotherapy strategies to cure cancer. In the last part of this chapter the aim and outline of this thesis are presented.

\section{TUMOR ANGIOGENESIS}

\section{Tumor growth and angiogenesis}

Without the formation of new blood vessels out of pre-existing ones (angiogenesis) the outgrowth of tumors is limited to $1.2 \mathrm{~mm}$ in size because of insufficient supply of oxygen and nutrients, a concept first proposed by Dr J. Folkman in $1971^{23}$. Many tumors will not grow beyond this size and, therefore, stay clinically undetected for years ${ }^{24}$. The process of angiogenesis is regulated by angiogenic and angiostatic factors. When the balance between these factors is in favol of the angiogenic ones, it may lead to the progression of tumors to an angiogenic phenotype, the so-called angiogenic switch ${ }^{25,20}$.

The angiogenic cascade involves activation, migration and proliferation of vascular endothelial 


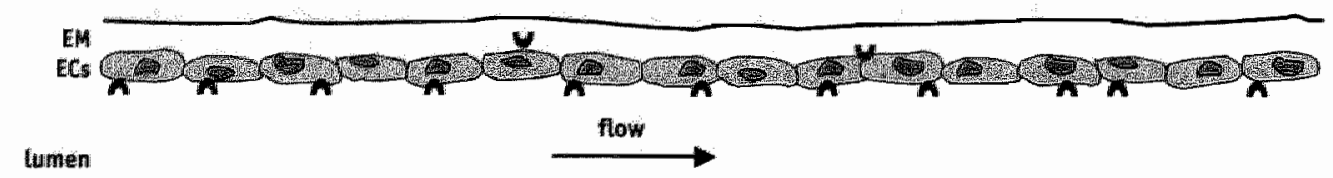

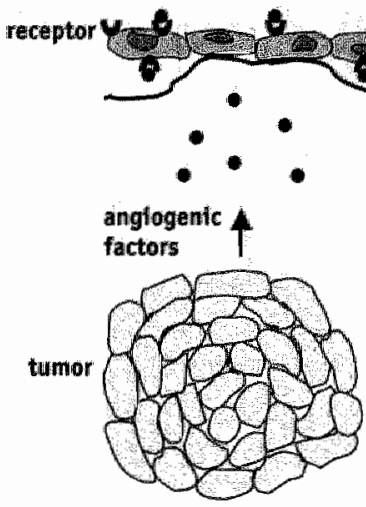

activation
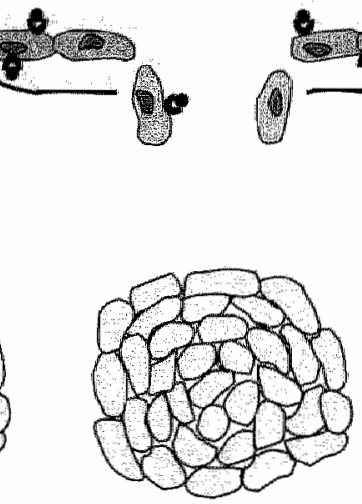

migration
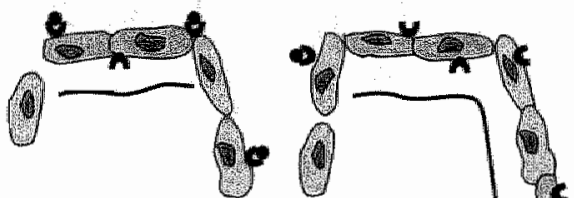

19.
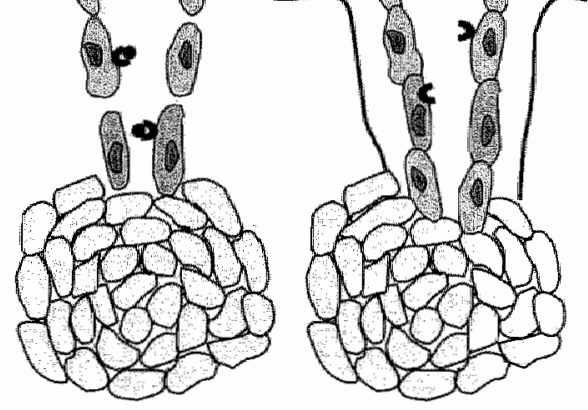

proliferation maturation

\section{Figure 1.1 The angiogenic cascade}

After the angiogenic switch has occurred, at tumor stants to produce several angiogenic factors which bind to receptors present on nearby endothellal cells (ECS). Subsequently, the extracellular matrix (EM) is degraded by matrix metalloproteinases, allowing activated ECs to migrate in the direction of the stimultss. The ECs start to proliferate and form a lumen. Eventually, the newly formed vessel is maturated due to the formation of an extracellular matrix and the presence of pericyies.

cells (ECS) and, eventually, vessel maturation (Figure 1.1). After a tumor has changed from a quiescent to an anglogenic phenotype in response to hypoxic or ischemic conditions, angiogenic factors are being produced which diffuse to nearby blood vessels and bind to counterreceptors on ECs. As a result, these $\mathrm{ECs}$ become activated and start to produce matrix metalloproteinases, which degrade the extracellular matrix. ECs are then able to migrate and proliferate in the direction of the tumor; ultimately, they will form a tube with a lumen. Vessel maturation is completed by recruitment of accessory cells and deposition of extracellular matrix, providing stabilization of the newly formed vessels $, 8,10$. Besides allowing the tumor to grow, angiogenesis also provides a route for metastasing tumor cells to leave the tumor and enter the blood stream ${ }^{27,28}$. On the other hand, the presence of blood vessels in a tumor also enables various immune cells to enter the tumor and perform their particular immune function. These immune cells may also secrete angiogenic and angiostatic factors (see chapter 5$)^{29}$.

\section{Angiogenic factors in tumor formation}

Among the known angiogenic growth factors involved in human cancer, the VEGF family appears to play a dominant role $e^{27,30}$. VEGF, or vascular endothelial cell growth factor, is produced by hypoxic tumor cells and also by macrophages ${ }^{27}$. The VEGF family consists of the prototype member VEGF 
(also referred to as VEGF-A), placenta growth factor (PICF), VECF-B, VEGF-C and VEGF-D, in which the latter two are primarily associated with the formation of lymphatic vessels and Jymphatic metastasis ${ }^{31}$. Alternative exon splicing results in the generation of four principal VEGF-A tsoforms: VEGF ${ }^{21}, V_{E G F}^{165}$, VEGF ${ }^{189}$ and VEGF ${ }^{206}$, having $121,165,189$ and 206 amino acids, respectively. $\mathrm{VEGF}^{165}$, which is the predominant isoform, lacks the residues encoded by exon 6 , while VEGF ${ }^{121}$ lacks those encoded by exons 6 and 7. Less frequent occurring splice variants have been reported as well, including VEGF ${ }^{145}$, VEGF ${ }^{183}$, VEGF ${ }^{162}$ and VEGF ${ }^{165} \mathrm{~b}$ (for further information see review by Ferrara et al.32). From in vitro and in vivo studies it is known that VEGF promotes growth of vascular endothelial cells derived from arteries, veins and lymphatics ${ }^{32,33}$. In addition to a stimulatory effect on every part of the process of angiogenesis, VEGF increases vascular permeability ${ }^{34}$ and prevents upregulation of endothelial adhesion molecules induced by inflammatory cytokines ${ }^{19}$. In vitro, VEGF is known to prevent endothelial cell apoptosis, mediated by the phosphatidylinositol 3' kinase (PI3K)/Akt pathway and by induction of anti-apoptotic proteins in $\mathrm{ECS}^{34}$. In wivo, the prosurvival effects of VEGF are mainly developmentally regulated: VEGF inhibition results in apoptotic changes in the vasculature of neonatal but not adult mice ${ }^{35}$. Moreover, VEGF has been described to be a chemoattractant involved in monocyte recruitment to tumors via activation of VEGFR1 ${ }^{27,36 \cdot 38}$. At present, two VEGF receptors are known: VEGFR1 (or Flt-1) and VEGFR2 (also known as Flk-1), which are expressed by ECs, tumor cells and monocytes/macrophages. VEGFR2 is considered to be the main mediator of the mitogenic, angiogenic and permeability enhancing effects of VEGF, while VEGFR1 does not seem to be directly involved is these processes. However, this receptor has been observed to be involved in the induction of matrix metalloproteinases and in the paracrine release of other endothelial cell derived growth factors ${ }^{34}$. Both VEGF monoclonal antibodies and VEGF inhibitors are potentially interesting clinical tools in cancer:

Another family of angiogenic growth factors are the fibroblast growth factors, or FGFs. The most studied one is basic fibroblast growth factor (bFGF). This factor is secreted by macrophages, mast cells, lymphocytes, fibroblasts and by certain tumor cells ${ }^{39-41}$. bFGF belongs to a large family of homologous polypeptide growth factors and promotes every phase of the angiogenic process, including synthesis of proteinases, EC migration and differentiated capillary tube formation in vitro ${ }^{39}$. bFGF induces angiogenesis through the high-affinity heparin binding receptors FGFR-1 and FGFR$2^{42}$. Increased bFGF expression has been correlated with poor prognosis and bFGF expression by cancer cells shows a direct correlation with increased microvessel density ${ }^{A I}$. bFGF is also able to induce angiogenesis indirectiy by its capability to promote VEGF synthesis. In addition, there is a synergistic interaction between bFGF and VEGF in inducing EC proliferation and angiogenesis ${ }^{30,42}$. Unfortunately, however, immunoneutralization of bFGF appears to induce little or no reduction in tumor angiogenesis ${ }^{43,44}$, suggesting that other modulators of angiogenesis are more suitable targets for anti-angiogenesis treatment.

Besides VEGF and bFGF there are several other important factors that modulate angiogenesis, like tumor necrosis factor- $\alpha$ (TNF $\alpha$ ), interleukin 8 (IL-8) and the matrix metalloproteinases (MMPS). TNF $\alpha$ is an inflammatory cytokine with angiogenic activity that is mainly expressed by tumor associated macrophages ${ }^{45}$. Other sources are mast cells, T-lymphocytes, NK cells, neutrophils and some malignant cells ${ }^{46}$. This cytokine has been found to promote the production of other angiogenic factors by tumor cells, like IL-8, bFGF and VEGF, through activation of transcription factors ${ }^{28,46}$. IL.8 is a potent angiogenic factor in several cancers and associated with metastasis. It is reported to be produced by tumor cells, ECs, fibroblasts and macrophages ${ }^{47}$. IL-8 expression significantly correlates with microvessel density ${ }^{48}$, indicating the angiogenic potential of this interleukin. MMPs, released by both tumor cells and endothelial cells, are a family of zinc-dependent endopeptidases 
Which can cleave all major molecules of the extracellular matrix $27,49,50$. During tumor growth, MMPs can enhance angiogenesis and degrade connective tissue and basement membranes to enable tumor growth and metastasis ${ }^{49}$.

\section{HIV-tat as an angiogenic factor}

In patients infected with the human immunodeficiency virus-1 (HIV-1) the aortic endothelium is often severely damaged, which results in an increased risk of cardiovascular diseases and atherosclerosis. In addition, they frequently develop malignancies such as Kaposi's sarcoma. Kaposi's sarcoma is an angio-proliferative tumor, producing bFGF and VEGF, with prominent infiltration of monocytes and $\mathbb{T}-c e l l s^{51,52}$. The HIV 1 genome encodes several regulatory proteins that coordinate the expression, transport and assembly of virus particles, leading to virus production and transmission ${ }^{51}$. Among these regulatory proteins, HIV-tat appears to be essential for virus gene expression and replication ${ }^{53-55}$. The release of HIV-tat occurs already early after HIV-1 infection. However, it appears to be undetectable in chronically infected cells. During acute infection of $\mathrm{T}$ cells by HIV-1, HIV-tat is released from these cells in an active form ${ }^{55-57}$. The tat-protein has been detected in sera of HIV-1-infected individuals ${ }^{58}$ and in Kaposi Sarcoma lesions ${ }^{59,60}$. One of the most striking properties of extracellular HIV-tat is its capability to mimick the effect of extracellular matrix proteins (such as fibronectin and vitronectin) on the locomotion, adhesion and growth of Kaposi Sarcoma cells and ECs, thereby enhancing angiogenesis and Kaposi Sarcoma progression ${ }^{51}$. Being considered as an angiogenic factor, HVVtat differs from true angiogenic factors in that it can only act on ECs that are activated by inflammatory cytokines like IFN $\gamma$, TNF $\alpha$ and IL $\beta 1,{ }^{51,01.64}$. Furthermore, this protein is known to increase bFGF mediated angiogenesis and to bind VEGFR2 $2^{51}$. The angiogenic properties of HIV-tat are mediated by three regions of the protein: the basic region that retrieves bFGF from heparan sulfate proteoglycans of the extracellular matrix ipromoting EC growth $)^{65-67}$, the cysteine-rich region which exerts a direct angiogenic effect by an unknown mechanism68 and the RGD region that binds to the $a 5 \beta_{1}$ and av $\beta_{3}$ integrins inducing EC migration ${ }^{69}$.

\section{INHIBITION OF ANGIOGENESIS TO INHIBIT TUMOR GROWTH}

The newly formed blood vessels, which are essential for a tumor to grow and survive, can also be used by modern medicine to deliver anti-cancer drugs in efficient quantities to all regions of a tumor $^{r 0}$. In addition, the cells lining the luminal side of these blood vessels, the turnor ECs, are considered to be interesting targets for the delivery of certain agents, like inhibitors of angiogenesis, in order to modify their function.

Angiostatic agents work through various mechanisms, like inhibition of EC proliferation and migration, unduction of $\mathbb{E C}$ apoptosis, or interference with MMP activity. It has been shown that when vessel formation is impaired or ECs are induced to undergo apoptosis, resulting in impaired oxygen and nutrient supply, tumor cells become apoptotic as well. At the moment, a variety of angiostatic agents has been discovered and developed, and numerous pre-clinical experiments involving angiogenesis inhibition are performed. There are also some chemotherapeutic agents known with claimed angiostatic properties, of which these angiostatic effects in animal models of cancer are tested. Moreover, clinical trails with human subjects using either direct or indirect angiostatic agents are carried out. Examples of such agents and their effects are discussed below.

One method to interfere with angiogenesis is the blockage of angiogenic factors like VEGF or FGFs and their receptors. This can be performed by treatment with specific antibodies against these factors and their receptors, with soluble receptors functioning as antagonists or VEGF antisense 
constructs $^{10}$. Tumor growth unhibition by VEGF neutralization has been demonstrated by laboratories using several anti-VEGF approaches. At present, the furthest clinically developed VEGF inhibitor is bevacizumab (Avastin, deweloped by Genentech) ${ }^{34}$. This agent is a humanized anti VEGF nonoclonal antibody, neutralizing all VEGF.A isoforms but not other members of the VECF family. For the treatment of metastatic colorectal cancer, the addition of bevacizumab to chemotherapy results in improved overall survival and improved progression-free survival. The rote of this agent in other tumor types is currently under investigation, including phase III clinical trials in non-small-cell lung cancer (NSCLC), renal-cell cancer and metastatic breast cancer ${ }^{34}$. Another way to interfere with VEGF signalling is through VEGF receptor blockade by tyrosine kinase inhibitors like 545416 (Semaxinib), SU6668 and SU11248 (all developed by Sugen), ZD4190 and ZD6474 (both developed Astrazeneca) and PTK787 (developed by Novartis). In spite of earlier encouraging results, the VEGFR2 blocking agent SU5416 failed to demonstrate efficacy in a controlled phase III trial in colorectal cancer patients in combination with chemotherapy ${ }^{34,7}$. SU6668 (blocking VEGF, FGF and PDGF receptors) and SU11248 (an oral multitargeted tyrosine kinase inhibitor with antitumor and antiangiogenic activity through targeting, amongst others, VEGF and PDGF receptors] are both being investigated in clinical trials ${ }^{7,72}$. ZD4190 and ZD 6474 are both VEGFR-2 blocking agents, being in phase II and II respectively 7 . PTK787, a receptor tyrosine kinase acting on both VEGFR.1 and VEGFR-2, is in phase III clinical trials for colorectal cancer and is also in phase II clinical trials for a number of other tumors ${ }^{34,72}$. An alternative way to neutralize VEGF is represented by the VEGFtrap, soluble receptors developed by Regeneron which is currently in phase $1 / 1]$ trials.

One of the first alternative compounds with angiostatic properties studied was AGM-1470 on TNP-470. TNP-470 is a synthetic analogue of fumagillin, that blocks the growth of new blood vessels by inhibiting methionine aminopeptidase, an enzyme that plays a key role in EC proliferation". Preclinical studies support a role for TNP-470 in slowing tumor growth, although it does not seem able to shrink existing tumors ${ }^{73}$. Combination of TNP-470 with paclitaxel results in tumor regression, disease stabilization and improved survival ${ }^{74}$. TNP-470 combined with paclitaxel and carboplatin was recently evaluated in the phase $\mathbb{I}$ setting in several tumor types ${ }^{75}$. Overall, this regimen was well tolerated and resulted in a partial response in $24 \%$ of the patients and a stable disease in $47 \%$. In conclusion, TNP-470, preferably in combination with other drugs, may prove to be a promising tool in the treatment of cancer.

Angiostatin is a potent endogenous angiogenesis inhibitor identifled by O'Reilly et al ${ }^{12}$ in Lewis lung carcinoma models. This agent is a cleavage product of plasminogen, which has been shown to inhibit EC proliferation and impairs both primary and metastatic tumor growth through inhibition of angiogenesis ${ }^{50}$. It was shown in animal models that continuous exposure to angiostatin is more effective in inhibiting tumon growth than bolus injections ${ }^{76}$. For clinical purposes, recombinant angiostatin was developed by EntreMed and given to patients in a twice daily schedule (mimicking the pharmacological profile of continuous infusion) ${ }^{77}$. Treatment with recombinant anglostatin appears to be safe and feasible even after prolonged use (> 6 months). However, none of the patients included in this clinical trial had obvious tumor responses; in only one patient $30 \%$ reduction of tumor volume was observed.

Endostatin, a fragment of collagen XVIII, is an endogenous angiostatic factor (like angiostatin), inhibiting EC proliferation and increasing the rate of apoptosis in tumor cells ${ }^{78}$. It has been shown to reduce tumor growth and even to induce nearly complete regression of established tumors in murine Lewis lung cancer models ${ }^{78}$. The antitumor effects of both endostatin and anglostatin are associated with a downregulation of vascular endothelial growth factor (VECF) expression by tumor cells $^{79}$. Recently, endostatin has entered phase I clinical trials ${ }^{80,81}$, from which it is known to be 
well tolerated. Although significant death of tumor ECs and reduced microvessel density were observed in response to a dose response curve, endostatin failed to induce high levels of tumor cell death resulting in only minor anti-tumor activities ${ }^{82}$. Further studies are needed to investigate the effects of endostatin on survival.

In search of novel angiostatic molecules, we have designed a -sheet forming peptide named anginex. This peptide is designed by using a combination approach employing basic folding principles and incorporating short sequences from the, sheet domains of angiostatic proteins like endostatin, platelet factor-4 (PF4), tumor necrosis factor- $\alpha$ (TNFo) and bactericidal permeability-increasing (BPI) protein $^{83}$. Anginex has been shown to be a potent inhibitor of angiogenesis by blocking EC proliferation, adhesion and migration and by inducing EC apoptosis ${ }^{83}$. Moreover, we have shown that anginex is capable of angiogenesis inhibition in an In vivo tumor model, resulting in reduced tumor proliferation as compared to untreated mice ${ }^{83,84}$. The current results indicate that anginex is a powerful anti-tumor angiogenesis inhibitor that shows promise of being developed to treat human cancers.

Conventional cytotoxic chemotherapeutics have been developed for the treatment of cancer by directly killing the tumor cells or inhibiting their proliferation. Several of these agents have been shown to possess anglostatic activity as well, presumably due to the presence of dividing ECs in newly forming tumor blood vessels ${ }^{85}$. Maximal angiostatic activity typically requires prolonged exposure to low drug concentrations, using frequent schedules at doses substantially lower than the maximum tolerated dose (metronomic dosing) ${ }^{86}$. Paclitaxel (Taxol) is one such agent of which the cytotoxic activities as a microtubule-stabilizing antineoplastic drugg are well known. In addition, paclitaxel has been described to possess angiostatic activities, inhibiting EC proliferation ${ }^{87}$, motility, invasiveness, and cord formation on Matrigel in a dose-dependent manner ${ }^{88}$. In clinical trials, paclitaxel showed to be effective against several tumors, including ovarian, breast, lung, head and neck carcinomas ${ }^{89}$. At the moment, the angiostatic properties of this agent are being tested in phase III trials where optimai dosing and treatment strategies are being adjusted ${ }^{90,91}$.

Cyclophosphamide is a widely-used cytotoxic chemotherapeutic drug in cancer therapy that has been described to inhibit EC proliferation and, hence, angiogenesis as well ${ }^{87}$. When cyclophosphamide was administrated according to a low-dose, frequent schedule, it decreased tumor volumes ${ }^{22}$ and increased apoptosis of tumor ECs and tumor cells were observed in several tumor models $^{93}$. These angiostatic effects observed with low doses of cyclophosphamide, or agents like paclitaxel, may be due to induction of thrombospondin-1, a potent endogenous and endothelial specific inhibitor of angiogenesis ${ }^{85}$. In a pre-clinical setting, a combination of cyclophosphamide and TNP.470 even eradicated drugresistant Lewis lung carcinomas ${ }^{93}$. Thus far, only few clinical trials have directly tested angiostatic schedules of chemotherapy ${ }^{86}$, so further clinical studies are needed to exploit the interesting field of chemotherapeutic drugs and anti-angiogenesis.

\section{LEUKOCYTE-VESSEL WALL INTERACTIONS}

Immune responses can be classified as acquired (adoptive) or innate (non-adoptive) immunity. Both types of immune responses are carried out by leukocytes, which can be divided in two major groups: polymorphonuclear (PMN) cells or granulocytes, and monomorphonuclear (MMN) cells. PMNs can be divided in neutrophils, eosinophils and basophils and are part of the innate immune system, since they use non-specific mechanisms to recognise and destroy pathogens. Monocytes, lymphocytes and natural killer (NK) cells belong to the MMNs. Monocytes and NK cells are also part of the innate immunity, whereas lymphocytes are involved in acquired immunity, generating a specific 
immune response against individual pathogens ${ }^{94}$.

In order to obtain a proper inflammatory response it is necessary to recruit leukocytes from the circulation into infected extravascular locations. This recruitment process is complex and involves interactions between leukocytes and $\mathrm{ECs}^{95}$. The migration of leukocytes from the vasculature into the extravascular tissue occurs in several steps, as illustrated in Figure 1.2: capture, rolling, activation, firm adhesion, diapedesis and migration ${ }^{96}$. This multistep cascade, in which every step needs to be completed for the next step to occur, depends on cell adhesion molecules expressed by both ECs and leukacytes, under tight control of the local microenvironment ${ }^{9}$. First, the endothelium is activated by substances released at a site of inflammation or by a tumor. As a result, ECs stant to express adhesion molecules which can weakly bind marginated leukocytes. These captured leukocytes may start rolling along the vessel wall. Because of their low velocity and, hence, longer transit times, rolling leukocytes can become activated by chemotactic cytokines as well. These activated leukocytes will then spread and firmly adhere to the endothelium. Finally, they may migrate through the vessel wall (diapedesis) into the underlying tissue.

The first contact of marginated leukocytes with activated endothelium is referred to as leukocyte capture or tethering. This is a weak, reversible binding and leukocytes can be observed 'jumping' along the endothelium. Once leukocytes are captured, they may start to roll along the vascular endothelium. Rolling occurs at a velocity significantly lower than that of the free flowing cells in the same blood vessel. The weak binding of rolling leukocytes to the endothelium is reversible

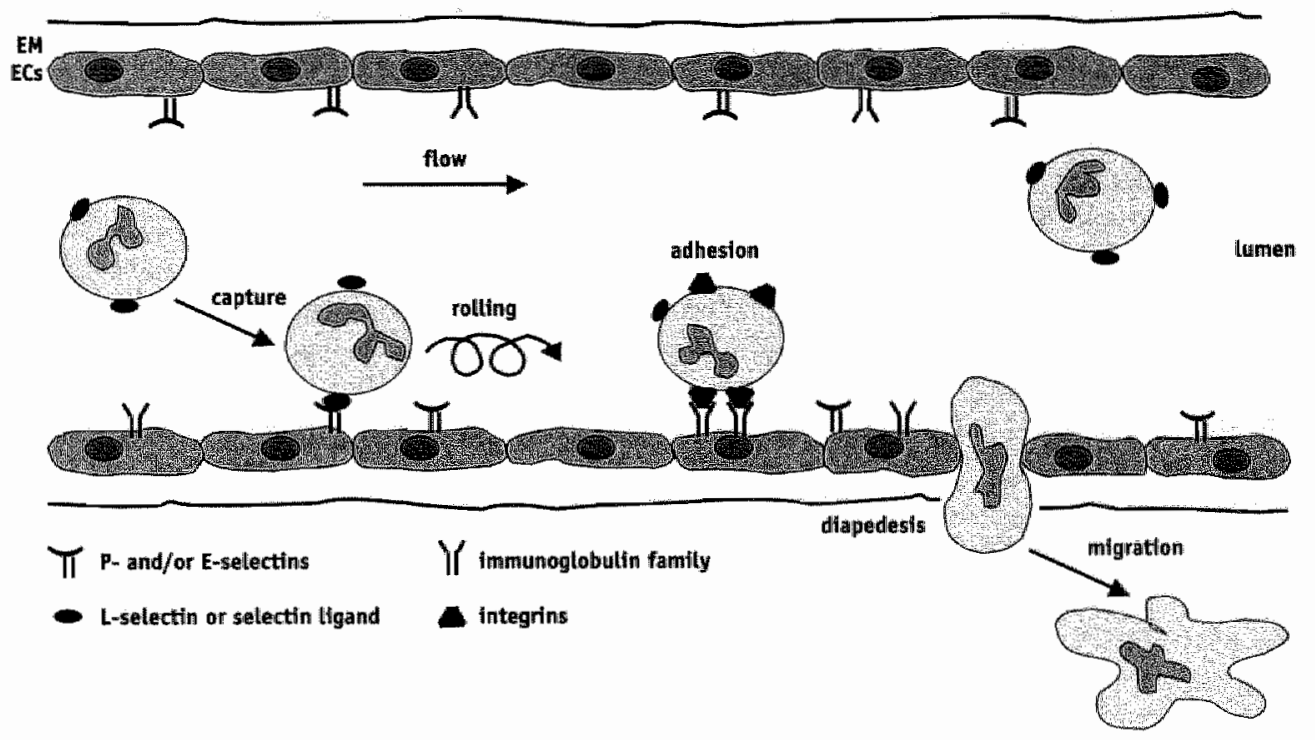

\section{Figure 1.2 Leukocyte-vessel wall interactions}

When leukocytes marginate from the blood stream in the direction of the vessel wall, they can be captured and may start roling along activated endothelial cells (ECS) that express adhesion molecules. During the process of rolling, leukocytes may become activated as weth, resulting in increased expression and binding affirity of integrins. As a result, they can firnty adhere to the endothelium and migrate through the vessel wall (diapedesis) into the surrounding tissue. EM: Extracellular Matrix. 
as well and, hence, leukocytes can detach agair. Both leukocyte capture and rolling are mediated by adhesion molecules of the selectin family that bind to glycoprotein ligands (Table 1.1$)^{98,99}$.

Table 1 1. Selectins and hetr counterteceptors involved in leukocyte rolling

\begin{tabular}{|c|c|c|}
\hline Selectins & Expression & Ligands \\
\hline Lselectin & granulocytes, monocytes, most lymphocyte subsets & $\begin{array}{l}\text { PSGL1, PNAd, P-selectin, E-selectin, } \\
\text { MadCAM 1, unlknown }\end{array}$ \\
\hline Pselectin & artivated EC 5 , activated platelets & PSGL1, L-selertin, unknown \\
\hline Eselectin & activated $\mathrm{ESS}$ & PSGL-1, L-selectin, unknown \\
\hline
\end{tabular}

Three selectin family members are known: $\underline{L}$-selectin on Leukocytes, $\underline{P}$-selectin on Platelets and ECs, and E-selectin on ECs. L-selectin is constitutively expressed on all granulocytes and monocytes, and on most lymphocytes. P-selectin is stored in $\alpha$-granules of platelets and in WeibelPalade bodies of ECs; it is quickly translocated to the cell surface after activation ${ }^{98}$. E-selectin is not stored in granules but requires de novo mRNA and protein synthesis to be expressed on the surface of activated $\mathrm{ECs}^{98}$. In non-inflamed skin microvessels, $\mathrm{P}$ - and E-selectin are constitutively expressed on $\mathrm{ECS}^{100}{ }^{101}$. P-selectin glycoprotein ligand (PSGL-1) is a ligand for all three types of selectins and is expressed by neutrophils, lymphocytes and monocytes ${ }^{102}$. PSGL-1 accounts for about $90 \%$ of P. selectin binding and is also the most important counterreceptor for L-selectin. In addition, both $\mathrm{E}$ and P-selectin are known to bind L-selectin. Other L-selectin ligands have been identified in high endothelial venules and are collectively known as peripheral node addressins (PNAd) ${ }^{98}$. Although PSGL-1 is able to bind E-selectin as well, the major E-selectin ligand remains poorly defined ${ }^{102}$. The crucial role of selectins in leukocyte recruitment is demonstrated in mice that lack selectins or PSGL$1^{103}$, and in patients suffering from a rare disease called leukocyte adhesion deficiency type II ILADIII. These individuals are not capable to effectively incorporate fucose into their selectin ligands; as a result, these ligands fail to bind $\mathrm{L}$; $\mathrm{P}$; , and E-selectin. These patients frequently have bacterial. infections and are treated with oral fucose and/or antibiotics ${ }^{98}$.

The adhesion molecules on leukocytes that are involved in adhesion and diapedesis are usually present on the cell surface or have to be released from intracellular granules. These so-called integrins can be upregulated through an increase in the number of molecules expressed on the cell surface, while their activity can be enhanced through conformational changes that increase their binding affinity. For this purpose, leukocytes need to become activated by chemotactic cytokines or chemokines ${ }^{104}$ like, for instance, complement factor $5 \mathrm{a}$, TNFo, lipopolysacharide (LPS), interleukin$8(I L-8)$, RANTES and leukotriene-B4 (LTB4) $)^{34}$. Upon activation, the expression and affinity of these integrins are greatly enhanced. Integrins consist of two non-covalently bound polypeptides $(\alpha$ and $\beta$ chains), traversing the cell membrane. $\beta_{1}$-integrins, like the very late antigens (VLA.4 and VLA.5), are mainly involved in binding of leukocytes to the extracellular matrix ${ }^{94}$. Integrins with a $\beta_{2}$ subunit, like lymphocyte function-related antigen (LFA-1) and membrane attack complex-1 (Mac-1), are only expressed by leukocytes and involved in leukocyte-endothelium interactions. In patients with leukocyte adhesion deficiency type I (LAD-I), recurrent, life threatening bacterial infections are seen due to the absence of $\beta_{2}$-integrins ${ }^{105}$. Patients with LAD-I fail to recruit leukocytes, indicating the importance of the integrin family in immunity. A number of integrins relevant for leukocyte adhesion to the endothellum are summed in Table 1.2 .

The endothelial counterreceptors for the integrins are members of the immunoglobulin gene 
Table 12: integrins and their counterneceprors wowed in leukochte athesion

\begin{tabular}{|c|c|c|}
\hline Integrins & Expression & Ugand(s) \\
\hline $\operatorname{VLA}-4\left(\alpha A_{1},\right)$ & lymphocytes, some phagocytes & VAM-1, fibronectin \\
\hline VIA-5 $(a, 1)$ & leukocytes, platelets & Fibronection ? \\
\hline$L F A-1(\alpha, 2)$ & most leukocytes & ICAM-1, $1 \mathrm{CAM} 2$ \\
\hline Mac- $1(\alpha M, 2)$ & granulocyles, phagocytes & ICAMI, ICAM-2 \\
\hline
\end{tabular}

superfamily, which consists of glycoproteins with multiple immunoglobulin-like domains. These proteins are expressed by vascular ECs, leukocytes and platelets. The intercellular adhesion molecules (ICAM-1 and ICAM-2) and vascular cell adhesion molecule (VCAM-1) are examples that are involved in leukocyte adhesion. Platelet endothelial cell adhesion molecule (PECAM) and mucosal addressin cell adhesion molecule-1 (MadCAM-1) are members of the same family ${ }^{94}$ (Table 1.3).

Table 1.3: Immunagtobulin gene superfamily members and their counterneceptors involved in lewkogte adheston and diqpedests:

\begin{tabular}{|c|c|c|}
\hline $\begin{array}{l}\text { Immunoglobulin } \\
\text { gene superfamily }\end{array}$ & Expression & Ligand(s) \\
\hline ICAM-1 & ECs, leukocytes & LFA-1, Mac-1 \\
\hline ICAM-2 & ECs, leukocytes & LAA-1, Mac-1 \\
\hline VCAM-1 & activated ECs, macrophages & VIA-4 \\
\hline PECAM-1 & Leukocytes, ECs, platelets & PECAM-I \\
\hline MadCAM-1 & high endothelial cells & Lselectin \\
\hline
\end{tabular}

Following leukocyte adhesion diapedesis may occur, after which leukocytes can migrate into the surrounding (tumor) tissue. Diapedesis occurs within a few minutes during which the leukocyte extends itself by forming pseudopodia across the endothelial border ${ }^{106}$. For diapedesis to occur, adhesion molecules of the integrin and the immunoglobulin gene superfamily are needed, like PECAM-1 (CD31) and CD99\%,100. Furthermore, this process requires an increase in intracellular free calcium in ECs that are adjacent to a transmigrating leukocyte. The increase in intracellular free calcium activates myosin light chain kinase which leads to unfolding of myosin II, leading to EC retraction that might facilitate leukocyte passage ${ }^{100}$.

Once leukocytes have transmigrated from the blood stream into the tissue, they can migrate through the tissue in the direction of the stimulus, like a site of inflammation or a tumor, and exert their local effects. Under normal physiological circumstances, leukocytes are recruited to a site of inflammation by the local synthesis of chemokines (chemoattractive cytokines) and cytokines and by products of tissue breakdown ${ }^{100}$. In tumors, similar chemoattractive factors and adhesion molecules are thought to play a role in leukocyte recruitment. In contrast to cells at a site of inflammation, tumor cells do not stop proliferating and migrating and they continue to send out signals that recruit leukocytes to the tumor site ${ }^{10 ?}$. This concept has contributed to the characterization of tumors as "wounds that fail to heal" 108. 


\section{TUMOR ANGIOGENESIS AND THE IMMUNE SYSTEM}

It is currently well established that tumor anglogenesis and the immune system do influence each other. On the one hand, components of the inmune system appear to be involved in the regulation of tumor angiogenesis. A number of studies show that several leukocyte subsets can induce blood vessel formation in tumors. Examples are polymorphonuclear (PMN) granulacytes that produce matrix metalloproteinases (MMPS), VEGF and $\left[L \cdot 8^{14,107}, \mathrm{CD} 4+\right.$ and CD8+ T-lymphocytes that produce VEGF and bFGF100,110, mast cells that produce MMP9, VEGF, IL-8, bFGF, TNFa 107,111 and monocytes/macrophages producing e.g. VEGE, IL-8, bFGF, TNFo, IL-1 and MMP.9 112 (for further elaboration see chapter 5). On the other hand, angiogenic processes can have a major impact on immune cells and the development of an immune response ${ }^{10}$. As depicted in Figure 1.2 , ECs are involved in leukocyte recruitment to sites of inflammation by the expression of adhesion malecules. In tumors, the process of anglogenesis increases the EC surface, enhancing the possibilities for leukocytes to interact with the vessel wall. Interestingly, however, relatively low levels of leukocytevessel wall interactions are being observed in tumors (see chapter 2$)^{10,10,22,113,114}$, which may be considered as a tumor-evolved mechanism to escape immune surveillance. It has been shown that exposure of ECs to angiogenic factors (that are produced by cancer cells, such as VEGF and bFGF) downregulates adhesion molecule expression ${ }^{115,110}$ and, hence, leukocyte-vessel wall interactions in witro ${ }^{17}$ and also In vivo ${ }^{118}$. Moreovet, an angiogenic environment hampers the upregulation of adhesion molecule expression by proinflammatory cytokines, a phenomenon called endothelial cell anergy ${ }^{119}$. Angiogenesis inhibition, either by specific angiostatic compounds or by chemotherapeutic agents with claimed anglogenesis inhibitory activity, may be a way to increase leukocyte-vessel wall interactions and subsequent infiltration in tumors (see chapter 3) and may be applicable for the improvement of various immunotherapeutic approaches ${ }^{20}$.

\section{AIM AND OUTLINE OF THE THESIS}

In European and American countries, cancer is one of the most important causes of death. For" the treatment of cancer, it is necessary to fundamentally understand the process of angiogenesis and its effects on the immune system. The aim of the present study was to investigate the relationship between angiogenesis and immunity in tumors and to explore ways to modulate this relationship in order to contribute to the development of new anticancer therapies. As presented in this thesis, we have deweloped a new tumor model in which both angiogenesils and leukocyte-vessel wall interactions in- and outside a tumor can be quantified noninvasively, allowing longitudinal analysis during tumor development and/or in the course of anticancer treatment. Using this tumor model, focus will be on leukocyte-vessel wall interactions in vessels both in- and outside a tumor as well as in healthy venules. Furthermore, an attempt was made to influence leukocyte interactions with the vessel wall by using both inhibitors and stimulators of angiogenesis. Understanding the behavior of leukocytes in tumor blood vessels may be of major impact when improving immunotherapy strattegies in order to cure cancer.

The first experimental study, described in chapter 2, focuses on the development of a noninvasive method to investigate leukocytevessel wall interactions in both healthy and tumor vessels. By injecting a dense tumor cell suspension in mouse ear skin or on the flank we grew a small or a large tumor, respectively. The transparent mouse ear was chosen, since it allows intravital microscopic measurements on Jeukocytevessel wall interactions and local fluid dynamic conditions. In addition, these measurements can be performed noninvasively, allowing longitudinal analysis during tumor development and/or course of cancer treatment. Moreover, we performed ex vivo 
and in vitro experiments to detect the expression of adhesion molecules on both freshly isolated and cultured endothelial cells using flow cytometry. We observed a significantly decreased level of leukocytevessel wall interactions in tumor vessels due to a decreased expression of adhesion molecules on tumor endothelial cells in response to angiogenic factors. This observation was identified as a tumor derived mechanism to escape immune surveillance.

Since we hypothesize that immune infiltration is detrimental to a tumor, we trijed to upregulate leukocyte-vessel wall interactions in tumor vessels by antiangiogenic therapy in the next study (chapter 3). We used several specific inhibitors of angiogenesis (the new designer peptide anginex, endostatin, angiostatin and TNP-470) and two antineoplastic drugs (paclitaxel and cyclophosphamide) with claimed angiostatic properties. Using some of these compounds we indeed observed an upregulation in the number of interacting leukocytes in tumor vessels. Moreover, we showed that this increase in leukocyte-vessel wall interactions was due to an increase in endothelial cell adhesion molecule expression by antiangiogenic therapy. As a result we observed an increased leukocyte infiltration in tumors, presumably leading to increased anti-cancer activity.

In the study described in chapter 4 , we investigated the influence of human immunodeficiency virus-1 (HIV-1) infection on angiogenesis and the development of angioproliferative lesions such as Kaposi's sarcoma. HIV-tat, the transactivator protein of HIV-1 released by infected cells, was found to increase leukocyte-endothelium interactions both in vitro and In vivo (alone and synergistically with TNF $\alpha$ ), indicating that these proteins may contribute to the prominent infiltration of monocytes and T-cells in Kaposi's sarcoma.

In the chapters $2-4$, we describe the effects of the process of angiogenesis and angiogenic factors on the function of the immune system. In chapter 5 we review the effects of the immune system (in this case monocytes/macrophages specifically) on the process of angiogenesis. Some tumors have been observed to contain a high number of infiltrated monocytes/macrophages, leading to a worse prognosis for the patient. In this chapter we discuss the pro- and anti-angiogenic factors produced by these immune cells and their effects on tumor angiogenesis, proliferation and metastasis.

Chapter 6 is a general discussion, in which the findings of the various chapters are discussed in an integral way, with suggestions for future investigation. 
chapter 1 


\section{REFERENCES}

1. Cargett C.E. \& Rogers P.A. 20011 Human endometral angiogenesis. Reproducton 121, 181486.

2. Witting ], Brand-Saberi B., Kurz H., G Christ B. (1995) Development of the embryonic wascular system. Cell Mol Biol.Res 41, 219-232.

3. LJ., Zhang YP. \& Kirner R.S. (2003) Angiogenesis in wound repain: anglogente growth factors and the extracellular matrix. Mrorosc.Res Tech. 60, 107-114.

4. Crowther M., Brown N.J., Bishop E.T., Lewis C.E. (2001) Microenvironmental influence on macrophage regulation of angiogenesis in wounds and matignant tumors. Joumat of Lewockte Botogy $70,478.490$.

5. Martin A., Komada M.R., \&ane D.C. (2003) Abnomal angiogenesis in diabetes mellitus: Med Res Rev 23, 117.145.

6. Paleolog EM. (2002) Angiogenesis in meumatoid arthrits. Arhrits Res 4 Suppl 3, S81-590.

7. Lutun A., Dewerchin M., Collen D., Cameliet P. (2000) The role of protemases in angiogenesis, heart development, restenosis, atherosclerosis, myocardial ischemia, and stroke: insights from genetic studies. Cur.AtherosclerRep. 2, 407-416.

8. Folkman J. (1995) Angiogenesis in cancer, vascular, rheumatoid and other disease. Nature Medicine 1, 27.31.

9. Risau W. (1997) Mechanisms of angiogenesis. Nature 386, 671-674.

10. Griffioen A.W. Molema G. (2000) Angiogenesis: potentials for pharmacologic intervention in the treatment of cancer, cardiovascular diseases and chronic inflammation. Pharmacol Rev 52, 237.268.

11. Ingber D., Fujita T., Kishimoto S., Sudo K., Kanamaru T., Brem H., \& Folkman J. (1990) Synthetic analogues of fumagilin that inhibit angiogenesis and suppress tumour growth. Natare $348,555.557$.

12. O'Reilly M.S., Holmgren L., Shing Y, Chen C., Rosenthal R.A., Moses M., Lane W.S., Cao Y., Sage EH., \& Folkman J. (1994) Angiostatin: a novel angiogenesis inhibitor that mediates the suppression of metastases by a Lewis Lung Carcinoma. Cell $79,315-328$.

13. Vrchow R. (1989) "Die Krankenhaften Geschwiliste", August Hirschwald, Berlin, 1863, cited by Paweletz $N$ and Knierim $\mathrm{M}$ in: Tumor related angiogenesis. Crit.Rev Oncol.Hematol. 9, 197-242.

14. Brigati C., Noonan D.M., Albini A., Benelli R. (2002) Tumors and infammatory infiltrates: friends or foes? Cin. Exp. Metastasis 19,247.258.

15. Borgstrom P., Hughes G.K., Hansell P., Wolisksy B.A., \& Sriramarno P. (1997) Leukocyte adhesion in angiogenic blood vessels. Role of E- selectin, P-selectin, and beta 2 integrin in lymphotoxin-mediated leukocyte recruitment in tumor microvessels. The loumal of Clintical hwestigation $99,2246.2253$.

10. Fukumura D., Salehi H.A., Witwer B., Tuma R.F, Melder R.J, \& Jain R.K. (1995) Tumor necrosis lactor alpha. induced levkocpte adhesion in normal and tumor vessels: effect of tumor type, transplatitation sile, and host strain. Cancer Res. 55, 4824-4829.

17. Wu N.2., Klitzman B., Dodge R., \& Dewhirst M.W. (1992) Diminished leukocyte endothelium anteraction in tumor microwessels. Cancer Res. 52, 4205.4208.

18. Jain R.K., Koenig G.C., Dellian M., Fukumura D., Munn L.L., \& Melder R.]. (1996) Leukocyte-endothelial adhesion and angiogenesis in tumors. Cancer Metastasis Rev. 15, 195.204.

19. Dirkx A.E.M., Oude Egbrink M.G., Kuipers M.J., van der Niet S.T. Heimen VV., Boumater Steege J.C., Wagstaff J., \& Grffioen A.W. 12003 ) Tumor angiogenesis modulates leukocyte-vessel wall Interactions In wivo by reducing endothelial adhesion molecule expression. Cancer Res. 63,23222329 .

20. Chen Q. Wang W.C. \& Evans S.S. (2003) Tumor microvasculature as a barrier to antitumor immunity. Camcer Immunol Immunother. 52, 070.679 .

21. Camos T.M. (2001) Leukocyte recruitment at sites of tumor: dissonant orchestration. J.Leukoc. Biol. 70, 171.184.

22. Melder R.)., Koenig C.C., Witwer B.P., Safabakhsh N., Munn L.L., \& Jain R.K. (1096) During angiogenesis, vascular endothelial growth factor and basic fibroblast growth factor regulate natural killer cell adhesion to tumor endothelium. Nature Med 2, 992997. 


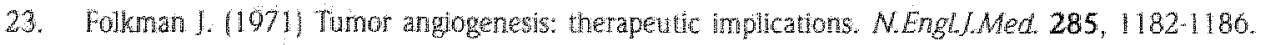

24. Holmgren L. ORelly M.S. Fokman I. (1095) Domancy of Micrometastases - Balanced Prohteration and Apoptosis in the Presence of Angogenesis Suppression. Nature Medicine 1, 149-153.

25. Hanahan D. Folkman J. 11996$)$ Pafterns and enterging mechanisms of the angiogenic switch during mimorigenesis: Cell 86, $353-364$.

26. Folkman ]. (2002] Role of andogenesis in tumor growth and metastasis. Semin. Oncol. 29, 15 -18.

27. Bingle L, Brown N.]., \& Lewis C.E. (2002) The role of tumour associated macrophages in tumour progression: implicatons for new anticancer therapies. /Pathol. 196, 254-265.

28. Torisu H, Ono M. Kiryu H., Furue M., Ohmoto Y, Nakayama J., Nishioka Y, Sone S. \& Kuwano M. [2000] Macrophage intitution correlates with tumor stage and angogenesis in humam malignant melanoma: possible involvement of TNFalpha and IL Ialpha. International Joumal of Cancer 85,182188 .

29. Dirkx A.E.M, oude Egbrink M.G.A., Castermans K., Thijssen W.L.J.L., Wan der Schat D.W., Kwee L. Mayo K.H., Wagstaff J., Boumater Steege J.C., \& Griffioen A.W. (2005) Anti-angiogenesis therapy can overcome endothelial cell anergy and promote levkocytewendothelium interactions and infitration in tumors. FASEB J. (in press).

30. Eubank T.D., Galloway M., Montague C.M., Waldman W. \&, Marsh C.B. (2003) M.CSF induces vascular endothelial growth factor production and angiogenic activity from human monocytes. Joumal of Immunology $171,2637-2643$.

31. Coussens L.M. \& Werb Z. (2002) Inflammation and cancer. Nature 420, 860.867.

32. Ferrara N., Gerber H.P. \& LeCouter 1 . $2003 \rrbracket$ The biology of VEGF and its receptors. Nature Medicine 9 , $669-670$.

33. Ferrara N. \& Keyt B. (1997) Vascular endothelial growth factor: basic biology and clinical implicaions. EXS. $79,209.232$.

34. Ferrara N., Hillan K..., Gerber H.P., \& Novotny W. (2004) Discovery and development of bevacizumab, an antJ-VEGF antibody for treating cancer. Nat.Rev Drug Discov. 3, 391-400.

35. Gerber H.P., Hillan K.J., Ryan A.M., Kowalski J., Keller G.A., Rangell L., Wright B.D., Radtke F, Aguet M., \& Ferrara N. (1999) VEGF is required for growth and surwiwal in neonatal mice. Dewelopment 126, 1.49 1159.

36. Clauss M., Gerlach M., Gerlach H., Brett J., Wang F, Familletti P.C., Pan Y.C., Olander J.V., Connolly D.T, \& Stem D. (1990) Vascular pemeabilicy factor: a tumorderived polypeptide that induces endothelial cell and monocyte procoagulant activity, and promotes monocyte migration. Joumal of Experimental Medicine 172 , $1535 \cdot 1545$.

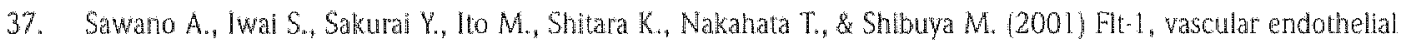
growth factor receptor $\mathbb{I}$, is a novel cell surface marker for the lineage of monocytemacrophages in humans. Blood $97,785.791$.

38. Leek R.D., Hunt N.C., Landers R.J., Lewis C.E., Royds J.A., \& Harris A.l... 2000 Macrophage infiltration is associated with VEGF and EGFR expression in breast cancer. J.Patho: 190, 430-430.

39. Fujloka S., Yoshida K., Yanagisawa S., Kawakami M., Aoki T, \& Yamazaki Y. [2001] Angiogenesis in pancreatic carcinoma: thymidine phosphorylase expression in stronal cells and intratumoral microvessel density as independent predictors of overall and relapse-fiee survwal. Cancer $92,1788.1797$.

40. Lewis C.E., Leek R., Harris A., \& MCGee 1.0 . (1995) Cytokine regulation of angiogenesis in breast cancer: the role of tumonassociated macrophages. J.Letkoc.Biol. 57, 747.751.

41. Esposito I., Menicagli M., Funel N., Bergmann F., Boggi U., Mosca F, Bevilacqua G., \& Campani D. [2004] Intammatory cells contribute to the generation of an angiogenic phenorype in pancreatic ductal adenocarcinona. J.Chin. Pathol. 57, $030 \cdot 030$. 
42. Thang H. \& Issekutz A.C. (2002) Down-modulation of monocyte transendothelial migration and endohellal adhesion molecule expression by fbroblast growth factot: reversal by the anti-angiogenio agent SU6608. Am.J.Pathol 160, 2219.2230 .

43. Matsuzaki K., Yoshitake Y, Matuo Y., Sasaki H., \& Nishilkawa R. (1989) Monoclonal antibodies against heparinbinding growth factor I/basic fibroblast growth factor that block its biological acivity: invalidity of the antibodies for tumor angiogenesis. Proc.NatLAcadSci. U.S.A 86, $9911-0915$.

44. Dennis P.A. \& Rifkin D.B. (1990) Studies on the role of basic fibroblast growth factor In wro: inability of neutralizing antibodies to block tumor growth. J.Cell Physiof 144, 84.98 .

45. Leek R.D. \& Harris A.L. (2002) Tumorassociated macrophages in breast cancer. JMammary. Gand Biot Neoplasia. 7, 177-189.

46. Ono M., Torisu H., Fukushi J., Nishie A., \& Kuwano M. (1090) Biological implications of macrophage infil|tration in human tumor angiogenesis. Cancer Chemother Phamacal. 43 Suppl, 569.571.

47. Chen II., Yao PLL, Yuan A., Hong T.M., Shun C.T., Kuo M.L., Lee Y.C., \& Yang P.C. (2003) Upregulation of tumor interteukin-8 expression by inflitrating macrophages: its correlation with tumor angiogenesis and patient survival in non-small cell lung cancer. Clin.Cancer Res $9,729-737$.

48. Fujimoto J., Aoki I., Khatun S., Toyoki H., \& Tamaya T. (2002) Clnical implications of expression of interleukin" 8 related to myometrial invasion with angiogenesis in uterine endometrial cancers. Ann. Oncol 13,430-434.

49. Kerkela E., Ala-aho R., Kemi P., Grenman S., Shapiro S.D., Kahari V.M., \& SaarialhoKere U. (2002) Metalloelastase (MMP-12) expression by tumour cells in squamous cell carcinoma of the wulwa correlates with inwasiveness, winte that by macrophages predicts better outcome. JPathol 198, 258.269.

50. Comellus L.A., Nehring L.C., Harding E., Bolanowski M., Welgus H.G., Kobayashi D.K., Pierce R.A., \& Shapiro S.D. (1998) Matrix metalloproteinases generate anglostatin: effects on neovascularization. Joumal of Immunology 161, 6845-6852.

51. Barillari G. \& Ensoli B. (2002) Angiogenic effects of extracellular human immunodeficiency virus type 1 Tat protein and its role in the pathogenesis of AlDS.associated Kaposi's sarcoma. Cin.Microbiol.her. 15, 310-326.

52. Stural M. Zietz C., Monini P., \& Ensoli B. (2001) Human herpesvirus.8 and Kaposi 's sarcoma: relationship with the multistep concept of tumorigenesis. Adv Cancer Res 81, 125.159.

53. Chang H.K., Gallo R.C., \& Ensoli B. (1995) Regulation of Cellular Gene Expression and Function by the Human Immunodeficiency Virus Type 1 Tat Protein. J.Biomed.Sci. 2, 89-202.

54. Arya S.K., Guo C., Josephs S.F, \& Wong Staal F (1.985) Trans activator gene of human T-lymphoutopic virus type 111 (HTLVIII). Science 229, 6973.

55. Ensoli B., Buonaguro L., Barilari G., Fiorelii V., Gendelmala R., Morgan R.A., Wingleld P. \& Gallo R.C. (1093) Release, uptake, and effects of extracellular human immunodeficiency virus type I Tat protein on cell growth and viral transactwation. J.Virol 67, 277.287.

50. Chang H.C., Samaniego E., Nair B.C., Buonaguro L., \& Ensoli B. (1997) HW.I Tat protein exits from cells via a leaderless secretory pathway and binds to extracellular matrix associated heparan sulfate proteoglycanth ihough its basic region. ADS 11, 1421.1431.

57. Ensoli B., Barilari G., Salahudain S.Z, Gallo R.C., \& WongStal F. llogol Tat protein of HW.1 stimulates growth of cells derived from Kaposi's sarcoma lesions of AIDS patients. Narure 345, 84.86.

58. Westendorp M.O., Frank R., Ochsenbauer C., Stricker K., Dhein I., Walczak H., Debatin K.M., Krammer P.H. (1905) Sensitization of T cells 10 CDO5-mediated apoptosis by HIV-1 Tat and gp 120 . Nature 375, 497-500.

59. Ensoli B., Gendelman R., Markham P, Forelli V., Colombini S., Raffeld M., Cafaro A. Chang H.K., Brady J.N., \& Gallo R.C. [1994) Synergy between basic fibroblast growth facior and HV.I Tat proteln in inducion of Kaposi's sarcoma. Nature 371, 674.680.

60. Ensoli B., Sgadari C., Barillari G., Siramni M.C., Sturzl M., \& Monin P. (2001) Biology of Kaposi's sarcoma. Eur. Cancer 37, $1251-1269$. 
61. Albirif A. Barllar G., Denelf R., Gallo R.C. \& Ensoli B. (1905) Angiogenic properies of human inmunodefictency virus type 1 Tat protein. Proc.Nall.ACad ScL. US.A 92, 4838-4842.

62. Barilan $G$., Buonaguro L, Forell V, Hofman J, Mchaels F, Gallo R.C. B Ensoil B. $(1992)$ Effecs of cytokines from actwated inmune cells on vascular cell growth and HV. 1 gene expression. Implications for ADS Kapasi"s sarcona pathogenesis. Ammunol 149, 3727-3734.

63. Battlafi, $G_{*}$, Gendelman $\mathrm{R}$, Gallo RC. Ensol B. (1993) The Tat protein of human immunodeficiency virus type 1, arowth factor for ADS Kaposi sarcoma and cytokine-actiwated vascular cells, induces adhesion of the same cell rypes by using integrin receptors recognizing the RCD amino acid sequence. Proc Natl.Acad SciU.5.A $90,7941-7945$.

64. Fiorell V, Gendeiman R., Samaniego F, Markham PD., \& Ensoli B. (1995) Cytokines from activated T cells induce tomal endothellal cells to acquire the pherotypic and functional features of ADS-Kaposi's sarcoma spindle cells. J.Chn Invest 95, $1723 \times 1734$.

65. Barillari G., Sgadari C., Palladino C.y Gendelman R., Caputo A. Morris C.B., Nair B.C., Markham P., Nel A., Stural M., Ensoli B. (1999) Inflammatory chokines synergize with the HVI Tat protein to promote anglogenesis and Kaposit's sarcoma via induction of basic fbroblast growth factor and the alpha weta 3 integrin. Jimnunat. 163, 1929.1935.

66. Barillari G., Sgadari C., Forell V., Samaniego F, Colombini S., Manzari V, Modesti A., Naír B.C., Cafaro A., Stural $\mathrm{M}_{n}$ \& Ensoli B. (1999) The Tat protein of human immunodeficiency virus type-1 promotes vascular cell growth and lacomotion by engaging the alpha5betal and alphavbeta3 integrins and by mobilizing sequestered basic fibroblast growth factor. Blood 94, 663-672.

67. Chang H.C., Samaniego F, Nair B.C., Buonaguro L., \& Ensoli B. [1997) HIV. Tat protein exits from cells via a leaderless secretory pathway and binds to extracellular matrix-associated heparan sulfate proteoglycans through its basic region. ADS 11, 1421-1431.

68. Boykins R.A., Mahieux R., Shankavaram U.T., Gho Y.S., Lee S.F, Hewlett I.K., Wahl L.M., Kleinman H.K., Brady J.N., Yamada K.M., \& Dhawan S. (1999) Cutting edge: a short polypeptide domain of HV-1.Tat protein mediates pathogenesis. Jounal of Immumology 163, 15-20.

69. Barillari G., Gendetman R., Gallo R.C., Ensoli B. (1993) The Tat protein of human immunodeficiency vimus type 1, a growth factor for AlDS Kaposi sarcoma and cytokine-activated vascular cells, induces adhesion of the same cell types by using integrin receptors recognizing the RGD ammo acid sequence. Proc. Natl.Acad.SCiU.S.A $90,7941 \cdot 7945$.

70. Carmeliet P. Jain R.K. (2000) Angiogenesis in cancer and other diseases. Nature 407, 249.257.

71. Tozer G.M. (2003) Measuring tumour vascular response to antivascular and antiangiogenic diugs. Br..Radol. 70 Spec No $1, \$ 23 \$ 35$.

72. Augustin H.G. (2003) Translating anglogenesis research into the clinic: the chaltenges ahead. Br. Radiol. 76 Spec No $1,53.10$.

73. Teicher B.A., Holden S.A., Ara G., Konbut T., Menon K. (1996) Comparison of several antiangiogenic regimens alone and with cytotoxic therapies in the Lewis lung carcinoma. Cancer Chemother Phamacol 38, 160.177.

74. Teicher B.A., Dupuis N. P., Robinson M.E, Emi Y. \& Gof D.A. (1995) Antiangiogenic veatment [TNP.470/minocycline) increases tissue levels of anticancer drugs in mice beating Lewis lung carcinoma. Oncol Res 7, 237243.

75. Tran H.T., Blumenschein G.R., Jr, Lu C., Meyers C.A, Papadimitrakopoulou V, Fossella F. ., Zmmer R., Madden T. Smythe L.G., Puduvalli V.K., Munden R., Truong M., \& Herbst R.S. 2004) Clinical and pharmacokinetic study of TNP.470, an angiogenesis inhibitor, in combination with paclitaxel and carboplatin in patients with solid tumors. Cancer Chemother Pharmacol. 54, 308314.

70. Drixler T.A., Rinkes I.H., Ritche E.D., wan Vroonhoven T.J., Gebbink M.E, \& Voest E. E. [20001 Continuous administration of angiostatin inhibis accelerated growth of colorectal liver metastases after partial hepatectomy. Cancer Research 60, 1761-1765. 


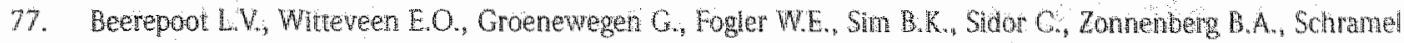
F. Gebbink M.F, \& Vest E.E. (2003) Recombinant human angiostatin by wice-dally subcutaneous infection in advanced cancer: a pharmacokinetc and longtem saifty study. Chn.Cancer Res $9,4025 \cdot 4033$.

78. O'Reily MS., Boehm T., Shing Y., Fukai N, Vasios G, Lane WS., Fhn E., Birkhead J.R., Osen B.R., \& Folkman J. (1997) Endostatin: an endogenous inhibitor of angogenesis and tumor growth. Cef 88,277285 .

79. Hajitou A., Grignet C., Dewy L., Berndt S., Blacher S., Deroanne C.F, Bajou K., Fong T., Chiang K, Foidant $J \mathrm{M}$, \& Noel A. (2002) The antitumoral effect of endostatin and anglostatin is associated with a downtegulation of vascular endothelial growth factor expression in tumor cells. FASEB J. 16. 1802-1804.

80. Herbst R.S., Hess K.R., Tran H.T., Tseng J.E, Mulani N.A., Chansangavei G, Madden T., Dawis D.W. McConkey D.I., O'Reilly MS., Elis L.M., Pluda 1., Hong W.., \& Abbruzzese IL. (2002) Phase I study of recombinant human endosiatin in patients with advanced solld tumors. $/$ Clin Oncol 20, 3792 3803 .

81. Thomas J.P., Arzoomanian R.Z, Alberti D., Mamocha R., Lee F, Friedl A. Tutsch K.. Dresen Ax, Geiger P., Pluda J., Fogler W., Schiller J.H., \& Widing G. (2003) Phase I pharmacokinetic and pharmacodvnamic sudy of recombinant human endostatin in patients with advanced solid tumors. 1.Cln. Oncol. 21, 223.231.

82. Dayis D.W., Shen Y., Mullani N.A., Wen S., Herbst R.S., O'Reilly M., Abbruzzese J.L. \& MeConkey D.J. (2004) Quantitative andysis of biomarkers defines an optimal biological dose for recombinant human endostatin in primary human tumors. Clin. Cancer Res 10, 33-42.

83. van der Schaft D.W. Dings R.P., de Lussanet Q.G., van Eik L.L, Nap A.W., Beets-Tan R.G., Boumater Steege J.C., Wagstaff J., Mayo K.H., \& Grifioen A.W. (2002) The designer anti-angiogenic peptide anghex largers tumor endothelial cells and inhibits tumor growth in animal models. FASEB I. 16, 1991-1993.

84. Griffioen A.W., Van der Schaft D.W.J., Barendsz.lanson A.F, Cox A., Struiker Boudier H.A.1., Hillen H.F., \& Mayo K.H. [20011 Anginex, a desingned peptide that inlibits angiogenesis. Biochem.) 2001, 233242.

85. Bocci G., Francia G., Man S., Lawler I., \& Kerbel R.S. (2003) Thrombospondin 1, a mediator of the antangiogenic effects of low-dose metronomic chemotherapy. Proc.Nat.Acad.SciU.S.A.100, 12917.12922.

86. Miller K.D. (2004) Recent transtational research: antiangiogenic therapy for breast cancer - where do we stand? Breast Cancer Res 6, 128.132.

87. Bocci G., Nicolaou K.C., \& Kerbel R.S. (2002) Protracted low dose effects on human endothelial cell proliferation and survival in vitro reveal a selective antiangogenic window for various chemotherapeutic drugs. Cancer" Res. 62, 6938-6943

88. Beloti D. Vergani W., Drudis T, Borsott P., Pitelli M.R., Viale G., Giavazzl R. \& Tarbolett G. (1006) The

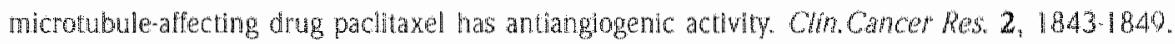

89. Rowinsky E.K. \& Donehower R.C. (11905) Paditaxel (taxol). N.Engl.M.Med 332, 10041014.

90. Sledge G.W., Neuberg D., Bernardo P., Ingle J.N., Martino S., Rowinsky E.K., \& Wood W.C. 2003 l Pase 11 trial of coxorubicin, paclitaxel, and the combination of doxorubicin and paclitaxel as front-line chemotherapy for metustatic breast cancer: an intergroup trial (E:193). LChn. Oncol. 21, 588.592.

91. Forastere A.A., Leong T., Rowinsky E., Murphy B.A., Vlock D.R., DeGonti R.C., \& Adams G.L. (2001) Phase III comparison of high-dose paclitaxel + cisplatin + gramulocyle colony-simulating factor versus low-dose paclitarel + cisplatin in advanced head and neck cancer: Easten Cooperative Oncology Group Study E1393. J.Cin. Oncol. 19, 1088-1095

92. Man S., Bocci G., Francia G., Gren S.K., Jothy S., Hanahan D., Bohlen P, Hicklin D.j, Bergers G. \& Kerbel R.S. 2002) Antitumor effects in mice of low dose (metronomic) cyclophosphatmide administered continuously through the drinking wate. Cancer Research 62,2731-2735.

93. Browder T., Butterfield C.E., Kraling B.M., Shi B., Marshall B., OReilly M.S., f Folkman 1. 2000) Antiangiogenic sched uling of chemotherapy improves efficacy against experimental drugresistant cancer. Cancer Research 60, $1878 \cdot 1880$.

04. Roitt I., Brostoff I., \& Male D. [1099] /mmunology. 
95. Mistone D.S. Fukumura D., Padget R.C., ODonnell PE, Dawis WM. Benawdez O.I. Monsky W.L. Melder R..,

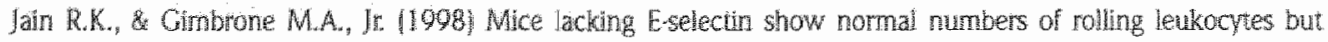

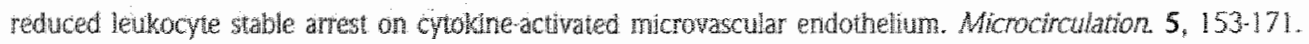

90. Kunkel EJ \& Ley K. (1990) Distinct phenotype of Eselectin-deficient mice. E-selectin is required for slow Leukocyte rolling in wyo. Cirches. 79, 11061204.

97. Springer T.A. (1994) Traffic Signals for Lymphocyte Recirculation and Lenkocyte Emigration. The Multistep Paradigm. Cell 76,301314 .

98. Ley K. (2003) The role of selectris in inflammation and disease. Thends MolMed. 9, 263268.

99. Vestweber D. \& Blanks I.E. (1099) Mechanisns that regulate the function of the selectins and uheir ligands. Physiol Rev. 79, 181-213.

100. Oude Egbrink M.G., Janssen G.H., Ookawa K., Slaaf D.W. Reneman R.S., Wehrens X.H., Maaijwee K.J, Ohshima N., Strulker Boudier H.A., \& Tangelder G.J. (2002) Especially polymorphonuclear leukocytes, but also monomorphonuclear leukocytes, roll spontaneously in venules of intact rat skin: involvement of Eselectin. J.thest Dermatol. $118,323 \cdot 320$.

101. Weninger $W_{,}$, Ulman L.H., Cheng $G$, Souchkowa N., Ouackenbush E.J, Lowe J.B., Von Andrian U.H. (2000) Specialized contributions by alpha(1,3)-fucosyltransferase.IV and FucT.VII during leukocyte rolling in dermal microvegsels. Immunity 12, 065676.

102. Ley K. Kansas G.S. (2004) Selectins in T-cell recruitment to non-lymphoid tissues and sites of inflammation. Nat Rew Mmunol 4, 325.335.

103. Jung U. \& Ley K. (1999) Mice lacking two or all three selectins demonstrate overlapping and distinct functions for each selectin. Journal of Immunoiogy 162, 6755-6762.

104. Butcher E.C. 11991$]$ Leukocyte-endothelial cell recognition: three [or more] steps to specificity and diversity. Cell 67, 10331036.

105. Anderson D.C. \& Springer T.A. (1987) Leukocyte adhesion deficiency: an inherited defect in the Mac-1, LFA. 1, and p150,95 glycoproteins. Annu. RewMed 38, 175-194.

106. Mutler W.A. (2003) Leukocyte-endothelia-cell interactions in leukocyte transmigration and the inflammatory response. Trends Immunol. 24, 327-334.

107. Lin E.Y. \& Pollard J.W. (2004) Role of infiltrated leucocytes in tumour growth and spread. British foumal of Cancer 90,20532058 .

108. Dvorak H.F. (1986) Tumors: wounds that do not heal. Similarities between tumor stroma generation and wound healing. N.Engl.M.Med. 315,1650-1659.

109. Freeman M.R., Schneck F.X., Gagnon M. L., Corless C., Soker S., Niknejad K., Peoples G.E., \& Kagsbrun M. 10051 Peripheral blood $\mathrm{T}$ lymphocytes and Jymphocytes infiltrating human cancers express vascular endothelial growth factor: a patental role for T cells in angiogenesis. Cancer Res. 55, 4140-4145.

110. Peoples G.E., Blotnick S., Takahashi K., Freeman M.R., Klagsibun M., \& Eberlein T.J. (1995) I lymphoctes that influte tumors and atheroscletotic plaques produce heparinbinding epidermal growth factor ike growth

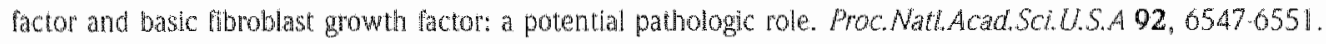

111. Hiromatsu Y. \& Toda S. (2003) Mast cells and angiogenesis. Microsc.Res Tech. 60, 6469.

112. Dirk A.E.M., oude Egbrink M.G., \& Griffioen A.W. (2005) Monocyte/macrophage infiltration in tumors: modulators of angogenesis. J.Leukoc. Biol. (accepted for publication)

113. Pawelec G. Heinzel S. Kiessling R. Mudler L., Ouyang O., \& Zeuthen J. (2000) Escape mechamisms in tumor Immunity: a year 2000 update. Crit RevOncog. 11, 97.133.

114. Zhang H. \& lssekutz A.C. (2001) Growth factor regulation of neutrophilendothelial cell interactions. I. Letukoc.Biol. 70, 225-232.

115. Grimoen A.W., Damen C.A., Martinotu S. Blijham G.H., \& Groenewegen G. (1990) Endothelial ICAM-1 expression is suppressed in human malignancies; role of angiogenic factors. Cancer Res. 56, 1111-1117. 
116. Hellwig S.M.M., Damen C.A., Van Adrichem N.P.H., Groenewegen G., Blihan G.H., G Grithoen A.W. (1097) Endothelial CD34 is suppressed in human malignancies; role of angiogente factors. Cancet Letters 120,203 . 211.

117. Griftioen A.W., Relou I.A.M., Gallardo Torres H.I., Damen C.A., Martinoti S., De Graal J.C., Zwaginga IJ., \& Groenewegen $G$. (1999) Tumor angiogenesis impairs lethocye adhesion and roling under low conditons. Angiogenesis 2, 45.50 .

118. Tromp S.C., oude Egbrink M.G.A., Dings R.P.M., Wan Velzen S., Slaf D.W., Hillen H.E.P., Tangelder O.J., Reneman R.S., \& Griffioen A.W. 2000 Tumon angiogenesis factors reduce leukocyte adhesion In wo. Int.Immunol 12,671.676.

119. Griffioen A.W., Damen C.A., Bliham G.H., \& Groenewegen G. (1990) Tumor angiogenesis is accompanied by a decreased inflammatory response of tumor associated endothelium. $B 100 d .88,667.673$. 


\section{CHAPTER 2}

\section{Tumor angiogenesis}

modulates leukocyte-vessel

wall interactions in vivo by

reducing endothelial

adhesion molecule

\section{expression}

Anita E.M. Dirkx, Mirjam G.A. oude Egbrink, Marijke J.E. Kuijpers, Sandra T. van der Niet, Viviane V.Th. Heijnen, Jessica C.A. Bouma-ter Steege, John Wagstaff and Arjan W. Griffioen 


\section{ABSTRACT}

The expression of endothelial cell $(\mathrm{EC})$ adhesion molecules involved in leukocyte-vessel wall interactions is suppressed in malignancies. In the present study, we investigated in wivo the regulation of leukocyte-vessell wall interactions by the presence of a tumor. By means of intravital microscopy, TNFo-stimulated leukocyte-vessel wall interactions were studied in ear skin microvessels of nude mice bearing small human LS174T colon carcinomas and in C57Bl/6 mice bearing murine B16F10 melanomas. Leukocyte-vessel wall interactions were studied both within and outside small tumors growing in the ear, and in ear microvessels of mice with a large tumor growing on their flank. Tumor-free mice were used as controls. Compared to values measured at the edge of the ear and in the contralateral ear, leukocyte adhesion was found to be significantly diminished in vessels inside the ear tumor in both mouse models. This reduction disappeared with increasing distance from the tumor. Surprisingly, the level of leukocyte adhesion in ear venules of mice with a large flank tumor was also significantly reduced. Leukocyte rolling, i.e. the step preceding adhesion, was not influenced by the presence of a tumor in nude mice, but was downregulated in immune competent $C 57 \mathrm{Bl} / 0$ mice. Treatment of mice bearing a small ear tumor with a humanized antiVEGF antibody prevented the dowregulation of leukocyte-vessel wall interactions inside the tumor vessels compared to the non-treated group FACS-analysis showed that isolated tumor endothelial cells [ECS] have suppressed levels of ICAM-1 as compared to ECs from normal mouse tissues. In cultured b.END5 cells the INFo:thduced upregulation of ICAM-1 and VCAM-1 was reduced in ECs that were pre-incubated with bFGF or VEGF. The current results may have an impact on the effectiveness of clinical Immunotherapeutic treatment protocols, becaise immune effector cells may not be able to enter tuminor tissue: 


\section{INTRODUCTION}

It has been known for some time that both immunotherapy and intlammation ${ }^{2}$ can contribute to the regression of solid tumors. To infiltrate tissues, including tumors, leukocytes have to interact with the venular vessel wall. These interactions start with leukocytes becoming tethered to and then slowly rolling along the vascular wall. This may result in firm adhesion with subsequent activation of the leukocytes, followed by their diapedesis and emigration into the surrounding tissue ${ }^{3}$. ECs can influence the selection of leukocyte subtypes that compose the immune infiltrate, by regulating adhesion molecule expression. By interfering with this regulated expression, tumors may have developed a mechanism of escaping from immune infiltration ${ }^{4.7}$.

Angiogenesis, the formation of new blood vessels from pre-existing ones, is a prerequisite for outgrowth and metastasis of tumors ${ }^{8,9}$. To achieve this, tumors secrete high levels of angiogenic factors such as vascular endothelial ceil growth factors (VEGF) and fibroblast growth factors (FGF). Previously, we have shown that these factors are responsible for downregulating endothelial adhesion molecules such as intercellular adhesion molecule-1/-2 (ICAM-1/-2) and CD34 4,10. Angiogenic factors also inhibit inflammatory cytokine induced expression of vascular cell adhesion molecule-1 (VCAM-1) and Eselectin $^{1 l_{*} 12}$. In addition, it has been established both in vitro ${ }^{13}$ and in wiwo ${ }^{14}$ that suppressed adhesion molecule expression by angiogenic factors results in diminished leukocyte-ressel wall interactions.

The present study aimed to investigate the regulation of adhesion molecule expression and leukocyte-vessel wall interactions in vivo by the presence of a tumor. To this end, a mouse model was developed that allows the investigation of leukocyte-vessel wall interactions, both inside and outside a tumor. The effects of a small tumor in the ear were compared with those of a larger tumor on the flank. Intravital microscopy was used to quantify the effects of the tumor on leukocytevessel wall interactions and on local fluid dynamic conditions in ear skin microvessels. To this purpose, a xenograft model was used, in which a human tumor (LS174T) was grown in nude mice. These experiments were repeated using immune competent mice (C57Bl/6) with a mouse tumor (B16F10). In addition, ex vivo and in vitro experiments were performed in order to detect ICAM-1 and VCAM-1 expression on ECs isolated from both tumor and healthy tissues (obtained from Swiss/nude mice and C57Bl/6 mice) and on mouse b.END5 brain endothelioma cells using flow cytometry.

\section{MAterials AND MethodS}

\section{Animals}

The experiments were approved by the local Ethical Review Committee on Animal Experiments. We used Swiss/mude mice (23-31 g, Charles River, Maastricht, the Netherlands), housed under sterile conditions, and $\mathrm{C} 57 \mathrm{Bl} / 6$ mice (25-30 g, Charles River), housed under standard conditions.

\section{Cell culture}

Tumor cells (LS174T) were cultured in Dulbecco's MEM (Life Technologies, Paisley, Scotland) containing 10\% inactivated fetal calf serum (FCS, Bio Whittaker, Verviers, Belgium), glutamine and antibiotics, and harvested using $0.25 \%$ trypsinMouse B 16 F 10 melanoma cells (kindly provided by dr. J. Fidler, Houston, Texas) were cultured similarly using Hank's MEM (Life Technologies) containing 5\% FCSand antibiotics, and harvested using $0.25 \%$ trypsinMouse b. END5 brain endothelioma cells (ECACC, Salisbury, United Kingdom) were cultured in Dulbecco's MEM (Life Technologies! containing $10 \%$ FCS. 


\section{Experimental protocol and intravital microscopy}

In wive experments were performed in 4 groups of $S$ wiss/nude mice. After anesthetizing these mice briefly (i.p.) using a mixture of ketamine $10.1 \mathrm{mg} / \mathrm{g}$ body welght (b.w.) Nimatek, Ad Usem Veterinarium, Cuik, the Netherlands) and xylazine $(0.05 \mathrm{mg} / \mathrm{g}$ b.w. in nude mice and $0.02 \mathrm{mg} / \mathrm{g}$ b. w. in C57BI/6 mice, Sedamun, Ad Usem Veternamium), the first group (ear tumor group; $n=6$ ) received $10 \mu$ of a dense tumor cell suspension $\left(10^{\circ}\right.$ cells) intradermally in the dorsal side of the left ear. Within $3-5$ days the ear tumor grew to a diameter of about $2 \mathrm{~mm}$, at which time point the experiment was performed. In the second group (flank tumor group; $n=4$ ) $100 \mu$ l of a tumor cell suspension $\left(10^{\circ}\right.$ cells) was injected subcutaneously into the flank. In this group experiments were performed after $2-3$ weeks, at which time the flank tumor had reached a diameter of about $1.5 \mathrm{~cm}$. The third group served as control $(\mathrm{n}=4)$. These mice were not injected with tumor cells, but were otherwise treated similarly. Two additional. mice bearing a small LS174T ear tumor $(n=2)$ were treated with HuMV833 (a humanized anti-VEGF antibody, $3.0 \mathrm{mg} / \mathrm{kg}$, i.p.; kindly provided by Protein Design Labs, Fremont, USA] on the $5^{\text {th }}$ and $7^{\text {th }}$ day after injection of the LS174T cells in the left ear. On day 8 , intravital microscopy was performed. The experiments were repeated with three groups of $\mathrm{C} 57 \mathrm{~B} / 6$ mice carrying $\mathrm{B} 16 \mathrm{~F} 10$ murine melanoma tumors: an ear tumor group $(n=7)$, a flank tumor group $(n=4)$ and a control group $(n=4)$.

Four hours prior to the start of the intravital microscopic observations, Swiss/nude mice received 750 ng recombinant murine TNFo R\&D Systems, Abingdon, U.K.) while C57Bl/6 mice received $500 \mathrm{ng}$ TNFa. Two additional Swiss/nude mice as well as two C57BI/6 mice were investigated that did not receive TNF $\alpha$, to serve as control for the TNF $\alpha$ effects in the present setup.

After TNF $\alpha$ administration 13.5 hours), mice were anesthetized by subcutaneous (s.c.) administration of the ketamine/xylazine mixture (see above). Body temperature was kept at $37^{\circ} \mathrm{C}$ by means of an infrared heating lamp. To enable intravital microscopic observation of leukocytes, 10 . $20 \mu \mathrm{ll}$ of a Rhodamine $6 \mathrm{G}$ solution $(1 \mathrm{mg} / \mathrm{ml}$ in $0.9 \% \mathrm{NaCl}$ solution) was injected into the tail vein when needed. In all mice, venules $(10-40 \mu \mathrm{m})$ in both ears were visualized using a Leitz Intravital microscope adapted for telescopic imaging ${ }^{15}$. Images were recorded on videotape for off-line analysis.

To enable quantification of systemic leukocyte counts, 20 pl blood was sampled from the vena cava at the end of every experiment, and added to Türks solution (Merck) in a 1:10 dilution. Leukocytes were counted and differentiated as polymorphonuclear (PMN) or monomorphonuclear (MMN) in a counting chamber (Clay Adams, Parsippany, NI, USA).

\section{Experimental parameters}

Venular diameters were determined with a home-built image shearing device ${ }^{10}$. Centerline blood flow velocity was measured by frame-to-frame analysis, using the fastest passing fluorescent leukocyte as a marke. The level of leukocyte rolling was determined by counting the number of rolling cells passing a vessel segment per minute. Leukocytes were considered as rolling when their velocity along the vessel wall was at least an order of magnitude lower than that of the free flowing blood cells. The level of leukocyte adhesion was assessed in a $100 \mu \mathrm{m}$ segment of the venule, and expressed as number of cells per endothelial surface area lassuming the cross-section of the vessels to be circular). Leukocytes were considered adherent when they remained stationary for at least 30 seconds. We also examined the total number of interacting leukocytes at a particular moment; this parameter includes not only the number of adhering and rolling leukocytes, but also the velocity of the latter. This parameter was determined by counting in a frozen video frame the total number of rolling and adhering leukocytes in a $100 \mu \mathrm{m}$ vessel segment; at each time point, this count was performed in 4 randomly chosen video frames and the data were averaged. In the tumor bearing 
ears, leukocyte-vessel wall interactions were quantified in venules in three different regions: (i) within the tumor, (ii) adjacent to the tumor (within a radius of $2.5 \mathrm{~mm}$ around the tumor), and (iii) at the edge of the ear. In ears without a tumor the venules were chosen at random.

\section{Real time quantitative RT-PCR}

In order to detect VEGF and bFGF gene transcription, RNA was extracted from frozen IJS174T tumor tissue using a RNeasy mini kit (Oiagen, Valencia, USA) and fron proliferating LS174T cells using TRIzol reagent (Invitrogen, Breda, the Netherlands). Subsequently, a real time quantitative RTPCR was performed in order to quantitate transcription levels of VEGF and bFGF as described by Meulemans et al. (submitted).

\section{Adhesion molecule expression on isolated endothelial cells and b.END5}

To culture mouse microvascular ECs, normal (lung, heart, kidney) and tumor tissues obtained from both Swiss/nude and $\mathrm{C} 57 \mathrm{Bl} / 6$ mice were mechanically and enzymatically digested during 1 hour at $37^{\circ} \mathrm{C}$, using a mixture of $1 \mathrm{mg} / \mathrm{ml}$ collagenase and $2.5 \mathrm{Ul} / \mathrm{ml}$ dispase (Life Technologies). After 30 minutes of incubation, $75 \mu \mathrm{g}$ DNase (Sigma Chemical Co.) was added for another 30 minutes. The single-cell suspensions were allowed to adhere for 3 hours to gelatin coated tissue culture flasks (Costar, Corning, USA). The remaining adherent cell population consisted of $2.15 \%$ ECs as determined by CD31 expression. Cells were cultured for three days inDulbecco's MEM (with 1000 $\mathrm{mg} / 1$ glucose) containing $20 \%$ fetal calf serum. In one experiment, cells obtained from normal $\mathrm{C} 57 \mathrm{Bl} / 6$ tissues were cultured for three days in the presence of $0,10,25,50$ or $100 \mathrm{ng} / \mathrm{ml} \mathrm{bFGF}$ (Sanvertech, Heerhugowaard, the Netherlands). b.END5 cells were cultured for three days with 50 $\mathrm{ng} / \mathrm{ml} \mathrm{bFGF}$ or $50 \mathrm{ng} / \mathrm{ml}$ VEGF. When applied, TNF $\alpha$ was added 6 hours prior to harvesting. Finally, the expression of ICAM-1 and VCAM-1 was determined flow cytometrically (see below).

\section{FACS-analysis of endothelial and leukocyte adhesion molecules}

Cells were harvested and fixed for 30 minutes in $1 \%$ paraformaldehyde (Merck) at room temperature. Afterwards, cells were resuspended in $20 \mu \mathrm{l}$ appropriately diluted rat anti-ICAM-1 monoclonal antibody (R\&D systems, Abingdon, UK) or rat anti-VCAM-1 monoclonal antibody (Pharmingen, San Diego, CAl and incubated for 1 hour on ice. Subsequently, the cells were incubated for 1 hour with goat-anti-rat IgG conjugated to FITC (Pickcell Laboratories, Amsterdam, the Netherlands). Finally, the cells were incubated with phycoerythrin (PE) conjugated rat anti-mouse CD31 (Dako, Glostrup, Denmark). Stained cells were analyzed on a FACS calibur flowcytometer. Data analysis was performed using Cellquest software (Becton Dickinson, Mountain View, CA).

Mouse blood leukocytes were isolated by Ficoll density gradient centrifugation (Ämersham, Uppsala, Sweden]. Cells were fixed for 30 minutes in $1 \%$ paraformaldehyde [Merck) at room temperature. Cells were incubated with the supernatant of the following hybridoma cell lines, R1. 2 (rat anti-mouse Vla-4), Mell4 (rat anti-mouse L-selectin), M17.4 (rat anti-mouse LFA-1 $\alpha$ chain) or M18.2 (rat anti-mouse LFA-1 $\beta$ chain) (all obtained from Pharmingen, San Diego, CA) for 1 hour at $4^{\circ} \mathrm{C}$. Subsequently, the cells were incubated with FITC conjugated goat anti-rat IgG (Pickcell Laboratories, Amsterdam, the Netherlands) for 1 hour at $4^{\circ} \mathrm{C}$.

\section{Statistics}

Because of their non-symmetrical distribution, data obtained by intravital microscopic experiments are presented as medians with interquartile ranges (i.e. the spread from the 25 th to 75 th percentile). Data abtained by FACS analysis are presented as means with corresponding standard error of the 
mean (SEM). Differences between two independent data groups were tested with the Mann-Whitney $\mathrm{U}$ test. Differences between paired data groups were tested with the Friedman test (more than two groups), followed by a multiple-comparison procedure. Correlation between variables was determined using Spearman's correlation test. In all tests the level of significance was set at 0.05 .

\section{RESULTS}

\section{Leukocyte-vessel wall interactions are inhibited in tumor vessels}

Previously, we showed that angiogenic factors downregulate leukocyte-vessel wall interactions in $v i w^{14}$. To investigate whether this observation also holds in the presence of a growing tumor, we developed a non-invasive mouse tumor model that can be used for intravital microscopic determination of leukocyte interactions with the microvascular endothelium.

LS174T human colon carcinoma tumor cells were injected in the ears of nude mice (Figure 2.1A and Bj, and after the outgrowth of small tumors TNFo-induced leukocyte-vessel wall interactions as well as local fluid dynamic parameters were examined in ear skin vessels. In the tumor-free control group, the median level of leukocytes interacting with the vascular endothelium after treatment with TNF $\alpha$ was 813 leukocytes $/ \mathrm{mm}^{2}$. Inside the ear tumor, this level was significantly lower (382 leukocytes $/ \mathrm{mm}^{2}, p<0.05$ ). The totall level of leukocyte-vessel wall interactions increased as a function of distance from the tumor (significant correlation of 0.35 [Rs); $p<0.01$ ), being 728 leukocytes $/ \mathrm{mm} 2$ in areas adjacent to the tumor and 953 leukocytes $/ \mathrm{mm} 2$ at the outer edge of the ear. The latter level is comparable to the one measured in the contralateral ears ( 885 leukocytes $/ \mathrm{mm}^{2}$ ) and with the level measured in the control group (Figure $2.1 \mathrm{C}$ ). Examples of intravital microscopic images of control and tumor vessels are presented in Figures 2.1D and 1E. Without TNFa pretreatment, the total level of interacting leukocytes in ear skin venules was 318 cells $/ \mathrm{mm}^{2}$ (not shown), which indicates that the tumor microenvironment completely eradicated the TNFa-induced inflammatory response. These results demonstrate a local effect of a small tumor on leukocyte interactions with the vascular endothelium.

The total level of leukocyte-vessel wall interactions includes both leukocyte rolling and adhesion. Discrimination between these two processes revealed that the reduction in leukocyte-vessel wall interactions inside a tumor is due to an effect on leukocyte adhesion (Figure 2.2A). Whereas the level of leukocyte adhesion in tumor vessels was drastically diminished to almost undetectable levels as compared to venules in the contraiateral ear ( 375 leukocytes $/ \mathrm{mm}^{2}$ ) and in the control group (331 leukocytes $/ \mathrm{mm}^{2}$ ), such differences were not found the level of leukocyte rolling (Figure 2.2B).

We showed previously that angiogenic factors are able to downregulate leukocyte-vessel wall interactions ${ }^{14}$. Using TaqMan real time quantitative RT.PCR we were able to show that LS174T tumors, grown in vivo as well as cultured in vitro, show mRNA expression of VEGF. MRNA expression of bFGF was below detection level. To investigate whether VEGF contributed to the effect of a tumor on leukocyte-vessel wall interactions, mice bearing a small LS174T ear tumor were treated with an anti-VEGF antibody. In these mice the median level of leukocyte-vessel wall interactions was 790 cells $/ \mathrm{mm}^{2}$ in the tumor vessels, which is significantly higher $(p<0.05)$ compared to the non-treated ear tumor group. In the vessels adjacent to the tumor $[1592$ leukocytes $\left./ \mathrm{mm}^{2}\right)$, at the edge of the ear (1375 leukocytes $/ \mathrm{mm}^{2}$ ) of the contralateral ear (1157 leukocytes $/ \mathrm{mm}^{2}$ ) the level of interaction was not influenced by anti-VEGF treatment.

To investigate whether leukocyte-vessel wall interactions are similarly influenced in mice with an intact immune system, similar experiments were performed in the B16F10 mouse melanoma 
Figure 2.1: Leukocytevessel wall interactions are diminished in tumors. (A and Bi Small tumors were growh in ears of

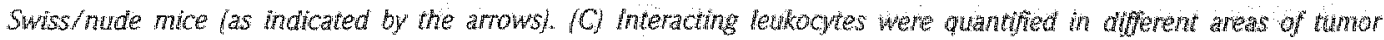
bearing and control mice (all treated with $750 \mathrm{ng}$ TWhol. Data are presented as medtans and interquarithe ranges:

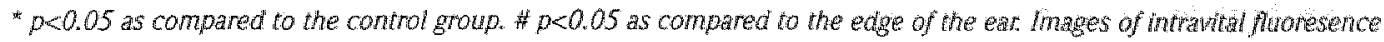
microscopy are shown of a verule in a contralateral ear (D) and a vessel in a small car tumor (b) note the large difference in leukocyte-wessel wall interactions between control and wmor vessels. Leukocytes were fluorescenty tabeled using Rhodamin $6 \mathrm{G}$. The bars represent $25 \mathrm{\mu m}$. Video images can be observed at the webstice of our labotatory: http//wmwfogunimas.nil angiogenesislab. For numbers of mice and vessels see Table 2.1 .
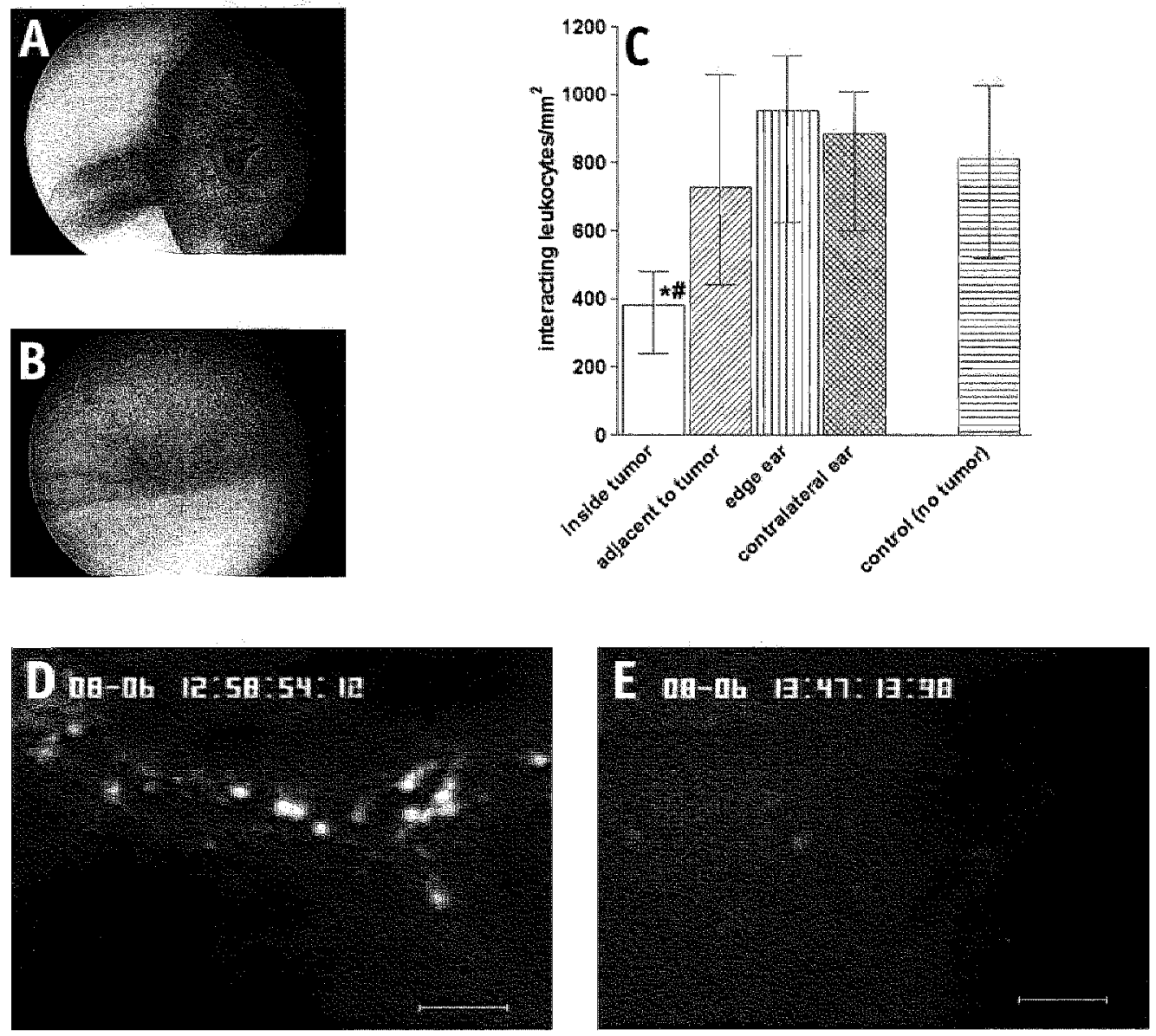

model in C57BL/6 mice. These experiments revealed comparable results, showing reductions in total level of interacting and adhering leukocytes in tumor vessels as compared to vessels outside the tumor (significant correlation of 0.55 (Rs) between leukocyte-vessel wall interactions and distance to the tumor; $p<0.01$ ) and in tumon-free control mice (Figure $2.3 \mathrm{~A}$ and $\mathrm{B}$. Interestingly, in the immunocompetent mice we did find a significant inhibition in the level of rolling leukocytes inside the tumor (3 leukocytes/min) as compared to the edge of the ear $(15$ leukocytes $/ \mathrm{min}, \mathrm{p}<0.05)$ (Figure 2.3C). 
Figure 2.2: Letkocyte adherence but not rolling is diminished in ear tumor vessels in TNFo treated Swiss/nude mice 750 nig Tho./ mousel. (A) Number of adhering leukocytes per $\mathrm{mm}^{3}$ ard (B) number of rolling leukocytes per minute in ear wenules. Data are presented as medians and inierquartile ranges. For numbers of mice and wessels see Table 2.1.

* pe0.05 as compared to the control graup. \#p pe0.05 as compared to the edge of the ear.

\section{A large tumor has a systemic effect on leukocyte-vessel wall interactions}

Injection of LS174T tumor cells on the flank of a nude mouse resulted in a large [about $1500 \mathrm{~mm}^{3}$ ), non-infiltrating and non-metastasizing tumor within approximately three weeks. Analysis of the ear venules of this group lead to the surprising finding of a significantly suppressed level of leukocyte-vessel wall interactions (509 leukocytes $/ \mathrm{mm}^{2}, \mathrm{p}<0.05$ ), as compared to the control group without a tumor $[813$ leukocytes $/ \mathrm{mm}^{2}, \mathrm{p}<0.05$ ) (Figure 2.4A). Again, comparable to the situation in the small ear tumors, this reduced level of leukocyte-vessel wall interactions can be attributed to a diminished level of leukocyte adhesion (Figure 2.4B). The level of leukocyte rolling was not found different from control (Figure $2.4 \mathrm{C}$.

These experiments were also performed in the B $16 \mathrm{~F} 10$ mouse melanoma model in $\mathrm{C} 57 \mathrm{Bl} / 6$ mice. A significant reduction of leukocyte-vessel wall
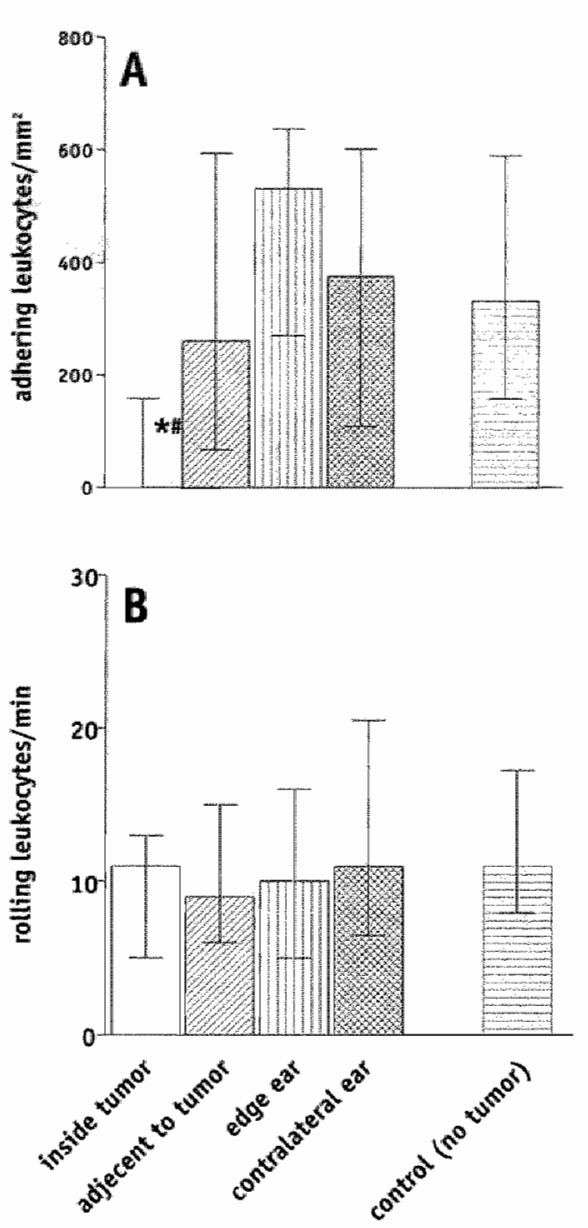
interactions was found in mice with a large flank tumor (1364leukocytes $\left./ \mathrm{mm}^{2}\right)$ as compared to the control mice without a tumor $\left(1842\right.$ leukocytes $\left./ \mathrm{mm}^{2}, \mathrm{p}<0.05\right\}$ (Figure $\left.5 \mathrm{~A}\right)$. This decline of leukocyte-vessel wall interactions can also be attributed to a decreased level of leukocyte adhesion as compared to the control group (Figure $2.5 \mathrm{~B}$ ). No significant differences were found in leukocyte rolling (Figure $2.5 \mathrm{C}$ ).

\section{Leukocyte adhesion molecule expression, systemic leukocyte counts and fluid dynamic parameters}

One explanation for the observed tumor effect on leukocyte-vessel wall interactions could be that leukocytes themselves are affected by the presence of a tumor. To exclude this effect, we investigated adhesion molecule expression on circulating leukocytes in mice bearing a small ear tumor and in healthy controls. We found no difference in expression of LFA-1 $\alpha$, LFA-1B, VLA-4 or L-selectin between these two groups (data not shown), suggesting that the decreased level of interacting leukocytes we observe inside an ear tumor is not due to altered adhesion molecule expression on leukocytes. TNFa induced a decrease in the number of circulating leukocytes from $2.4 \times 10^{6}$ leukocytes $/ \mathrm{ml}$ to $0.9 \times 10^{6}$ leukocytes $/ \mathrm{ml}(\mathrm{p}=0.05)$ in nude mice. This is probably due to the fact that $\mathrm{TNF} \alpha$ induces 
leukocyte adhesion systemically. This effect was evident for both MMNs and PMNs, but was most prominent for MMNs ( $80 \%$ reduction versus $55 \%$ for PMNs $(\mathrm{p}<0.011)$. In contrast to a small ear tumor $\left(1.3 \times 10^{6}\right.$ leukocytes/ml), the presence of a large flank tumor tended to mask these TNF $\alpha$ induced changes $\left(1.8 \times 10^{\circ}\right.$ leukocytes $\left./ \mathrm{ml}\right)$, aiso suggesting a systemic effect of the tumor.

No significant differences in blood flow velocities were detected between the vessels of the various experimental groups of both Swiss/nude and $\mathrm{C} 57 \mathrm{Bl} / 6$ mice (Table 2.1), except for deviating centerline velocities in the vessels inside the tumor in both mouse models. However, no correlation between centerline velocity values and any of the leukocyte-vessel wall interaction related parameters could be found in any of the groups. Therefore, the observed differences in leukocyte-vessel wall interactions cannot be explained by differences in fluid dynamic parameters.

\section{Diminished leukocyte adhesion in tumors is the result of suppressed endothelial adhesion molecule expression}

In previous studies, it was demonstrated that human tumor ECs express suppressed levels of adhesion molecules that are involved in leukocytevessel wall interactions $s^{4,11}$. In the present study we investigated the expression of JCAM-1 fan important adhesion molecule involved in leukocyte emigration/ on tumor ECs. To this purpose, ECs were freshly isolated from LSI74T and Bl6F10 tumors and from normal tissues. Adhesion molecule expression on ECs was determined by double staining, using CD31 and ICAM-1 antibodies, and flow cytometry ${ }^{4}$. ICAMI expression was found to be downregulated in tumor associated endothelium as compared to ECs obtained from normal tissue (Figure $2.6 \mathrm{~A}$ and $\mathrm{B}$ ).
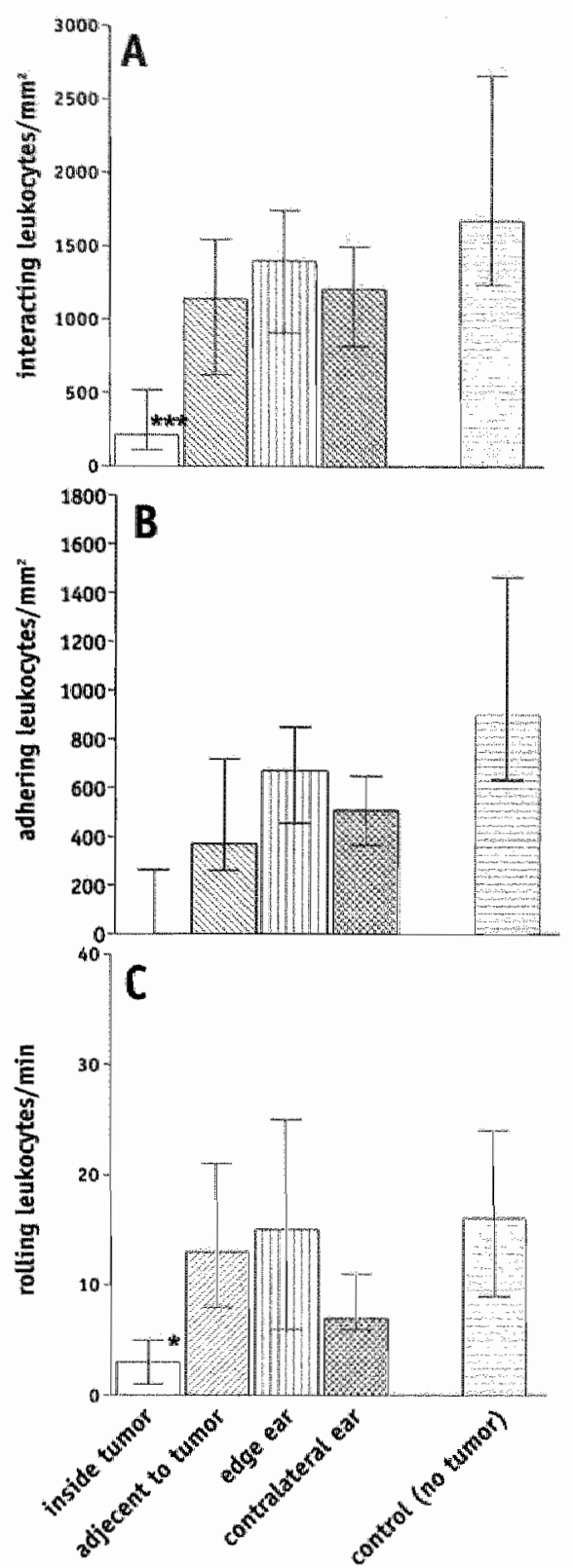

Figure 2.3: Leukocyte adherence and rolling are both diminished in tumor vessets in TWFo treated C57BL 10 mice 1500 ng $T$ NFO/mouse). (A) Total level of interacting leukocytes per mm, (B) number of adhering leukocytes per mm and (C) number of rolling leukacytes per minute in ear venutes. Data are presented às medians and interquarthe manges. For rumbers of mice and vessels see Table 21 .

* p<0.05 and * p p 0.001 as compared to the control group. 

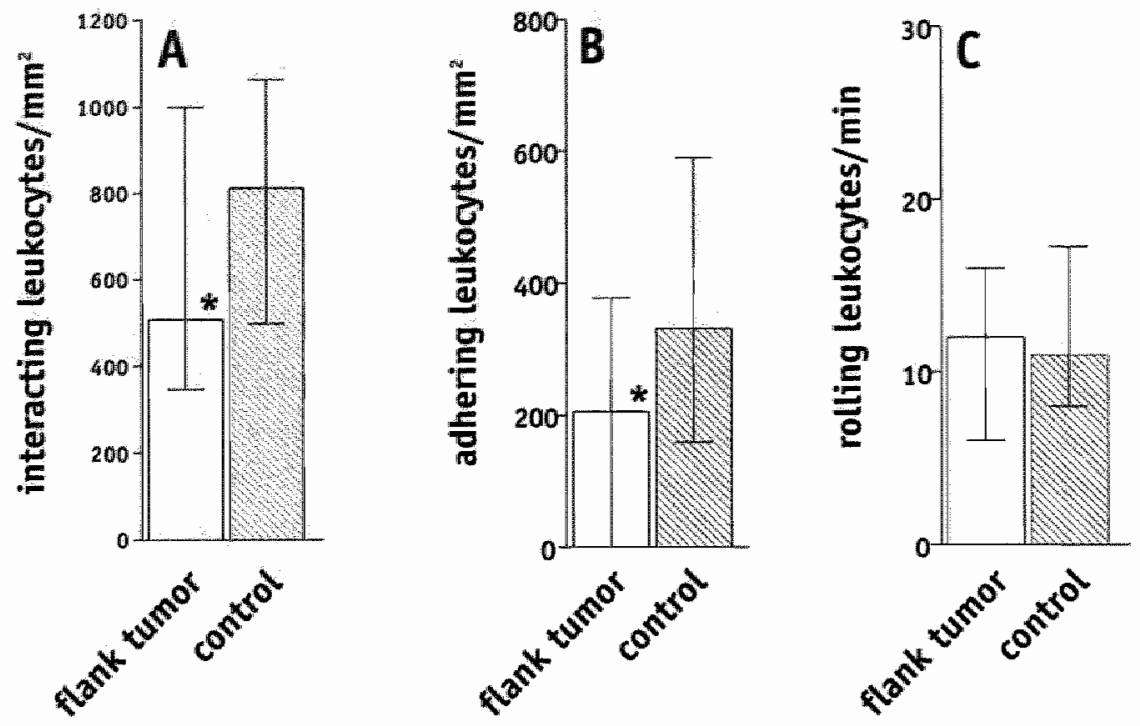

Figure 2.4: A large flank tumor has a systemic effect on leukocytevessel wall interactions in TNFo treated Swiss/nude mite $1750 \mathrm{ng}$ TNFo/mouse). (A) Level of interacting leukocytes per mm*, (B), mumber of adhering leukocytes per mm and (C) number of rolling leukocytes per minute in ear venules. Data are presented as medians and interquartile ranges. For numbers of mice and vessels see Jable 2.1. * p<0.05 as compared to the control group.
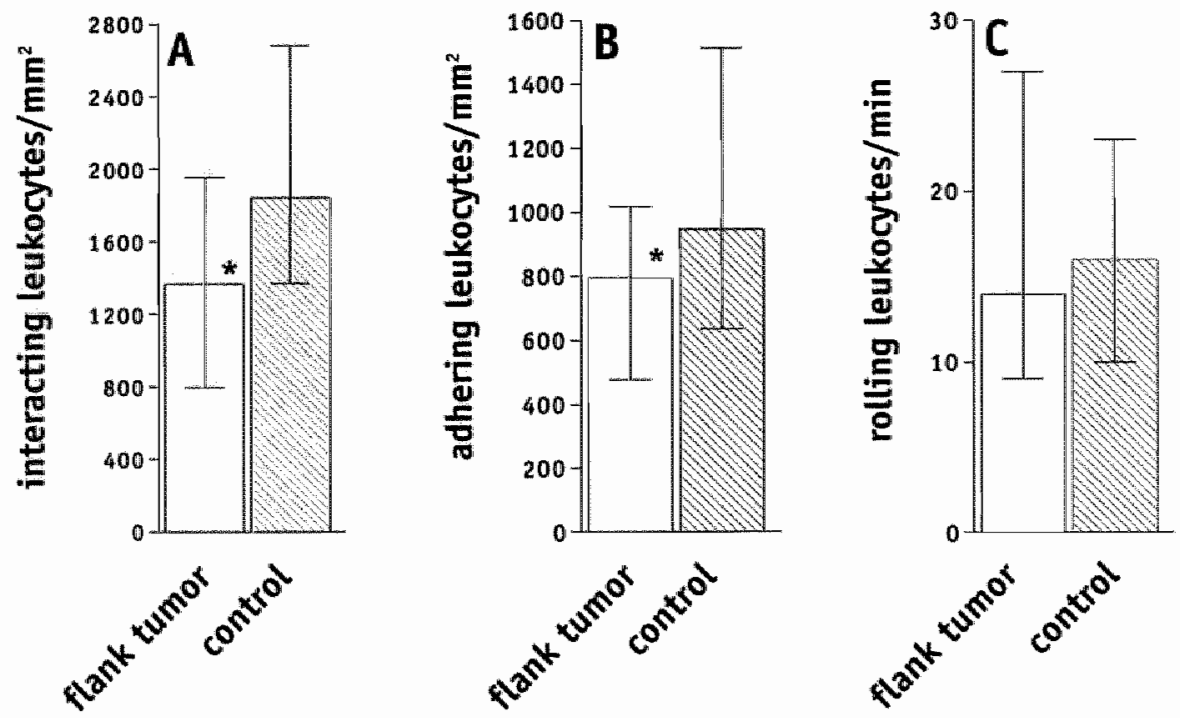

Figure 2.5: A large flank tumor has a systemic effect on leukocyte-vesset wall interactions in TNFo treated C57BV/ mice $1500 \mathrm{ng}$ WNFo/mouse). (A) Level of interacting leukocytes per mm2, (B) number of adhering leukochtes per mm2 and (C) number of rollingy leukocytes per minute in ear venules. Data are presented as medians and interquarite ranges. For numbers of mice and vessels see Table 2.1. ${ }^{*}$ p<0.05 as compared to the control group. 
Whereas ICAM-1 levels in the tumor were low (mean fluorescence intensity of 2 in LS174T tumors and 1.5 in B16F10 tumorsi), in normal tissues these values ranged between 40 and 57 . In order to investigate whether angiogenic factors produced by the tumor are responsible for this downregulation of ICAM-1, normal tissue ECs were cultured for three days in the presence of various concentrations of bFGF (Figure 2.6C). bFGF was observed to downregulate ICAM-1 on freshly isolated ECs in a dose dependent manner. In separate experiments, the mouse EC line b.END5 was cultured with or without $\mathrm{bFGF}$ or VEGF and in presence or absence of TNFo (Figure 2.6D). In the absence of TNF $\alpha$, bFGF was abserved to downregulate ICAM-1 expression $(p<0.05)$. On the contrary, TNF $\alpha$ was able to significantly upregulate both ICAM- $1(p<0.01)$ and VCAM-1 $(p<0.01)$. The TNF $\alpha$ induced upregulation of ICAM-1 and VCAM- 1 was reduced in cells that were pre-incubated with bFGF (ICAM-1: $p<0.05$, VCAM-1: $p=0.07$ ) or VEGF (ICAM-1: $p=0.06$, VCAM-1: $p=0.06$ ). These results suggest angiogenic factors as regulators of leukocyte-vessel wall interactions.

\section{Discussion}

The present study demonstrates, in two separate mouse models, that leukocyte-vessel wall interactions are locally suppressed within a tumor. Surprisingly, large tumor burdens were observed to generate a systemic downregulation of leukocyte-vessel wall interactions. The reduction in leukocyte-vessel wall interactions in tumor vessels appeared to be caused by a decreased expression of adhesion molecules on endothelial cells (ECS), and not by suppression of adhesion molecules on leukocytes. Our finding that pre-stimulation with bFGF or VEGF reduces the TNF $\alpha$-induced expression of ICAM1 and VCAM-1 on cultured mouse ECs strongly suggests that tumor derived growth factors are involved. A reduced level of leukocyte-vessel wall interactions is likely to result in impaired extravasation and infiltration of leukocytes into the tumor. Through this mechanism a tumor has the opportunity to escape the immune system.

We developed a new tumor model in which leukocyte-vessel wall interactions in and outside a tumor can be measured non-invasively, allowing longitudinal analysis during tumor development and/or in the course of an anti-cancer treatment. Several other investigators have also used animal models to examine leukocyte-vessel wall interactions in the presence of a tumor ${ }^{1723}$. However, these studies used invasive techniques such as dorsal skin fold chambers, cranial windows or skin-flaps. These techniques are more time-consuming, carry a higher risk of fallure and may induce an inflammatory reaction by surgical procedures at the site of interest. In the present study, athymic nude mice were selected to enable implantation of a tumor of human origin. These mice have large transparent hairless ears, which is a clear advantage for intravital microscopic measurements. The use of athymic mice to study immune functions may be problematic, because of limited cognate immunity due to the lack of mature T-lymphocytes. However, innate immunity (i.e. granulocytes, monocytes and natural killer cells) and B-lymphocytes are present and functional in this model. Nevertheless, we repeated the experiments using syngeneic B16F10 melanoma cells in immune competent $\mathrm{C} 57 \mathrm{Bl} / 6$ mice. This model was chosen because of the availability of a large body of literature on immunological anti-tumor responses in these mice ${ }^{2326}$.

It has previously been demonstrated that the expression of adhesion molecules is suppressed in human tumor $\mathrm{ECS}^{6,27,28}$. Furthermore, we have shown earlier in vitro and in vivo ${ }^{14}$ that this is most probably due to differences in metabolic state and phenotype of tumor EC by exposure to tumor-derived angiogenic factors such as basic fibroblast growth factor (bFGF) and vascular endothelial cell growth factor (VEGF). Other studies have shown that bFGF reduces monocyte and natural killer cell adhesion and migration by downregulating adhesion molecules on human 


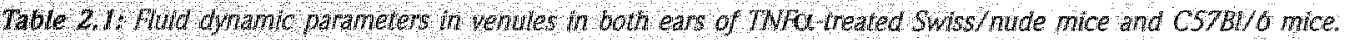

\begin{tabular}{|c|c|c|c|c|c|c|c|}
\hline & & Ear : & umor & Flank & tumor & $\mathrm{Col}$ & tral \\
\hline & & $\begin{array}{l}\text { Within } \\
\text { tumor }\end{array}$ & $\begin{array}{l}\text { Adjacent } \\
\text { fumor }\end{array}$ & $\begin{array}{l}\text { Edge } \\
\text { ear }\end{array}$ & $\begin{array}{c}\text { Contra lat. } \\
\text { ear }\end{array}$ & & \\
\hline Swiss/ & $n_{6}$ & 6 & 6 & 6 & 6 & 4 & 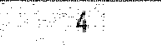 \\
\hline ude & $n_{4}$ & 17 & 20 & 21 & 31 & 60 & 48 \\
\hline & Diameter $($ im) & $20(20-26)$ & $24(20-29)$ & $25(20.27)$ & $25(22-29)$ & $23(20-27)$ & $25(23-28)$ \\
\hline & Centerl, vel, $(\mathrm{mm} / \mathrm{s})$ & $10(0.64,3)$ & $0.6(0,5-1,0)$ & $0,6(0,50,8)$ & $0.6(0.5-1.1)$ & $0.6(0.4-0.8)$ & $0.6(0.4-1.3)$ \\
\hline C57BU/6 & $\mathrm{n}_{\mathrm{m}}$ & $147=$ & 17 & 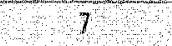 & 7 & 4 & 4 \\
\hline & $n_{r}$ & 19 & 24 & 21 & 15 & 46 & 41 \\
\hline & Diameter $(\mu / \bar{m})$ & $15(10-17)$ & $20(19-35)$ & $22(19-28)$ & $24(17-25)$ & $24(20-27)$ & $25(20-30)$ \\
\hline & Centerl, vel, $(\mathrm{mm} / \mathrm{s})$ & $0.3(0,20,6)$ & $0.4(0,2-0.6)$ & $0.6(0,40,8)$ & $0.5(0.4-0.6)$ & $0.6(0.4-0.8)$ & $0.6(0.5-1.3)$ \\
\hline
\end{tabular}

Data are presented as nedian values and interquartile ranges in parentheses.

$n_{\text {m }}$ enumber of mice, $n_{4}$ - number of vessels.

Q p 0,05 as compared to the tantrol group.

umbilical vein endothelial cells (HUVECs) ${ }^{7,29}$. Here, we show that in our mouse models tumor ECs also have suppressed ICAM-1 expression. In addition, TNFa-induced upregulation of ICAM1 and VCAM-1 was reduced in cultured b.ENDS cells (mouse endothelioma cells) pretreated with either bFGF or VEGF. Since we also show that LS174T tumor cells contain mRNA for VEGF, while it is known from literature that B16F10 tumor cells express high levels of bFGF and VEGF ${ }^{30,31}$, our data strongly suggest that the downregulation of leukocyte-vessel wall interactions in tumor vessels, as observed in the present study, is a result of exposure of $\mathbb{E C s}$ to these angiogenic factors. This hypothesis is supported by our observation that treatment of mice bearing a small ear tumor with humanized anti-VEGF antibody prevents the downegulation of leukocyte-vessel wall interactions inside the tumor.

Our finding that leukocyte-vessel wall interactions are decreased inside a tumor was confirmed in several previous studies ${ }^{1722}$. In literature, however, there is some dispute with regard to the effects of VEGF on the expression of adhesion molecules on ECs. Whereas the results of some studies are in agreement with our data and show a role for VEGF as an inhibitor of leukocyte-vessel wall interactions ${ }^{32}$, the results of other studies seem to be in contrast with our findings ${ }^{7,33}$. These latter studies report an increase in adhesion molecule expression on HUVEC after VEGF stimulation. However, in these studies VEGF stimulation was always 24 hours ol less. In a pilot study, we also observed an initial upregulation of ICAM-1 expression after VEGF stimulation of HUVECs; in contrast, prolonged stimulation (which is also the case in the presence of a tumor) results in a downregulation of ICAM-1 expression and leukocyte adhesion (data not shown). In one other study, performed by Detmar and colleagues ${ }^{34}$, leukocyte-vessel wall interactions were found to be increased in skin vessels of VEGF-transgenic mice. However, this experimental approach in which the effects of a continuous overexpression of VEGF were investigated is completely different from the situation within tumors where VEGF (and also other (growth) factors) is produced locally in increasing quantities.

The present sudy is the first to show a systemic effect of a large tumor: leukocyte-vessel wall interactions appeared to be downregulated in ear microvessels of mice bearing a large 
tumor on their flank. This systemic effect is less pronounced as compared to the situation within a tumor; leukocyte adhesion was only partially downregulated, while inside a tumor the level of adhesion was reduced to zero. This may be due to the fact that the circulating concentration of angiogenic factors in mice with a large flank tumor is lower than the local
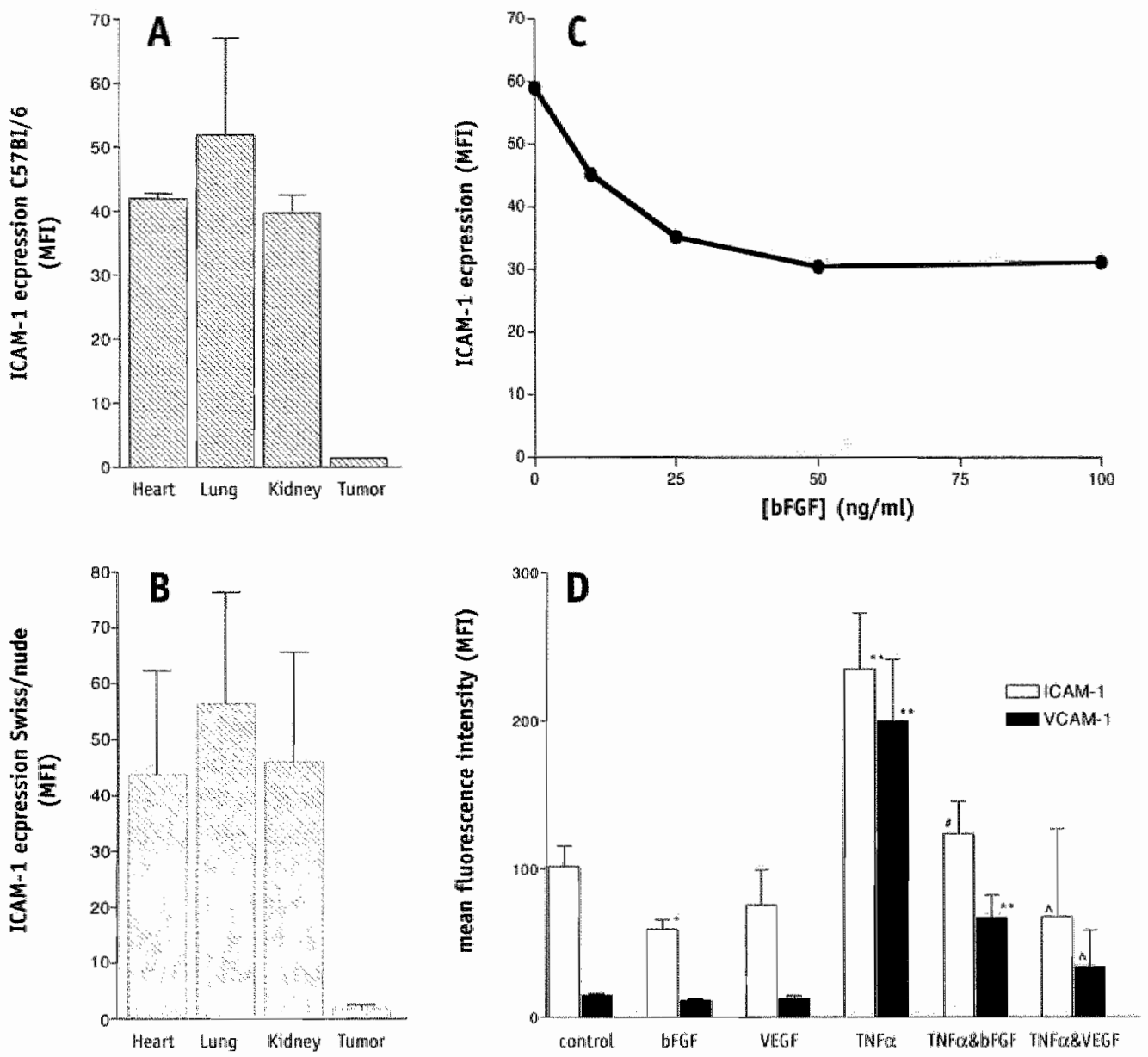

Figure 2.6: ICAM-1 is downregulated on mouse ECS isolated from a tumor as compared to ECS isolated from nomal tissue. Normat and tumor tissues from Swiss/nude (A) and CS7BV/O mice (B) were mechanically and enzymatically digested. The obtained singlecell suspensions were cultured for three days. Subsequenty, the cells were harvested and the expression of ICAM II On ECs was determined by FACS analysis. Data were divided by control values and presented as means of fluorescence intersity and corresponding standard error of the mean (SEM) values. (C) Normal C57BWo ECs were cultured with various concentrations of bFGE Subsequently the cells were harvested and the expression of ICAMI on ECS was determined by FACS analysis. (D) D.ENDS cells were cultured for three days with 50 ng/mi bFCF or $50 \mathrm{ng} / \mathrm{m}$ VECE TNRo was added o hous prior to hatvesting. Afterwards, the cells were harvested and the expression of ICAM- 1 and VCAMI on ECS was determined by FACS analysis. * $p<0.05, * * 0.01$ as compared to the control group, \# $p<0.05, \wedge, 0 \leq 0.07$ as compared to TNFa group. 
concentration inside a small ear tumor. The fact that the systemic leukocyte count was higher in TNF $\alpha$-treated mice with a large tumor on their flank than in TNFo-treated control mice also suggests a systemic inhibitory effect of the flank tumor on leukocyte-vessel wall interactions. Since it is known for that some tumors produce soluble TNFo-receptors ${ }^{35,36}$, this might also be an explanation for the observed systemic effect of a large tumor on leukocytevessel wall interactions. However, we also show data (Figure 2.6D) on the direct effect of angiogenic factors on EC, which exclude tumor cell interference in this process. Therefore we believe that the observed effects are explained by an endothelial cell mediated mechanism rather than a mechanism controlled by tumor derived signals.

The current results indicate that in the nude mouse model adhesion but not rolling is modulated by tumor derived factors. This suggests that ICAM-1 but not the selectins are sensitive to regulation by these factors, which would be a discrepancy with the human situation, where $\mathrm{E}$ - and P-selectin were found to be suppressed in tumor $\mathrm{ECs}^{11,37}$. It is more likely that the absence of effects on leukocyte rolling is due to selection of the nude mouse model, because we did observe a significant effect on leukocyte rolling inside the tumor in $\mathrm{C} 57 \mathrm{Bl} / 6$ mice. We hypothesize that either tumor regulation of leukocyte rolling is confined to a functional $T$ cell population or that this effect is dependent on specific (combinations of) cytokines that are expressed by an intact immune system. However, the observed differences between the two tumor models on leukocyte rolling may also be due to other mouse strainspecific characteristics.

During its development a growing tumor needs to undergo the so-called angiogenic switch, which is the starting point of the attraction of new blood vessels to grow beyond the size of 1-2 $\mathrm{mm}$ in diameter. It is possible that the small ear tumors studied in our experiments did not display a full angiogenic profile. Although this certainly would be an issue for spontaneous tumor models, in our model the injected cells already expressed VEGF and/or bFGF during culture. Evidence for the fact that we injected the cells in an advanced angiogenic state is provided by the fact that we observed the formation of an haematoma-like spot within 24 hours after injection, which might be due to a permeability increase induced by VEGF, and the presence of new vasculature already after 2.3 days (Figure 2.1A and B). Moreover, it was established that the small ear tumors are able to grow to the size of more adwanced tumors (diameter $>3 \mathrm{~mm}$ ), indicating that angiogenic factors are being excreted by the tumor cells. Also, the results we obtained using real time quantitative RTPCR show that LS174I" cells contain mRNA for VEGF in culture already. Therefore, we favor the view that our ear tumor model is relevant for the study of the early outgrowth of metastases rather than the outgrowth of a primary tumor.

In conclusion, the currently described tumor models introduce a non-invasive method for studying leukocyte-vessel wall interactions in wivo. We have demonstrated that leukocyte-vessel wall interactions are suppressed within a tumor, but increase as a function of distance from the tumor. Moreover, in case of a large tumor burden there appears to be a systemic downregulation of leukocyte interactions with the vessel wall. This effect is mediated by downregulation of endothelial adhesion molecules, probably by angiogenic factors, leading to the escape of turnors from the immune system. Future studies will address the issue of the reversal of the observed phenomena by treatment with anglogenesis inhibitors and the improvement of (adoptive) immunotherapy by inhibitors of angiogenesis as a novel treatment strategy for cancer. 
chapter 2 


\section{REFERENCES}

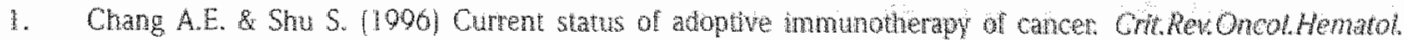
22, 213228 .

2. Arca M., Mule 3., Chang A.E. $(1906)$ Geneic approaches to adoptive cellutar therapy of malighancy. Semin. Oncol 23, 108-117.

3. Springer T.A. (1094) Traffic Signals for Lymphocote Recirculaton and Leukocyte Enigration - The Muldstep Paradign. Cell 76, 301-314.

4. Grffioen A.W., Damen C.A. Martinoti S., Bhighm G.H., Groenewegen G. (1006) Endomelial ICAM-I expression is suppressed in human malignancies; role of angiogenic factors. Cancer Res. 50, $1111 \cdot 1117$.

5. Pawelec G., Hehzel S., Kessimg R., Muller L., Ouyang $\mathrm{Q}$, Zeuthen 1. (2000) Escape mechanshs in tumon immunity: a year 2000 update. Crit Rev Oncog. 11, 97-133.

6. Grifioen A.W. (1997) Phenotype of the tumor vasculature; cell adhesion as a target for tumor therapy. Camcer I. $10,249 \cdot 255$.

7. Melder R.J., Koenig G.C., Witwer B.P., Salabakhsh N., Munn L.L., \& Jain R.K. (1996) During angiogenesis, vascular endothelial growth factor and basic fibroblast growth factor regulate natural killer cell adhesion to umor endothelium. Nature Med. 2, 992-997.

8. Grifioen A.W. \& Molema G. (2000) Angiogenesis: potentials for phamacologic intervention in the treatment of cancer, cardiovascular diseases and chronic inflammation. Phamacol.Rev. 52, 237-268.

9. Folkman 1. (1995) Angiogenesis in cancer, wascular, theumatoid and othet disease. Nature Mediche 1, 27.31.

10. Hellwig S.M.M. Damen C.A., Van Adrichem N.P.H., Groenewegen G., Blilham G.H., \& Grffioen A.W. (199\%) Endothelial CD34 is suppressed in human malignancies; role of angiogenic lactors. Cancer Letters 120, 203211.

11. Grifioen A.W., Damen C.A. Blifham G.H., Groenewegen G. (1906) Tumor angiogenesis is accompanied by a decreased infammatory response of tumor associated endothelium. Blood. 88, 667.673.

12. Grifioen A.W., Tromp S.C., \& Hilen H.E. (1908) Angiogenesis modulates the tumor immune response. Int. Exp.Pathol 79, 363-308.

13. Griffioen A.W., Relou I.A.M., Gallardo Torres H., Damen C.A., Martinoti S., De Graa I.C., Zwaginga J.L, \& Groenewegen $G$. (1999) Tumor angiogenesis Impairs leukocyte adhesion and rolling under flow conditions. Anglogenesis 2, 45-50.

14. Tromp S.C., oude Egbrink M.G.A., Dings R.P.M, Van Velzen S., Slat D.W., Hillen H.F.P, Tangelder G.,., Reneman R.S. B Griftoen A.W. (2000) Jumor angiogenesis faciors reduce leukocyte adhesion in vivo. Int.mmumol. $12,671.670$.

15. Slaaf D.W. Alewinse R, \& Wayland H. (1982) Use of telescopic Imaging in intravital mictoscopy: a simple solution for conventional microscopes. Int/Microcic. Chro.Exp. 1, 121/134.

16. Intaglietta M. \& Tompkins W. R. (1973) Microvascular measurements by wideo image shearng and splitting. Mrorowasc.Res. $5,309-312$.

17. Bessa X., Elizalde J. T., Mitjans F., Pinol V. Miquel R., Panes J., Piulats J., Pique 1.M., \& Castells A. 120021 Leukocyte recrutment in colon cancer: role of cell adhesion molecules, nitric oxide, and transforming growth factor betal. Gastroenterology 122, $1122-1132$.

18. Ryschich E., Schmidt J., Hanmerling G.J., Kar E., \& Ganss R. (2002) Transtiormation of the microvascular system during muttistage tumorigenesis. Intemational Joumal of Cancer $97,719.725$.

19. Schmidt ]. Ryschich E., Maksan S.M., Wemer J., Gebhard M.M. Herlarth C., \& Klar E. (1909) Reduced basal and stimulated leukocyte adherence in tumor endohelium of experimental pancreatic cancer. frut. Pancreatol. $26,173179$.

20. Fukumura D., Salehi H.A., Witwer B., Tuma R.s., Melder R.J. \& Jain R.K. (1995) Tumor necrosis factor alphar induced leukocyte adhesion in normal and tumor vessels: effect of tumor type, Uansplantation site, and hos! strain. Cancer Res. 55, 4824,4829. 
21. Wu N.2, Kitzman W., Dodge R, Dewhirst M.W. (1992) Diminished leukocyte-endothelum interaction in tumor microvessels. Cancer Res. $52,4265-4268$.

22. Wu N.Z., Ross B.A., Gultedge C., Klitzman B., Dodge R. Bewhirst M.W. (1994) Differences in leucocyteendothelum interacions between normal and adenocarchoma bearng tissues in response to radiation. British fournal of Cancer $69,883889$.

23. Teshima $T$, Mach $N$., HW G.R, Pan L., Gillessen S., Dranoff G, \& Ferrara J.L. (2001) Tumor cell vaccine elicits potent antitumor immunity after allogeneic T- cell-depteted bone marrow transplantation. Cancer Res. $61,16217 \%$.

24. Schreurs M.W., Eggert A.A., de Boer A.J., Vissers J.L., wan Hall T., Offringa R., Figdor C.G., \& Adema G.J. (2000) Dendritic cells break tolerance and induce protective immunity against a melanocyte differentiation antigen in an autologous melanoma model. Cancer Res. 60, 6995-7001.

25. Todryk S.M., Birchall LJ., Erlich R., Halanek N., Orleans-Lndsay J.K. \& Dalgleish A.G. (2001) Efficacy of cytokine gene transfection may differ for autologous and allogeneic tumour cell vaccines, Immunology 102, 190-198.

20. Akiyama Y. Watanabe M., Maruyama K., Ruscetú FW. Wiltrout R.H., \& Yamaguchi K. (2000) Enhancement of antitumor immunty against B16 melanoma tumor using genetically modifed dendritic cells to produce cytokimes, Gene Thet: $7,2113.2121$.

27. Piali L., Fichtel A., Terpe H.J., Imhof B.A., \& Gisler R.H. 11995 Endothelial vascular cell adhesion molecule 1 expression is suppressed by melanoma and carcinoma. Journal of Expermental Medicine 181, 811.816.

28. Madhawan M., Srinivas P., Abraham E., Ahned I., Vijayalekshum N.R., \& Balaram P. (2002) Down regulation of endothelial adhesion molecules in node positive breast cancer: possible fallure of host defence mechanism. Pathol. Oncol.Res. 8, 125-128.

20. Zhang H. \& Issekutz A.C. (2002) Down-modulation of monocyte transendothelial migration and endathelial adhesion molecute expression by fibroblast growth factor: reversal by the anti-angiogenic agent SU6608. Aml.Pathol. 160, 2219-2230.

30. Torcia M., Lucibello M., De Chiara G., Labardi D., Nencioni L., Bonini P., Garaci E., \& Cozzolino F. (1999) Interferon-alpha-induced inhibition of $B 16$ melanoma cell proliferation: interference with the bFGF autocrine growth circuit. Biachem Biophys. Res. Commun 262, 838-844.

31. Huang T.F, Yeh C.H., \& Wu W.B. (2001) Viper venom components affecting angiogenesis. Haemostasis 31 , 192200.

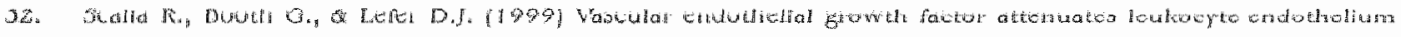
interacton during acute endothelial dysfuncton: espental role of endothelium-derved nitric oxide. FASEB I. 13. 1039.1040 .

33. Kin 1., Moon S.O., KIm S.H. Km H.J., Kon YS., \& Koh G.Y. (2001) Vascular endothelial growth factor expression of intercellular adheston molecule 1 (ICAM-1), vascular cell adhesion molecule I VCAM-1), and

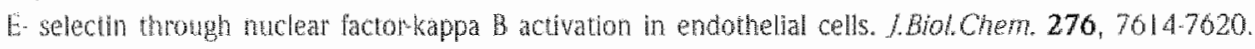

34. Detmar M, Brown L.F., Schon M.P., Elicker B.M., Velasco P., Richard L., Fukumura D., Monsky W, Claffey K.P. \& Jain R.K. (1998) Increased microvascular density and enthanced leukocyte roling and adhesion in the skin of VEG transgenic mice. Jihves:Dematol. $111,1-6$.

35. Gadduco A., Ferdeghin M., Fanucchi A. Annicchiarico C. Prato B., Prontera C., Facchini V., \& Genazzani A.R. 11090$)$ Serum levels of soluble receptors for tumor necrosis lactor (p55 and p 55 s WFin) in endometrial Cancer, Anticancer Res. 16,3125-3128.

30. Aderka D., Englemann H., Hornik V., Skomick Y., Levo Y., Wallach D., \& Kushta: G. (1991) Increased serum levels of soluble receptors for tumor necrosis factor in cancer patients. Cancer Res. 51, 5602-5607.

37. Nooften P.T., Westphal J.R., Eggermont A.M., Shalkwikk C., Max R., de Waal R.M., \& Ruiter D.J. (1098) Endothelial P-selectin expression is reduced in advanced primary melanoma and melanoma metastasis. Am. J Pathol 152, $070 \cdot 682$. 


\section{CHAPTER 3}

\section{Anti-angiogenesis therapy}

\section{can overcome endothelial}

cell anergy and promote

\section{leukocyte-endothelium}

interactions and infiltration

in tumors

Anita E.M. Dirkx, Mirjam G.A. oude Egbrink, Karolien Castermans, Daisy WJ. van der Schaft, Victor L.J.L. Thijssen, Ruud P.M. Dings, Lucy Kwee, Kevin H. Mayo, John Wagstaff, Jessica C.A. Bouma-ter Steege, and Arjan W. Griffioen 


\section{ABSTRACT}

Tumor escape from immunity, as well as the failure of several anti-cancer vaccination and cellular immunotherapy approaches, is suggested to be due to the angiogenesis mediated suppression af endothelial cell (EC) adhesion molecules involved in leukocyte-vessel wall interactions. We hypothesized that inhibition of angiogenesis would overcome this escape from immunity. We investigated this in vivo by means of intravital microscopy and ex vivo by immunohistochemistry in two mouse tumor models. The angiogenesis inhibitors anginex, endostatin and angiostatin, and also the chemotherapeutic agent paclitaxel were found to significantly stimulate leukocyte-vessel wall interactions by circumvention of EC anergy in vivo, i.e. by the upregulation of endothelial adhesion molecules in tumor vessels. This was confirmed by in vitro studies on cultured $\mathrm{EC}$ at the protein and mRNA levels. The new angiostatic designer peptide anginex was most potent at overcoming EC anergy; the enhanced leukocyte-vessel interactions led to an increase in the numbers of tumor infiltrating leukocytes. While anginex inhibited tumor growth and microvessel density (MVD) signiffcantly, the amount of infiltrated leukocytes (CD45), as well as the number of CD8+ cytotoxic Tlymphocytes, was enhanced markedly. The current results suggest that immunotherapy strategies can be inproved by combination with anti-angiogenesis. 


\section{INTRODUCTION}

Over the last decades, immuno-directed anti-tumor strategies, based on adoptive- or vaccination approaches, have been developed ${ }^{1,2}$. This approach has not been as effective as had been anticipated. Several explanations for this have been put forward. Firstly, most vaccines have been directed towards stimulating cytotoxic THymphocyte (CD8) responses and the continuous stimulation of these cells without T-cell help (CD4) eventually leads to anergy and tumor escape. Secondly, regulatory host T-cell responses may counteract induced immunity. Thirdly, the antigens towards which the immunity is directed are not tumorspecific enough. An alternative explanation might be that although immune effector cells are being generated in wwo, they are unable to migrate into tumor sites and therefore cannot exert an anti-tumor effect.

Angiogenesis, a pivotal process in the outgrowth and metastasis of tumors ${ }^{3.5}$, has been described to be involved in the escape of tumors from immune surveillance. We and others have previously shown that tumor EC have a suppressed expression of adhesion molecules (EC anergy \%), such as intercellular adhesion molecule-1/-2 (ICAM-1/-2), vascular endothelial cell adhesion molecule-1 (VCAM-1) and $\mathrm{CD} 34^{7.9}$, due to exposure to angiogenic factors such as vascular EC growth factors (VEGFs) and fibroblast growth factors (FGFs) ${ }^{6,10,11}$. We have recently demonstrated in several mouse tumor models that tumors indeed inhibit leukocyte-vessel wall interactions by downregulation of vascular adhesion molecules ${ }^{12}$.

The role of angiogenesis in anti-tumor immunity is an emerging theme in both angiogenesis and immunology research fields. This is exemplified by recent studies on the major prognostic value of T-lymphocyte infiltration in tumors and the relationship with expression of angiogenic factors ${ }^{13}$, immunization against angiogenesis related proteins ${ }^{14,15}$ and $\mathrm{ECs}$ as vaccines ${ }^{16}$. In this study, we use several angiostatic molecules to demonstrate that angiogenesis inhibition can be a way to increase leukocyte-vessel wall interactions and subsequent infiltration. Anginex is a designed 33-mer peptide angiogenesis inhibitor that inhibits vasculature formation by induction of apoptosis in endothelial cells ${ }^{17,12}$. Angiostatin and endostatin are two other angiogenesis inhibitors with a direct effect on endothelial cells ${ }^{19-21}$. TNP-470 was described in the early 90 s as an angiostatic derivative of the fungus antibiotic fumagillin 22,23 . Also several chemotherapeutic agents with claimed angiostatic activity ${ }^{24}$ such as paclicatxel and cyclophosphamide were included in these studies. It is suggested that the stimulating effect of angiogenesis inhibition on leukocyte-vessel wall interactions may be applicable for the improvement of various immunotherapy approaches.

\section{METHODS}

\section{Cell culture}

Human LS174T colon carcinoma cells were grown in DMEM (Life Technologies, Paisley, Scolland), supplemented with $10 \%$ fetal calf serum (FCS, Bio Whittaker, Verviers, Belgium), $1 \%$ glutamin. Mouse B16Flo melanoma cells (kindly provided by dr. J. Fidler, Houston, Texas) were cultured using Hank's MEM (Life Technologies, Paisley, Scotland) containing 5\% FCS, $1 \%$ non-essential amino acids (Life Technologies), $1 \%$ sodium pyruvate (Life Technologies), $1.5 \%$ MEM vitamins (Life Technologies), and $2 \%$ sodium bicarbonate (Life Technologies).

Mouse b.ENDS brain endothelioma cells (obtained from ECACC, Salisbury, United Kingdom) were cultured in Dubbecco's MEM (Life Technologies) containing 10\% FCS, $1 \%$ glutamine (Life Technologies, Paisley, Scotland), 5 mol/12-mercaptoethanol (Sigma, st Louis, MO), 1\% non-essential amino acids (Life Technologies) and $1 \mathrm{mmol} / 1$ sodium pyruvate (Life Technologies). All cells were 
harvested using $0.25 \%$ trypsin (Difco Laboratories, Detroit, MI)/0.02\% EDTA (Merck, Darmstadt, Germany] in $0.9 \% \mathrm{NaCl}$ solution.

Human umbilical vein endothelial cells (HUVEC) were cultured in RPMI-1640 (Life Technologies, Breda, The Netherlands) supplemented with $20 \%$ heat inactivated human pooled serum (provided by the Unversity Hospital Maastricht), $2 \mathrm{mM}$ L-glutamin (Life Technologies), 50 $\mathrm{ng} / \mathrm{ml}$ streptomycin and $50 \mathrm{~J} / \mathrm{ml}$ penicilin (ICN Biomedicals, Maidenhead, UK) in $0.2 \%$ gelatin coated tissue culture flasks at $37^{\circ} \mathrm{C}, 5 \% \mathrm{CO}_{2}$.

\section{Intravital microscopy}

In vivo experiments were approved by the local Ethical Review Committee on Animal Experiments. Small tumors were grown in the left ear of $\mathrm{C} 57 \mathrm{BL} / 6$ mice $125-30 \mathrm{~g}$, obtained from Charles Riwer, Maastricht, the Netherlands), as described before ${ }^{12}$. Briefly, $10 \mu \mathrm{l}$ cell suspension containing $10^{6}$ B16F10 cells was injected intradermally into the dorsal side of the ear. Within $3-5$ days ear tumors grew to a diameter of about $2 \mathrm{~mm}$, at which time point the treatment started. Three anti-angiogenic drugs were used, i.e., the designer peptide anginex ${ }^{17,25}$, endostatin and angiostatin (EntreMed, Rockville, MD) ${ }^{26}$, and TNP.470 (Takeda Chemical Industries, Osaka, Japan) ${ }^{27}$, as well as two antineoplastic drugs with claimed anti-angiogenic properties, i.e. paclitaxel (Taxol, Bristol-Myers Squibb B.V., Woerden, the Netherlands) and cyclophosphamide (Asta Medica, Diemen, the Netherlands).

For treatment of tumor bearing mice with anginex $(\mathrm{n}=6)$, Alzet osmotic minipumps (Durect Corporation, Cupertino, USA) were implanted on the flank on day 5 after tumor cell administration. Pumps administered $6 \mathrm{mg} / \mathrm{kg}$ /day of anginex, a dose that proved to inhibit tumor growth in this model by approximately $70.80 \%{ }^{17}$. Other groups of mice were similarly treated with endastatin 12 $\mathrm{mg} / \mathrm{kg} /$ day, $\mathrm{n}=5)$ and angiostatin $(2 \mathrm{mg} / \mathrm{kg} / \text { day, } \mathrm{n}=5)^{26,28}$. In two additional mice an osmotic minipump was implanted that administered equivalent amounts of control protein (bovine serum albumin). In these groups, intravital microscopic measurements were performed on day 12 after tumor cell inoculation. TNP-470 was administered according to a previously optimized protocol ${ }^{27}$, by i.p. Injections of $20 \mathrm{mg} / \mathrm{kg}$ (in $5 \%$ glucose/ethanol solution) on days $5,8,11$ and 13 after tumor cell administration $(n=4)$. In these mice intravital microscopy was performed on day 14 . Paclitaxel $16 \mathrm{mg} / \mathrm{kg}$ in $0.9 \% \mathrm{NaCl}$ solution, i.p.; $\mathrm{n}=7)$ and cyclophosphamide $(12.5 \mathrm{mg} / \mathrm{kg}$ in sterile water, i.p.; $n=4$ ) were administered on days 5 and 7 after tumor cell administration. Intravital microscopy was performed on day 8 , at which time point tumor growth was already inhibited significantly (Bouma-ter Steege, unpublished results), while no toxic side effects were observed. As a control group, 5 tumor bearing mice were used which were not treated with any of the anti-angiogenic or anti-neoplastic compounds, but treated similarly otherwise. To investigate the effect of the drugs in heaithy blood vessels, we also used mice without a tumor and treated them with anginex $(n=2)$, endostatin $(n=2)$, angiostatin $(n=2)$, TNP-470 $(n=2)$, pacitaxel $(n=4)$ and cyclophosphamide $(n=2)$; as control 5 mice were left untreated.

On the day of the experiment, mice received $500 \mathrm{ng}$ recombinant murine TNFo (R\&D Systems, Abingdon, U.K.) i.p., 4 hours prior to intravital microscopy. Administration of TNFa was performed to upregulate leukocyte-vessel wall interactions; without cytokine pretreatment adhering leukocytes are hardly present in mouse ear venules, which would preclude the assessment of a possible reduction in leukocyte adhesion ${ }^{29}$. Mice were anesthetized by S.c. administration of a mixture of ketamine $(0.1 \mathrm{mg} / \mathrm{g}$ b.w. Nimatek) and xylazine $(0.02 \mathrm{mg} / \mathrm{g}$ b.w. Sedamun, Ad Usem Veterinarium, Cuyk, the Netherlands). Intravital microscopy was performed as described before 12 . Briefly, body temperature was kept at $37^{\circ} \mathrm{C}$ by an infrared heating lamp. In all mice, venules $(10-40 \mu \mathrm{m})$ in both ears were visualized using a Leitz intravital microscope adapted for telescopic imaging ${ }^{30}$. To enable 
intravital microscopic observation of leukocytes, 10-20 $\mu$ l of a Rhodamine 6G solution (Signa Chemical Co., St. Louis, $\mathrm{MO} ; 1 \mathrm{mg} / \mathrm{m} \rrbracket$ in sterile $0.9 \% \mathrm{NaCl}$ was injected into a tail vein. As many vessels as possible (typically 8-12) were recorded for 3-5 minutes each, in areas within the tumor, outside the tumor $(<2.5 \mathrm{~mm}$ from the tumor), at the edge of the ear ( $>5 \mathrm{~mm}$ from the tumor) and in the contralateral tumor-free ear. To enable quantification of systemic leukocyte counts, $20 \mu$ l blood was sampled via heart puncture at the end of every experiment. Leukocytes were counted and differentiated as polymorphonuclear (PMN) or monomorphonuclear (MMN).

\section{Experimental parameters}

Vessel diameters were measured using an in-house built image shearing device. Centerline blood flow velocity was determined by frame-to-frame analysis, using the fastest passing fluorescent leukocyte as a marker. The level of leukocyte rolling was determined by counting the number of rolling cells passing a vessel segment per minute. Leukocytes were considered as rolling along the vessel wall when their velocity was at least an order of magnitude lower than that of the free flowing blood cells. The level of leukocyte adhesion was assessed in a $100 \mu \mathrm{m}$ vessel segment, and expressed as number of cells per endothelial surface area (assuming the cross-section of the venules to be circular). Leukocytes were considered adherent when they remained stationary for at least 30 seconds. The total number of leukocytes interacting with the vessel wall at a particular moment was determined as well. This paramater includes not only the numbers of adhering and rolling leukocytes, but also the velocity with which the latter roll along the endothelium within a vessel segment of $100 \mu \mathrm{m}$ length. When leukocytes roll slowly, the number of interacting leukocytes observed in such a vessel segment will be higher than when they roll faster, despite similar numbers of rolling and adhering leukocytes. This information is important, because it tells something about the adhesion molecules involved; leukocytes are known to roll very slowly on E-selectin, whereas rolling on P-selectin is much faster. In addition, slowly rolling leukocytes are the first to become adherent. To determine this parameter, we counted in a frozen video frame the total number of rolling and adhering leukocytes in a $100 \mu \mathrm{m}$ vessel segment. At each time point, this count was performed in 4 randomly chosen video frames and the data were averaged.

\section{Tumor growth experiments}

At day $0,10^{6}$ LSI74T human colon carcinoma cells or $2 \times 10^{5}$ B16F10 melanoma cells were inoculated subcutaneously on the right flank of 6 week old Swiss nu/hu or C57BL/ 6 mice, respectively. At day 5, when established tumors were present (approx. $50 \mathrm{~mm}^{3}$ ), an Alzet osmotic minipump (Durect, Cupertino, CA) was placed on the left llank. For LS174T tumors, treatment was performed for 2 weeks with $6 \mathrm{mg} / \mathrm{kg} /$ day anginex in $0.9 \% \mathrm{NaCl}$ solution (saline). In the $\mathrm{B} 16 \mathrm{~F} 10$ tumors, treatment was performed for 11 days with a dose range of $0,2,6$, or $12 \mathrm{mg} / \mathrm{kg} /$ day of anginex in saline). Tumor volumes were measured daily and calculated as follows: width ${ }^{2} \mathrm{X}$ length $X 0.52$. At the end of experiments tumors were excised and snap frozen for histochemical analysis. Statistical differences in tumor growth curves were analyzed using the two way ANOVA test.

\section{Immunohistochemistry}

Five $\mu \mathrm{m}$ sections were made, dried overnight, and fixed in acetone for 15 minutes at $-20^{\circ} \mathrm{C}$. After blocking of endogenous peroxidase, sections were blocked with BSA for aspecific staining in $1 \% \mathrm{BSA} / 20 \% \mathrm{FCS} / 0.1 \%$ Tween-20 in PBS for 30 minutes) and stained using rat ant-mouse CD3.1 (Pharmingen, San Diego, CA), CD8 or CD45 (both kind gifts from Dr. A Duijvestijn, Maastricht). CD31 was detected by HRP-labelled goat anti-rat lg antibody (Chemicon), whereas CD8 and CD45 
were detected by biotinylated donkey anti-rat Ig antibody flackson Immuno Research Laboratories, Inc) and avidin-biotin-HRP complex (Dako). Microvessel density (MVD), CD45 ${ }^{+}$and CD $8^{+}$cells were counted in 4 independent areas in each section (using a $0.25 \mathrm{~mm}^{2}$ grid at a 200 times magnification) by two independent observers. Statistical analysis was done using the Mann-Whitney U test.

\section{FACS analysis}

b.END5 cells were cultured with or without $50 \mathrm{ng} / \mathrm{ml} \mathrm{bFGF}$, with or without either 30 or 10 $\mathrm{gg} / \mathrm{ml}$ anginex, $500 \mu \mathrm{g} / \mathrm{ml}$ endostatin, $1 \mathrm{mg} / \mathrm{ml}$ angiostatin, $100 \mathrm{ng} / \mathrm{ml} \mathrm{TNP}-470$, or $10 \mathrm{ng} / \mathrm{ml}$ paclitaxel. $40 \mathrm{ng} / \mathrm{ml}$ TNFo was added 6 hours prior to harvesting. ICAM-1 and VCAM-1 expression was determined by rat anti-mouse ICAM-1 (CD54; R\&D systems) or rat anti-mouse VCAM-1 (CD106; Pharmingen) monoclonal antibodies, as described previously ${ }^{12}$. Similar experiments were done with HUVECs, using $10 \mathrm{ng} / \mathrm{ml}$ bFGF. ICAM-1 was detected by MEM111 mouse anti-human ICAM-1 antibody (Monosan, Uden, The Netherlands). Mouse blood leukocytes were isolated by Ficoll density gradient centrifugation (Amersham, Sweden), and incubated with R1-2 rat anti-mouse VLA-4, Mel14 rat anti-mouse L-selectin, M17.4 rat anti-mouse LFAl $\alpha$, or M1 8.2 rat anti-mouse LFA1, (Pharmingen), as described before ${ }^{12}$.

\section{Quantitative real time $R T-P C R$ ( $q R T-P C R)$}

qRT-PCR was performed with murine specific primers ${ }^{31}$ detecting beta-actin, cyclophilin, ICAM-1, VCAM-1, and E-selectin (Sigma-Genosys, UK) and analyzed with Sequence Detection System software (Applied Biosystems). The expression of each target gene was normalized to the control genes.

\section{Statistics}

Data obtained from intravital microscopic experiments are presented as medians with interquartile ranges (i.e. the spread from the 25th to 75 th percentile). Other data are presented as means with standard errors (SEM). Differences between two independent data groups were tested with the Mann. Whitney U test. Differences between paired data groups were tested with the Friedman test (more than two groups), followed by a multiple-comparison procedure. Correlation between variables was determined using Spearman's correlation test. In all tests the level of significance was set at 0.05 .

\section{RESULTS}

\section{Leukocyte-vessel wall interactions are reduced in tumor vessels in vivo; restoration by anti-angiogenesis treatment}

It was previously shown in different mouse models that pro-angiogenic factors reduce cytokine (TNFo.) induced leukocyte-vessel wall interactions in tumors and also in control tissues ${ }^{10,12}$. To investigate whether angiogenesis ininibitors can revert this process in tumors, tumor bearing mice were treated with the angiostatic peptide anginex, using a protocol $16 \mathrm{mg} / \mathrm{kg} /$ day for 7 days) which inhibits tumor growth by $70-80 \% 17$. Interestingly, this treatment completely restored the total level of cytokine induced leukocyte-vessel wall interactions inside the tumor $(p<0.001)$, as well as in vessels adjacent to the tumor $(p<0.05)$, to the level observed in healthy control mice (Figure 3.1). Discrimination between leukocyte rolling and adhesion revealed that treatment with anginex significantly increased both leukocyte adhesion $(p<0.05)$ and rolling $(p<0.01$, Figure 3.1$)$ in tumor vessels. Interactions in the contralateral ears of tumor bearing mice were highly similar to results observed in healthy control mice (data not shown). In ear skin venules of mice without a tumor anginex did not significantly 
Figume 3.1: Leukocytekessel wall interachons are suppressed in tumor morovessels; nomalization by treatment with anginex.

C57B10 mice with esablished Bl6F10 tumors were treated for 7 days with anginex, bovine sepum albumin (BSA) as protein control or received no treatment all all Leukocyte vessel wall interactions were analyed using intrawital microscopy 4 hours after in injection with 500 ng TNFa. Effects of treatment on the total level of interacting lewhocytes (A), on lewkocyte adhesion (B) and on leukocyle rolling (C). Data are presented as medians and interquarile ranges. Statistical significance was assessed in comparison to values in whtreated control mice $(* 0<0.05, * * 0<0.01$, $* * * 0 \times 0.0011$.

influence the total level of leukocyte-vessel wall interactions. Administration of bovine serum albumin as a protein control had no significant effect on leukocyte-vessel wall interactions (Figure 3.1). Intravital microscopic images of normal tissue, B16F10 tumor tissue and anginex treated tumor tissue are shown in Figure 3.2. Video images of these experiments can be viewed at http://www.fdg. unimaas.nl/AngiogenesisLab.

These experiments were performed in a suboptimal TNFa-induced situation in which both rolling and adhering leukocytes are present, at least in the control situation. In pilot experiments, in which no TNFo was used, leukocyte-vessel wall interactions appeared to be reduced inside a tumor as well, although the difference was smaller, and anginex also upregulated these interactions (unpublished data).

To investigate whether the effect of anginex is common among angiogenesis inhibitors, three other angiostatic drugs were tested (Figure 3.2A).

Treatment of mice with endostatin $\left(2 \mathrm{mg} / \mathrm{kg} /\right.$ day $\left.{ }^{32}\right)$ induced an increase in leukocytevessel wall interactions in tumor vessels as well $(p<0.01)$. Similarly, treatment of mice with angiostatin $[2$ $\mathrm{mg} / \mathrm{kg} /$ day $^{33}$ ) also increased leukocyte-vessel wall interactions in tumor vessels $(p<0.05)$, although to a lesser extent than anginex and endostatin. The effects of both inhibitors were due to an increase in leukocyte adhesion in tumor vessels, whereas leukocyte rolling remained unchanged (Table 3.1). As with anginex, endostatin and angiostatin did not influence leukocyte-vessel wall interactions in the absence of a tumor (Table 3.1). TNP-470 did not induce an increase in the total level of leukocytevessel wall interactions in tumor vessels (Figure 3.2A). Instead, this compound tended to decrease both leukocyte adhesion and rolling and, hence, the total level of interactions (Table 3.1). This effect 


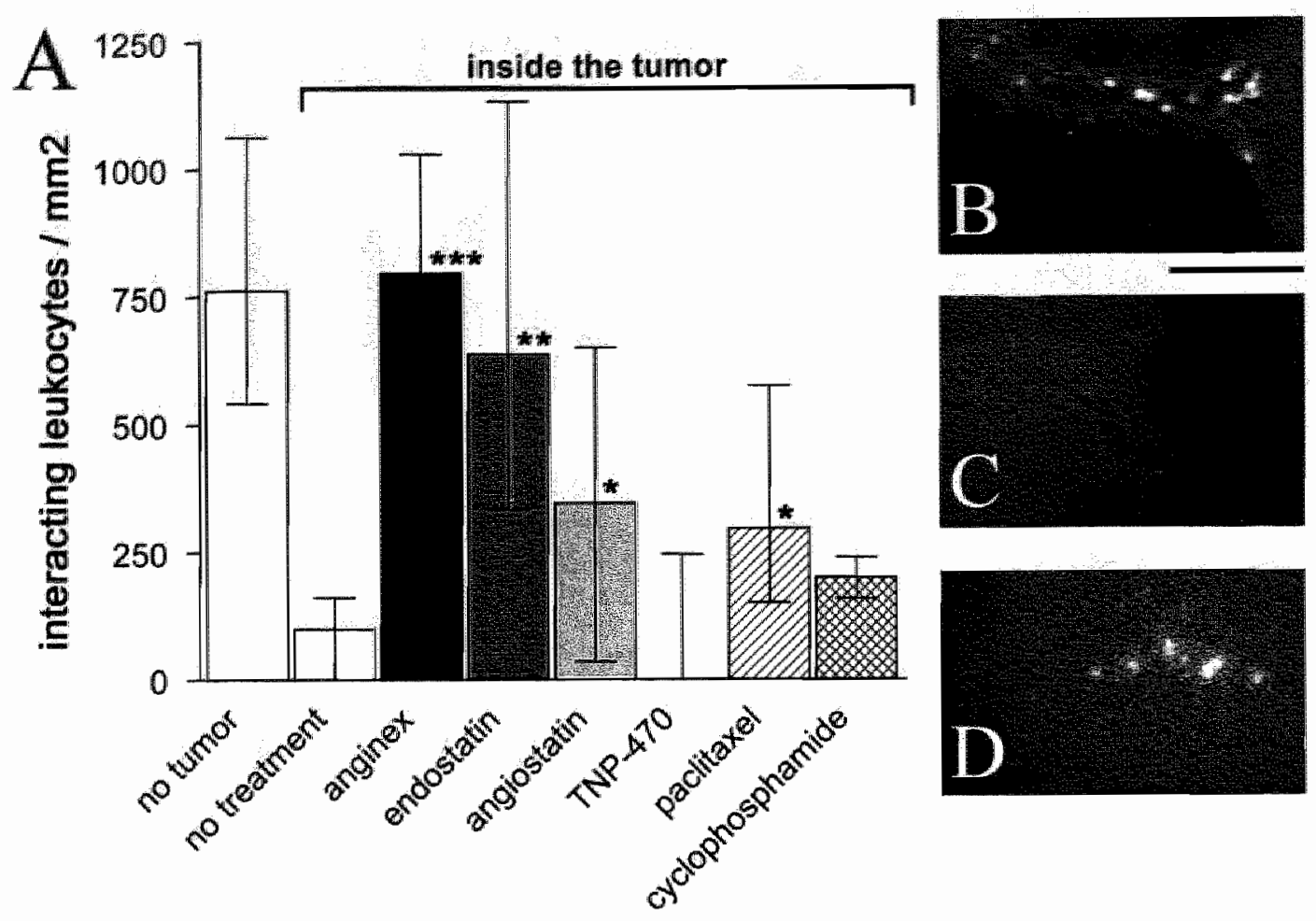

Figure 3.2: Suppressed leukocytewessel wall interactions in tumor wessels can be normalized by angiostatic and chemotherapeutic compounds.

A. Normalization of the total number of interacting leukocytes in mouse tumor vessels to numbers observed in vessels of mice without a tumor. Data are presented as medians and interquartile ranges. Statistical significance was assessed in comparison to values in tumor vessels of antreated mice $\left({ }^{*} p<0.05, *{ }^{*} p<0.01, * * 0<0.001 \%\right.$

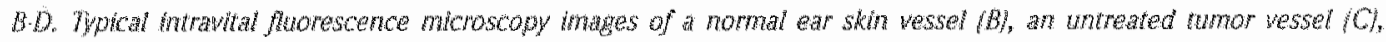

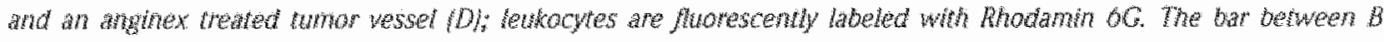

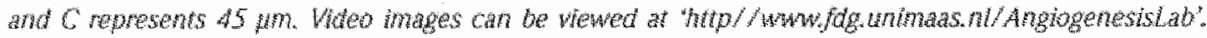

was seen especialy in tumorfee mice, where TNP-470 significantly decreased the total level of leukocytevessel wall interactons $(0<0.001)$ as well as both leukocye rolling and adhesion $1 p<0.01$; Table 3.11.

To test whether chemotherapeutic agents with claimed anglostatic properties ${ }^{3 *}$ share the capacity to overcome tumor EC anergy with spectic angogenesis mhibitors, tumor bearing mice were also treated with either paclaxel or cyclophosphamide. Pacitaxel increased the total level of leukocytevessel wal interactions in tumor vessels significandy $(p<0.05)$, although interactons were still clearly lower than in healthy control vessels (Figure 3.2A). The effect of pacitaxel appeared to be due to an increase in both leukocyte adherence and leukocyte rolling (Table 3.1). In tumor free mice, pacitaxel exhbited a dual effect by inducing an increase in leukocyte rolling $(p<0.01)$ and, at the same time, decreasing leukocyte adherence $(0<0.001)$. This resulted in a neary significant decrease $(0<0.07)$ in the total leve of leukocytevessel wall interactions (Table 3.1). The increase 


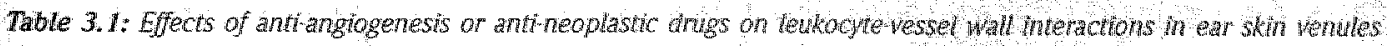
of That treated CSFBL 6 mice.

\begin{tabular}{|c|c|c|c|c|c|}
\hline & & & Ear tumor & & No tumor \\
\hline 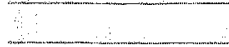 & & Inside tumor & Adjacent to tumor & Edge ear & \\
\hline Control & Interacting/mm2 & $99(0-161)$ & $429(257-610)$ & $632(378-1030)$ & $758(544-1061)$ \\
\hline \multirow[t]{2}{*}{ (no treatment) } & Adhering/mm2 & $0(0-0)$ & $114(24-356)$ & $415(209-549)$ & $434(236-720)$ \\
\hline & Rolling/min & $3(1-6)$ & $12(6-20)$ & $13(10-17)$ & $15(9-24)$ \\
\hline \multirow[t]{3}{*}{ Anginex } & Interacting $/ \mathrm{mm} 2$ & $796^{* *}(318-1030)$ & $937 *(638-1235)$ & $965(764-1421)$ & $979(518-1655)$ \\
\hline & Adhering/mm2 & $168 *(0-374)$ & $371(241-772)$ & $503(298-672)$ & $332(157-459)$ \\
\hline & Rolling/min & $9 *(7-16)$ & $16(10-24)$ & $26(8-33)$ & $23(11-32)$ \\
\hline \multirow[t]{3}{*}{ Endostatin } & Interacting/mm2 & $637^{* *}(332-1133)$ & $693(354-1038)$ & $796(474-1384)$ & $819(503-1222)$ \\
\hline & Adhering/mm2 & $282 *(0-700)$ & $157(0-321)$ & $400 \cdot(163-621)$ & $233^{*}(92-479)$ \\
\hline & Rolling/min & $6(2-12)$ & $25(10-47)$ & $20(8-37)$ & $18(11-23)$ \\
\hline \multirow[t]{3}{*}{ Angiostatin } & Interacting/mm2 & $346^{*}(35-651)$ & $758(355-908)$ & $1038 \times(902-1664)$ & $803(549-973)$ \\
\hline & Adhering/mm2 & $142^{*}(0-374)$ & $227(138-365)$ & $472(101-638)$ & $274(99-557)$ \\
\hline & Rolling/min & $3(1-8)$ & $12(5-27)$ & $19(13-31)$ & $18(15-32)$ \\
\hline \multirow[t]{3}{*}{ TNP -470} & Interacting/mm2 & $0(0-245)$ & $249(109-484)$ & $442(255872)$ & $152^{* * *}(84-345)$ \\
\hline & Adhering/mm2 & $0(0-0)$ & $0 *(0-0)$ & $277(141-408)$ & $205^{* * *}(55-236)$ \\
\hline & Rolling/min & $1(1-1)$ & $7(3-13)$ & $9+(1-11)$ & $5^{*}(3-8)$ \\
\hline \multirow[t]{3}{*}{ Paclitaxel } & Interacting $/ \mathrm{mm} 2$ & $296^{*}(150-576)$ & $332(263-454)$ & $438 *(290-648)$ & $571(434-860)$ \\
\hline & Adhering/mm2 & $155^{*}(0-297)$ & $138(109-297)$ & $367(216-463)$ & $199 *(94-354)$ \\
\hline & Rolling/min & $8^{* *}(5-13)$ & $30 *(24=40)$ & $25^{*}+(21-39)$ & $22^{* *}(12-42)$ \\
\hline \multirow[t]{3}{*}{ Cyclophosphamide } & Interacting/mm2 & $199(158-239)$ & $265(166-435)$ & $364:(315-583)$ & $303^{* * *}(133-411)$ \\
\hline & Adhering/mm2 & $187^{\star}(0-239)$ & $138(0-466)$ & $364(233-599)$ & $277^{*}(133-407)$ \\
\hline & Rolling/min & $a^{*}(0-1)$ & $1^{* * *}(1-3)$ & $1^{* * * *}(1-4)$ & $1 *(0-1)$ \\
\hline
\end{tabular}

Data are presented as median values and interquartile ranges in parentheses; * $p<0.05$,**p<0.01 and *** $p<0.001$ as compared to the control group;

number of vessels per category: control 10-47, anginex 12-24, endostatin 12-24, angiostatin 14.24, $T N P_{4} 470$ 4 $4-10$, paclitaxel 11-49, cyclophospharnide $11-23$

in interactions that is observed inside a tumor is, therefore, particularly striking.

Treatment of mice with cyclophosphamide also induced an increase in leukocyte-vessel wall interactions in tumor vessels (Figure 3.2A), but this effect did not reach the level of significance $1 p<0.095)$. This effect of cyclophosphamide resulted from an increase in leukocyte adherence $(p<0.05)$, whereas leukocyte rolling appeared to be decreased $(p<0.05$; Table 3.1$)$. In tumor-free mice, treatment with this compound clearly reduced both leukocyte rolling $(p<0.001)$ and adhesion $(p<0.05)$ and, hence, also the total level of interactions $(p<0.001$; Table 3.1). Therefore, as with paclitaxel, the non-significant increase in leukocyte-vessel wall interactions in tumor vessels after treatment with cyclophosphamide is remarkable.

\section{Leukocyte adhesion molecule expression, systemic leukocyte counts and fluid dynamic parameters}

The decrease in leukocyte-vessel wall interactions in tumor vessels cannot be explained by altered 
adhesion molecule expression on leukocytes ${ }^{12}$. We also found that the effects of the angiogenesis inhibitors were not due to changes in leukocyte adhesion molecule expression. Dufferences in expression of VLA-4, L-selectin, LFA-1 $a$, and LFA-1, on the circulating leukocytes were not observed between the different treatment groups (data not shown).

The number of leukocyte-vessel wall interactions can also be influenced by the level of leukocyte delivery to the observed blood vessels. This parameter depends on leukocyte conceritration in the passing blood and on local blood fow. Treatment with anginex, endostatin, angiostatin and paclitaxel did not influence the number of circulating leukocytes or the percentage of polymorphonuclear (PMNs) and monomorphonuclear cells (MMNs; Table 3.2). TNP-470 had no effect on the systemic leukocyte count as well, although the percentage of PMNs was increased. Treatment with cyclophosphamide, however, induced a significant decrease in systemic leukocyte count $(p<0.01)$ with a concomitant decrease in the amount of PMNs $(p<0.01)$.

In all treatment groups, local vessel diameters and blood flow were not influenced (data not shown]. Therefore, it is suggested that the observed effects of all angiogenesis inhibitors except cyclophosphamide on leukocyte-vessel wall interactions in and around the tumor cannot be explained by changes in leukocyte delivery to the vessels. In the present mouse model, cyclophosphamide treatment appears to be associated with a decrease in leukocyte delivery to vessels due to a significant reduction in systemic leukocyte concentration.

Table 32, ffect of treatment with ant anglogenesis or antheoplastic drugs on systemic leukoche concentration and

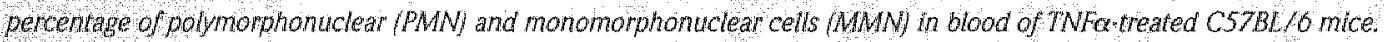

\begin{tabular}{lccc}
\hline & Systemic leukocyte count & PMNs & MMNs \\
& $\left(\times 10^{6} / \mathrm{ml}\right)$ & $(\%)$ & $(\%)$ \\
\hline Control (no treatment) & $6.6 \pm 0.9$ & $16 \pm 2$ & $84 \pm 2$ \\
Anginex & $9.0 \pm 0.8$ & $17 \pm 1$ & $83 \pm 1$ \\
Endostatin & $6.0 \pm 0.2$ & $12 \pm 2$ & $88 \pm 2$ \\
Angiostatin & $7.7 \pm 1.4$ & $16 \pm 3$ & $84 \pm 3$ \\
TNP-470 & $6.5 \pm 1.0$ & $33 \pm 4^{*}$ & $67 \pm 4^{*}$ \\
Paclitaxel & $5.5 \pm 0.9$ & $22 \pm 3$ & $78 \pm 3$ \\
Cyclophosphaninde & $2.1 \pm 0.3^{*}$ & $5 \pm 2^{*}$ & $95 \pm 2^{*}$ \\
\hline
\end{tabular}

Data are presented as means \pm SEM; * $p<0.01$ as compared to control.

\section{Anti-angiogenesis treatment prevents downregulation of endothelial ICAM-I and VCAM-1 expression}

To investigate whether the effects of the angiogenesis inhibitors are due to a normalization of the suppressed adhesion molecule expression on tumor ECs, in vitro experiments were performed using cultured b.END5 mouse EC. When cultured in the presence of $50 \mathrm{ng} / \mathrm{ml} \mathrm{bFGF}$, the proliferation rate of b.END5 cells is enhanced and ICAM-1 and VCAM-1 expression is downregulated by $60 \%$ and $81 \%$, respectively (Figure $3.3 \mathrm{~A}$ and $\mathrm{B}$ ). Comparable but less pronounced results were observed by culturing in the presence of VEGF (data not shown). The bFGF-mediated downregulation of ICAM1 was also observed in HUVEC (Figure 3.3C), which is in agreement with previous observations 0,7 . 

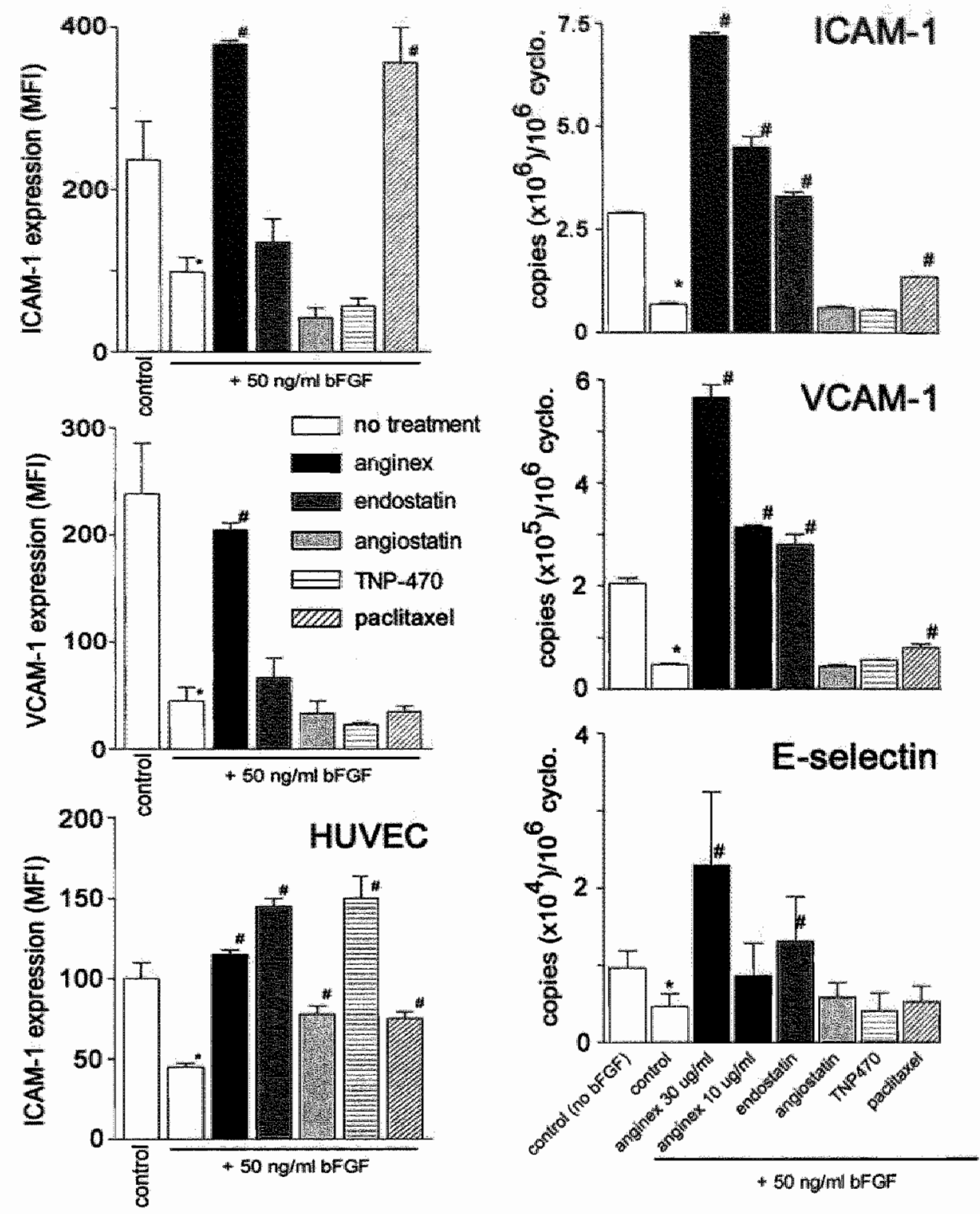

Figure 3.3: Growth facror /OFCF induced downregulation of adhesion molecule expression on mouse EC, nomallzation by angiostatic and chemotherapeutic agents.

A,B. FACS analysis of ICAM 1 and VCAM 1 expression in b. ENDS mouse EC, with or withou DFCF and after treatment with angiostatic and chemotherapeutic agents. Data are expressed as mean flurescence interisily (MNI). C. CACS anialysis of ICAM-I expression in HUVEC. D,EF Quantiative real-time RT.PCR analysis of the effect of tratment on expression

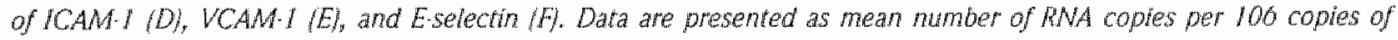
cyclophilin RNA. For all panels, datia are means (t2SEM) of four independent experiments. " $B<0.05$ versus cells without BFGF, $0<0,05$ versus untreated celis. 
Culture in the presence of anginex completely prevented the bFGF-mediated downregulation of both ICAM-1 and VCAM-1 at the protein level (Figure 3.3A-C) and also at the RNA level (Figure 3.3CE, for ICAM-1, VCAM- 1 and E-selectin). Endostatin treatment increased adhesion molecule expression at the RNA level (Figure 3.3D-F). Angiostatin and TNP-470, the compounds with less and no activity in vivo (see Figure 3.2), did not significantly influence adhesion molecule expression in b.END5 mouse $\mathrm{EC}$ this in vitro bFGF-driven model. The latter compounds did have an effect on ICAM-1 expression in HUVEC, suggesting a difference in reactivity between mouse and human endothelial cells. Paclitaxel did prevent the downregulation of ICAM-1, but not VCAM-1.

To investigate adhesion molecule levels in vivo, BJ 6F10 tumor tissues were analyzed. In untreated B16F10 tumors, low mRNA expression levels of both ICAM-1 and VCAM-1 were detec Table whereas the expression of E-selectin was virtually absent (Figure 3.4A). In lung, the expression of all three adhesion molecules was over 100-fold higher as compared to expression in tumors (data not shown). Interestingly, in tumors of mice treated with anginex the expression of the EC specific molecules VCAM- $]$ and E-selectin was significantly upregulated by the treatment $[2.38$-fold $(p<0.05)$ and 2.43 fold $(p<0.05)$, respectively; Figure $3.4 \mathrm{~B}$ ). When the change in microvessel density is also taken into account (a 3.3-fold decrease as compared to control, see Figure 3.5F) the relative increase in expression of both VCAM-1 and E-selectin is over 8-fold. The enhancement of ICAM-1 expression was not detectable using this method, most likely because this adhesion molecule is also expressed by tumor and/or stromal cells which are not affected by specific anti-angiogenesis treatment.
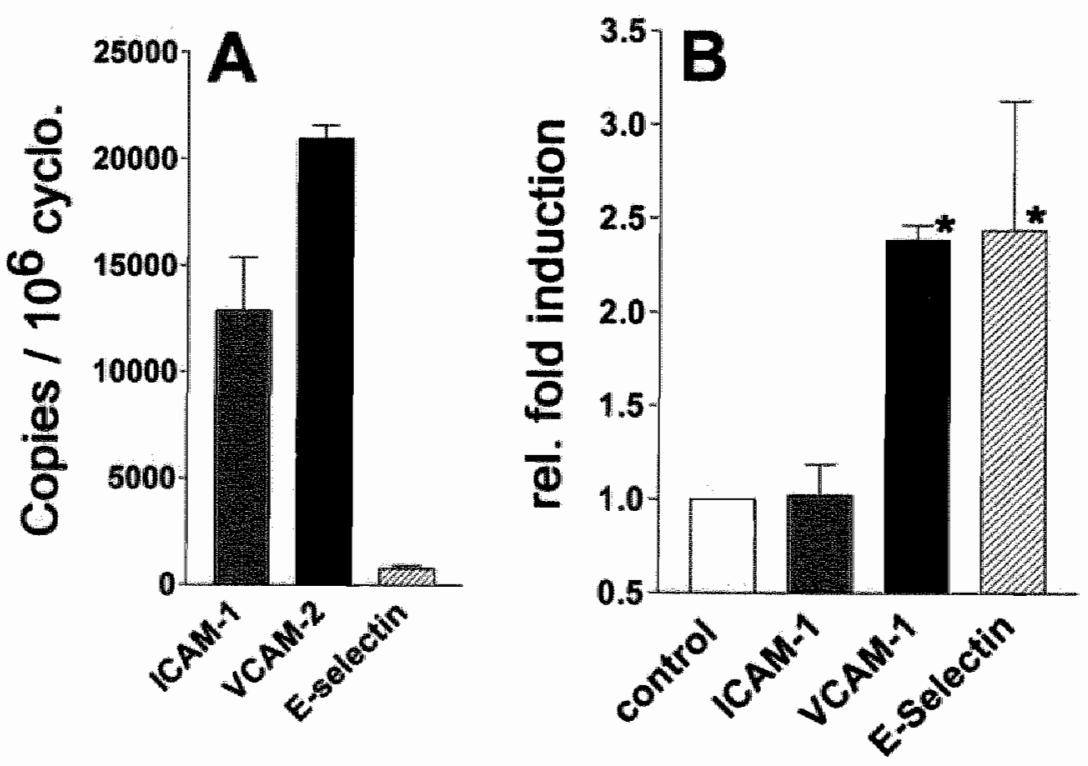

anginex

Figure 3.4: Effect of treatment with anginex on adhesion molecule expression in tumor tissue in wivo.

A. Expression levels of ICAM I, VGAMI, and E-selectin in non-treated tumor tissules by quantitative real-time RTPCR analysis, nomalized to cyclophitim expression. B. Effect of anginex on ICAM-1, VCAM1, and E-selectin expression in tumor tissue. Data are presented as average relative fold induchon. Expression in untreated tumors was set to 1.

* pe0.05 as compared to untreated control iumors. 


\section{Leukocyte infiltration is enhanced by angiogenesis inhibition}

We also invesigated in two different mouse tumor models whether the enhancement of andothelial adhesion molecules and leukocyte-vessel wall interactions contributes to an increased leukocyte inflitration in a tumor. After a two-week period of treatment of human LSI74T bearing Swiss nu/nu mice with anginex, tumor growth $(p<0.05$, Figure $3.5 A)$ and microvessel density $(p<0.0005$, Figure 3.5B were significanty reduced. At the same time, anginex treatment enhanced the number of influtrating leukocytes in the tumor over 2 -fold $(p<0.01)$, as determined using the panleukocyte marker CD45 (Figure 3.5C). Similar but more pronounced results were observed in the $B 16$ F] 0 melanoma model in immunocompetent C57BL6 mice (Figure 3.5D-G). Treatment of mice with anginex at $6 \mathrm{mg} / \mathrm{kg} / \mathrm{day}$ resulted in a dose dependent inhibitory effect on tumor growth. The inhibition of angiogenesis, resulting in a 3.3-fold decrease in microvessel density, caused a 6.7 -fold increase in infiltrated leukocytes (Figure 3.5D and G). It was interesting to see that in this immunocompetent model also cognate immunity (cytotoxic $T$ lymphocytes, CD8) was directed to the tumor as well (4.4-fold increase, Figure 3.5D and H).
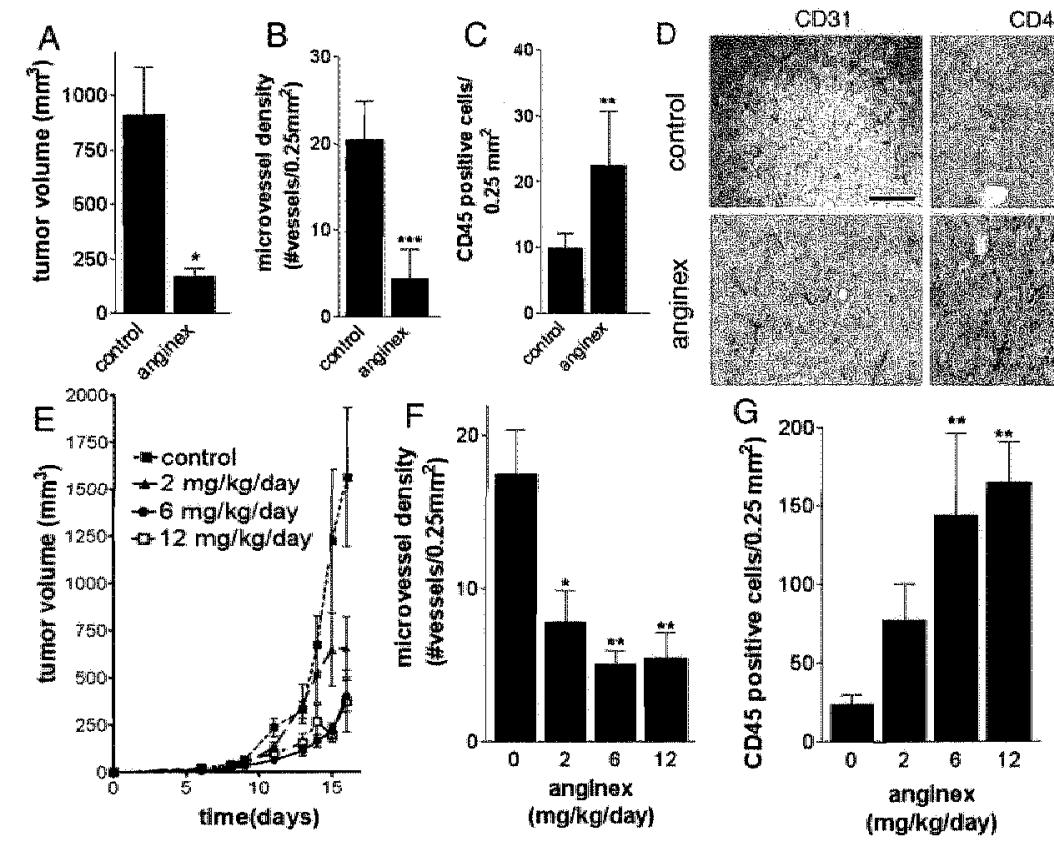

045

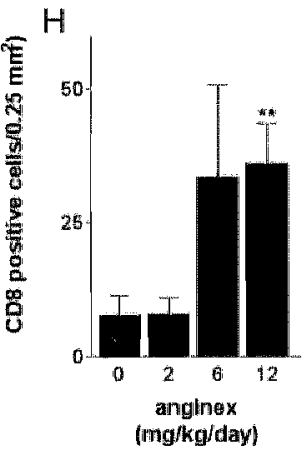

Figure 3.5: Relationship between angiogenesis inhibition and leukocyte infittration.

Tumor size (A), microvessel density assessment by CD3/ staining (B) and infiltration by CDAS + leukocytes (C) of LSITAT human colon carcinoma with and without anginex treatment. D. Immunohistochernical mages of microvessel densily (CD31), and infitration by CD45+ leukocytes and CD8+T lymphocytes in B/DFlO melanoma of control and anginex treated mice. Bar in upper left panel represents $50 \mu \mathrm{m}$. EH: Effect of increasing doses of anginex $(2,6,12 \mathrm{mg} / \mathrm{kg} / \mathrm{day}$ on tumor size, microvessel density, total leukocyte (CD45), and cytotoxic Timphocyte (CD8) infitration in Blof 10 melanoma. "p<0.01, **0<0.001 and ** $0<0.0001$ as compared to control. 


\section{Discussion}

The present study demonstrates in an orthotopic syngeneic mouse model and in a human xenograft model that anti-angiogenesis treatment can overcome the suppression of endothelial adhesion molecules in tumors, leading to the amelioration of leukocyte-vessel wall interactions and to an increased inflammatory infiltrate in tumors.

It is known that turnors have the capacity to prevent the formation of a proper anti-tumor immune response by downregulation of endothelial adhesion molecules that are necessary for leukocytevessel wall interactions $11,12,35$. This regulation is mediated by angiogenic growth factors 0,7 . It was recently demonstrated in ovarian carcinoma patients that the expression of VEGF in tumor tissue is negatively correlated with the presence of infiltrating. $T$ lymphocytes, which was found to be the strongest prognostic factor in ovarian carcinoma ${ }^{36}$. Similarly, we showed that the characteristic intense leukocyte infiltration in medullary breast carcinoma, as compared to ductal breast carcinoma, can be explained by their difference in angiogenic potential ${ }^{37}$. We hypothesized that when angiogenesis eradicates the infiltration of leukocytes, inhibition of angiogenesis would circumvent tumor escape from immunity and would lead to increased leukocyte infiltration. Previously, we showed in vitro that the angiogenesis inhibitors platelet factor-4 (PF4) and thrombospondin-1 not only prevent the downregulation of adhesion molecules by bFGF or VEGF, but also induce re-expression of these molecules in cultured human umbilical vein derived endothelial cells ${ }^{38}$. Similarly, angiostatin was found to enhance the expression of E-selectin ${ }^{39}$, while the synthetic angiogenesis inhibitor SU6668 reversed the bFGF-mediated downregulation of ICAM-1, VCAM-1 and E-selectin ${ }^{40}$. Here, we have demonstrated that this phenomenon is shared by more angiogenesis inhibitors and that it has impact on in vivo leukocyte-vessel wall interactions and the formation of an immune infiltrate.

In the present study, we show in vivo as well as in vitro, both at the mRNA and protein level, that angiostasis leads to re-expression of adhesion molecules on endothelial cells. The major role of ICAM- 1 in leukocyte extravasation ${ }^{41}$ and the marked upregulation of ICAM-1, VCAM-1 and Eselectin in response to angiogenesis inhibition does not rule out a role for other adhesion structures. CD31, CD34 and ICAM-2, molecules with important functions in leukocyte-vessel wall interactions, are also described to be suppressed in tumor vessels ${ }^{7,42}$. The same holds true for P-selectin, a molecule involved in leukocyte and platelet binding ${ }^{43}$. It is expected, but remains to be proven, that these molecules are also part of angiogenesis-associated regulation.

The present results indicate that not all angiogenesis inhibitors tested showed the same inflammatory response. For treatment of cancer, the agent of choice would presumably combine the strongest vessel growth inhibitory activity with the most potent inflammatory properties. Apparently, these properties are not interdependent; e.g. TNP-470 and anginex differ largely in immune modulatory activity (see Figures 4.2 and 4.3 ), while they are equipotent angiogenesis and tumor growth inhibitors in the B16F10 melanoma model ${ }^{17}$, which suggests that the mechanisms of these effects are different. Anginex increased the expression of endothelial adhesion molecules on tumor endothelial cells both at. mRNA and protein level. As a consequence, anginex significantly increased leukocyte-vessel wall interactions in tumor vessels to levels found in healthy control animals. This, in turn, led to increased infiltration of leukocytes into the tumor. Interestingly, angiogenesis inhibition is also suggested to be a promising approach for the treatment of diseases with a chronic inflammatory component, such as rheumatoid arthritis and psoriasis ${ }^{4 / 4}$, in which a concomitant pro-inflammatory activity is undesirable. It is tempting to speculate that the good results with TNP-470 in arthritis models are due to the lack of pro-inflammatory activity. It might be important, therefore, to screen a larger array of compounds for this activity in order to better judge applicability in various diseases. 
Interestingly, the inflammatory activity of angiostatic compounds is also shared with certain chemotherapeutic agents. It has been observed previously that chemotherapeutic compounds such as cyclophosphamide and paclitaxel can induce leukocyte infiltration in tumors ${ }^{45}$. Currently, there is an ongoing discussion concerning the intrinsic angiostatic activity of several chemotherapeutic drugs ${ }^{46}$. We and others have demonstrated for the tubulin binding compounds (taxanes and the vascular targeting agent combrestastatin) that an intrinsic anti-angiogenesis activity exists at the level of endothelial migration and tube formation, at concentrations that do not affect cell growth ${ }^{t}$. The presently shown shared activity of paclitaxel and angiogenesis inhibitors at the level of adhesion molecule regulation and leukocyte-vessel wall interactions may support the theory that certain chemotherapeutics are angiostatic and may be used at ultra low dosages for prolonged periods of time as treatment of cancer.

The effects of the angiogenesis inhibitor TNP-470 on leukocyte-vessel wall interactions and adhesion molecule expression contrasted with the results obtained with the specific angiogenesis inhibitors anginex, endostatin and angiostatin. This may be explained by the fact that TNP.470 has other indirect effects, which is also suggested by the systemic decrease in leukocyte-vessel wall interactions in tumor-free mice (Table 3.1) and the change of leukocyte composition in peripheral blood (Table 3.2). Like TNP-470, cyclophosphamide also decreased leukocyte-vessel wall interactions in healthy microvessels in vivo, while paclitaxel only reduced the level of leukocyte adhesion in these vessels. This decrease in leukocyte-vessel wall interactions in a tumor-free environment may masks the upregulating effect of these agents on leukocyte-vessel wall interactions in tumor vessels.

Here, we used recently developed tumor models ${ }^{12}$ in which leukocyte-vessel wall interactions can be measured non-invasively, allowing longitudinal analysis during tumor development and over the course of anti-cancer treatment. The combined assessment of leukocyte-vessel wall interactions inside the vascular system and leukocyte infiltration into the tissue provides a functional meaning to changes in leukocyte adhesion. Our findings indicate that the increase in leukocyte-vessel wall interactions in tumor vessels is followed by increased infiltration of leukocytes into the tumor tissue, where they can help to suppress tumor growth. It is an interesting observation that both angiogenesis inhibitors and chemotherapeutic compounds can elucidate this effect. It is tempting to speculate that the reported, sometimes very good, results from combining both treatment strategies ${ }^{18,48}$ is explained by this enhancement of inflammatory infiltrate. In a preliminary pilot study we found that combination of paclitaxel and anginex leads to an enhanced leukocyte infiltrate as compared with ejther paclitaxel or anginex alone (unpublished results). It remains to be elucidated, however, which leukocyte subtypes are involved in increased homing to the tumor.

The present study was focused on investigating the escape of tumors from immunty and how the leukocyte infiltrate can be augmented in tumors. Although the beneficial effect of cognate ant. tumor immunity is not debated at all, it should be kept in mind that several studies have shown that leukocytes, by their inflammatory cytokine/chemokine production, and by their release of matrix metalloproteinases, can contribute to angiogenesis programs and thereby to tumor progression as well 49,50. Tumor associated macrophages have been mostly recognized for this phenomenon ${ }^{51}$. We, however, favor the view that leukocyte infiltration should be promoted in order to drive anti-tumor immunity. In conclusion, the present study demonstrates that angiogenesis inhibitors increase leukocyte-vessel wall interactions in tumor vessels, which leads to increased leukocyte infiltration into tumor tissue. This anti-tumor inflammatory effect of angiogenesis inhibitors is mediated by increased expression of adhesion molecules on tumor endothelial cells, and not by altered expression of leukocyte adhesion molecules, effects on the amount of circulating leukocytes, or other direct or indirect vascular effects modulating fluid dynamic parameters. These data strongly support the concept of combining modern 
immunotherapeutic approaches with angiostatic therapies. At least additive and hopefully synergistic anti-tumor responses would be expected from this combination. 


\section{REFERENCES}

1. Ribas A., Butterfeld L.H., Glaspy J.A., \& Economou J.S. (2003) Curent developments in cancer wacches and celluar immunotherapy. J.Cin. Oncol. $21,2415,2432$.

2. Rosenberg S.A. (2004) Shedding light on immunotherapy for cancer. N.Engl.M.Med. 350, 1401-1403.

3. Dworak H.F. (2005) Anglogenesis: update 2005. J.Thromb. Haemost: 3, 18351842.

4. Griffioen A.W. \& Molema G. (2000) Angiogenesis: potenijals for phamacologic intervention in the treatment of cancer, cardiovascular diseases and chronic intlammation. Phamacol.Rev 52, 237-268.

5. Kerbel R. \& Folkman I. (2002) Clinical tans ation of angiogenesis inhibitors. Nat. Rev Cancer 2, 727.739.

6. Griffioen A.W. Damen C.A., Bliham G.H., Groenewegen $G$, 11900$)$ Tumor angogenesis is accompanied by a decreased inflammatory response of tumor associated endothelium. Biood. 88, 667-673.

7. Grifioen A.W., Damen C.A., Martinoti S., Bliham G.H., Groenewegen G. (1996) Endothellal ICAM-1 expression is suppressed in human malignancies; role of angiogenic factors. Cancer Res. 56, $1111111 \%$.

8. Piali L., Fichtel A., Terpe H. I. Imhof B.A. \& Gisler R.H. (1995) Endothelial vascular cell adhesion molecule 1 expression is suppressed by melanoma and carcinoma. Joumat of Experimental Medicine 181,811-816.

9. Hellwig S.M.M., Damen C.A. Van Aơrichem N.P.H., Groenewergen G., Blijham G.H., \& Griftoen A.W. (1997) Endothelial CD34 is suppressed in human malignancies; role of angiogenic factors. Cancer Letrers 120, 203 . 211.

10. Tromp S.C., oude Egbrink M.G.A., Dings R.P.M., Van Velzen S., Slaaf D.W., Hillen H.EP., Tangelder G.., Reneman R.S., \& Griffioen A.W. $(2000)$ Tumor angiogenesis lactors reduce leukocyte adhesion in vivo. Int.mimunol. 12, $671-676$.

11. Meider R.J., Koenig G.C., Witwer B.P., Safabakhsh N., Munn L.L. \& Jain R.K. (1996) During angiogenesis, vascular endothelial growth factor and basic fibroblast growth factor regulate natural killer cell adhesion to tumor endothelium. Nature Med. 2, 992997.

12. Dirkx A., oude Egbrink M.G.A., Kuipers M, van de Niet S.T., Heijnen V.V.T., Bouma-ter Steege I.C.M., Wagstaff J.\& Griffioen A.W. (2003) Tumor angiogenesis modulates leukocyte-vessel wall interactions in vivo by reducing endothelial adhesion molecule expression. Cancer Res. 63, 23222329.

13. Zhang L., Conejo Garcia J.R., Katsaros D., Gimoty P.A. Massobrio M., Regnani G., Makrigiannakis A., Gray H., Schlienger K., Liebman M.N., Rubin $S_{.} C$. , \& Coukos $G$. (2003) Intratumorall th cells, recurrence, and survival in epithelial ovarian cancer. N.EnglJ.Med 348, 203-213.

14. Nair S., Boczkowski D., Moeller B., Dewhirst M., Vieweg J., \& Gilboa E. (2003) Synergy between tumor immunotherapy and antiangiogenic therapy. Blood 102,964971.

15. Niethammer A.G., Xiang R., Becker I.C., Wodrich H., Pert U., Karsten G., Eliceiri B.P. \& Reisfeld R.A. (2002) A DNA vaccine against VEGF receptor 2 prevenis effectipe angiogenesis and inthibits tumol growh. Nat.Med 8,136941375 .

16. Wei Y.Q., Wang O.R., Zhao X., Yang L, Tian L., Lu Y, Kang B., Lu C.J., Huang M.J., Lou Y.Y., Xao F, He Q.M., Shu J.M., Xie X.J., Mao YQ., Lei S., Luo F, Zhou L. Q., Liu C.E., Zhou H., Jiang Y., Peng F., Yuan L.P., Li O., Wu Y., \& Liu J.Y. (2000) inmunotherapy of tumors with xenogeneic endotrelial cels as a vaccine. Nat.Med 6, $1160-1160$.

17. Van der Schaft D.W.., Dings R.P.M., De Lussanet Q.R., Van Eijk L..., Nap A.W., Beets Tan R.G.H., BoumaTer Steege J.C.A., Wagstaff J., Mayo K.H., \& Griffoen A.W. (2002) The designer anti-angiogenic peptade anginex targets tumor endothelial cells and inhibits iumor growth in animal models. AASEB /. 63, 1991-1905.

18. Dings R.P.M., Yokoyama Y., Ramakrishnan S., Griffoen A.W. \& Mayo K.H. 2003) The designed anglostatic peptide anginex synergistically improves chemotherapy and antiangiogenesis therapy with angiostatin. Cancer Res. 03, 382.385. 
19. Kisker O., Becher C.M, Prow D. Fannon M., DAmato R, Flyn E., Fogler WE., Sim B.R. Alred E.N. PirgeShepherd S.R. \& Folkman 1. 2001 . Conthuous administration of endostatin by intrapertoneally implanted osmotic pump improves the efficacy and potency of therapy in a mouse xenograft tumor model. Cancer Res. 61,76097674 .

20. Wahl M.L, Kenan D.]., Gonzalez Gronow M., : Pizzo S.V (2005/ Angiostatin's molecular mechanism: Aspects of spedificy and reguloton elucidated. $1 . \mathrm{Cell}$ Biochem

21. Folkman I. (2002) Role of angogenesis in tumor growth and metastasis. Semin. Oncol 29, 15-18.

22. Kusaka M.; Sudo K., Fujita T, Marui S., Itoh F, Ingber D., \& Folkman J. (1991) Potent antiangiogenic action of AGM 1470: Comparison to the fumagilin parent. Biachem. Biophys.Res.Commun. 174, 1070-1076.

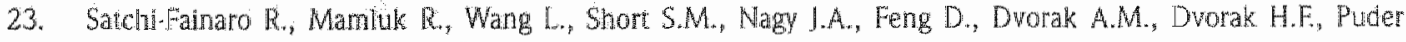
M., Mukhopadhyay D., Folkman J. (2005) Inhibiton of vessel permeability by TNP.470 and its polymer Conjugate, caplostatin. Cancer Cell 7, 251-201.

24. Bocci G., Nicolaou K.C., Kerbel R.S. (2002) Protracted low dose effects on human endothelial cell proliferation and survival in vitro reveal a selective antiangiogenic window for various chemotherapeutic drugs. Cancer Res. 62, 6938:6943.

25. Gulfioen A.W, Van der Schaft D.W., Barendsz-Janson A.F, Cox A., Struijker Boudier H.A.J., Hiller H.F.P. \& Mayo K.H. (2001) Angine, a designed peptide that imibits angiogenesis. Biochem.) 2001, 233242.

26. O'Relly M.S., Holmgren L.., Shing Y., Chen C., Rosenthal R.A., Moses M., Lane W.S., Cao Y., Sage E.H., \& Folkman 1. (1904) Anglostatin: a novel angiogenesis inhibitor that mediates the suppression of metastases by a Lewis Lung Carchoma. Cell 79, 315.328.

27. Yamaoka M., Yamamoto T., lkeyama S., Sudo K., \& Fujïa T. (1993) Angiogenesis inhibitor TNP.470 (AGM1470) potently intibits the tumor growth of hormone-independent human breast and prostate carcinoma cell lines. Cancer Res. 53, 5233-5236.

28. Kisker O., Becker C.M., Prox D., Fannon M., D'Amato R., Flynn E. Fogler W.E., Sim B.K., Altred E.N., Pirie. Shepherd S.R., \& Folkman J. (2001) Continuous administration of endostatin by intraperitoneally implanted osmotic pump improves the efficacy and potency of therapy in a mouse xenograft tumor model. Cancer Res. 61, 7669-7674.

29. Janssen G.H., Tangelder G.l., oude Egbrink M.G., \& Reneman R.S. (1994) Spontaneous leukocyte rolling in venules in untraumatized skin of conscious and anesthetized animals. Am.J.Physiol 267, H1199.41204.

30. Slaaf D.W., Alewinnse R. B Wayland H. (1982) Use of telescopic imaging in intravital microscopy: a simple solution for conventional microscopes. Int.MMcrocirc. Clin. Exp. 1, 121-134.

31. Thi|sser V.L.J.L., Brandwijk R., Dings R.P.M., Grifioen A.W. 2004) Angiogenesis gene expression profiling In xenograft models to study cellular interactions. Exp. Cell Res. 299, 293.

32. Kisker O, Becker C.M., Prox D., Fannon M., DAmato R. Fynn E. Fogler W.E., Sim B.K., Alred E.N., Pirie. Shephetd S.R., Folkman I. (2001) Continuous administration of endostatin by intraperitoneally implanted osmotic pump Improves the efficacy and potency of therapy in a mouse xenograft tumor model. Cancer Res. $61,7069.7074$

33. Kisker O., Becker C.M. Prox D., Fannon M., D'Amato R., Fynn E., Fogler W.E., Sim B.K., Allred E.N., Pirie. Shepherd S.R, \& Folkman \. (2001) Contnuous administration of endostatin by intraperitonealy implanted osmotic pump improves the efficacy and potency of therapy in a mouse xenograt tumor model. Cancer Res. $61,7609.7674$.

34. Bocci G., Nicolaou K.C., \& Kerbel R.S. (2002) Protracted low dose effects on human endothelial cell proliferation and survival in vitro reveal a selective antiangiogenic window for various chemotherapeutic drugs. Cancer Res. 02, 00386043 . 
35. Zhang H. \& Isekuz A.C. (2002) Down-nodulation of monocyte wansendothelal migration and endohelial adhesion molecule expression by fbroblast growth factor: reversal by the ant-angiogenc agent $9 \mathrm{D} 6008$. Am.j. Pathol 160, 2219-2230.

36. Zhang L., Conejo Garcia JR., Katsaros D., Gimoty P.A., Massobrio M., Regnani G., Makrtgiamakis A. Gray H., Schlienger K. Liebman M.M., Rubin S.C. \& Conkos G. 2003 Intratuhoral T cells, recurtence, and survival in epthelial ovarian cancer. NEngl.M.Med 348, 203213.

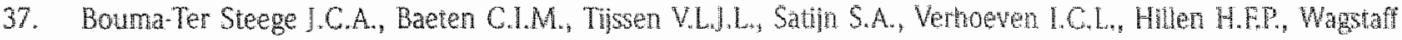
I. \& Griffioen A.W. (2004) Angiogenic profile of breast cancinoma determines leukocyte intituate. Chin Gancer Res. $10,7171.7178$.

38. Griffioen A.W., Damen C.A., Mayo K., BarendszJanson A.F, Marthoti S, Bliham G.H., \& Groenewegen G. (1999) Anglogenesis inhibitors overcome tumor induced endothelial cell anergy Intermational Joumal of Cancer $80,315 \cdot 319$.

39. Luo J., Lin J., Paranya G., \& Bischoff J. (1998) Angiostatin upregulates E-selectin in proliferating endothelial cells. Biochem.Biophys.Res. Commun. 245, 906-911.

40. Zhang H. \& Issekutz A.C. (2002) Down-modulation of monocyte transendothellal migration and endothellal adhesion molecule expression by fibroblast growth factor: reversal by the anti-angogenic agent SU6668. Am. Pathol 160, 2219.2230.

41. Reiss Y., Hoch G., Deutsch U., \& Engehardt B. (1098) T cell interaction with ICAM-1-deficient endothellum in vitro: essential tole for ICAM-I and ICAM-2 in transendothelial migration of T cells. Eur.hmmunol. 28, 3086-3099.

42. Griffioen A.W. [1997] Phenotype of the tumor vasculature; cell adhesion as a target for tumor therapy. Cancer J. $10,249-255$.

43. Nooijen P.T, Westphal J.R., Eggetmont A.M., Schalkwilk C., Max R., de Waal R.M., \& Ruiter D.J. $\|098\|$ Endothelial P-selectin expression is reduced in adwanced primary melanoma and melanoma metastasts. Am. Pathol. 152, 679-682.

44. Creamer D., Sullivan D., Bicknell R, \& Barker \. [2003) Angiogensis in psoriasis. Angiogenesis 5, 231-230.

45. Demaria S. Volm M.D., Shapiro R.L., Yee H.T, Oratz R., Forment S.C., Muggia F, \& Symmans W. (2001) Development of tumorinfiturating lymphocytes in breast cancer after neoadjuvant paclitaxel chemotherapy. Clin Cancer Res. 7, 3025-3030.

46. Boci G. Nicolaou K.C., \& Kerbel R.S. (2002) Protacted low.dose effects on human endothelial cell protferation and survival in vitro reveal a selective antangiogenic window for various chemotherapeutic drugs. Cancer Res. 02, 0938.0943 .

47. Ahmed B., Van Eik L., Bouma-Ter Stegge J.C.A., Van der Schaft D.W., Van Esch A.M., Lambin P., Landuith W. \& Grifioen A.W. (2003) A defined role of angiogenesis inhibition in the overall wascular largeting activily of combretastatin A-4 phosphate. Int.J.Cancet 104, 87.94.

48. Teicher B.A., Sotomayor E.A., Huang Z.D. (1992) Antiangiogenic agents potentate cytotoxic cancer the rapies against primary and metastatic disease. Cancer Res. 52,6702.0704.

49. Coussens L.M. Raymond W.W. Bergers G., Laig. Webster M., Behrendisen O., Werb Z., Caughey G.H., \& Hanahan D. $1909 \mathrm{Inllammatory}$ mast cells up regulate angogenesis during squamous epithellal carcinogenesis. Genes Der. 13, 1382.1397.

50. Coussens L.M., Tinkle C.L., Hanahan D., \& Werb Z. (2000) MMP.9 supplied by bone marrow derived cells contributes to skin carcinogenesis. Cell 103, 481-490.

51. Leek R.D., Lewis C.E., Whitehouse R., Greenall M., Carke I., \& Harris A.L. (1996) Association of macrophage intiltration with angiogenesis and prognosis in invasive breast carcinoma. Cancer Res. 56, 4625-4629. 


\section{Chapter 4}

\section{HIV-1 Tat increases the}

adhesion of monocytes and

T-cells to the endothelium

in vitro and in vivo:

implications for AIDS.

associated vasculopathy

Kathrin Matzen, Anita E. M. Dirkx, Mirjam G. A. oude Egbrink, Cornelia Speth, Matthias Götte, Gudrun Ascherl, Arjan W. Griffioen and Michael Stürzl

Kathrin Matzen and Anita E. M. Dirkx contributed equally to this work

Virus Research, 104(2): 145-155. 


\section{ABSTRACT}

HIV-1 infected patients exhibit severe damages of the aortic endothelium, develop angioproliferative lesions such as Kaposi's sarcoma (KS), and have an increased risk of cardiovascular diseases and atheroscierosis. An increased adhesion of leukocytes to the endothelium is a common pathogenic parameter of AIDS-associated vascular diseases. Here we show that the HIV-1 Tat protein, a regulatory protein of HIV-I released by infected cells, and TNFo, a cytokine increased in sera and tissues of HIV-1-infected patients, activate synergistically the adhesion of leukocytes to endothelial cells both in vitro and in wivo. This effect is selectively mediated by HIV-1 Tat, since HIV-1 Nef, another HIV1 regullatory protein, and the HIV-1 envelope protein gp41, had no effect. In vitro adhesion assays with PBMC and quantitative cell type analysis of adherent cells by FACS demonstrated that HIV-1 Tat selectively activates the adhesion of T-cells and monocytes but not of B-cells. Intravital microscopic studies in mice confirmed the synergistic activity of HIV1 Tat and TNFa on leukocyte adhesion to the endothelium in vivo. These data indicate that HIV-1 Tat in cooperation with TNFo may contribute to the vascular damage and cardiovascular diseases observed in AIDS patients but also to the prominent extravasation of T-cells and monocytes which is a key process in the formation and progression of KS lesions. 


\section{INTRODUCTION}

HIV-1 infection is accompanied by vascular diseases. Until recently, the clinically most evident manifestation of AIDS-associated vasculopathy was Kaposi's sarcoma (AIDS.KSI, an angio proliferative tumor with prominent infiltration of monocytes and T-cells!. In the era of the highly active antiretroviral therapy (HAART), also other diseases have been recognized that indicate chronic vessel activation and dysfunction in HIV-1 infection. For example, cardiovascular diseases account for up to $10 \%$ of the current death cases in HIV-1-infected patients ${ }^{2}$, evidence of atherosclerosis has been found in $75 \%$ of dyslipidemic HIV-1 patients ${ }^{3}$, and an increasing frequency of pulmonary hypertension has been reported ${ }^{4}$. These findings are in agreement with earlier observations by us demonstrating severe alterations of the structural integrity of the aortic endothelium of HIV-1-infected patients, concomitant with an increased adhesion of leukocytes.

HIV-1 Tat is a transcriptional activator of viral gene expression produced early after infection and is essential for virus replication ${ }^{6.8}$. During acute infection of T-cells by HIV-1, HTV.1 Tat is released from the cells in an active form and via a leaderless secretory pathway ${ }^{9.11}$. Consistent with these observations, HIV-1 Tat has been detected in sera of HIV-1-infected individuals ${ }^{12}$ and in AIDSKS lesions particularly in vessels ${ }^{13,14}$.

Extracellular HIV-1 Tat released by infected cells can enter infected or non-infected cells and can activate a variety of genes regulated by specific viral and cellular promoters ${ }^{15 \cdot 17}$. Of note, HIV1 Tat also increases angiogenesis mediated by bFGF and is capable of inducing the growth, migration and invasion of endothelial cell-like cultures derived from KS lesions ${ }^{18.22}$ and of normal endothelial cells that have been activated by inflammatory cytokines (IC) including TNFa ${ }^{23.26}$. This is due to the HIV-1 Tat molecular mimicry of extracellular matrix proteins and is mediated by two regions of the protein. The basic region that retrieves bFGF from heparan sulfate proteoglycans of the extracellular matrix ${ }^{2729}$ and the $R G D$ region that binds to the $\alpha 5 B 1$ and $\alpha v B 3$ integrins ${ }^{30}$ and through this mediates cell adhesion, migration and cell invasion, which in turn is associated with the induction of matrix metalloproteinase (MMP)-1 by HIV-1 Tat ${ }^{31,32}$. In addition, HIV-1 Tat induces the cell surface expression of intercellular adhesion molecule-1 (ICAM-1), vascular cell adhesion molecule-1 (VCAM-1) and endothelial leukocyte adhesion molecule-1 (E-selectin) in endothelial cells ${ }^{33}$, suggesting that it may induce the interaction of endothelial cells with leukocytes. In fact, it has been shown that HIV-1 Tat enhances the migration and the invasion of monocytes into reconstituted basement membranes ${ }^{34}$. In addition, HIV-1 Tat up-regulates the expression of, 2 integrins in these cells and increases their adhesion to TNFo-treated endothelial cell monolayers ${ }^{35}$. The latter is accompanied by a substantial disruption of the endothelial monolayer and it has been proposed that a HIV-1 Tat-induced up-regulation of MMP-9 may contribute to this effect ${ }^{35}$. The stimulation of monocyte adhesion has been attributed to the induction by HIV 11 Tat of autocrinely active cytokines, namely $\mathrm{IL}^{-1}$ and $\mathrm{TNF}^{36}$.

All the effects of HIV-1 Tat on endothelial cells and their interaction with monocytes are significantly increased by or require a previous exposure of the cells to $I C$, such as IFN $\gamma, 1 \mathrm{~L}-1$, and TNF $\alpha$. Of note, these same cytokines are present at increased concentrations in the sera of HIV-1. infected patients and in both sera and tissues of patients with KS or at risk of $\mathrm{KS}^{37.39}$. In particular, IL-1, and IFNy are more closely associated with acute infection ${ }^{40 \cdot 42}$, whereas increasing serum concentrations of TNF correlate with disease progression ${ }^{43.45}$.

Here we show that TNFo and HIV-1. Tat increase synergistically the adhesion of leukocytes to endothelial cells in vitro and that this effect is selectively mediated by HIV-1 Tat and not by other HIV-1-encoded proteins, including the core protein gp41 and HIV-1 Nef, another regulatory factor of HIV-1. Further, adhesion experiments with PBMC and FACS analysis of the adherent cells 
demonstrated that HW-1 Tat selectvely increases the adhesiveness of monocytes and Tcells but not of Bcels. Fnally, an intratal microscopic sudy m mice demonstrated for the first time that HI. 1 Tat and TNFa cooperate in the activation of leukocyte adhesion to the endothelium aiso in wiv.

\section{MATERIALS AND MeTHODS}

\section{Recombinant HIV-I proteins}

Tat from HV-1 type IIB-BH-10 (subtype B) was expressed in $E$. coli and purfied to homogeneity by heparin-affinty chromatography and HPLC, as described ${ }^{40}$. The purified HIV-1 Tat protein was fully biologically active, as tested by various assays, including rescue assays on the HLM-1. cell ine carrying a Tat-defective HV-1 provirus, or the induction of chloramphenicol acetyl transferase activity in HL3T1 cells containing a HIV-1-long terminal repeat chloramphenicol acetyl transferase construct and by uptake studies with dendritic cells ${ }^{47}$. To prevent oxidation, the HIV-1 Tat protein was stored lyophilized at $-80^{\circ} \mathrm{C}$ and reconstituted in degassed buffer before use $e^{48}$. To prevent attachment of the protein to surfaces, plastic tips and vials before use were rinsed in 0.1\% PBS-BSA or in RPMI 1640 (Invitrogen, Karlsruhe, Germany) supplemented with $20 \mathrm{mM}$ HEPES (Sigma.Aldrich, St. Louis, MO), $100 \mathrm{U} / \mathrm{m}$ penicilin, $100 \mu \mathrm{g} / \mathrm{ml}$ streptomycin, $2 \mathrm{mM} \mathrm{L}$-glutamine (Invitrogen) and $15 \%$ fetal bovine serum (FBS) (Invitrogen). In addition, because HIV-1 Tat is also photo- and thermosensitive ${ }^{40,50}$, the handling of the protein was always performed in the dark and on ice. In all cases endotoxin concentration was below the detection limit $(<0.05 \mathrm{EU} / \mu \mathrm{g})$, as determined by the Limulus Amoebocyte Lysate analysis (Pyrochrome, Associates of Cape Cod, Falmouth, MA).

Nef from HIV LAV-1 Bru was a gift from V. Erfle [GSF-National Research Center for Environment and Health, Germany). It was purified as described in detail by Kohleisen et al. ${ }^{51}$ and handled as described above for HIV-1 Tat.

Since gp4l is rather hydrophobic, a recombinant fusion protein between maltose-binding protein (MBP) and an 82-amino-acid-long extracellular region (amino acids 565 to 647) of gp41 was used for the experiments (nntracel, Cambridge, MA). To rule out possible side effects of MBP, recombinant MBP (New England Biolabs, Beverly, MA) was used as the negative control ${ }^{\$ 2}$.

\section{Cell Cultures}

PBMC were isolated from fresh blood of three different healthy donors by Percoll (Amersham Biosciences, Freiburg, Germany) density gradients $(d=1.080)$ at $800 \times g$ for 30 min. The PBMC were collected at the interface and washed twice with PBS. Then the cells were suspended at a concentration of $5 \times 105$ cells $/ \mathrm{mL}$ and maintaned in RPMI 1640 containing $5 \%$ FBS. The U937 monocytic cell line was obtained from ATCC and was grown in RPMI 1640-10\% FBS.

HMVEC were obtained from Bio Whittaker (Verviers, Belgium) and maintained further in endothelial basal medium (EBM-2 MV, Bio Whittaker) supplemented with $5 \%$ FBS as has been described ${ }^{53,54}$.

\section{Cell adhesion assay}

Cell adhesion experiments were carried out as described ${ }^{55}$. HMVEC were seeded at $7 \times 104$ cells/well in eight-well microchamber slides [Nunc, Wiesbaden, Germany) and incubated overnight in EBM.2.5\% FBS. Human tecombinant TNF (Roche Diagnostic, Mannheim, Germany) was added in EBM-0.5\% FBS for 6 h at the concentrations indicated in the Figures. Subsequently, 500 ml of a suspension of U937 cells $(5 \times 105$ cells/ml) or of PBMC $(1 \times 100$ cells $/ \mathrm{ml})$ were added, and after 
15 min non-adherent cells were gently removed by dipping the slides into RPMI $1640-1 \%$ FBS. Afterwards, the cells were fixed ( 30 min, RPMI 1640-1\% FBS-5\% glutaraldehyde) and the adherent cells were counted using a photo-imaging system (Optimas, Stemmer Imaging, Puchheim, Germany). Each experiment was carried out in triplicate and 8 different optical fields were counted of each well. Results are expressed as the mean $( \pm S D)$ of three independent experiments. Statistical significance was assessed using the student's $t$ test. $P \leq 0.05$ was regarded as statistically significant.

For FACS analysis HMVEC were seeded at $1 \times 10^{\circ}$ cells in culture dishes $\left(8 \mathrm{~cm}^{2}\right)$ and, as described above, incubated overnight in EBM-2.5\% FBS and stimulated in EBM-0.5\% FBS containing TNF $\alpha$ for $6 \mathrm{~h}$. Afterwards $2 \mathrm{ml}$ of a suspension of PBMC $\left(1 \times 10^{\circ} \mathrm{cells} / \mathrm{ml}\right)$ were added, and after $15 \mathrm{~min}$ non-adherent cells were removed by gentle washing of the cells twice with PBS. Subsequently the adherent cells were harvested by treatment with Accutase [PPA Laboratories, Coelbe, Germany? and re-suspended in PBS- $1 \% \mathrm{BSA}-0.01 \% \mathrm{NaAz}$. Then the cells $\left(1 \times 10^{6}\right.$ cells $\left./ 100 \mu \mathrm{\mu l}\right)$ were incubated with FITC-conjugated anti-CD $45 \mathrm{mAb}(5 \mu \mathrm{g} / \mathrm{m}), \operatorname{lgG} 1)$, anti-CD3 mAb $(5 \mu \mathrm{g} / \mathrm{ml}, \operatorname{lgG})$, anti-CD20 $\mathrm{mAb}(5 \mu \mathrm{g} / \mathrm{ml}, \mathrm{IgG} 1)$ or PerCP-conjugated anti-CD $14 \mathrm{mAb}(0.5 \mu \mathrm{g} / \mathrm{ml}$, IgG2b) for $30 \mathrm{~min}$ at RT. To prove staining specificity the cells were incubated for $30 \mathrm{~min}$ at RT with FITC-conjugated IgGI $(5 \mu \mathrm{g} / \mathrm{ml})$ and PerCP-conjugated $] \mathrm{gG} 2 \mathrm{~b}(5 \mu \mathrm{g} / \mathrm{ml})$ control antibodies. All mAbs were purchased from $\mathrm{BD}$ Biosciences (Heidelberg, Germany). After washing the cells twice they were fixed with $2 \%$ paraformaldehyde and analysed $(10,000$ events/measurement) with a FACSCalibur (BD Biosciences). The data were processed using the CellQuest programm (BD Biosciences). Experiments were repeated 6 times and the results are presented as the mean $( \pm$ SD). Statistical significance was assessed using the student's $t$-test. $\mathrm{P} \leq 0.05$ was regarded as statistically significant.

\section{Intravital microscopy}

The experiments were approved by the Ethical Committee on Animal Experiments of Maastricht University (The Netherlands). Intravital microscopy was performed with C57BV/ 0 mice of a body weight varying from $25 \mathrm{~g}$ to $30 \mathrm{~g}$. On the day of the experiments the mice were injected $\mathrm{i} . \mathrm{p}$. with either $100 \mathrm{ng}(\mathrm{n}=3$ ) recombinant murine TNF $\alpha$ (R\&D Systems, Abingdon, England), $20 \mu \mathrm{g}$ HIV-1 Tat $(\mathrm{n}=3), 20 \mu \mathrm{g}$ HIV-1 Tat and $100 \mathrm{ng}$ recombinant murine TNFo $(\mathrm{n}=2)$ or PBS-0.1\% $\mathrm{BSA}(\mathrm{n}=2)$ as a control. Four hours later the mice were anesthetized by subcutaneous injection of a mixture of ketamine $10.1 \mathrm{mg} / \mathrm{g}$ body weight (b.w.), Nimatek, Ad Usem Veterinarium, Cuijk, The Netherlands] and xylazine $10.02 \mathrm{mg} / \mathrm{g}$ b.w., Sedamun, Ad Usem Veterinarium, Culik). To enable intravital microscopic fluorescence-based observation of leukocytes, 10 - $20 \mu$ li Rhodamine6G (Sigma-Aldrich) dissolved in $\mathrm{NaCl} 0.9 \%$ solution $(1 \mathrm{mg} / \mathrm{ml})$ and filtered through a $0.22 \mu \mathrm{m}$ filter (Millipore, Etten-Leur, The Netherlands) were injected through a PE-10 catheter (Portrex, Kent, England) into the tail vein. Ear skin venules in both ears were visualized using a Leitz intravital microscope carrying a Leitz x 1.25 Ploemopak 2.2 for interchangeable filter sets and a Leitz $\times 25$ salt water immersion objective (numerical aperture 0.60). To this purpose, the mouse was positioned on a preheated platform $\left(37^{\circ} \mathrm{C}\right)$, the ear was placed on a glass ring with the dorsal side up and covered with a drop of paraffin oil and a cover slip. Trans-illumination was performed using a $60 \mathrm{~W}$ tungsten lamp, while for fluorescence microscopy a Leitz N2.1 filter set (excitation filter BP 515-560, dichroic mirror RHP 580, and barrier filter LP580) was used in combination with a $100 \mathrm{~W}$ mercury lamp. Images were projected on a charge coupled device camera (Hamamatsu Photonics, C2400, Hamamatsu City, Japan), coupled to an intensifier unit (Hamamatsu Photonics A4405), and recorded on videotape (sVHS recorder, Panasonic, Japanj for off-line analysis. The final optical magnification at the front plane of the camera was $x$ 40. In all experiments the mid-plane of a vessel was kept in focus. 


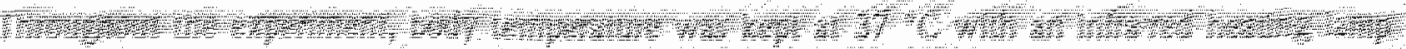

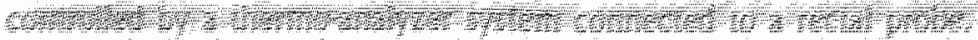

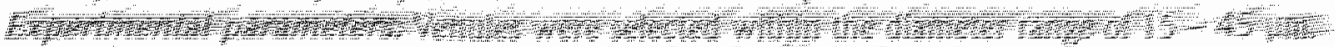
in

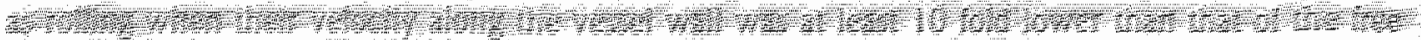

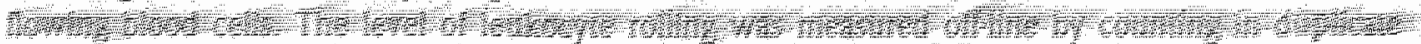

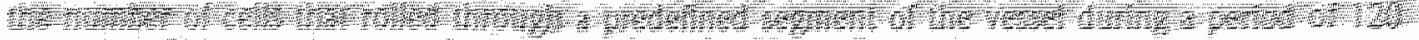

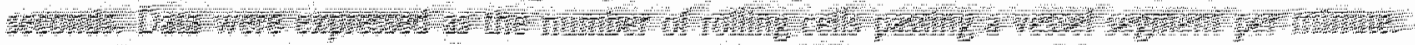

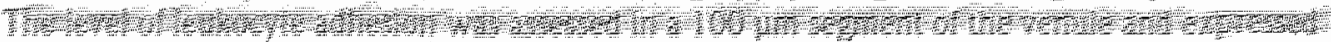

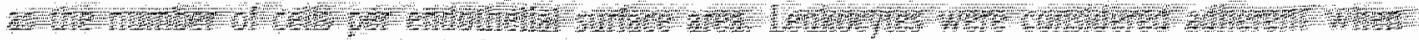

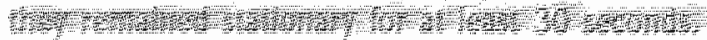

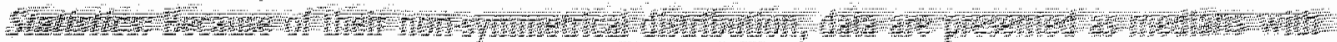

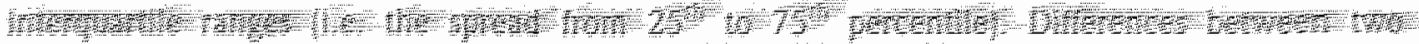

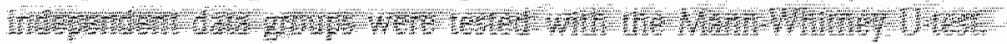

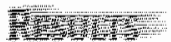

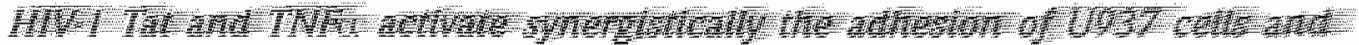

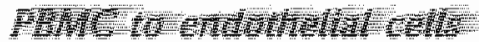

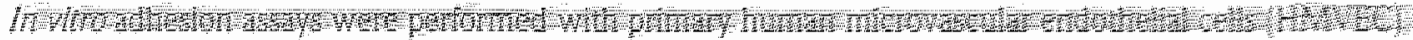

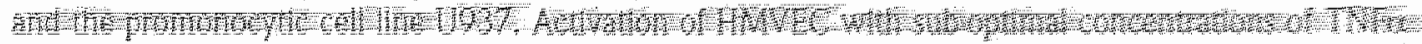

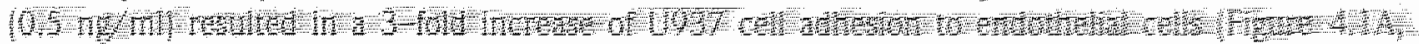

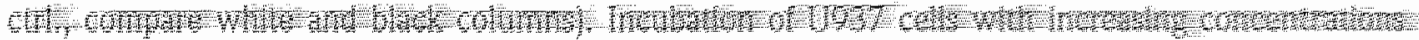

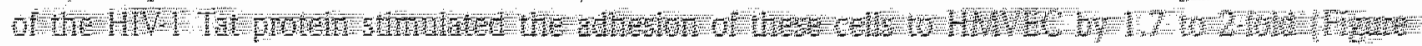

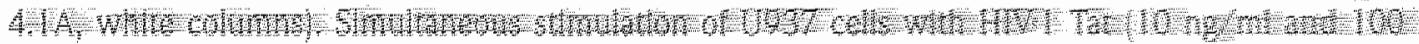

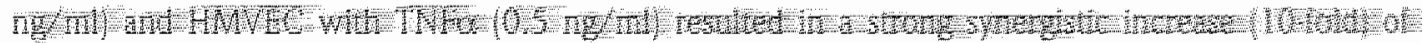

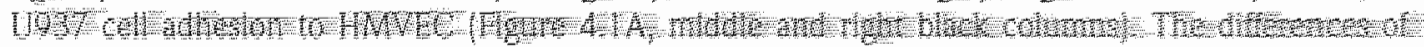

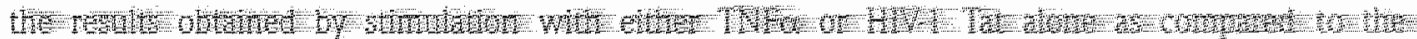

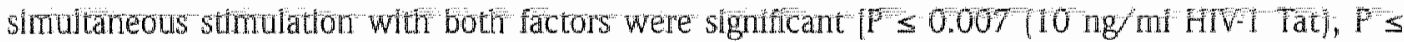
$0.003(100 \mathrm{ng} / \mathrm{mi} \mathrm{HT} \cdot \mathrm{H} \mathrm{Tar})$.

Adhesweness of U937 cells to TNFo-stimulated endothelia]. cells was significantly $[P \leq 0.01]$ and selectively activated by the HIV. 1 Tat protein but not by the HV-1. core protein gp41 or by Nef, another regulatory protein of HWV-1 [Figure 4.1 B). Similarly to U937 cells, also adhesion of PBMC was significantly $(\mathrm{P} \leq 0.03)$ and selectively increased $(1.6$ fold) by HIV 1 Tat but not by gp 41 and by Nef (Figure $4.1 \mathrm{C})$.

\section{HIV-1 Tat preferentially activates adhesion of primary monocytes and T- lymphocytes to HMVEC}

In order to examine which cell type (B-cells, T-cells or monocytes) present in PBMC is preferentially activated by HIV-1 Tat to adhere to the endothelium, adhesion experiments were performed with PBMC. Leukocytes bound to endothelial cells were stained with different cell-type associated markers and quantified by FACS analysils (Figures. 5.2 and 5.3).

TNFa treatment of HMVEC increased the numbers (within 10,000 counted cells) of adherent $\mathrm{CD} 45^{+}$leukocytes (Figure $4.2 \mathrm{~A}$ versus B), CD3 ${ }^{+}$T-cells (Figure $4.2 \mathrm{E}$ versus F), CD20+ $\mathrm{B}$-cells (Figure $4.2 \mathrm{G}$ versus $\mathrm{H}$ ) and $\mathrm{CD} 14^{+}$monocytes (FIgure 4.21 versus $\mathrm{K}$ ). The relative mumber of CD 45 endotheliall cells was decreased (Figure $4.2 \mathrm{C}$ versus D), due to increased numbers of $\mathrm{CD}_{4} 5^{+}$cells 

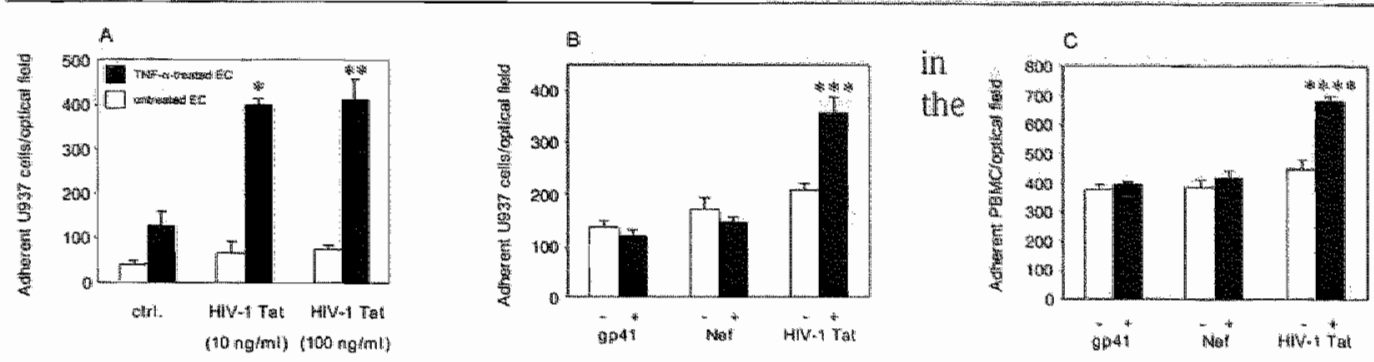

\section{Figure 4.1}

HWI Tat and TNFo increase synergistically the adhesion of leukocytes to HMVEC in vitro. In vitro adheston of Uo37 cells ( $A, B)$ and PBMC (C) to HMVEC. (A) HMVEC were either non-stimulated (white columns or stimulated with TWFa $10.5 \mathrm{ng} / \mathrm{ml}$, black columns). U937 cells were either non stimulated (ctrl., or activated with increasing concentrations of HIVI Tat. * $^{*} P \leq 0.007$ and $\left.f^{*}\right) P \leq 0.003$ for the differences of results obtained when only one cell type (U037 cells or HMVEC Was stimulated by TNFa or HWM Tat, respectively as compared to TNFa stimulated HMVEC and HW. I Tat stimulated U937 cells. (B) HMVEC were treated with TNF a $10.1 \mathrm{ng} / \mathrm{mil}$. UQ37 cells were either treated with

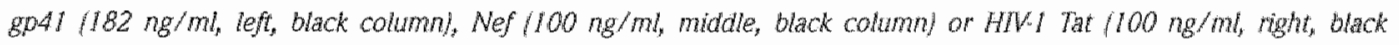
column ar were non-stimulated (white columns). (***) $P \leq 0.01$ compared to non-stimulated vo37-cells. (C) The same conditions as described in (B) but PBMC were used instead of U037 cells. (****) Ps 0.03 compared to non. stimulated PBMC. In each experiment stimulation of HMVEC was carried out for 6 h and stimulation of Uo37 cells and PBMC for 24 h. In each case the mean values and standard deviations of three different experiments are shown.

10,000 cells evaluated. Staining specificity was demonstrated whith isotype matched $\operatorname{IgG} 1$ and $\operatorname{IgG} 2 \mathrm{~b}$ control antibodies (Figure 4.2L-O). Calculation of the number of adherent cells per 1,000 endothelial cells confirmed that TNF $\alpha$ treatment of HMVEC increased (2-fold) the adhesiveness to endothelial cells of all leukocyte populations examined, including T-cells $(\mathrm{P} \leq 0.02)$, B-cells $(\mathrm{P} \leq 0.02)$ and monocytes ( $\mathrm{P} \leq 0.05$ ) (Figure 4.2P).

The treatment of PBMC with the HIV-1 Tat protein further increased the relative numbers (within 10,000 counted cells) of $\mathrm{CD}^{4} 5^{+}$leukocytes (Figure 4.3A and B) adhering to the TNFo. stimulated HMVEC. However, HIV-1 Tat selectively increased the numbers of $\mathrm{CD} 3^{+}$T-cells (Figure 4.3E and $\mathrm{F}$ ) and $\mathrm{CD} \mathrm{14} 4^{+}$monocytes (Figure $4.3 \mathrm{I}$ and $\mathrm{K}$ ) adherent to endothelial cells, but not of $\mathrm{CD} 20^{+}$B-cells (Figure 4.3G and H). Again and in agreement with the experimental set-up the increase in leukocyte adhesion was paralleled by a relative decrease of the numbers of CD 45 endothelial cells (Figure 4.3C and D). Staining specificity was demonstrated whith isotype matched $\lg \mathrm{gl}$ and $\operatorname{IgG} 2 \mathrm{~b}$ control antibodies (Figure 4.3L-O). Calculation of the number of adherent cells per 1,000 endothelial cells indicated that HIV-1 Tat increases adhesion of leukocytes by 1.8 fold $(\mathbb{P} \leq$ 0.02 (Figure 4.3P) which is consistent with the previous adhesion experiments (Figure 4. 1C). Within the adherent cells the numbers of monocytes were increased 2.2 -fold $(\mathrm{P} \leq 0.02)$ and those of $\mathrm{CD} 3+\mathrm{T}$-cells 1.8 -fold $(\mathrm{P} \leq 0.02)$. In contrast, the number of adherent B-cells was not significantly increased by HIV-1 Tat stimulation (Figure 4.3P).

\section{HIV-1 Tat and TNF- $\alpha$ activate synergistically the adhesion of leukocytes to endothelial cells in vivo}

To investigate the effect of HIV-1 Tat and TNF $\alpha$ on leukocyte adhesion in wivo an intravital microscopy study was performed. In the present mouse model TNF $\alpha$ at concentrations of $500 \mathrm{ng}$ 

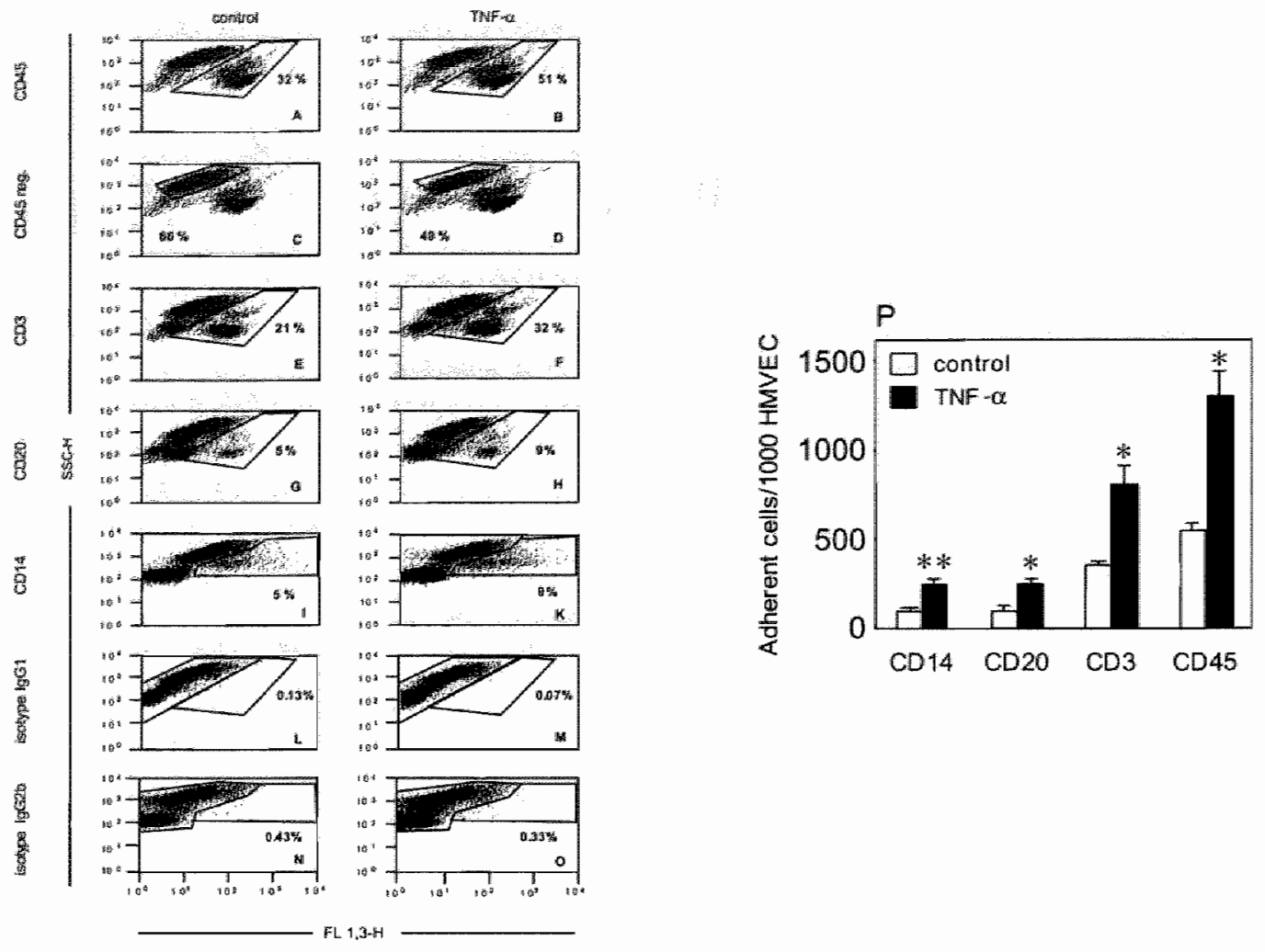

\section{Figure 4.2}

TNF stimulation of HMVEC increases the adhesion of Tcells, Bicells and monocytes. HMVEC that were either nonstimuiated /controll or treated for o h with TNFa $10.1 \mathrm{ng} / \mathrm{m} / \mathrm{l}$ were overlaid with freshly isolated PBMC. Non alherent cells were removed by washing. Adherent cells and HMVEC were harvested, stained with FTC (FL H) coupled antibadies

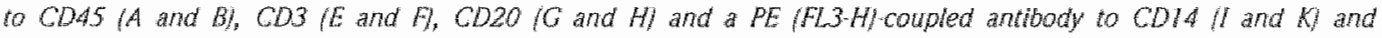
quartitatively detetmined by FACS analysis of 10,000 cells. CD45 negative cells (CD45 neg) represent the HMVEC (C and D). To prove staining specificily the cells were incubated with isotype matched controt anibodies (L.O). A representative result of three independent experiments is shown. In (PI the relative numbers of CD45+, CD3+, CD20. and COI $4+$ cells that bound to 1,000 HMVEC are graphicaliy displayed. The mean values and standard deviations were calculated from three different experimental poirts. (*) $P \leq 0.02$ and $*$ *) $P \leq 0.05$ compared to unstimulated HMVEC.

significantly increases adhesion of leukocytes (Dirkx et al. 2003)57. In order to evaluate potential synergistic effects of HIV-1 Tat and TNF $\alpha$ sub-optimal concentrations of TNF $\alpha$ (100 ng) were used that still significantly $(\mathrm{P} \leq 0.001$ ) increased leukocyte rolling (Figure $4.4 \mathrm{~A})$ but had no effect on the adhesion of leukocytes to the vessel wall (Figure 4.4B). HIV-1 Tat was also used in a concentration $(20 \mu \mathrm{g})$ that significantly $(\mathrm{P} \leq 0.001)$ stimulated rolling (Figure $4.4 \mathrm{~A})$ but only slightly stimulated cell adhesion (Figure 4.4B). The combined application of HIV-1 Tat and TNFo significantly increased adhesion of leukocytes ( $\mathrm{P} \leq 0.00 \mathrm{l}$, Figure $4.4 \mathrm{~B}$ ) at the expense of the number of rolling cells (Figure 4.4A). From earlier studies it is known that the rolling of leukocytes along the endothelium is the necessary step preceding leukocyte adhesion (von Andrian et al. 1991). The present data strongly suggest that the combination of HN-1 Tat and TNF $\alpha$ significantly upregulates endothelial expression 

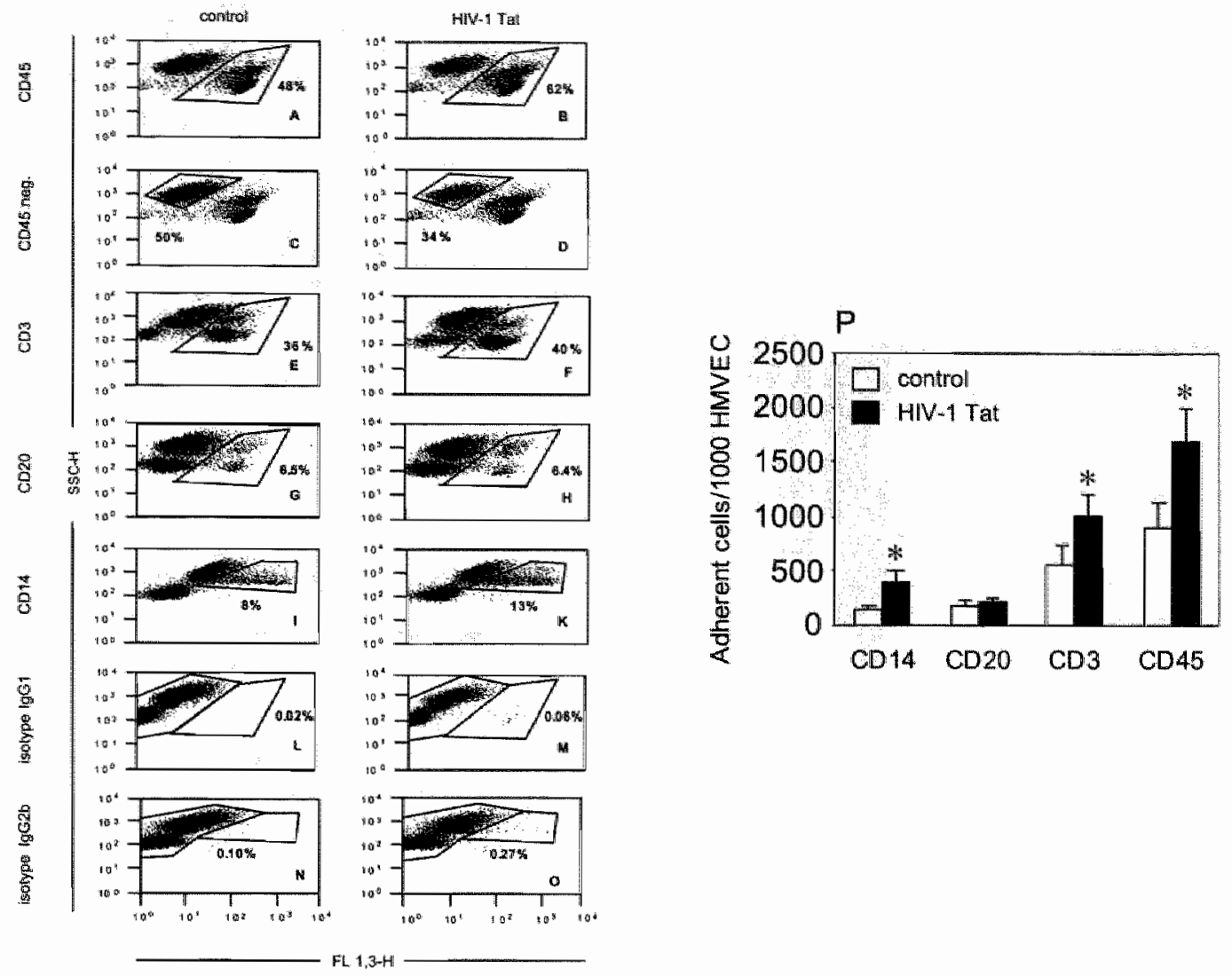

\section{Figure 4.3}

HWI Tat stimulation of PBMC increases selectively the adhesion of monocytes and Tcells. Freshly isolated PBMC were

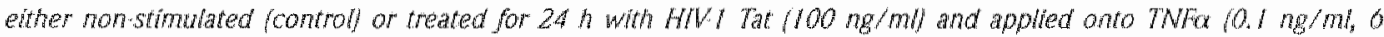
hitreated HMVEC. Non-atherent cells were removed by washing. Adherent cells and HMVEC were harvested, staitred

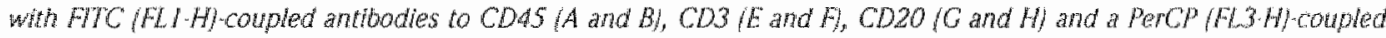
antibody to CDIA $(I$ and $K$ ) and quantiratively determined by FACS analysis of 10,000 cells. CDA5 negative cells ICDAS neg. represent the HMVEC $/ C$ and D/. To prove staining specificty the cells were incubated with isolype matched control antibodies (L.O). A representative restut of three independent experiments is shown. In $I P \mathrm{l}$ the relative numbers of CD45+, CD3+, CD2O+ and CDH4+ cells that bound to 1,000 HMVEC are graphically displayed. The mean values and standard deviations were calculated from three different experimental points. " I s 0.02 compared to controt.

of adhesion molecules, resulting in a fast transition of rolling to adhesion. This is illustrated by photographs of microvessels in the different groups (Figure 4.4C-F). In the control situation a low level of leukocyte-vessel wall interactions is observed (Figure $4.4 \mathrm{C}$ ), which is increased after administration of TNF $\alpha$ (Figure 4.4D), or HIV-1 Tat (Figure 4.4E) in which case most leukocytes roll along the vessel wall. Administration of both substances also induces an increase in leukocytevessel wall interactions, but now most cells adhere (as indicated by the black arrows) and less are rolling (Figure $4.4 \mathbb{F}$ ). 

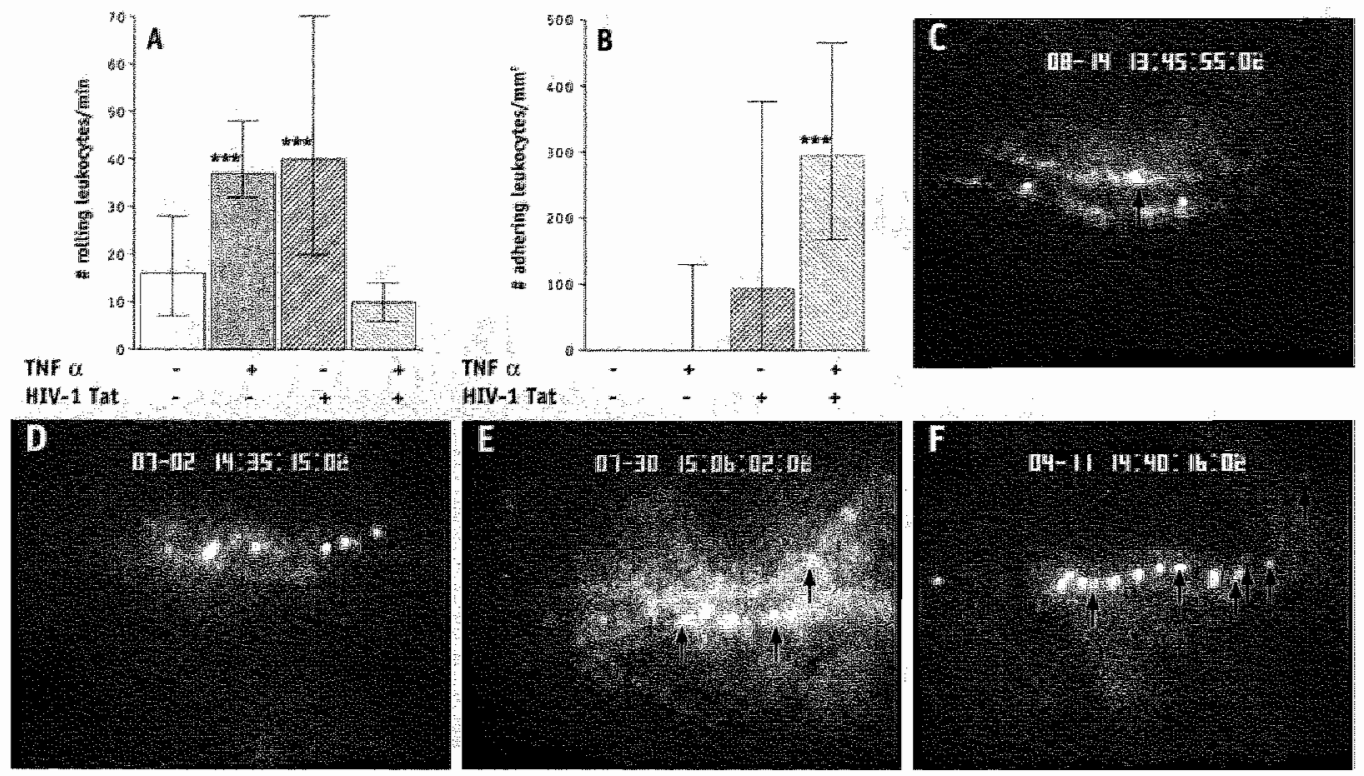

\section{Figure 4.4}

HWI Tat and TNFa increase synergistically the adhesion of leukachtes to the endothelium in who. C57BV wice were injected i. $p$. with either TNF $(100 \mathrm{ng}, n=3)$, HN 1 Tat $(20 \mathrm{\mu g}, n=3)$, a combination of both factors $(n=2)$ or with an equivalent wolume of dilution medium (PBS/O.1\%BSA, $n=2$ ). By intravital microscopy. (A) the numbers of rolling cells passing a vessel segment per minute and (B) the number of adherent leukocytes per mmi endothelial surface area were deternined. Because of their non symmetrical distribution data are presented as medians and interquartile ranges. 1 * I $P \leq 0.001$ compared to untreated mice. Images of intravital fuorescence microscopy are shown of ear venules in mice treated with PBS $10.1 \%$ BSA (C), $100 \mathrm{ng}$ TNF (D), $20 \mathrm{~kg}$ Tat (E) and a combination of both factors (F). Adhering leukocytes are indicated by black arrows, all other leukacytes can be considered as rolling.

\section{Discussion}

The endothelium of HIV-1.infected patients is characterised by increased numbers of adherent leukocytes as compared to non-infected patients ${ }^{58}$. This may support the recruitment of lympho/monocytes and of human herpesvirus- 8 into AIDS-KS lesions 1,59 . In addition, in the era of HAART, whith significantly elongated survival times of the patients, this may contribute to the increased risk of cardiowascular diseases and atherosclerosis in HIV-1-infected individual $\mathrm{s}^{60,61}$.

The HIV-1 Tat protein in vitro has been shown to affect the monocyte/endothelial cell interaction. HIV-1 Tat up-regulates the expression of B2-integrin adhesion molecules and MMP.9 expression in monocytes, which increases monocyte/endothelial cell adhesion, enhances monocyte dependent damage of endothelial cell monolayers, and promotes invasive behaviour of monocytes ${ }^{62-64}$.

HIV-1 Tat has also been shown to be active in mice. Transgenic mice expressing HIV-1 Tat develop tumors ${ }^{65,60}$, and inoculation into mice of purified HIV-1 Tat in combination with IC or bFGF can lead to the formation of vascular lesions ${ }^{67-70}$. Tn the present study we demonstrated for the first time that HIV-1 Tat and TNF- $\alpha$ can synergistically increase the adhesion of leukocytes to the endothelium in vivo. Although high concentrations of HIV-1 Tat $(20 \mu \mathrm{g})$ as compared to TNFo (100 
ng) were used, it has to be considered that two features of HIV-1 Tat may quickly reduce the effective concentration of the protein in the circulation after intra-peritoneal injection. First, HIV-1 Tat with its basic sequence binds rapidly to heparan sulfate proteoglycans of the cell surface and the extracellular matrix ${ }^{7 T}$. Second, it has been shown that $4 \mathrm{~h}$ after injection in mice HIV-1 Tat is delivered to all tissues and incorporated into the cells ${ }^{72}$. For these reasons high concentrations of HIV-1 Tat were used. However, in HIV-1 infected patients HIV-1 Tat is highly expressed and released by infected cells and may activate leukocytes in the near proximity, possibly in lymph nodes. Activated leukocytes after re-entering the circulation may adhere with increased efficiency to the endothelium of HIV-1-infected patients that is chronically exposed to increased concentrations of IC.

Our findings may be specifically of relevance for the pathogenesis of AIDS-KS. Early stage KS lesions are characterized by an inflammatory-granulation-type reaction with activated proliferating endothelial cells forming new vessel-like (for review see ${ }^{1,73}$ ). The nature of the inflammatory cell infiltrate of KS is important since it is the first to appear and precedes the appearance of the tumor cells, the so-called KS spindle cells. Immunohistochemical studies indicate a prevalent intiltration of monocyte-macrophages (CD68+, MAC387+) together with CD4-positive and CD8-positiv T-cells $(\mathrm{CD} 3+)$, whereas $\mathrm{B}$-cells $(\mathrm{CD} 19+, \mathrm{CD} 20+)$ are rare or absent ${ }^{74.79}$. Our findings that the co-operative activity of HIV-1 Tat and TNFo on adhesion selectively targets monocytes and T.cells is well in agreement with the leukocyte infiltration observed in AIDS-KS lesions. The co-operative activity of both factors may explain the 20.000 -fold increased incidence of KS in AIDS ${ }^{80}$ and possibly may contribute to other vascular defects in AIDS that are associated with increased leukocyte adhesion and extravasation into tissues, including cardiovascular diseases and artherosclerosis. 


\section{REFERENCES}

1. Sturzl M., Zietz C., Monini P. E Ensoli B. (2001) Human herpeswirus-8 and Raposi's sarcona: relationship with the multistep concept of tumorigenesis. Adv Cancer Res $81,125159$.

2. Bonnet F., Morlat P., Chene G., Mercie P., Neau D., Chossat I., Decoin M., Diossou F, Beylot J., Deabis F. (2002) Causes of death among HWinfected patients in the era of highly active antiretroviral therapy, Bordeaux, France, 1998-1909. HWMed. 3, 195-199.

3. Acevedo M., Sprecher D.L., Calabrese L., Pearce G.L., Copner D.L., Halliburton S.S., White R.D., Sykora E., Kondos G.T. \& Hoff J.A. (2002) Pilot study of coronary atherosclerotic risk and plaque burden in HIV paitents: "a call for cardiovascular prevention". Atherosclerosis 163, 349-354.

4. Pellicelli A.M., Palmieri F. Cicalini S., \& Petrosilio N. (2001) Pathogenesis of HIV-pelated pumonary thypertension. Ann.N.Y.Acad.Sci. 946, 82,94.

5. Zietz C., Holz B., Sturzl M., Rauch E., Penning R., \& Lohrs U. (1996) Aortic endothelium in HIV-1 infection: chronic injury, activation, and increased leukocyte adherence. Am.J.Pathol. 149, 1887-1898.

6. Arya S.K., Guo C., Josephs S.F., \& Wong Staal E. (1985) Trans-activator gene of human T-lymphotropic wirus type III (HTLW-III). Science 229, 69-73.

7. Chang H.K., Gallo R.C., E Ensoli B. 19959 Regulation of Cellular Gene Expression and Function by the Human Immunodeficiency Virus Type 1 Tat Protein. J.Biomed Sc. 2, 189.202.

8. Ensoli B., Buonaguro L., Barillari G., Fiorelli W, Gendelman R., Morgan R.A., Wingfield P. \& Gallo R.C. (1093) Release, uptake, and effects of extracellular human immunodeficiency virus type 1 Tat protein on cell growth and viral transactivation. J.Virol. 67, 277.287.

Q. Chang H.C., Samaniego F, Nair B.C., Buonaguro L., \& Ensoli B. (1997) HIV.1 Tat protein exils from cells wa a leaderiess secretory patirway and binds to extracellular matrix-associated heparan sulfate proteoglycans through its basic region. AIDS $11,1421-1431$.

10. Ensoli B., Buonaguro L., Barillari G., Fiorelli V., Gendelman R., Morgan R.A., Wingfield P., \& Gallo R.C. (1993) Release, uptake, and effects of extracellular human immunodeficiency wirus type I Tat protein on cell growth and viral transactivation. J.Virol. 67, 277.287.

11. Ensoli B., Barillari G., Salahuddin S.Z., Gallo R.C., \& Wong.Staal F. (1900) Tat protein of HIV-1 stimulates growth of cells derived from Kaposi's sarcoma lesions of ATDS patients. Narure 345, 8486.

12. Westendorp M.O., Frank R., Ochsenbauer C., Stricker K., Dhein J., Walczak H., Debatin K.M., \& Krammer P.H. (1995) Sensitization of T cells to CD95mediated apoptosis by HIV.1 Tat and gp 120. Natume 375, 497-500.

13. Ensoli B., Gendelman R., Markham P., Fiorell V., Colombun S., Raffeld M., Cafaro A., Chang H.K., Brady J.N., Gallo R.C. (1994) Synergy between basic Itbroblast growth factor and HIV 1 Tat protein in induction of Kaposits sarcoma. Nature 371, 674680.

14. Ensoll B., Sgadari C., Barillari G., Sirianni M.C., Sturzl M., \& Monini P. (2001) Biology of Kaposi's sarconta. Euri.Cancer 37, $1251 \cdot 1209$.

14. Fanales-Belasio E., Moretit S., Nappi F, Barillari G., Micheleti F, Calaro A., \& Ensoli B. (2002) Native HIV. I Tat protein targets monocytederived dendritic celss and enhances thelr maturation, function, and antigen. specific T" cell responses. A.Immunol 168, 197-200.

16. Kumar A. Manna S.K., Dhawan S., \& Aggawal B.B. (1908) HIV Tat protein activates c.Jun N-terminal kinase and activator protein-1. J./mmunol. 161, 776-781.

17. Vaishnav YN. \& Wong Staal F. (1901] The biochemistry of AlDS. AnnuRev Blochem 60,577.630.

18. Albini A., Barlhari G., Benelli R., Gallo R.C., \& Ensoli B. (1095) Angiogenic properties of human immunodeficiency virus type 1 Tat protein. Proc Natl.Acad SciUS.A 92, 4838-4842.

19. Barilari G., Buonaguro L., Fiorelli V., Horman I., Michaels E, Gallo R.C., \& Ersoli B. (1992) Effects of cylokines from activated immune cells on vascular cell growth and HIV I gene expression. Implications for ADDS Kaposi's sarcoma pathogenesis. IImmunot 149, 3727 3734. 


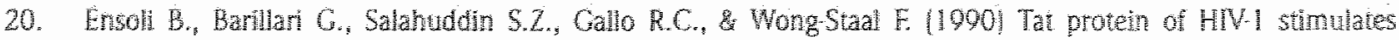
growth of cells denved tron Kaposi's sarcoma lesions of ADS patsents. Nature 345, 8480.

21. Ensoli B., Buonaguro L., Batillari G., Fiorelli V., Gendeman R., Morgan R.A., Wingfield P. \& Gälo R.C. (1993) Release, uptake, and effects of extracelluar human immunodeficiency virus type 1 Tat proten on cell growh and viral transactivation. J. Virot 67, 277-287.

22. Ensoli B., Markham P., Kao V, Barllan G., Forell V., Gendelman R, Raffeld M., Zon G., \& Gallo R.C. $\{1094\}$ Block of ADS Kaposis sarcoma (KS) cell growth, amgingenesis, and lesion formation in nudie mice by antisense oligonucleotide targeting baste fibroblast growth facto. A novel strategy for the therapy of KS. /Clin. Invest $94,1736-1746$.

23. Abmin A., Barllari $G_{n}$, Benelli R., Gallo R.C., Ensole B. (1995) Angiogenic properies of human Immunodeficiency virus type I Tat protein. Proc.Natl.AcadSct.U.S.A 92, 4838-4842.

24. Barllati G., Buonaguro L., Fiorelli V., Hoffman I., Michaels F, Callo R. C., \& Ensoli B. (1992) Effects of cytokines from activated immune cells on vascular cell growth and HV-1 gene expression. Implications for AlDS Kapasis sarcoma pathogenesis. J.Immunol. 149, 3727-3734.

25. Barllari G., Gendelman R. Gallo R.C., \& Ensoll B. (1993) The Tat protein of human immunodeficiency virus. type 1, a growth factor for ADS Kaposi sarcoma and cytokne-activated vascular cells, induces adhesion of the same cell types by using integrin receptors recognizing the RGD amino acid sequence. Froc.Natl.Acad.SciU.S.A $90,7941.7945$.

26. Firelli V., Gendelman R., Samaniego F, Markham P.D., E Ensoli B. (1995) Cytokines from activated T" cells induce normal endothelial cells to acquire the phenotypic and functional features of ADS-Kaposi's sarcoma spindle celis. Y.Chn./nvest $95,1723-1734$.

27. Barillari G., Sgadari G., Palladino C., Gendelman R, Caputo A., Morris C.B., Nair B.C., Markham P., Nel A., Sturzl M., \& Ensoll B. $\$ 1909 \rrbracket$ Inflammatory cytokines synergize with the HIV Tat protein to promote angiogenesis and Kaposits sarcoma via induction of basic fibroblast growth factor and the alpha $v$ beta 3 integrin. J.Immunot. 163, 1929-1935.

28. Barillari O., Sgadari C., Forelli V., Samaniego F, Colombini S., Manzari V., Modesti A., Nair B.C., Cafaro A., Sturzl M., \& Ensoli B. (1999) The Tat protein of human immunodeficiency virus type-1 promotes vascular cell growth and locomotion by engaging the alphasbetal and alphavbeta 3 integrins and by mobilizing sequestered basic fibroblast growth factor. Blood 94,603672 .

29. Chang H.C., Samaniego Fi, Nair B.C., Buonaguro L. \& Ensoli B. (1997) HIV-I Tai protein exils from celis via a leaderless secretory pathway and binds to extracellutar matrix.associated heparan sulfate proteoglycans through its basic region. ADS $11, \llbracket 421 \cdot 1431$.

30. Barltari G., Gendelman R., Gallo R.C., \& Ensoll B. (1993) The Tat protein of humam immunodeficiency virus type 1, a growell factor for AIDS Kaposi sarcoma and cytokine-activated vascular cells, induces adhesion of the same cetl types by using integrin receptors recognizing the RGD amino acid sequence. Proc.Nat. Acad.Sci.U.S.A $90,7941.7945$

31. Albini A. Barillari G., Benelli R., Gallo R.C., Ensoli B. (1995) Angiogenic propentes of human immunodeficienor virus type I Tat protein. Proc NatA.Acad.SciU.S.A 92, 4838-4842.

32. Ensoli B., Gendelman R., Markham P., Fiorell V., Colombini S., Raffeld M., Cafaro A., Chang. H.K., Brady IN. \& Gallo R.C. (1994) Synetgy between basic fibroblast growth factor and HW.1 Tat protein in induction of Kaposi's sarcoma. Nature 371, 074.680.

33. Dhawan S., Purl R.K., Kurnar A., Duplan H., Masson 1.M., \& Aggarwal B.B. (1997) Humam immunodeficiency virus-1.tat proten induces the cell surface expression of endothelat leukocyte adhesion molecule-1, vascular cell adhesion molecule 1 , and intercellutar adhesion molecule 1 in human endothelial cells. Blood 90, 1535-1544.

34. Latrenie R.M., Want L.M., Epstein J.S., Hewlett I.K., Yamada K.M., \& Dhawan S. (1090) HIV-1 Tat protein promotes chemotaxis and invasive behavior by monocytes. Jlmmunol 157, 974-977. 


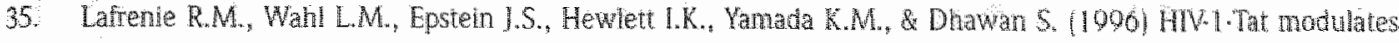
the function of monocytes ard alters their interactions with microvessel endothelial cells. A mechanism of HN pathogenesis. Joumat of Immunology $156,1039-1045$.

36. Lafrenie R.M., Wahl L.M. Epstein I.S., Yamada K.M. \& Dhawan S. (1997) Activation of monocyles by HIV Tat treatment is mediated by cytokine expression. J.lmminol $1159,4077-4083$.

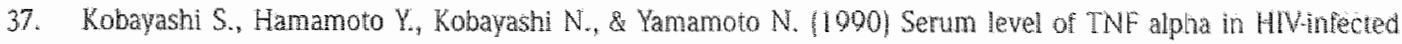
individuals. AVDS 4, 169-170.

38. Lahdevirta I., Maury C.P., Teppo A.M. \& Repo H. (1988) Elevated levels of circulating cachectin tumor necrosis factor in patients with acquired immunodeficiency syndrome. Amu.Med. 85, 289291.

39. Pugliese A., Torre D., Saini A., Pagliano G. Gallo G., Pistono P.G., \& Paggi G.C. (2002) Cytokine detection in HTV.MHV-8 coinfected subjects. Cell Biochen Funct. 20, 191194.

40. Rinaido C.R., Jr., Amstrong I.A., Kingsley L.A., Zhou S. \& H. 1990 ) Rêlation of alpha and gamma interferon levels to development of ADS in homosexual men. J.Exp. Pathol 5, 127.132.

41. Sinicco A., Bighino A., Sciandra M. Forno B., Pollono A.M., Raiteri R., \& Gioannim P. (1993) Gytokine network and acuie primary HN-1 intection. ADS 7, 1167-1172.

42. Wllum H., Cozzi L.A., Bendzzen K., Victor J., Gotzsche P.C., Phillips A.N., Skinhoj R, \& Klartund P.B. (1097) Low production of interferon gamma is related to disease progression in HV infection: evidence from a colwort of 347 HIVinfected individuals. AlDS Res Hurnt Retrovinuses 13, 1039-1046.

43. Kobayashi S., Hamamoto X., Kobayashi N., \&amamoto N. (1990) Serum level of TNF alpha in HNVinfected individuals. AIDS 4, $169-170$.

44. Lahdevirta J., Maury C.P., Teppo A.M., \& Repo H. (1988) Elevated levels of circulating cachectin/tumor necrosis factor in patients with acquired immunodeficiency syndrome. Am./Med 85, 289291.

45. Medrano F., Leal M., Arienti D., Rey G., Zagliani A., Torres X., Sanchez-Quijano A. Lissen E. \& Clerici M. 11998) Tumor necrosis factor beta and soluble APO-1/Fas independenty predict progression to ADS in HIVseropositive patients. AIDS Res Hum.Rerowiruses 14, 835.843.

46. Fanales-Belasio E., Moretti S., Nappi F, Barillari G., Micheletti F, Calaro A., \& Ensoli B. 2002J Native HIV 1. Tat protein targets monocytederived dendritic cells and enhances their maturation, function, and antigenspecific $T$ cell responses. fummunol 108, 197200.

47. Fanales-Belasio E., Moretti S., Nappi F, Barillari G., Micheletti F, Calaro A., \& Ensoli B. (2002) Native HIV. I Tat protein targets monocytederived dendricic cells and enthances their maturation, lunction, and antigenspecific T cell responses. Jinmunol 168, 197.206.

48. Fanales Belasio E., Moreti S., Nappi F, Barllari G., Micheletti F, Calaro A. \& Ensoli B. 2002) Native HW 1 Tat proteir targets monocyederived dendrilic cells and entances their maturation, function, and andigen. specific T cell responses. I.Mmunol 168, 197.200.

49. Chang H.C., Samaniego F., Nair B.C., Buonaguro L., E Ensoli B. (1997) HUV-1 Tal protein exits from cells vat a leaderless secretory pathway and binds to extracelluar matrix-associated heparan sulfate proteoglycans through Its basic region. AlDS $11,1421 / 1431$.

50. Ensoli B., Buonaguro L., Barillari G., Fiorell V., Gendelman R., Morgan R.A., Wingfield P., \& Gaillo R.C. (10031 Release, uptake, and effects of extracellular human immunodeficiency wirus type I Tat protefn on cell growth and viral transactivation. J. Virol. 67, 277-287.

51. Kohteisen B., Gaedigk Nitschko K., Ohlmann M., Gotz E, Ostolaza H., Goni FM., \& Erte V. $11996 /$ Heparm binding capacity of the HrV NEF protein allows onestep purfication and biochemical characterization. 1. Virol Methous $60,89-101$.

52. Speth C., Schabeisberger T., Mohsenipour 1., Stockl C., Wurzner R., Stober H., Lass. For C., Bierich M.P. (2002) Mechanism of human immunodeficiency vitusinduced complement expression in astrocytes and neurons. J. Vhol. $76,3179.3188$. 


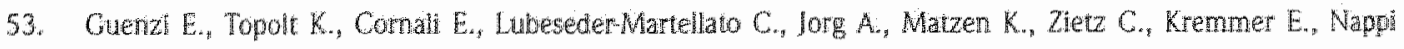
F, Schwemmle M., Hohenad C., Barilar G., Tschachler E., Monn P., Ensoli B., \& Sturd M. 2001, The helical domain of GBP. 1 mediates the inhibition of endothelial cell prohleraton by inflammatory cytokines. EMBO 20,55605577 .

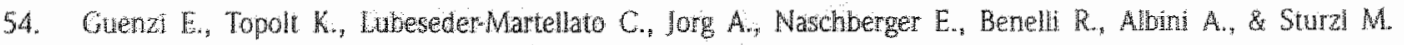
(2003) The guanylate binding protein-1 GTPase controls the irvasive and angiogenic capability of endotheial cells through inhibition of MMP-1 expression. EMBO J. 22, 3772-3782.

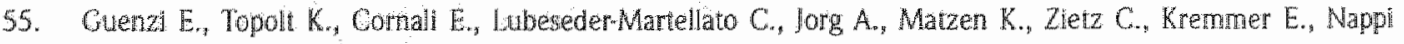
F, Schwemme M., Hohenad C., Barilhat G., Tschacher E., Monini P., Ensoli B., \& Sturzl M. [2001] The helical domain of GBP. I mediates the inhibition of andothelial cell proliferation by inflammatory cytokines. EMBO ) $20,556685577$.

50. Tromp S.C., Oude Egbrink M.G., Dings R.P, van Velzen S., Slaaf D.W., Hillen H.F. Tangelder G. R., Reneman R.S., \& Griftioen A.W. (2000) Tumor angiogenesis factors reduce leukocyte adhesion in vivo. Int Immunol 12,671.676.

57. Dirk. A.E.M, Oude Ggbrink M.G., Kuipers M.J., wan der Niet S.T., Heinen VV, Boumater Steege J.C., Wagstaff J., \& Grffioen A.W. (2003) Tumor angiogenesis modulates leukocyte-vessel wall interactions in vivo by reducing encothelial adhesion molecule expression. Cancer Res. 63, 2322-2329.

58. Zietz C., Hotz B., Sturzl M., Rauch E, Penning R., Lobrs U. (1990) Aortic endothelium in HTV-1 infection: chronic injury, actiwtion, and increased leukocyte adherence. Am. Pathol 149, 1887-1898.

59. Blasig C., Zletz C., Haar B., Neipel F., Esser S., Brockmeyer N.H., Tschachler E., Colombini S., Ensoli B., \& Sturz M. (1907) Monocytes in Kaposis sarcoma lesions are productively infected by human herpeswirus 8. J. Virol 71, 7963-7968.

60. Acevedo M., Sprecher D.L., Calabrese L., Pearce G.L., Coyner D.L., Halliburton S.S., White R.D., Sykora E. Kondos G.T., Hoff J.A. (2002) Pilot study of coronary atherosclerotic risk and plaque burden in HV patients: "a call for cardiowascular prevention". Atherosclerosis 163, 349.354.

61. Bonnet F, Morlat P., Chene G., Mercie P., Neau D., Chossat I., Decoin M., Djossou F, Beylot I., \& Dabis E. (2002) Causes of death among HVinfected patients in the era of highly active antiretroviral therapy, Bordeaux, France, 1998-1900. HIMMed. 3, 195-199.

62. Laftenie R.M., Wahl L.M., Epstein J.S., Hewlet I.K, Yamada K.M., \& Dhawan S. (1096) HIV.1.Tat modulates the function of monocytes and alters their interactions with microvessel endothelial cells. $A$ mechanism of HV pathogenesis. Jimmunat. 156, $1638 \cdot 1645$.

63. Lafrenie R.M., Wahl L.M., Epstein J.S., Hewlet I.K., Yamada K.M., \& Dhawan S. (1996) HIV.Tat proten promotes chemotaxis and invasive behavion by monocytes. J.lmmunof. 157, 974.077.

64. Lafrenie R.M., Wan L.M., Epstein J.5., Yamada K.M., \& Dhawan S. 11997 Activation of monocytes by HIV. Tat treatment is mediated by cytokine expression. Almmunot $159,4077-4083$.

65. Corallini A. Altavilla G., Pozzi L., Bignozzi F., Negrini M., Rimessi B. Gualandi F, B Barbanti-Brodano G. 11903 Systenic expression of HIV 1 tat gene in transgenic mice induces endothelia profiferation and tumors of different histotypes. Cancer Res 53,5569-5575.

60. Vogel J. Hinrichs S.H., Reynolds R.K., Luciw P.A., \& Jay G. (1988) The HIV tat gene induces dermal lesions resembling Kapos:s sarcoma in transgenic mice. Nature 335, 606-61.1.

67. Abini A., Fontanini G., Masielo L.. Taccheti C., Bigini D., Luzzi P. Noonan D.M., \& Stetler-Stevenson W.G. (1904) Angiogenic potential in vivo by Kaposi's sarcoma cell-free supematanis and HW-1 tat product: inhibition of KSHike lesions by tissue inhibitor of metalloproteinase.2. ALDS 8, 1237.1244.

68. Barlilari G., Sgadan C. Palladino C., Gendelman R. Caputo A., Morris C.B., Nair B.C., Markham P., Nel A., SturzI M, \& Ensoli B. (1909) Inlammatory cytokines synergize with the HIV T Tat protein to promote angogenesis and Kapos's sarcoma via induction of basic fibroblast growth factor and the alpha wela 3 integrin. Itmmonol 163, 1929-1935. 
69. Ensoli B., Gendelman R., Markham P., Fiorelli V, Colombini S., Rafield M., Cafaro A., Ghang M.K., Brady J.N., Gallo R.C. (1994) Symergy between basic fibroblast growth factor and HW-1 Tat protein in induction of Kaposi"s sarcoma. Nature 371, 674680.

70. Forelli V., Gendelman R., Sirianni M.C., Chang H.K., Colombini S., Markham P.D., Monini P., Sonnabend I., Pintus A., Gallo R.C., \& Ensoli B. (1908) gamma-Interferon produced by CD8+ T cells infiltrating Kaposi's sarcoma Induces spindle cells with angiogenic phenotype and synergy with human immunodeficiency virus.1 Tat protein: an immune response to human herpesvirus-8 infection? Blood 91, 956-967.

71. Chang H.C., Samaniego F., Nair B.C., Buonaguro L., \& Ensoll B. 1997 ) HIV.I Tat protein exits from cells via a leaderless secretory pathway and binds to extracellular matrix associated heparan sulfate proteoglycans through its basic region. AIDS $11,1421 \cdot 1431$.

72. Schwarze S.R., Ho A., Vocero-Akbani A., \& Dowdy S.F. (1099) in viwo protein transduction: delivery of a biologically active protein into the mouse. Science $285,1569 \cdot 1572$.

73. Ensoli B. \& Sturzl M. (1998) Kaposi's sarcoma: a result of the interplay among inflammatory cytokines, angiogenic factors and viral agents. Cytokine Growth Factor Rev $9,63.83$.

74. Forelli V, Gendelman R., Sirianni M.C., Chang H.K., Colombini S., Markham R.D., Monini P., Sonnabend J., Pintus A, Gallo R.C., \& Ensoli B. (1998) gamma-lnterferon produced by CD8+ T cells infiltrating Kaposi"s sarcoma induces spindle cells with angiogenic phenowpe and synergy with human immunodeficiency virus-1 Tat protein: an immune response to human herpeswirus-8 infection? Blood 91,956-967.

75. MacPhail L.A., Dekker N.P., \& Regezi J.A. (19961 Macrophages and vascular adheston molecules in oral Kaposi's sarcoma. J.Cutan Pathol. 23, 464-472.

76. Nickoloff B.J. \& Griffiths C.E. [1989) The spindle-shaped cells in cutaneous Kaposits sarcoma. Histologic simulators include factor Xllla dermal dendrocytes. Am.J. Pathol 135, 793-800.

77. Regezi J.A., MacPhail L.A. Daniels T.E., DeSouza Y.G., Greenspan J.S., \& Greenspan D. (1993) Human immunodeficiency virus-associated oral Kaposi's sarcoma. A heterogeneous cell population dominated by spindleshaped endothelial cells. Am.f. Pathol. 143, 240.249.

78. Tabata M., Langford A., Becker J., \& Reichart P.A. [1993) Distribution of immunocompetent cells in oral Kaposi's sarcoma (AlDS). Ear.J.Cancer B Oral Oncol 29B, 209213.

79. Uccini S., Sirianni M.C., Vincenzi L., Topino S., Stoppacciaro A., Lesnoni L.P., I, Capuano M., Masini C., Cerimele D., Cella M., Lanzavechia A., Allawena P., Mantovani A., Baroni C.D.y \& Ruco L.P. (1997) Kaposi's. sarcoma cells express the macrophage-associated antigen mannose receptor and develop in peripheral blood cultures of Kapasi's sarcoma patients. Am.J.Pathol 150, 929.938.

80. Beral W. Peterman T.A., Berkelman R.L., \&affe H.W. (1990) Kaposi's sarcoma among persons with AIDS: a sexually transmitted infection? Lancet $335,123-128$. 


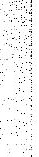




\section{Chapter 5}

\section{Monocyte/macrophage}

infiltration in tumors:

\section{modulators of angiogenesis}

Anita E.M. Dirkx, Mirjam G.A. oude Egbrink and Arjan W. Griffioen

J. Leukocyte Biology (accepted for publication) 


\section{ABSTRACT}

The role of a tumor immune infiltrate in cancer progression and metastasis has frequently been debated. Although often considered to be associated with improved prognosis and leading to the enhanced survival of cancer patients, inflammatory cells have also been described to assist the tumor's capabilities to progress, proliferate and metastasize. Tumor associated macrophages (TAMs), for example, have shown to be symbiotically related to tumor cells: tumor cells recruit TAMs and provide them with survival factors, while TAMs in turn produce a variety of angiogenic factors in response to the tumor microenvironment. This review will describe the composition of an immune infiltrate in tumors, and the angiogenic and angiostatic properties of the cells present. Special emphasis will be on the angiogenesis-associated activities of TAMs. The development of immunoand gene therapies using TAMs to mediate tumor cytotoxicity or to deliver gene constructs will be discussed as well. Since immunotherapy has so far not been as effective as anticipated, a combination therapy in which angiostatic agents are used as well is put forward as a novel strategy to treat cancer. 


\section{INTRODUCTION}

Without the formation of new blood vessels (angiogenesis), expansion of a tumor mass is limited to $1.2 \mathrm{~mm}$ in size because of insufficient supply of oxygen and nutrients, a concept first proposed by $\mathrm{Dr}$ J. Folkman in $1971^{1}$. Many tumors remain dormant at this size and, therefore, stay clinically undetectable for years ${ }^{2}$. A dys-equilibrium between positive and negative angiogenesis regulators eventually results in the progression of these in situ tumors to an angiogenic phenotype, the so called angiogenic switch ${ }^{3,4}$. Tumor angiogenesis is promoted by hypoxia resulting in enhanced expression of angiogenic factors such as vascular endothelial growth factor (VEGF), interleukin-8 (IL-8) and basic fibroblast growth factor (bFGF), and in decreased expression of angiogenesis inhibitors such as platelet factor-4 (PF-4), thrombospondin and angiostatin ${ }^{5}$.

Once a tumor is vascularized it is infiltrated by leukocytes, a phenomenon observed in all solid cancers. The first observation of leukocyte infiltration in tumors was done by Virchow in $1863^{6}$ and was thought to be the result of chronic inflammation that was already present before tumor development. Nowadays, however, it is known that the presence of leukocytes is a consequence of an immune reaction to the tumor itself -first innate and later specific immunity, since the immune system is able to recognize tumor-associated antigens ${ }^{7}$. In cancer patients, specific cytotoxic $T$ lymphocytes recognizing tumor antigens have been reported and the presence of these cells is related to a better prognosis. In addition, antibodies to tumor-associated antigens produced by B-cells may also play a role in limiting tumor growth ${ }^{8,9}$. Leukocyte infiltration in tumors is, therefore, often associated with better prognosis and overall survival ${ }^{7}$. Moreover, the ability of the immune system to recognize antigens expressed by tumors or tumor microvasculature can be used to identify molecules to define targets for cancer immunotherapy ${ }^{8}$.

Under normal physiological circumstances, leukocytes are recruited in response to inflammation by the local synthesis of chemokines and other cytokines and by products that are associated with tissue breakdown. These processes are all part of a complex signalling system including recognition of the pathological state, organisation of a proper cellular response and subsequent suppression of this response once the situation is resolved. In wound healing, these processes include proliferation and migration of epithelial cells, angiogenesis and tissue remodelling ${ }^{10}$. In tumors, similar chemoattractive factors are thought to play a role in leukocyte recruitment. Tumor cells, however, continuously send out signals that are associated with growth and migration processes, which recruit

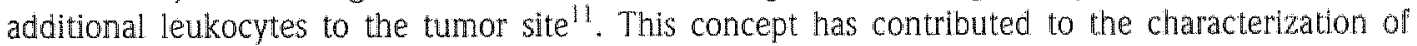
tumors as "wounds that fail to heal"12.

Although associated with better prognosis, immune responses to a tumor are often weak and not able to completely destroy a tumor ${ }^{7}$, suggesting that tumors have developed mechanisms to escape immune surveillance. Among a series of mechanisms that can explain this escape, including tolerance induction and activation of regulatory immune functions ${ }^{13}$, one mechanism to escape tumor-directed immunity is inhibition of leukocyte-vessel wall interactions in tumor vessels ${ }^{14 \cdot 17}$, due to suppressed expression of endothelial adhesion molecules ${ }^{18.21}$ and induction of endothelial cell anergy ${ }^{22}$. As a result, tumors frequently show only limited leukocyte infiltration, predominantly by cells of the innate immune system ${ }^{19}$. Leukocytes that do reach the tumor, often remain localized in the tumor periphery or stroma and are often not able to exert strong antitumor effects ${ }^{12}$. Moreover, it is known that infiltrated leukocytes show impaired maturation due to exposure to the tumor microenvironment ${ }^{7,23}$. Therefore, infiltrated leukocytes are often not capable of destroying the tumor completely. By contrast, some leukocyte subsets have been described to promote proliferation and metastasis and, hence, tumor development. Tumor associated macrophages (TAM), for example, can exert protumor effects through the secretion of immunosuppressive cytokines, the release of free 
radicals like nitric oxide (NO) and hydrogen peroxide (rendering immune cells hyporesponsive of even apoptotic) and, last but not least, the secretion of angiogenic cytokines and enzymes ${ }^{24}$. This review will focus on the angiggenic effects of leukocytes that are infiltrated in a tumor. It will discuss the composition of a leukocyte infiltrate in tumors, and the angiogenic and angiostatic properties of the immune cells present. Special emphasis will be on the role of tumor associated macrophages, their capability to reach a tumor in large quantities and, hence, their possible role in immunotherapy.

\section{IDENTITY AND ANGIOGENESIS RELATED EFFECTS OF CELLS IN A TUMOR IMMUNE INFITRATE}

In tumor immune infiltrates, practically all cells involved in inflammation can be found. Leukocytes are known to accumulate in a tumor through a series of interactions with tumor endothelial cells, including leukocyte tethering, rolling, firm adhesion and eventually diapedesis ${ }^{25}$. The notion that tumor infiltration by leukocytes is always a prognostically positive phenomenon has changed in recent years; the finding that angiogenic factors cannot only be produced by tumor cells, but also by infilitrating leukocytes indicates possible stimulating effects on tumor angiogenesis of the latter ${ }^{20}$. Polymorphonuclear granulocytes (PMNs), and more specifically neutrophilic granulocytes, are the first-line of defense against infections and since they do not show any specificity for antigens, their predominant roles are cell killing and phagocytosis ${ }^{27}$. Furthermore, PMNs are known to infiltrate tumors and constitute an important part of the immune infiltrate. They may be considered as potential antitumor cells, but clinical studies have been contradictory with respect to the function of tumor infiltrated PMNs. Whereas in patienis with adenocarcinoma the presence of increased numbers of tumor infiltrating neutrophils was linked to poorer outcome ${ }^{28}$, studies of gastric carcinoma suggested a correlation of neutrophil infiltration with good prognosis ${ }^{29}$. In order to improve PMN recruitment for immunotherapy, bispecific antibodies (with one specificity for FcyRI and another for a tumor associated antigen) can be used. Results from a phase I clinical trial with a bispecific anti-FcrRI / anti-HER2/neu show that although the clinical course of the disease was not altered by the treatment, immunohistochemical analyses of tumor biopsies in individual patients documented infiltration of monocytes and PMN after antibody infusion ${ }^{30}$. Interestingly, PMNs can be induced to produce substances that either stimulate or inhibit the angiogenic process. Activated PMNs contain granules which harbor matrix metalloproteinases capable of degrading the extracellular matrix ${ }^{27.31}$ and, hence, stimulate angiogenesis. In addition, they have been reported to produce a number of other angiogenic factors (VEGF, IL-8). On the contrary, PMNs are also known to be involved in the generation of endogenous angiogenesis inhibitors (e.g., angiostatin and other angiostatic factors (LL12, inducible protein $10(\mathrm{IPIO})$, interferon- $\gamma(\mathrm{IFN} \gamma \mathrm{l})]^{7}$. Despite this body of information, the actual role of infiltrated PMNs in tumors is poorly investigated and remains unclear. Next to these angiogenesis-related effects, PMNs are strong producers of chemotactic proteins to recruit other PMNs, monocytes, immature dendritic cells and T-ymphocyte subsets, in a self-sustained process ${ }^{7,27}$.

Like PMNs, natural killer (NK) cells can recognize and lyse tumor cells without having to be primed and without the need for MHC recognition, and they are thought to be involved in immune surveillance against cancer ${ }^{7,21,32}$. Although not frequently seen in tumors ${ }^{33,34}$, there is some evidence that NK cells can play a critical role in angiogenesis inhibition by IL-12 induced IFNy secretio ${ }^{35}$. In a study by Yao et a $\mathrm{I}^{35} \mathrm{IL}-12$ was inoculated in a human Burkitt tumor in mice; subsequently, extensive vascular damage and tumor tissue necrosis was observed as well as an accumulation of activated NK cells in necrotic areas surrounding blood vessels. In another study by Hayakawa and co-workers ${ }^{36}$ it was shown that IFNy secreted by NK cells is involved in inhibition of tumor angiogenesis by alpha-galactosylceramide [ $\alpha$-Galer], as presented by the MHC class-I like molecule 
CDId, a ligand for NK cells. Depletion of NK cell activity markedly reduced angiogenesis intibition ${ }^{35}$ and enhanced tumor growth ${ }^{36}$, providing evidence that NK cells can play a critical role in the regulation of angiogenesis. Activated NK cells have also been reported to effectively kill both tumor cells and endothelial cell targets and, hence, inhibit angiogenesis ${ }^{37,38}$. Therefore, NK cells can be considered to have a central role in inhibiting tumor angiogenesis at the interplay between host inmunity and tumor-cell biology.

T-lymphocytes secrete a repertoire of molecules (e.g. IL-2, tumor necrosis factor- $\alpha$ (TNFo) and IFN $\gamma$ that regulate intercellular signalling events involved in host responses to foreign antigens, like recruitment of immune effector cells $(\mathrm{IL}-2$, IFNy) and regulation of expression of cell surface proteins on endothelial cells (TNFos) $)^{39}$. T-cell infiltration is commonly seen in tumors $160 \%$ of an infiltrate can be composed of lymphocytes of which a large majority is $T$-cells ${ }^{34}$ ) and is often associated with improved prognosis and survival ${ }^{33,40-42}$. UFNy secretion by CD4+ T cells of the Th1 subset has been shown to be important in wivo in inhibiting tumor cell proliferation, activating macrophages and enhancing the secretion of angiostatic chemokines ${ }^{43}$. Interleukin 4 secretion by Th2 cells might be involved in tumor development as well by inhibiting both VEGF and bFGF induced angiogenesis in vitro ${ }^{44}$. Although tumor infiltrating lymphocytes have been reported to show cytolytic activity induced by tumor cells ${ }^{39}$, tumors have evolved mechanisms to escape their effects in vivo. Some tumors contain anergic lymphocytes, probably due to local secretion of immunosuppressive factors (i.e. TGFB, ${ }^{45}$ in the tumor microenvironment ${ }^{39,46}$ or the loss of $\mathrm{MHC}$ expression by tumor cells ${ }^{7}$. Alternatively, a decreased activity of the T-cells may be due to the presence of CD25-positive regulatory $\mathrm{T}$-cells antagonizing a specific $\mathrm{T}$-cell response. For this reason, current clinical immunotherapy approaches are combined with simultaneous infusion with antiCD25-antibodies to eliminate these regulatory T-cells ${ }^{47,49}$. Although T-cell infiltrates in tumors are mostly seen as evidence of a protective immune response and, hence, associated with better prognosis, it has been demonstrated that both $\mathrm{CD} 4+$ and $\mathrm{CD} 8+$ lymphocytes are capable of promoting angiogenesis in vivo as well ${ }^{39}$. Both in and outside a tumor Tylymphocytes can produce the angiogenic compounds bFGF and VEGF in response to hypoxia, suggesting an important role for these cells in tumor proliferation and metastasis s9,49,50. Although B-lymphocytes $^{51,52}$ zet deze refs er maar achter are also described to be present in a tumor immune infiltrate, no specific information on angiogenesisrelated effects of these cells has been found. However, since B-lymphocytes are a known source of cytokines like IL-1 and IL.6, some positive effects of this lymphocyte subset on the process of angiogenesis may be speculated.

Dendritic cells (DCs) are not often found in tumor infiltrates ${ }^{33,34}$ and if found, they are mostly in an immature state and incapable of inducing an effective immune response ${ }^{53,54}$. Normally, DCs are the most efficient antigen-presenting cells with the unique ability to present tumorspecific antigens and subsequently activate a specific antitumor T-cell response in vivo. Immature DCs are capable of antigen ingestion and processing, but they must mature to activated DCs to elicit a productive immune response. Conflicting data have been published on the effect of infiltrated DCs on tumor development. Immature DCs have been shown to silence immunity and induce tolerance, either by deleting T-cells or by expanding regulatory $\mathrm{T}$-cells $5^{53,55}$. This phenomenon appeared to be mediated by tumor derived factors like VEGF, IL-6 and macrophage colony stimulating factor (M-CSF or CSF-1) ${ }^{23,54}$ "On the other hand, it was also shown that DC infiltration in tumor lesions is associated with improved survival rates and reduced incidence of recurrent disease in different types of malignancies ${ }^{50}$. Additionally, immunotherapy using DCs has thoroughly been investigated and has proven to be feasible, nontoxic and effective in some patients, particularly when DCs are mature and active before administration ${ }^{53,57}$. 59 . It is unknown, however, whether DCs themselves serve as angiogenesis mediators. 
Mast cells are bone marrow-derived accessory cells which are not found in circulation (and do not migrate into tumor areas), but associated with certain structures as blood vessels or nerves ${ }^{60}$. They are often associated with allergic reactions to certain allergens, but are also known to stimulate irnmunity by enhancing the inflammatory reaction. Mast cells have been found in a variety of human cancers (such as melanoma, breast and colorectal cancer) and their accumulation at tumor sites is associated with enhanced tumor growth and invasion 11,60 . They have been reported to support tumor proliferation and progression by their ability to induce tumor angiogenesis ${ }^{60}$. Activated mast cells are known to produce a number of angiogenic factors, like VEGF, bFGF, IL-8 and TNFa, and matrix metalloproteinase-9 (MMP-9, which is involved in degrading the extracellular matrix) ${ }^{1,60}$. Furthermore, they are able to produce the angiogenic mediators histamine and heparin, which can stimulate endothelial cell proliferation (directly or indirectly by the stabilization of growth factors) and may have a role in the hyperpermeable nature of newly formed vessels in tumor angiogenesis ${ }^{61}$. Reduction of tumor mast cell density by transfection of a vector containing antisense stem cell factor CDNA (SCF, which stimulates mast cell migration, proliferation and degranulation) has been shown to inhibit angiogenesis and, therefore, tumor growth ${ }^{62}$. Therefore, interfering with mast cell recruitment to tumor sites might be a possible therapy for cancer.

When monocytes are released from the bone marrow into the blood, they are still immature. They only differentiate into macrophages once they are infiltrated into tissues ${ }^{63}$. The majority of malignant tumors appears to be infiltrated by macrophages, which can comprise up to $80 \%$ of the total tumor mass ${ }^{33,64,05}$. These tumor associated macrophages (TAMs) are capable of killing tumor cells and releasing angiostatic compounds, but they can also stimulate tumor growth by producing angiogenic factors and metalloproteinases 7,65 . During tumor development the tumor stimulating effects of these infiltrated macrophages often overrule the tumor inhibiting ones ${ }^{7}$. Overexpression of macrophage chemoattractants within tumors has been shown to correlate with poor prognosis ${ }^{66}$ and the level of macrophage infiltration in tumors is known to be positively correlated with microvessel density, tumor stage and angiogenesis in tumors ${ }^{67}$. TAM presence is, therefore, associated with reduced relapse-free and overall survival ${ }^{65,67.70}$ in several tumor types (i.e. melanoma ${ }^{67}$, cervical ${ }^{68,69}$ and breast ${ }^{65,70}$ cancer). On the other hand, however, in other tumor types [i.e. prostate ${ }^{71}$ and stomach ${ }^{72}$ tumors) TAM presence appears to be associated with improved prognosis. It is suggested that extensive monocyte invasion in a tumor results in elimination of tumor mass, while a low level of monocyte recruitment provides an angiogenic stimulus which permits tumor proliferation ${ }^{73}$.

All together, a tumor infiltrate both stimulate and inhibit anglogenesis, depending on the type, timing, number and activation state of all the cells present ${ }^{7}$. In the next part of this review, we will focus more explicitly on the recruitment and the possible angiogenic and angiostatic activities of tumor-associated macrophages (TAMs).

\section{RECRUITMENT OF TAMS BY TUMORS}

\section{Chemokines and cytokines}

Monocytes, like other leukocytes, are actively attracted to the tumor site due to the production of cytokines and chemokines by tumor cells. Chemokines are divided in major subfamilies, like CXC and $\mathrm{CC}$, depending on the arrangement of the $2 \mathrm{~N}$-terminal cysteine residues. They play major roles in all aspects of tumor biology, including recruitment of leukocytes, regulation of angiogenesis and tumor growth (mainly CXC chemokines ${ }^{74}$ ), and control of the movement of tumor cells during 
metastasis ${ }^{75}$. Several CC chemokines, like monocyte chemotactic protein-1 (MCP-1 or CCL2) and RANTES (or CCL5), produced by tumor cells, endothelial cells, fibroblasts and also by TAMs, are known to attract monocytes ${ }^{75,76}$. MCP.1 is highly expressed in several tumor types and is associated with infiltration of monocytes. Interestingly, MCP- 1 expression has been shown to correlate significantly with levels of VEGF, TNF $\alpha$ and IL-8, suggesting a possible role for MCP-1 as an angiogenesis regulator as well ${ }^{6,77,78}$. The expression of another CC chemokine, RANTES, in breast tumor cells is known to be elevated synergistically by IFN $\gamma$ and TNFa, regulating monocyte migration into tumor sites and promoting cancer progression. Moreover, RANTES has been found to stimulate monocytes to secrete MMP-9 and MMP.19, indicating its indirect involvement in degrading the basement membrane and, therefore, in angiogenesis ${ }^{79,80}$. Although the involvement of $\mathrm{CXC}$ chemokines in regulating angiogenesis is well studied ${ }^{74}$, their role in directing tumor infiltration by TAMs is less well defined. The angiogenic factor IL-8 (CXCL8), however, has been shown to cause rolling monocytes to adhere firmly onto endothelial cell monolayers expressing E-selectin, indicating that $1 \mathrm{~L}-8$ is not only acting as a chemoattractant but is also involved in translating initial monocyte tethering into firm adhesion through activation of leukocyte integrin ${ }^{81}$.

Monocytes are directed to the tumor by other cytokines as well. While VEGF is a well known angiogenic cytokine, it is also a chemotactic protein for monocytes via activation of flt- 1 (vascular endothelial growth factor receptor-11 ${ }^{63,82-84}$. It is produced by both tumor cells and TAMs and is controlled by oxygen tension ${ }^{85}$. Since VEGF is mainly expressed in response to hypoxia, TAMs are often seen to accumulate in poorly vascularized tumor areas ${ }^{63}$. Macrophage colony stimulating factor (M-CSF or CSF-1) is another cytokine with chemoattractive properties for monocytes and it is being produced by tumor cells and TAMs. Elevated expression of M-CSF and its receptor (CSF-1R) have been found in human breast, endometrial and ovarian tumors ${ }^{86,87}$. High M-CSF expression is associated with high TAMs accumulation in breast carcinomas ${ }^{88}$ and poor prognosis ${ }^{89.91}$. It has also been described to be involved in induction of VEGF and IL-8, suggesting a possible role in regulation of angiogenesis for this cytokine as well ${ }^{77,92}$.

\section{Adhesion molecules}

Next to chemoattractants, adhesion molecule expression on endothelial cells as well as on monocytes are eminently involved in monocyte recruitment to tumors ${ }^{10,20,93}$. To actually infiltrate tissues, monocytes have to interact with the venular vessel wall. This process of monocyte-vessel wall interaction appears to be a multistep cascade in which each step has to be completed for the next step to occur ${ }^{94}$. The first step is the tethering and, subsequently, rolling of leukocytes along the vessel wall. Monocyte rolling is mainly mediated by adhesion molecules of the selectin family $(\mathrm{L}$ selectin found on monocytes and both P. and E-selectin on activated endothelial cellss, binding to their counterreceptors on opposing cells (e.g. CD34 on endothelial cells and P-selectin glycoprotein1 (PSGL-1) on monocytes) ${ }^{95}$. Rolling monocytes can become activated by chemoattractants or cell contact-mediated signalls inducing secondary adhesion molecules $\%$, by which they can firmly adhere to the endothelium. Monocyte adhesion to the vessel wall is mediated by adhesion molecules of two families: the integrins (e.g. LFA-1 and VLA-4, expressed on monocytes) and the immunoglobulin gene superfamily (e.g. ICAM-1 and VCAM-1, expressed on activated endothelial cells and on leukocytes or macrophages ${ }^{97}$. Adhering monocytes can then transmigrate through intercellular junctions between endothelial cells and migrate into the surrounding (tumor) tissue ${ }^{98}$.

Previously we have shown that tumor-derived angiogenic factors such as VEGF and bFGF are responsible for downregulation of endothelial adhesion molecules such as ICAM-1, VCAM-1 and E. selectin, resulting in diminished leukocyte-vessel wall interactions in tumor vessels ${ }^{18,90,100}$. 


\section{ANGIOSTATIC PROPERTIES OF TUMOR ASSOCIATED MACROPHAGES.}

Macrophages are known to accumulate mainly in poorly vascularized, hypoxic areas, due to specific upregulation of various chemoattractants (recently reviewed by Murdoch et al ${ }^{75}$ ). Once macrophages arrive at the tumor site they start to produce their own set of proteins to attract more leukocytes and to influence the process of angiogenesis. TAMs are reported to have a number of angiostatic properties (Table 5.1), which will be discussed in this section.

Table 5 . I Anglostatic factors secreted by MMs

\begin{tabular}{|c|c|c|}
\hline Cytokines/chemokines & Regulation and effects & References \\
\hline 112 & $\begin{array}{l}\text { 1L12 } \rightarrow \text { IFN/ and TNFa by Th1 cells } \rightarrow \text { lu } \\
\text { angiostatic factors IPIO (CXCL10) and MIG (CXCl9) }\end{array}$ & $63,101,103-107,109$ \\
\hline 1418 & $\begin{array}{l}\text { 1L18 } \rightarrow 1 \text { IFNg by Th1 cells } \rightarrow 1 \text { angiostatic factors } \\
\text { IP10 (CXCL10) and MIG (CXCL9) } \\
1 \text { bFGF-1nduced endothelial cell proliferation }\end{array}$ & $101,104,108,7144-117$ \\
\hline MMP 12 & $\begin{array}{l}\text { l M-CSF/IL-1, TNFa/NEGF } \rightarrow 1 \mathrm{MMP}-12 \rightarrow 1 \\
\text { cleavage of plasminogen to angiostatin }\end{array}$ & $27,63,118,119,121,122$ \\
\hline
\end{tabular}

\section{Interleukin-12}

Interleukin-12 ([L-12) is produced by monocytes/macrophages and also by dendritic cells and Bcells; it is known for its antitumor and antimetastatic activity ${ }^{101}$. IL-12 activates a T-cell-dependent antitumor immune response that is able to eradicate established large tumors in a number of immunogenic tumor modes ${ }^{102}$. Moreover, activated macrophages appear to function as effector cells in this $1 \mathrm{~L}-12$-induced tumor eradication by inducing apoptosis ${ }^{102}$. IL-12 appears to have angiostatic capacities as well ${ }^{103,104}$, which induce tumor necrosis ${ }^{105}$. Angiogenesis inhibition by $1 \mathrm{~L}-12$ is not carried out via direct interaction with endothelial cells " but merely via initiation of IFNy production by Th1 cells and NK cells $s^{63,106,107}$. The production of IL-12 by macrophages enhances immune function by shifting CD4+ cells towards the Th1 subset, which secrete IL-2 and IFNy ${ }^{108}$, facilitating in turn the proliferation and activation of CD8+ cytotoxic T cells, NK cells and macrophages, which may contribute to tumor regression ${ }^{104}$. IFNy is, in turn, able to induce the production of IFN-inducible protein 10 (IP10 or CXCL10) and monokine induced by IFNy (MI or CXCL9), which both have angiostatic properties ${ }^{105,109}$. Moreover, IFN $\gamma$ is able to induce additional non-antigen specific antitumor mechanisms, including a retardation ofcellular proliferation and production of nitric oxide ${ }^{104}$. In a murine model of breast cancer, $\mathbb{I L}-12$ therapy has shown potent angiostatic effects and subsequent tumor regression. Levels of tumor VEGF and MMP-9 were declined markedly and eventually undetectable ${ }^{110} .1 \mathrm{~L}-12$ is able to accelerate a variety of anti-tumor mechanisms, some of which are antigen specific and some of which are not. At the moment, the use of $\mathbb{L}-12$ is investigated in phase I and I\| trials with promising results, including improved immunological antitumor responses ${ }^{111-113}$.

\section{Interleukin-18}

IL-18 is another substance known to induce tumor regression via angiogenesis inhibition ${ }^{104}$. It is being produced by (activated) macrophages, dendritic cells and Kupffer cells ${ }^{101,104}$. Similar to IL-12, IL-18 inhibits anglogenesis through stimulation of IFN $\gamma$ production (by both Th1 lymphocytes and 
NK cells $)_{\text {, esulting in a systemic antitumor response }}{ }^{108}$. It appears to be more potent as IFNy inducen than $1 \mathrm{~L}-12$, apparently through a separate intracellular signal-transduction pathay ${ }^{114,115}$. IL-18 treated tumors show a significant decrease of microvessel density 110 . Administration of IL-18 inhibits the growth of fibrosarcoma by hypovascularization ${ }^{115}$. One of the angiostatic mechanisms of $\mathrm{LL}-18$ is its ability to inhibit bFGF-induced endothelial cell proliferation which was demonstrated in vitro, while $1 \mathrm{~L}-12$ lacks such an effect ${ }^{116}$. Therefore, the angiostatic pathway of IL-18 may not be completely dependent on activation of IFN $\gamma$. Interestingly, IL-18 and $\mathrm{I}-12$ have been reported to have synergistic antitumor effects ${ }^{15,117}$ and synergistically inhibit angiogenesis ${ }^{104}$. Systemic administration of $1 \mathrm{~L}-18$ was shown to potentiate inhibition of proliferation of carcinoma cells modified to express $1 \mathrm{~L}-12^{115}$. In a murine sarcoma model, intratumoral injection of dendritic cells engineered to produce $I \mathrm{~L} \cdot 12$ or IL-18 showed to decrease tumor proliferation and even complete tumor rejection, more strongly then either one of them ${ }^{117}$. Beside its inhibitory effects on angiogenesis, IL-18 has also proven to be a proinflammatory cytokine and a strong inducer of immune responses ${ }^{115}$. Taken together, IL18 , particularly in combination with $\mathrm{IL}-12$, may be a promising antitumor agent.

\section{Matrix metalloproteinase-12}

Matrix metalloproteinases (MMP) are a family of zinc-dependent endopeptidases which can cleave all major molecules of the extracellular matrix $x^{63,118,119}$. During tumor growth, MMP can enhance angiogenesis and degrade connective tissue and basement membranes to enable tumor growth and metastasis ${ }^{118}$. Next to a tumor promoting effect, some MMP, like metalloelastase (MMP-12), matrilysin (MMP-7) and gelatinase-B (MMP-9) have also been shown to possess anglostatic properties $^{118,119}$. MMP-12 is generally expressed in macrophages, although tumor cells were shown to express this enzyme as well ${ }^{18,120}$. Pro-MMP-12 is released by macrophages in response to several factors (like M-CSF, IL-1, "TNF $\alpha$ and VEGF). The amount of macrophage-derived MMP. 12 appears to be higher in grade I and II vulvar tumors compared to the more aggressive grade IIl tumors, indicating that the level of MMP- 12 positive macrophages correlates with a better prognosis ${ }^{118}$. Moreover, in a study of colorectal carcinoma, patients with high expression of MMP. 12 mRNA significantly demonstrated better survival compared with those patients who did not show high MMP-12 expression. Patients with high MMP-12 expression showed lower microvessel density (MVD), demonstrating that MMP-12 is able to inhibit angiogenesis in vivo in human tumors ${ }^{121}$. MMP-12 is capable of generating angiostatin ${ }^{122}$, a potent angiogenesis inhibitor identified by $O^{\prime}$ Reilly et al ${ }^{123}$ in Lewis lung carcinoma. Angiostatin is a cleavage product of plasminogen, which has been shown to inhibit endothelial cell proliferation and impairs both primary and metastatic tumor growth through inhibition of angiogenesis ${ }^{119}$. All together, MMP. 12 and angiostatin appear to play an important role in the inhibition of angiogenesis and tumor progression in patients.

\section{ANGIOGENIC PROPERTIES OF TUMOR ASSOCIATED MACROPHAGES.}

In contrast to the limited knowledge concerning angiostatic activities of TAMs, more research has focused on their angiogenic properties (Table 5.2). Understanding the angiogenic activity of TAMs in a tumor will hopefully rise opportunities to counteract these activities in order to treat cancer.

\section{Interleukin-1}

The cytokine interleukin-1 (IL-1) is produced mainly by monocytes/macrophages and appears to be a highly inflammatory cytokine, also possessing various immune, degradative and growth 
Table 5.2 : Angiogento factors produced by TAMs

\begin{tabular}{|c|c|c|}
\hline Cytokines/chemokines & Regulation and effects & References \\
\hline & $\begin{array}{l}-\mathrm{IL}-1,-\mathrm{LL}-1, \rightarrow \uparrow \mathrm{HIF} \rightarrow \uparrow \mathrm{VEGF} \\
-\mathrm{IL}-1, \uparrow \rightarrow \mathrm{MHP}-2 / \mathrm{HGF} / \mathrm{TNF} \\
-\mathrm{IL}-1, \rightarrow 1 \text { angiogenim }\end{array}$ & $63,124-127$ \\
\hline VEGF & $\begin{array}{l}\text { Hypoxi } \rightarrow \uparrow \text { HIF } \rightarrow \text { \VEGF } \\
-M-C S F \rightarrow \uparrow \text { VEGF } \\
\text { - } \text { TWF } / / \mathrm{IL}-1 \rightarrow \uparrow \text { VEGF } \\
\text { Chemotactic for monocytes }\end{array}$ & $92,130,140$ \\
\hline M.8 & $\begin{array}{l}- \text { Activation NFkB } \rightarrow \uparrow \mathbb{I L}-8 \\
-\uparrow \text { TWFa/IL-1 } \rightarrow \uparrow \text { IL-8 } \\
-M-C S F / M C P-1 / \text { GGF }_{1} \rightarrow \uparrow I L-8\end{array}$ & $77,78,135,140$ \\
\hline bFGF & 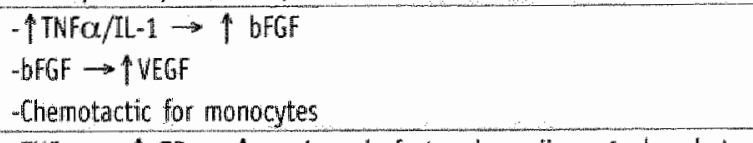 & $137,138,140$ \\
\hline TNFA & 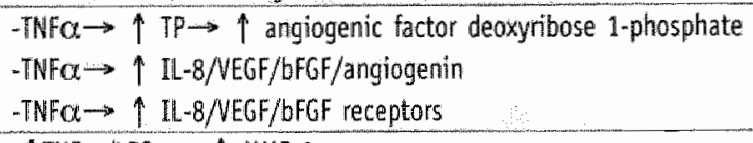 & $63,66,67,127$ \\
\hline MMP-9 & $\begin{array}{l}-\uparrow \text { TNFO/LPS } \rightarrow \uparrow \text { MMP-9 } \\
\text {-VEGFR-1 } \rightarrow \uparrow \text { MMP-9 } \\
- \text { - MMP-9 } \rightarrow \uparrow \text { VEGF }\end{array}$ & $11 B_{*}, 143,144,162$ \\
\hline M-CSF & $\begin{array}{l}\text { M-CSF } \rightarrow \uparrow \text { WEGF/IL-8 } \\
\text {-Chemotactic for monocytes }\end{array}$ & 77,92 \\
\hline$M C P-1$ & $\begin{array}{l}-M C P-1 \rightarrow \uparrow \text { VEGF/IL-8/TNF } \alpha \\
\text { - Chemotactic for monocytes }\end{array}$ & 77,78 \\
\hline MIF & $-\mathrm{MIF} \rightarrow \uparrow \mathrm{TMF} \alpha / \mathrm{IL}-1 / \mathrm{CXC}$ chemokines & 148,149 \\
\hline $\mathrm{uPa}_{\mathrm{P}}$ & - degradation extracellular matrix & $63,66,147$ \\
\hline PAF & $-\mathrm{PAF} \rightarrow \uparrow \mathrm{TNF} \alpha / \mathrm{IL}-1 / \mathrm{bFGF} / \mathrm{VEGF}$ & 150 \\
\hline TGFB & $\begin{array}{l}\text {-TGFB } \rightarrow \text { IL-8/TNFO/NEGF/LFFF/IL-1 } \\
\text {-Chemotactic for monocytes }\end{array}$ & 78 \\
\hline$H B=E G F$ & $\begin{array}{l}-H B-E G F \rightarrow \uparrow \text { WEGF/MMP-9/MMP-3 } \\
-\mathrm{VEGF} \rightarrow \uparrow \text { HB-EGF }\end{array}$ & 151 \\
\hline PDGF & $\begin{array}{l}\text { - Macrophage recruitment and migration } \\
\text {-Vessel stabilization }\end{array}$ & 33,852 \\
\hline
\end{tabular}

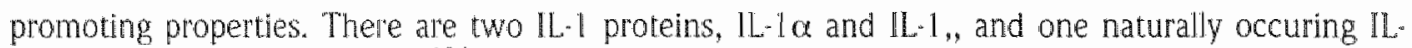
1 receptor antagonist (IL-1Ra) ${ }^{124}$. All $\| L-1$ associated proteins bind to the same receptor, but exert different effects. Both $\mathbb{L}-1 \alpha$ and $\mathbb{L}-1 B$ are involved in tumor angiogenesis, but the role of $\mathbb{L}-1 B$ appears to be more evident ${ }^{24}$. This is probably due to the fact that $\|_{-1}-1 B$ is secreted in the tumor microenvironment and, hence, activates tumor cells. IL I $\alpha$ has a less prominent effect, since this. cytokine is largely cell-associated and remains cytosolic ${ }^{24}$. It is demonstrated by Song et al ${ }^{125}$ that $\mathbb{L}-1 \alpha$ potentiates the development of an antitumor immune response, thereby limiting tumor growth, whereas IL- IB enhances invasiveness of the tumor and induces angiogenesis and immune suppression in the patient. IL-1B has been shown to selectively induce the expression of HWF-1, thereby promoting 
VEGF production. Macrophages used from IL-1 $\alpha$ or IL-1, knockout mice showed reduced VEGF secretion $^{124}$. It has been demonstrated that $\mathrm{IL}-1 \mathrm{~B}$ is able to accelerate tumor growth of lewis lung carcinoma ( $L L C)$ in transplanted mice by neovascularization and induction of angiogenic factors, like VEGF, macrophage-inflammatory protein-2 and human growth factor 126 . Another effect of IL$1 \mathrm{~B}$ on angiogenesis is through its involvement in the production of TNFo ${ }^{124}$ and angiogenin ${ }^{127}$. The properties of IL-1 associated with tumor growth and metastasis make it an attractive target for therapeutic intervention. Bar et al ${ }^{128}$ genetically engineered NIH/3T3 cells to continuously secrete [L-1 receptor antagonist and encapsulated these cells within microspheres to provide a barrier for the immune system. The microspheres were injected subcutaneously in mice with fibrosarcoma cells. It was shown that both tumor development and tumor angiogenesis where inhibited, and that survival was prolonged. In conclusion, as many tumors and. TAMs have been shown to express IL1, IL-1 receptor antagonist may be useful in anti-cancer therapies.

\section{Vascular endothelial growth factor}

Vascular endothelial growth factor (VEGF) promotes endothelial cell proliferation and new blood vessel formation, and is produced by TAMs and also by tumor cells in a variety of human cancers ${ }^{63}$. Although there are multiple angiogenic factors that promote blood vessel formation in human cancer, VEGF appears to play a dominant role ${ }^{92}$. The VEGF family consists of the prototype member VEGF (also referred to as VEGF-A), placenta growth factor (PIGF), VEGF-B, VEGF-C and VEGF-D. Besides VEGF, TAMs also express VEGF-C and VEGF-D, both associated with the formation of lymphatic vessels and lymphatic metastasis ${ }^{129}$. Next to a stimulatory effect on the process of angiogenesis, VEGF increases vascular permeability ${ }^{130}$ and prevents the upregulation of endothelial adhesion molecules induced by inflammatory cytokines ${ }^{18}$. At present, two VEGF receptors, VEGFR1 (or Flt1 and VEGFR2 (or Flk-1) are known. While inactivation of both receptors resulted in embryonic lethality, there is now consensus that VEGFR2 is mainly involved in the angiogenic, mitogenic and permeability enhancing effects of VEGF ${ }^{130}$, while VEGFR1 is likely to have important roles in the recruitment of monocytes to tumors ${ }^{82,83}$ and in the induction of MMP-9 ${ }^{131}$. VEGF expression in macrophages ${ }^{132}$ and tumors is induced via hypoxia-inducible factor (HIF), a major mediator of hypoxic responses, regulated by the product of von Hippel-Lindau (VHL) tumorsuppressor gene (for review see Mole et al ${ }^{133}$ J. In monocytes, VEGF is also induced via M-CSF and MCP-1, indicating a role for these macrophage chemoattractants in angiogenesis regulation ${ }^{77,02}$. TAMs preferentially migrate to hypoxic areas within tumors and strongly express HIF.2 $\alpha$, while normal tissue macrophages do not, resulting in expression of HIF-2 $\alpha$ responsive angiogenic factors, like VEGF, and high tumor vascularity. This high macrophage HIF-2 $\alpha$ appears to be an independent prognostic factor for poor outcome. The mechanisms up-regulating HIF-2 $\alpha$ in macrophages may include inflammatory cytokines as well as hypoxia ${ }^{134}$.

Tumor growth inhibition has been demonstrated by several laboratories using a number of anti-VEGF approaches, including anti-VEGFR 2 antibodies ${ }^{130}$. In vivo treatment of mice with antiVEGF antibodies was shown to result in higher leukocyte-vessel wall interactions in tumor vessels compared to non-treated animals ${ }^{18}$. Moreover, combining anti-VEGF treatment with chemotherapy or radiation results in greater antitumor effect than either treatment alone, indicating that anti-VEGF approaches for the treatment of cancer are promising.

\section{Interleukin-8}

Interleukin-8 (IL-8) is a potent angiogenic factor in several cancers and associated with metastasis ${ }^{135}$. It has been reported to be produced by TAMs and by endothelial cells, fibroblasts 
and tumor celis ${ }^{135}$. Monocytes can be induced to upregulate IL-8 secretion by M.CSF, MCP-1 and TGEB, suggesting an important role for these chemotactic factors in monocyte/macrophagemediated tumor angiogenesi ${ }^{77}, 78$. The interaction between infiltrated macrophages and tumor cells is also known to upregulate IL-8 (and VEGF) expression in both cell types, in a paracrine fashion $^{78,135}$. TAMs produce TNF $\alpha$ and $\mathrm{IL}-1$, which in turn induce tumor cells to produce higher levels of IL 8 and VEGF ${ }^{78}$. IL-B expression has been correlated negatively with patient survival and positively with macrophage infiltration in tumors, suggesting that $\mathrm{LL}-8$ might be dominantly derived from TAMs ${ }^{68}$. In contrast to these results, Chen et al. ${ }^{135}$ reported that cancer cells were the major source of IL-8. There is a significant positive correlation between IL-8 expression and microvessel density ${ }^{130}$, indicating the angiogenic potential of this interleukin. The induction of IL-8 mRNA expression involves activation of the NFKB pathway, which can be suppressed $>93 \%$ by anti-inflammatory agents ${ }^{135}$. Specific inhibition of tumor angiogenesis via NFKB and IL-8 using anti-inflammatory agents, like aspirin, might be a new approach to inhibit angiogenesis in cancer ${ }^{135}$.

\section{Basic fibroblast growth factor}

Basic fibroblast growth factor. (bFGF or FGF-2) is secreted by macrophages, mast cells, lymphocytes, fibroblasts and by some malignant cells ${ }^{64,137,138}$. bFGF belongs to a large family of homologous polypeptide growth factors and promotes every phase of the angiogenic process, including synthesis of proteinases, endothelial cell migration and differentiated capillary tube formation in vitro ${ }^{137}$. bFGF induces angiogenesis through the high-affinity heparin binding receptors FGFR-1 and FGFR-2 ${ }^{76}$. The number of bFGF positive mast cells and macrophages appears to be higher in pancreatic adenocarcinomas with bFGF positive cancer cells ${ }^{138}$, suggesting a cohesion between bFGF expression in these cell types. In various human tumors bFGF has also been localized to stromal macrophages and in vitro experiments showed expression of bFGF in macrophages, induced by tumor derived signals ${ }^{64}$. Increased bFGF expression correlates with poor prognosis and bFGF expression by cancer cells shows a direct correlation with microvessel density ${ }^{138}$. Stromal bFGF expression, however, did not correlate with either microvessel density or the frequency of metastasis in pancreatic carcinoma ${ }^{137}$. bFGF has been found to be chemotactic for macrophages ${ }^{138}$, implying that this factor also has indirect stimulatory effects on angiogenesis and negatively affects patient survival.

Another way for $\mathrm{bFGF}$ to indirectly induce angiogenesis is by its capacity to promote VEGF synthesis. In addition, there is a synergistic interaction between bFGF and VEGF in inducing endothelial cell proliferation and angiogenesis ${ }^{76,137}$. Zhang and Issekut $z^{70}$ reported that bFGF significantly reduces monocyte adhesion and migration to both resting and stimulated endothelial cells, even when these monocytes were activated with chemotactic factors like RANTES or MCP176. The underlying mechanism appeared to be bFGF-induced downregulation of the endothelial adhesion molecules ICAM-1, VCAM-1 and E-selectin, that are necessary for leukocyte capture, rolling, firm adhesion and emigration ${ }^{95,139}$. This effect of bFGF might interfere with infiltration of monocytes and other leukocyte subtypes in tumors. Overall, TAM-derived bFGF seems to be a less. prominent angiogenic factor as compared with the other factors described in this review. Since its explession has been correlated with decreased patient survival, bFGF presumably exerts its tumor growth stimulating effect via ways other than direct promotion of angiogenesis.

\section{Tumor necrosis factor $\alpha$}

Tumor necrosis factor- $\alpha$ (TNF $\alpha$ ) is an inflammatory cytokine with angiogenic activity that is mainly expressed by TAMs ${ }^{\text {ó }}$. Other sources are mast cells, T-lymphocytes, NK cells, neutrophils and some 
tumor cells ${ }^{140}$. This cytokine has been found to promote the production of angiogenic factors, like IL-8, bFGF and VEGF, through activation of transcription factors, in both tumor cells and surrounding other cell types ${ }^{67,140}$. The in vitro tube formation in vascular endothelial cells that is induced by TNF $\alpha$, is inhibited by administering anti-IE-8, anti-VEGF and anti-bFGF antibodies. When all these antibodies were administered together, an almost complete abrogation of tube formation was seen. in vivo, anti-IL-8 and anti-VEGF antibodies were shown to block angiogenesis induced by TNFa in rabbits cornea ${ }^{140}$. TNFo also stimulates tumor cells to express angiogenin, a potent angiogenic cytokine ${ }^{127}$. Angiogenin has found to be up-regulated in pancreatic cancer patients and contributed to the aggressiveness of pancreatic cancer. In colorectal cancer, increased serum angiogenin concentration is correlated with cancer progression ${ }^{127}$. TNF $\alpha$ is also known to upregulate the expression of the angiogenic enzyme thymidine phosphorylase (TP) in cancer cells ${ }^{66}$. TAM expression of TNFo has been correlated positively to upregulation of TP in breast tumors ${ }^{141}$. TP catalyses the reversible conversion of thymidine to thymine and the production of the angiogenic factor deoxyribose 1-phosphate, thereby influencing the angiogenic process. TP expression in breast TAMs appears to correlate with increased microvessel density and poor prognosis in patients with various tumor types ${ }^{60}$.

TNF $\alpha$ also up-regulates the expression of endothelial cell adhesion molecules, a necessary step for leukocyte-vessel wall interactions and, hence, leukocyte infiltration into the tumor to occur. Previously we have shown ${ }^{18}$ that TNF $\alpha$ induces a decrease in the number of circulating leukocytes in nude mice bearing a small LS174T colon carcinoma in their ear. This is probably due to the fact that TNF $\alpha$ induces leukocyte adhesion systemically. This effect was evident for both monomorphonuclear cells (MMNs) and polymorphonuclear cells (PMNs), but was most prominent for MMNs $(80 \%$ reduction versus $55 \%$ for PMNs $(p<0.01))$. In contrast to a small ear tumor, the presence of a large flank tumor tended to mask these TNF $\alpha$ induced changes, suggesting a systemic effect of tumor-derived signals on endothelial cells adhesion molecule expression and, hence, leukocyte-vessel wall interactions. In summary, TNFa is seen as a potent activator of tumor angiogenesis, which is modulated by various angiogenic factors, and an important factor in recruiting leukocytes to a site of injury or a tumor.

\section{Matrix metalloproteinase-9}

Expression of matrix metalloproteinase-9 (MMP.9), or gelatinase-B, is directly associated with increased tumor invasiveness and metastasis as well as poor patient outcome ${ }^{120,142}$. MMP.9 is expressed by cancer cells, stromal neutrophils, fibroblasts, mast cells and macrophages ${ }^{118}$. In a variety of invasive cancers, TAMs have been shown to be a major source of MMP.963. MMP.9 expression appears to be significantly higher in stage III and IV neuroblastoma than in stage I or II, suggesting an important role for this proteinase in tumor progression. Stromally derived MMP-9 has recently been shown to contribute to angiogenesis by promoting blood vessel morphogenesis and pericyte recruitment and, hence, vessel stabilization ${ }^{1 / 3}$. In monocytes/macrophages, MMP-9 is induced by inflammatory mediators like TNFa and bacterial lipopolysaccharide (LPS) ${ }^{144}$. VEGFR-1 is also described to be involved in MMP.9 induction in macrophages ${ }^{145}$, while MMP.9, in turn, increases availability of $\mathrm{VEGF}^{143}$. Furthermore, leukocyte infiltration and subsequent activation of MMP-9 expression has been associated with the 'angiogenic switch' in premaligant tissue and it promotes tumor angiogenesis in mouse models ${ }^{118}$. MMP-9 is known to degrade the vascular basement membrane by cleavage of type IV collagen ${ }^{144}$. Despite the angiogenic effects of this matrix metalloproteinase, MMP-9 has also been described to generate angiostatin, implying its involvement in angiogenesis inhibition as wel1 ${ }^{118}$. The net result, however, of MMP-9 presence in tumors seems 
to be promotion of angiogenesis. Further evidence that MMP.9 contributes to tumor progression came from studies on their endogenous tissue inhibitors (TIMPs). Overexpression or intraperitoneal injection of TIMPs was shown to reduce metastasis in experimental models ${ }^{146}$. However, effects of synthetic metalloproteinase inhibitors in phase III clinical trials have been disappointing, showing no significant difference in patient survival ${ }^{146}$. It remains to be seen whether these inhibitory substances become a standard cancer treatment.

\section{Other angiogenic factors produced by TAMs}

Beside the earlier mentioned angiogenic substances, TAM also express a number of other angiogenic factors (Table 5.2). Among them are the chemotactic proteins M-CSF and MCP-1, which induce both VEGF and IL-8; they have already been described previously in this manuscript. Furthermore, TAMs express urokinase-type plasminogen activator (UPA) and its receptor UPAR (CD87) $)^{63.66,147}$, macrophage inhibitory factor $(\mathrm{MIF})^{14 b_{1}, 49}$, platelet activating factor $(\mathrm{PAF})^{150}$, transforming growth factor-, $(T G,)^{78}$, heparin-binding epidermal growth factor $(\mathrm{HB}-\mathrm{EGF})^{151}$, and platelet derived growth factor (PDGF) ${ }^{33,152}$, which are described further in Table 5.2. Although these angiogenic factors might be of equal importance, knowledge atout them is limited compared with the ones described in this review.

\section{TUMOR ASSOCIATED MACROPHAGES (TAMS) IN IMMUNOTHERAPY?}

The data presented here on angiogenic and angiostatic activities of TAMs clearly show two faces of the presence of these cells in tumors. It is possible that tumors are eradicated by TAMs in a preclinical stage of cancer development. In most tumors studied, however, the balance between angiogenic and angiostatic effects of TAMs is in favor of the angiogenic ones. The ability of TAMs to infiltrate tumor tissue and their presence at the tumor site can and have been used to counteract their stimulating activities via immunotherapy, as described in the following section.

Although macrophages have the potential to mediate tumor cytotoxicity and to stimulate antitumor lymphocytes, some tumors are -apparently-capable of escaping these defence mechanisms. This could be due to the fact that malignant cells often do not express 'foreign' surface antigens, and are not recognized as such by circulating monocytes. It has also been suggested that tumorderived signals suppress TAM activity, because neither monocytes isolated from peripheral blood of cancer patients nor TAMs obtained from tumor sites showed any cytotoxicity towards tumor cells ex vivo. Moreover, macrophages isolated from metastatic tumors were shown to suppress tumor specific $T$ and NK cytotoxicity ${ }^{63,108}$. Even worse, tumors seem to benefit from the angiogenic capacities of TAMs, as described in this review. Nevertheless, the ability of macrophages to infiltrate tumors can be used to develop immunotherapeutic approaches for the treatment of cancer. In addition, it may be possible to emphasize their angiostatic properties via gene therapy.

Adoptive transfer of ex vivo generated macrophages in patents with cancer may be a way of overcoming immune silencing effects of the tumor micro-environment. This was performed for the first time by Fidler and co-workers in $1974^{153}$, using the B16 melanoma model. They demonstrated suppression of pulmonary metastases following infusion of ex vivo activated macrophages. This observation was confirmed by the results of additional rodent studies. However, regression of the primary tumor was seldom seen 154. In humans, monocytes have been isolated from the blood of cancer patients, matured (using M-CSF), activated (using LPS or IFNY) and, subsequently, infused back into the patient. Apart from low grade fever and other flu-like symptoms, no side effects were observed. There was, however, no clinical evidence of an antitumor effect of these ex vivo activated 
macrophages ${ }^{154}$. This may be explained by the observation that the infused macroplages concentrated only partially at sites of metastases, while many cells became trapped in lungs, spleen, liver or kidneys, being unable to exert a proper antitumor effect ${ }^{75,154}$. This may be due to the fact that macrophages instead of monocytes were used in these studies, because monocytes are the cells that are normally recruited from the vasculature into a tumor. The cytokines and chemokines released by tumors may be less effective in recruiting macrophages than their precursor cell $s^{75}$.

Macrophages have been transfected ex wivo with anti-cancer genes such as IFN $\gamma$ and M.CSF ${ }^{155}$, or therapeutic genes ${ }^{156}$; they may also be tagged with chemotherapeutic or angiostatic drugs. Griffiths et al. ${ }^{156}$ used an adenoviral vector to transfect human macrophages with a hypoxia response element (HRE)-regulated p450 gene construct. The p450 enzyme converts the pro-drug cyclophosphamide to an active toxic form, which is also known to possess angiostatic properties ${ }^{157}$. Transfected macrophages migrated into the hypoxic centre of tumor spheroids. When cyclophosphamide was subsequently administered, significant tumor killing was seen within the tumor mass. It is not yet known, however, whether p450 expression in healthy, normoxic tissues is low enough to avoid killing cells in these areas. Nevertheless, targeting hypoxic tumor tissue may prove to be a successful. innovative form of gene therapy strategy.

Another way to perform gene therapy is to use macrophage function itself as an in vivo target. Except for secreting a variety of angiogenic cytokines and enzymes, macrophages are able to exert tumoricidal functions after stimulation with IFNy and LPS, like phagocytosis of apoptotic tumor cells and presenting tumor-associated antigens to T-cells ${ }^{158}$. By transfecting macrophages with genes encoding for tumor antigen specific monoclonal antibodies, they become able to specifically kill tumor cells which express the antigens in vitro ${ }^{159}$. Whether this approach will be as effective in vivo remains to be seen.

Despite the fact that non-specific immunotherapy with cytokines has resulted in some dramatic antitumor responses, it has not been as effective as anticipated ${ }^{160}$. When using nonspecific forms of immunotherapy one has to keep in mind that the recruitment of some leukocyte subsets might be detrimental for patient survival. On the other hand, failure of specific ( $T$ cell mediated] immunotherapy might be explained by the fact that immune cells are unable to infiltrate the tumor in quantities large enough to effectively destroy it. Since endothelial cells are involved in the selection of leukocyte subsets to infiltrate a tumor, tumors have used this endothelial cell property to develop a mechanism to escape immune infiltration. We and others have previously shown that tumor endothelial cells have a suppressed expression of adhesion molecules $\$ 8,21,100$, thereby reducing leukocyte-vessel wall interactions. This downregulation has been shown to be due to exposure to tumor-derived angiogenic factors like bFGF and VEGF ${ }^{18,21,99}$. Recently, we have demonstrated ${ }^{161}$ that angiogenesis inhibition can be a way to increase leukocyte-vessel wall interactions in tumors, making them more vulnerable to various immunotherapeutic approaches. However, angiostatic therapy will not result in the attraction of specific leukocyte subsets, such as cytotoxic T-lymphocytes, which may be able to destroy the tumor. Macrophages are clearly not the type of immune cells desired in a tumor, because of their tumor supporting capabilities. However, since macrophages have been shown to produce a variety of angiogenic factors, it is expected that anti-angiogenesis therapy will also target and suppress macrophage pathways involving angiogenesis. Moreover, as monocytes/macrophages are known to infiltrate tumors, these cells may be exploited as vehicles or delivery systems for angiostatic compounds to perform anti-angiogenic treatment in situ and possibly avoid negative side effects of this treatment strategy on other physiological processes associated with angiogenesis. 


\section{CONCLUSIONS}

Tumor associated macrophages are important regulators of angiogenesis and, hence, play a major role in tumor progression and metastasis. A high macrophage density has been associated with poor prognosis for cancer patients and with failure of immune functions, indicating a role for macrophages in assisting the tumor to escape from immune surveillance. Macrophages have been used for immunotherapeutic and gene therapeutic treatments, but until now the results obtained here were not satisfactory. Another line of research has shown that in tumors leukocyte-vessel wall interactions are suppressed, resulting in reduced recruitment of inflammatory cells that can be detrimental to the tumor, like cytotoxic T-cells and dendritic cells. Angiostatic therapy has been shown to upregulate leukocyte-vessel wall interactions in tumors and, hence, the recruitment of immune cells that can destroy a tumor. We hypothesize that combining immunotherapy with angiostatic therapy will result in improved, and possibly synergistic, anti-tumor responses and better prognosis for cancer patients. 


\section{REFERENCES}

1. Folkman 1. (1971) Tumor angiogenesis: therapeutic implications. N.Engh/Med. 285, 1182.1186 .

2. Holmgren L., OReilly M.S., \& Folkman J. (1995) Domancy of Micrometastases - Balanced Proliferation and Apoptosis in the Presence of Angiogenesis Suppression. Nature Medicine 1, 149-153.

3. Hanahan D. \& Folkman ]. (1996) Patterns and emerging mechanisms of the angiogenic switch during tumorigenesis. Cell 86, 353-364.

4. Folkman J. (2002) Role of angiogenesis in tumor growth and metastasis. Semin. Oncol 29, 15-18.

5. Carmeliet P. \& Jain R.K. (2000) Angogenesis in cancer and other diseases. Nature 407, 240.257.

6. Virchow R. (1989) 'Die Krankenhaften Geschwü]ste', August Hirschwald, Berlin, 1863, cited by Paweletz $\mathrm{N}$ and Knierim $M$ in: Tumor related angiogenesis. Crit.Rev.Oncol.Hematol. 9, 197242.

7. Brigati C., Noonan D.M., Abini A., \&enelli R. 2002] Tumors and inflammatomy intiluates: friends or foes? Clin.Exp.Metastasis 19,247258 .

8. Scanlan M.J., Gout L, Gordon C.M., Williamson B., Stockert E., Gure A.O., Jager D., Chen Y.T., Mackay A., O'Hare M.]., \& Old L.) (2001) Humoral immunity to human breast cancer: antigen definition and quantitatwe analysis of mRNA expression. Cancer In mun. 1, 4.

9. Vaughan H.A., St Clair F, Scanlan M.J., Chen Y.T., Maraskovsky E., Sizeland A., Old L.J., \& Cebon J. (2004] The humoral immune response to head and neck cancer antigens as defined by the serological analysis of tumor antigens by recombinant cDNA expression cloning. Cancer Immun. 4, 5 .

10. Nathan C. (2002) Points of control in inflammation. Nature 420, 846-852.

11. Lin E.Y. \& Pollard J.W. (2004) Role of infiltrated leucocytes in tumour growth and spread. British foumal of Cancer $90,2053-2058$.

12. Dvorak H.F. (1980) Tumors: wounds that do not heal. Similarities between tumor stroma generation and wound healing. N.Engl.J.Med. 315, 1050-1659.

13. Schreurs M.W., Eggert A.A., de Boer A.J, Vissers J.L., van Hall T., Offinga R., Figdar C.G., \& Adema G.J. (2000) Dendritic cells break tolerance and induce protective immunity against a melanocyte differentialion antigen in an autologous melanoma model. Cancer Res. 60, 6995-7001.

14. Borgstron P., Hughes C.K., Hansell P., Wolitsky B.A., \& Sriramara P. (1997) Leukocyte adhesion in angiogenic blood vessels. Role of E- selectin, P-selectin, and beta2 integrin in lymphotoxin-mediated leukocyte recruitment in tumor microvessels. The Journat of Clinical Investigation 99, 2246-2253.

15. Fukumura D., Salehi H.A. Witwer B., Tuma R.F., Melder R.I., \& Jain R.K. (1095) Tumor necrosis tactor alphainduced leukocyte adhesion in nomal and tumor vessels: effect of tumor type, transplantation site, and host strain. Cancer Res. 55, 48244829.

10. Wu N.2., Klitzman B., Dodge R. \& Dewhirst M.W. (1992) Diminished leukocyte endathelium interaction in tumon microvessels. Cancer Res. 52, 4265.4268.

17. Jain R.K., Koenig G.C., Dellian M., Fukurnura D., Munn L.L., \& Melder R.J. (1990) Leukocyte-endothelial adhesion and angiogenesis in tumors. Cancer Metastasis Rev. 15, 105.204.

18. Dirkx A.E.M., Oude Egbrink M.G., Kuipers M.J, van der Niet S.T., Heinen V.V, Boumater Steege J.C., Wagstaff J., \& Grffioen A.W. (2003) Tumor angiogenesis moduates leukocyte-vessel wall interactions in viwo by reducing endothelial adhesion molecule expression. Cancer Res. $63,2322.2329$.

19. Chen O., Wang W.C., Evans S.S. (2003) Tumor microvasculature as a bartier to antitumor immunity. Cancer Immunol./mmunother. 52, $070-679$.

20. Canlos T.M. 12001 Leukocyte recruitment at sites of tumor: dissonant orchestration. J.Levkoc.B10/.70, 171.184.

21. Melder R.J., Koenig G.C., Witwer B.P., Safabakhsh N., Munn L.L., \& Jain R.K. (1006) Durirg angiogenesis, vascular endothelial growth factor and basic fibroblast growth factor regulate natural killer cell adhesion to tumor endothelium. Nature Med. 2, 992997. 
22. Grifloen A.W. Molema G. (2000) Anglogenesis: potentalis for phamacologic intervention in the treatnent of cance, cardiovascular diseases and chronic inflammation. PhamacolRev. 52, 237.268.

23. Inoshma N., Nakanishi Y, Miram T., lzumi M., Takayama K., Yoshino I. \& Hara N. (2002) The intuence of dendritic cell influtation and wasculat endothelial growth factor expression on the prognosis of non-small cell lung cancer: Clin Cancer Res 8, 3480-3480.

24. Malmberg K.1. (2004) Effectuve immunotherapy against cancerA question of overcoming immune suppression and inmune escape? Cancer lmmunol Immunother. 53, 879-892.

25. Zhang H. \& 1ssekutz A.C. (2001) Growth factor regulation of neutrophilendothelial cell interactions. 1.Leukoc.Biol. 70,225232 ,

20. Bodey B., Bodey B., Ir,; Siegel S.E. Kaiser H.E. (2000) Controversies on the prognostic significance of tumor infiltrating leukocytes in solid human tumors. Anticancer Res 20, $1759-1768$.

27. Scapini P., Nesi L., Morini M., Tanghetti E., Belleri M., Noonan D., Presia M., Abini A., \& Cassatella M.A. (2002) Generation of biologically active angiostatin kringle 1.3 by activated human neutrophils. Jourhal of Immunology 168,5798-5804.

28. Bellocg A., Antoine M., Flahault A, Philippe C., Crestani B., Bernaudin J.F, Mayaud C., Mileron B., Baud L., \& Cadranel J. (1998) Neutrophil alveolitis in bronchioloalveolar carcinoma: induction by tumorderived interteukin-8 and relation to clinical outcome. Amy.Pathoh 152, 83-92.

29. Caruso R.A., Bellacco R., Pagano M., Bertoli G., Rigoli L., \& Inferrera C. (2002) Prognostic value of intratumoral neutrophils in advanced gastric carcinoma in a high-risk area in northem Italy. Mod.Pathol 15, 831-837.

30. Repp R., van Ojik H.H., Valerus T., Groenewegen G., Wieland G., Oetzell C., Stockmeyer B., Becker W., Eisenhut M., Steininger H., Deo Y.M., Biihham G.H., Kalden J.R., van de Winkel J.G., \& Gramatzki M. 2003] Phase I clinical trial of the bispecilic antibody MDX.H210 (anti-FcgammaRT $x$ anti-HER-2/neul in combination with Filgrastim (G-CSF) for treatment of advanced breast cancer. Britsh Joumal of Cancer 89, 22342243.

31. Benelli R., Morini M., Carrozzino F., Ferrari N., Minglnelli S., Santi L., Cassatella M., Noonan D.M., \& Albini A. (2002) Neutrophils as a key cellular target for angiostatin: implications for regulation of angiogenesis and inflammation. FASEB J. 16, $267-269$.

32. Imai K., Matsuyama S., Miyake S., Suga K., \& Nakachi K. (2000) Natural cytotoxic activity of peripheral-blood lymphocytes and cancer incidence: an $1 \mathrm{l}$-year follow-up study of a general population. LANCET 356, 1795 . 1799.

33. Kataki A., Scheid P., Piet M., Matie B., Martinet N., Martinet Y., \& Vignaud J.M. (2002) Tumor infiltraing lymphocytes and macrophages have a potential dual role in lung cancer by supporting both host-defense and umor progression. JiLab Clin.Med. 140, 320-328.

34. Taz A., Bouchonnet I:, Grandsaigne M., Boumsell L., Hance A.J., \& Soler P. (1993) Evidence that granulocyte macrophage-colony-sumulating lactor regulates the distribution and differentiated state of dendritic cells/Langerhans cells in human lung and lung cancers. 1.Clin.Invest $91,566-576$.

35. Yo L., Sgadari G. Furuke K., Bloom E.T., Teruya FJ., \& Tosato O. (1999) Contribution of natural killer cells to inhibttion of angiogenessis by interteukin-12. Blood $93,16121021$.

36. Hayakawa Y., Takeda K., Yagita H., Smyth M.J., Van Kaer L., Okumura K., \& Saiki 1. (2002) IFN-gammamediated inhibition of tumor angiogenesis by natural killer T-cell ligand, alpha-galactosylceramide. Blood 100 , 1728.1733.

37. Allavena P., Paganin C., Martin-Padura L, Peri G., Gaboli M., Dejana E., Marchisio P.C., \& Mantovani A. (1091) Molecules and structures involved in the adhesion of natural killer cells to vascular endothelium. Jounal of Experimentai Medicine 173,430-448.

38. Danle N.K. \& Doyle L.V. [1989] 1L.2-activated human killer lymphocytes but not their secreted products mediate increase in albumin Ilux across cultured endothelial monolayers. Implications for vascular leak syndrome. Journat of lmmunology 142, $2600 \cdot 2609$. 


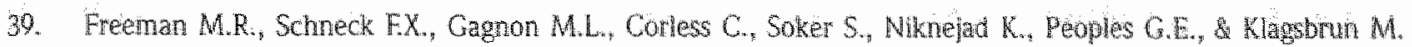
(1095) Peripheral blood T lymphocytes and lymphocytes influtating human cancers oxptess vascular endothellat growth factor: a potental role for $T$ cells in angiogenesis. .Cancer Res. 55,41404145 .

40. Nielsen H. ., Hansen U., Christensen IJ., Reimert C.M., Bruner N., Moesgaard fo (1009) Thdependent prognostic value of eosinophil and mast cell imfititation in colorectal cancer tisue. 1.Pathol $189,48 \%, 495$.

41. Thang L, Conejo-Garcia JR., Katsaros D., Gmoty P.A., Massobrio M., Regnani G., Makrigiannakis A., Gray H., Schlienger K. Liebman M.N., Rubin S.C. \& Coukos G. (2003) Intratumoral T cells, recurrence, and survival in epithelial ovarian cancer. N.Engl.J.Med. 348, 203213.

42. Kondratiev S., Sabo E., Wakirevich E., Lavie O., \& Resnick M.B. (2004) Intratumoral CD8+ T lymphocytes as a prognostic factor of survival in endometrial carcinoma. Chin. Cancer Res. $10,4450-4450$.

43. Beatry G. Paterson Y. (2001) IFN-gamma-dependent inhibition of tumor angiogenesis by tumoriniltrating $\mathrm{CD} 4+\mathrm{T}$ cells requires tumor responsiveness to IFN-gamma. Joumal of /mmunology 160,22762282 .

44. Lee I.Y., Kim I., Ko E.M., Jeoung E.J., Kwon Y.G. \& Choe J. (2002) Interleukin-4 inhibits the vascular endothellal growth factor and basic fibroblast growth factorinduced angiogenesis in vitro. Mol Cells 14, $15-121$.

45. Mizoguchi H., O'Shea J.1., Longo D.L., Laeffler C.M. McVicar D.W., \& Ochoa A.C. 1992\} Aterations ilt signal transduction molecules in T lymphocytes from tumorbearing mice. Science $258,1795 \cdot 1798$.

46. Luscher U., Filgueira L., Juretic A., Zuber M., Luscher N.)., Heberer M. \& Spagroli G.C. (1094) The pattern of cytokine gene expression in freshly excised human metastatic melanoma suggests a state of reversible anergy of tumorinfilltrating lymphocytes. International Joumal of Cances $57,612019$.

47. Javia L.R. \& Rosenberg S.A. (2003) CD4+CD25+ suppressor lymphocytes in the circulation of patients immunized against melanoma antigens. J./mmunoher. 26, 85-93.

48. Antony P.A., Piccirillo C.A., Akpinarli A., Finkelstein S.E., Speiss P., Surman D.R., Palmer D.C., Chan C.C., Klebanolf C.A., Overwijk W.W., Rosenberg S.A., \& Restifo N.P. (2005) CD8+ T cell immunity against a tumor/selifantigen is augmented by $\mathrm{CD} 4+\mathrm{T}$ helper cells and hindered by maturaly occurting $\mathrm{T}$ regulatory cells. Joumal of Immunology 174, 2591.2601.

49. Peoples G.E., Biotnick S., Takahashi K., Freeman M.R., Klagsbrun M., \& Eberlein T.J. (1905) T lymphocytes that infiltrate tumors and atherosclerotic plaques produce heparin binding epidernal growth factor-Hke growth factor and basic fibroblast growth factor: a potentiall pathologic role. Proc Nati.Acad SciU.S.A 92, 6547-6551.

50. Mor F, Guintana F., \& Cohen I.R. [2004] Angogenesis-inflammation cross-talk: vascullar endothelial growth factor is secreted by activated $T$ cells and induces Th1 polarization. Joumal of Immunology 172, 4618-4623.

51. de Visser K.E., Korets L.. V, \& Coussens L.M. 2005$]$ De novo carcinogenesis promoted by chronic inflammation is B lymphocyte dependent. Cancer Cell 7, 411-423.

52. de Visser K.E. Coussens L.M. (2005) The interplay between innate and adaptive immunity regulates cancet development. Cancer Immunol.Immuriother.

53. Figdor C.G., de Vries W., Lesterhuis W.), \& Melief C.) (2004) Dendritic cell immunotherapy: mapping the way. Nature Medicine $10,475-480$.

54. MenetrierCaux C., Thomachot M.C., Aberti L., Montmain G. \& Blay J.Y. (2001) IL.4 prevents the blockade of dendritic cell differentiation induced by tumor cells. Cancer Research $61,3090-3104$.

55. Steinman R.M. \& Nussenzweig M.C. (2002) Awoiding horror autotoxicus: the importance of dendritic cells in peripheral T cell tolerance. Proc Nati.Acad Sci U.S.A 99, 351-358.

56. Dadabayev A.R, Sandel M.H., Menon A.G., Morreau H., Mellef C.I., Ofringa R, Van Der Burg S.H., Rhin C.J., Ensink N.G., Tollenaar R.A., Van De Velde G.J. \& Kuppen P.J. (2004) Dendritic cells in colorectal cancer

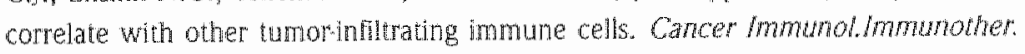

57. Nestle EO., Banchereau I. \& Hart D. 2001$)$ Dendritic cells: On the move from bonch to bedside. Nature Medicine 7,701-765. 


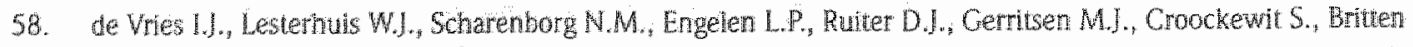
C.M. Torenma $\mathbb{R}$. Adema G.]., Figdor C.G., \& Punt C.J [2003) Maturation of dendritic cells is a premequisite for inducitig immune responses in advanced melanoma patients. Clin Cancer Res $9,5001-5100$.

59. Cibor E., Nair S.K., Lyery H.K. (1998) Immunotherapy of cancer with dendritucell based vaccines. Cancer Immunol Immunother. 46, 8287.

60. Hiromatsu Y, Toda S. (2003) Mast cells and angiogenesis. Mirosc.fes Tech. 60, 64-69.

61. Ribatt D., Vacca A., Nico B, Cnvellato E., Roncali L, \& Dammacco E. (2001) The role of mast cells in tumour angiogenests. Br. Haematol 115, 514-521.

62. Zhang W. Stoica G., Tasca S1., Kelly K.A. \& Meininger C.. (2000) Modulation of tumor angiogenesis by stem cell factor: Cancer Research 60,6757.6702.

63. Bingle L, Brown N.J, \& Lewis C.E. (2002) The role of tumour associated macrophages in tumour progression: implications for new anticancer therapies. I. Pathol 196, 254265.

64. Lewis CE., Leek R., Harts A. McGee J.O. (1995) Cytokine regulation of angiogenesis in breast cancer: the role of tumorassociated macrophages, J.Leukoc. Brol. $57,747.751$.

65. Leek R.D., Lewis C.E, Whitehouse R, Greenall M., Clarke J., \& Halris A.L. 11990 ) Association of macrophage inflthation with angiogenesis and prognosis in invasive breast carcinoma. Cancer Res. 56, 4625-4629.

66. Leek R.D. \& Hamis A.L. (2002) Tumotassociated macrophages in breast cancer. J.Mammary Gland Biol. Neoblasia 7, 177.189.

67. Torisu H., Ono M., Kiryu H., Furue M., Ohmoto Y, Nakayama J., Nishioka Y., Sone S., \& Kuwano M. (2000) Macrophage infiltration correlates with tumor stage and anglogenesis in thuman malignant melanoma: possible involyement of TNFalpha and IL I lalpha. International Joumal of Cancer 85, 182-188.

68. Fulmoto I. Sakaguchi H., Aoki $\mathrm{I}_{\text {, \& }}$ \& Tamaya T. (2000) Cinical implications of expression of interleukin 8 related to angiogenesis in uterine cervical cancers. Cancer Research 60, 2632.2635.

09. Salvesen H.B. \& Akslen L.A. (1999) Significance of tumour-associated macrophages, vascullar endothellal growth factor and thrombospondin. expression for tumour angiogenesis and prognasis in endometrial carcinomas. international Joumal of Cancer 84, 538-543.

70. Lee A.H., Happerfield L.C., Bobrow L.G., \& Mills R.R. (1997) Angiogenesis and inflammation in inwasive carcinoma of the breast. J.Clin.Pathol 50,669-673.

71. Shimura S., Yang G. Ebara S., Wheeler T.M., Frolov A., \& Thompson T.C. (2000) Reduced infiltration of tumonassociated macrophages in human prostate cancer: association with cancer progression. Cancer Research $60,5857.5801$.

72. Migila T., Sato E., Saito K., Mizal T., Shiba K., Matsuno S., Nagura H., \& Ontan H. (1999) Difering expression of MMPs. 1 and 9 and urokinase receptor berween diffuse- and intestinal-type gastric carcinoma. International Joumal of Cancer $84,74.79$.

73. Nesbit M., Schaider H., Miller T.H., \& Herlyn M. (2001) Low level monocyte chernoattractant protein-1 stimulation of monocytes leads to tumor formation in nontumorigenic melanoma cells. Journal of Immunology 166,04836490 .

74. Strieter R.M., Belperio J.A., Phillips R.J., Keane M.P. 2004] CXC chemokines in angiogenesis of cancer. Sernin. Cancer Bsol 14, 195.200.

75. Murdoch C., Giannoudis A., \& Lewis C.E. (2004) Mechanisms regutating the recrutment of macrophages into hypoxic areas of rumors and other ischemic tisstes. Brood.

76. Zhang H. \& Issekutz A.C. (2002) Down-modulation of monocyte transendothelial migration and endothelial adhesion molecule expression by fibroblast growth factor: reversal by the anti-angiogenic agent SU6608. Amw Pathol 160, 2219.2230. 
77. Wamey M.L., Olsen K.J., Mosley R.L., Bucana C.D., Talmadge JE, \& Sitgh R. K. (2002l Monocyte/macrophage recrument, activation and differentiation madulate interleukim production: a paracrine role of tumorassociated macrophages in tumor angiogenesis. in wo 16, 471-477.

78. Liss C., Fekete M., Hasina R., Lam C.D, \& Lingen M.W. (2001) Paracrine angiogenic loop beween head. and-neck squamous-ell carcinomas and macrophages, Internatonal Joumat of Cancer $93,781-785$.

79. Locati M., Deusche U., Massardi M.L., Martinez EO., Sironi M., Sozzani S., Barifai T, Mantovani A. 20021 Analysis of the gene expression profle activated by the $\mathrm{CO}$ chemokine ligand $5 / \mathrm{RANTES}$ and by lipopolysaccharide in human monocytes. Joumal of /mmunology $168,3557.3562$.

80. Azenshtein E., Luboshits $G_{*}$ Shina S., Neumark E. Shahbazian D., Weil M., Wigler M., Keydar I., Ben Baruch A. (2002) The CC chenokine RANTES in breast carcinoma progression: regulation of expression and potential mechanisms of promalignant activity Cancer Research $62,1093-1102$.

81. Gerszten R.E., Garcia.Zepeda E.A., Lim Y.C., Yoshida M., Ding H.A., Gimbrone M.A., In. Luster A.D. Luscinskas FW, \& Rosenzweig A. (1999) MCP.1 and L-8 trigger fim adhesion of monocytes to vascular endotheitum under flow conditions. Nature 398, 718723.

82. Clauss M., Gerlach M., Gerlach H., Brett J., Wang F, Farnilletii R.C., Pan Y.C., Olander I.V., Connolly D.T., \& Siern D. (1990) Vascular permeability factor: a tumorderived polypeptide that induces endothelial cell and monocyte procoagulant activily, and pronotes monocyte migration. Joumal of Experimental Medicine 172, $1535-1545$.

83. Sawano A., Iwai S., Sakurai Y., Ito M., Shitara K., Nakahata T, \& Shibuya M. (2001) Ft. , vascular endothelial growth factor receptor 1 , is a novel cell surface marker for the lineage of monocytemacrophages in humans. Blood 97, 785-701.

84. Leek R.D., Hunt N.C., Landers R., Lewis C.E, Royds I.A., \& Harris A.L. 22000) Macrophage Infittration is associated with VEGE and EGFR expression in breast cancel. /.Pathot. 190, 430-430.

85. Crowther M., Brown N.J., Bishop E.T., \& Lewis C.E. (2001) Microenvironmental influence on macrophage regullation of angiogenesis in woundis and malignant tumors. Journal of Leukocyte Biology 70, 478-490.

86. Kacinski B.M. (1995/ CSF. 1 and is receptor in ovarian, endometrial and breast cancer. Ann.Med. 27, 79.85.

87. Lin E.Y., Nguyen A.V., Russell R.G., \& Polland J.W. (2001) Colony stimulating factor 1 promotes progression of mammary tumors to malignancy. Journal of Experimental Medicine 193, 727.740 .

88. Tang R, Beuvon F, Ojeda M., Mosseri V., Pouillart P., \& Scholl. S. (1992) M-CSF (monocyte colony stimulating factory and MCSF receptor expression by breast tumour cells: M-CSF mediated recruitment of tumour infiltrating monocytes? J. Cell Biochem. 50, 350-350.

89. Scholl S.M. Pallud C., Beuvon F., Hacene K., Stanley E.R., Rohrschneider L., Tang R., Pouillast P., \& Ldereau R. (1994) Anti-colony-stmulating factor. antibody stainng in potmary breast adenocarcinomas correlates with matked inflammatory cell infiltrates and prognosis. J. Natl. Cancer Inst 86, 120-126.

90. Chambers S.K., Kacinski B.M., Ivins C.M., \& Carcangiu M.1. (1997) Overexpression of epithellal macrophage colony-stimulating factor $(\mathrm{CSF} \|$ ) and CSF 1 receptor: a poor prognostic factor in epithelial ovarlan cancer, contrasted with a protective effect of stromal CSF-1. Chin. Cancer Res 3, $990-1007$.

91. Toy E.P., Chambers J.T., Kacinski B.M., Fick M.B., Chambers S.K. (2001) The activated macrophage colony. stimulating factor (CSF 1 ) receptor as a predictor of poor outcome in advanced epithelial ovarian carcinoma. Gyecoloncol 80, 194200 .

Q2. Eubank T.D., Galloway M., Montague C.M., Waldman W., \& Marsh C.B. (2003) M-CSF induces vasculat endothelial growth factor production and angiogenic activity from human monocytes. Joumat of /mmunology $171,2637-2043$.

93. Etzioni A., Doerschuk C.M. \& Harlan I.M. 11999$)$ Of man and mouse: leukocyte and endothelial adhesion molecule deficiencies. Blood $94,3281 \cdot 3288$. 
94. Shnther TA. (1994) Trafic Sigrass for Lymphocyte Recirculation and Leukocyle Emigation - The Multistep Paradign. Cell 76, 301-314.

95. Vestweber 0.8 Blanks J.E. (1999) Mecharisms that regulate the function of the selectins and their ligands. Physiol Kev. 79. $181-213$.

90. Butcher E.C. 11991) Letukocyte endothellal cell recognition: three (or more) steps to specificity and diversity. Cell 67,10331036 .

97. Muller W.A. (2002) Leukocyte endothelial cell interactions in the inflammatory response. La6 Invest 82,521 533.

98. Mullex W.A. (2003) Leukocyteendothelialcell interactions in levkocyte transmigration and the inflammatory response. Thends Immurol $24,327-334$.

99. Tromp S.C., oude Egbrink M.G.A., Dings R.P.M, Van Velzen S., Slaal D.W., Hillen H.F.P., Tangelder G.J. Reneman R.S., \& Grifioen A.W. (2000) Tumor angiogenesis factors reduce leukocyte adhesion in vivo. Int immunct 12,671-676.

100. Grifhoen A.W. Damen C.A., Bliham G.H., G Goenewegen G. (1996) Tumor angiogenesis is accompanied by a decreased inflammatory response of tumol associated endothelium. Bhod. 88, 667.673.

101. Belardell I: \& Fermuntini M. (2002) Cytokines as a link between innate and adaptive antitumor immunity. Thends Immunol. 23, 201208.

102. Tsung K., Dolan J.P. Tsung Y.L. \& Norton J.A. (2002) Macrophages as effector cells in interleukin 12 induced T cell-dependent tumor rejection. Gancer Research 62,5069-5075.

103. Voest E.E., Kenyon B.M., O'Reilly M.S., Truitt G., D'Amato R.J., \& Folkman J. (1995) Inhibition of angiogenesis in wivo by interleukin 12. J. Nati. Cancer lnst. 87, 581-586.

104. Coughlin C.M., Sahnany K.E., Wysocka M., Aruga E., Kurzawa H., Chang A.E., Hunter C.A., Fox J.C., Trinchieri G., \& Le WM.F. (1998) Interleukin-12 and interleukin-18 synergistically induce murine tumor regression which involves inhibition of angiogenesis. J.Clin. Invest 101, 1441-1452.

105. Mitola S., Strasly M., Prato M.. Ghia P., Bussolino F. (2003) LL-12 regulates an endothelial cell-1ymphocyte network: effect on metalloprotenase-9 production. Journal of /mmunology 171, 3725-3733.

106. Strasly M., Cavallo F, Geuna M., Mitola S., Colombo M.P., Fomi G., \& Bussolino E. (2001) IL 12 inhibition of endohelial cell functions and angiogenesis depends on lymphocyte-endothelial cell crosstalk. foumal of Immunology 166, 3890-3899.

107. Sgadari G., Angiolillo A.L., \& Tosato G. (1990) Inhibition of anglogenesis by interleukin 12 is mediated by the interferon-inducible protein 10. Blood 87, $3877,3882$.

108. Wahl L.M. \& Kleinman H.K. (1908) Tumorasschated macrophages as targets for cancer therapy. J. Nati. Cancer Inst. $90,1583-1584$.

109. Strieter R.M. Polverin P.J., Kunkel S.L., Arenberg D.A., Burdick M.D., Kasper J., Dzuba J., Van Damme I. Walz A. Marrion D., \&. 1905] The functional role of the ELR motif in CKC chemokinemediated angiogenesis. 1.Biol.chem. 270,2734827357 .

110. Das S., Boyd R. \& Balkwill (1998) $1 \mathrm{~L}-12$ regulates VEGF and MMPs in a murne breast cancer model. International Joumal of Cancer $78,361-365$.

111. van Herpen C.M., Looman M., Zonneveld M., Scharenborg N., de Wilde P.C., van de L.L., Merkx M.A., Adema C.). \& de Muider P.H. (2004) Intratumoral adninistration of recombinant human interleukin 12 in head and neck squamous cell carcinoma patients elicits a Thelper 1 profie in the locoregional fymph nodes. Clin. Cancer Res 10, 2026.2635.

112. Wadler S., Lev D., Frederickson H.L., Falkson C.I., Wang Y., Weller E., Burk R., Ho G., \& Kadish A.S. (2004) A phase 1 trial of hnterleukin 12 in patients with adwanced cervical cancer: clinical and immunologic correlates. Eastem Cooperative Oncology Group study EIE06. Gyecol Oncol. 92, 957.964. 


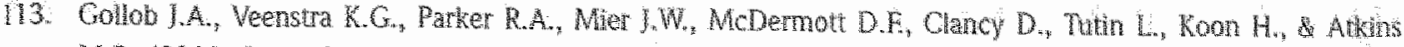

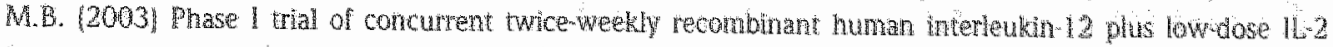

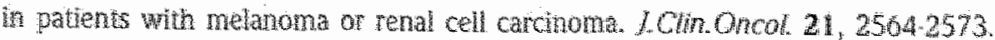

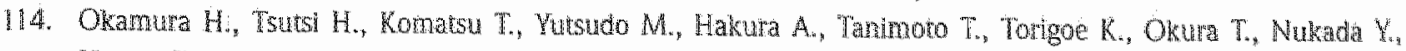

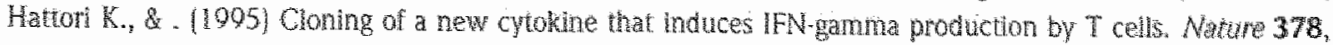
8891.

15. Nakanish K., Yoshmoto T., Tsutsul H. \& Okamura H. 2001 Interleukin 18 is a unique cytokine that stimulates both Th1 and Th2 responses depending on its cytokine milheu. Gytokine Growth Factor Rev 12, 53.72.

116. Cao R., Farnebo J. Kurinoto M. \& Cao K 11999$)$ interteukin-18 acts as an angiogenesis and tumor supprasson. FASEB I. 13,2195-2202.

117. Tatsumi T., Huang J. Gooding WE., Gambotto A., Robbins PD. Vuanovic N.L. Aber S.M., Watkins S.C.. Okada H. \& Storkus W. $12003 \mathrm{~J}$ Intratumoral delivery of dendritc cells engineered to secrete both intentatkin (14) 12 and $12-18$ effectively treats local and distant disease in association with broadly reactive Tcl-type immunity. Cancer Research 63,6378-6386.

118. Kerkela E., Alakho R., Klemi P., Greman S., Shapiro S.D., Kahari V.M., \& Sarialno-Kere U. (2002) Metalloelastase (MMP-12) expression by tumour cells in squamous cell carcinoma of the whive correlates with invasiveness, while that by macrophages predicts better outcome. 1 Pathot $198,258.269$.

119. Comelius L.A., Nehring L.C., Harding E., Bolanowski M., Welgus F.G., Kobayashi D.K., Pierce R.A., \& Shapiro S.D. (1908) Matrix metalloproteinases generata angiostatin: effects on neovascularization. foumal of Immunology $161,6845-6852$.

120. Kerkela E., Ala aho R, Jeskanen L,, Rechardt O., Gremman R., Shapiro S.D., Kahari VM. \& Saarialho.Kere U. (2000) Expression of human macrophage metalioelastase (MMP- 12) by tumor cells in skin cancer. Jinvest Dermatol. 114, $1113-1119$.

121. Gorrin-Rivas M.J., Aril S., Moni A., Takeda Y., Mizumoto M., Furutani M. \& Imamura M. (2000) Implications of human macrophage metalloelastase and vascular endothelial growth factor gene expression in angiogenesis of hepatocellular carcinoma. Ann.Surg. 231, 67.73.

122. Dong $Z_{n}$, Kumar $R_{n}$, Yang X, \& Fidler I.J. (1997) Macrophage-derived melalloelastase is responsible for the generation of angiostatin in Lewis lung carcinoma. Cell 88, 801.810.

123. ORelly M.S., Holngren L, Shing Y, Chen G., Rosenthal R.A, Moses M., Lane W.S., Cao Y., Sage E.H., \& Folkman J. (1994) Anglostatin: a movel angiogenesis inhibitor that mediates the suppression of metastases by a Lewis Lung Carcinoma. Cell 79, 315-328.

124. Voronov E., Shouval D.S., Krelin Y, Cagnano E, Benfiarroch D., Iwakura Y, Dinarello G.A., \& Apte R.N. $12003 \mathrm{~L} / \mathrm{L}-1$ is required for tumol invasiveness and angiogenesis. Proc.Nad.ACad.SCLU.S.A 100, 20452650.

125. Song X, voronov E, Drorkin T., Fima E, Cagnano E., Benharroch D., Shendler $Y$, Bjorkdaht O., Segal $S_{\text {, }}$ Dinarelo C.A., \& Apte R.N. (2003) Differential effects of IL I apha and L-1 beta on tumorigenicity palterns and invasiveness. Jownal of Immunology 171, 6448.6456.

126. Saijo Y., Tanaka M., Miki M. Usui K., Suzuki T., Maenondo M, Hong X., Tazawa K., Kikuchi T., Matsushima K., Nukiwa T. (2002) Proinflammatory cytokine L-1 beta promoles tumor growih of Lewis llung carcinoma by induction of angiogenic factors: in vivo analysis of tumorstromal interaction. Joumal of /mmunology 169 , 469.475.

127. Etoh T., Shibuta K., Bamard G.F, Kitano S., \& Mori M. 2000) Angiogenin expression in human colorectal cancer: the role of focal macrophage inflitration. Chin. Cancer Res $6,3545.3551$.

128. Bar D., Apte R.N., Voronov E, Dinarello C.A., \& Cohen S. (2004) A continuous delivery system of II." receptor antagonist reduces angiogenesis and inhibits tumor development. FASEB J. 18, 161-163.

129. Coussens L.M. \& Werb Z. (2002) Infammation and cancer. Nature 420, $800-867$. 
130. Fetrara N. Hilar K. ., Geber H.P., \& Novotny W. [2004) Discowery and development of bevacizunab, an ant VEGF antibody for treating cancer. NatRev. Drug Discow 3, 391.400.

131. Hiratuka S., Nakanura K., Wwai S., Murakami M. Itoh T., Kijma H., Shipley J.M. Senior R.M. \& Shbupa M. $120021 \mathrm{MMPQ}$ induction by vascular endothellal growth factor receptor-1 is involved in lung specific metastasis. Cancer Cel/ 2, 289-300.

132. Burke B., Tang N., Corke K. P., Tazzman D., Arwer K., Wells M. \& Lewis C.E. (2002) Expression of HIF Ialpha by human macrophages: Implications for the use of nacrophages in hyoxia regulated cancer gene therapy. JPathol 196,204212 .

133. Mole D.R., Maxwell P.H., Pugh C.W., \& Ratcliffe PJ. (2001) Regulation of HIF by the von Hippel-Lindaul tumour suppressor: implications for cellular oxygen sensing. /UBMB Life 52, 43-47.

134. Leek R.D., Talks K.L., Pezzella F., Turlley H., Campo L., Brown N.S., Bicknell R., Taylor M., Gatter K.C., 变 Harrss A.L. (2002) Relation of hypoxia inducible factor 2 alpha (HIF.2 alpha) expression in tumor-infiltrative macrophages to tumor angiogenesis and the oxidative thymidine phosphorylase pathway in Human breast cancer. Cancer Res 62, $1326-1329$.

135. Chen 1.J., Yao P.L., Yuan A., Hong T.M., Shun C.T, Kuo M.L., Lee Y.C., \& Yarg P.C. (2003) Up-regulation of tumor interleukin 8 expression by infiltrating macrophages: its correlation with tumor angiogenesis and patient Survival in non-small cell lung cancer. Clin. Cancer Res 9, 729-737.

136. Fujimoto ). Aoki I., Khatun S., Toyok H., Tamaya T. (2002) Clinical implications of expression of interleukin8 related to myometrial invasion with angiogenesis in uterine endornetral cancers. Ann Oncol 13, 430.434 .

137. Fujioka S. Yoshida K., Yanagisawa S., Kawakami M., Aoki T, \& Yamazaki Y. (2001) Anglogenesis in pancreatic carcinoma: thymldine phosphorylase expression in stromal cells and intratumoral microvessel density as Independent predictors of overail and relapse-free survival. Cancer 92, 1788.1797.

138. Esposito I., Menicagli M., Funel N., Bergmann F, Boggi U., Mosca F., Bevilacqua G., \& Campani D. (2004) Inflammatory cells contribute to the generation of an angiogenic phenotype in pancreatic ductal adenocarcinoma. J.Clin. Pathol. 57, 630.636.

139. Muller W.A. [2002) Leukocyte-endothelial cell interactions in the inflammatory response. Lab Irvest $\mathbf{8 2}, 521$. 533.

140. Ono M., Torisu H., Fukushi I., Nishie A., \& Kuwano M. (1999) Biological implications of macrophage infiltration in human tumor angiogenesis. Cancer Chemother:Phamacol. 43 Suppl, 569.571.

141. Leek R.D., Landers R., Fox S.B., Ng F., Harris A.L., Lewis C.E. (1008) Association of tumour necrosis factor alpha and its receptors with thymidine phosphorylase expression in invasive breast carcinoma. British Jourrat of Cancer 77, 2246-225l.

142. Huang S, Wan Arsdall M., Tedianati S., McCary M., Wu W., Langley R, \& Fidler I.f. (2002) Contributions of stromal metalloproteinase.9 to angiogenesis and growth of human ovarian carcinoma in mice. Nati.Cancer Mnst. $94,1134-1142$.

143. Chantrain C.E, Shimada H., Jodele S., Groshen S., Ye W., Shalinsky D. R., Werb Z., Coussens L.M., \& DeClerck V.A. (2004) Stromal matrix metalloproteinase 9 regulates the vascular architecture in neuroblastoma by promoting pericyte recruitment. Cancer Research 64, 1675-1686.

144. Valleála H., Hanemaajer R., Mandelin J., Salminen A., Teronen O., Monkkonen I., \& Kontunen Y.T. (2003) Regulation of MMP-9 (gelathase B) in activated human monocyte/macrophages by two different topes of bisphosphonates. Life Sci. 73, 24132420 .

145. Hiratsuka S. Nakamura K., Iwai S, Murakami M., loh T, Kijima H., Shipley J.M., Senior R.M., \& Shibuya M. (2002) MMPs induction by wascular endothelial growth factor receptor-1 is involved in lungspecific metastasis. Cancer Gell 2, 289-300.

140. Coussens L.M., Fingleton B., \& Matrisian L.M. (2002) Matrix metalloproteinase inhibitors and cancer; trials and tibutations. Science 295,23872392 . 
147. Hildenbrand R, Woll $G$., Bohme B., Bleyl U. \& Steinborn A. 1999$)$ Urokinase plasminogen actirator receptor [CD87) expression of tumar-associated macrophages in ductal carcinoma in situ, breast cancer, and resident macrophages of nomal breast tissue I. Leukoc. Btol. $66,40.49$.

148. Whive E.S., Flaherty K.R., Carskadion S., Brant A., lannetoni M.D., Yee I., Orringer M.B., Arenberg D.A. (2003) Macrophage migration imhibitory Iactor and CXC chemokine expression in non-small cell lung cancer: role in angiogenesis and prognosis. Chin. Cancer Res 9,853860 .

149. Nishihira I., Ishibashi T., Fukushima T., Sun B., Sato Y. \& Toco S. (2003) Macrophage migration inhibitory factor (MF): Its potential role in tumor growth and tumor-associated angiogenesis. Ann.N. KAca.Sct 995, 171.182.

150. Seo K.H., Ko H.M., Choi J.H., Jung H.H., Chun Y.H., ChoH.W, Lee H.K., \& Im S.Y. (2004) Essential role for platelet-activating factor-induced $N$ F kappa activation in macrophagederived angiogenesis. Eur./.mmunol. 34 , 2129.2137.

151. Ongusaha P.P., Kwak J.C., Zwible A.J., Macip S., Higashiyama S., Taniguchi N., Fang L., \& Lee S.W. (2004) $\mathrm{HB}-\mathrm{EGF}$ is a potent inducer of tumor growih and angiogenesis. Cancer Research $64,5283.5290$.

152. Uutela M., Wirzemius M., Paavonen K., Rajantie I., He Y., Karpanen T., Lohela M., Wig H., Salven P., Pajusola K., Eriksson U., \& Alitalo K. (2004) PDGF.D induces macrophage recruitment, increased interstitial pressure and blood vessel maturation during angiogenesis. Blood.

153. Fidler 1.). (1974) Inhibition of pulmonary metastasis by intravenous injection of specifically activated macrophages. Cancer Research 34, $1074-1078$.

154. Andreesen R., Hennemann B., \& Krause S.W. (1998) Adoptive immunotherapy of cancer using monocytederiwed macrophages: rationale, current status, and perspectives. Leukoc. Blol. 64, 419-426.

155. Lei H., Ju D.W., Yu Y., Tao O, Chen G., Gu S., Hamada H., \& Cao X. (2000) Induction of potent antituntion response by vaccination with tumor lysatepulsed macrophages engineered to secrete macrophage colonystimulating factor and interferongamma. Gene Ther: 7, 707-713.

150. Griffiths L., Binley K., Iqball S., Kan O., Maxwell P., Ratcliffe P., Lewis C., Harris A. Kingsman S, \& Naylor S. (2000) The macrophage - a novel system to deliver gene therapy to pathological hypoxia. Gene Ther: 7 , $255-262$.

157. Bocci G., Nicolaou K.C..\& Kerbel R.S. (2002) Protracted low-dose effects on human endathelial cell proliferation and survival in vitro reveal a selective antiangiogenic window for various chemotherapeutic drugs. Cancer Res. 62, 0938.6943 .

158. Burke B., Sumner S., Maitumd N., Lewis C.E. 2002 Macrophages in gene therapy; cellular dellvery vehtcles and in viwo targets. J.Leukoc.Biol. 72, $417 \cdot 428$.

159. Paul S., Snary D., Hoebeke J., Allen D., Balloul J.M., Bizouane N., Dott K., Geist M., Higers J., Kieny M.P., Burchell J., Taylor-Papadimitriou I., \& Acres R.B. (2000) Targeted macrophage cyiotowicity ushng a nonreplicaive live vector expressing a tumot-specific single chain wariable region fragment. Hum, Gene The: 11, 1417-1428.

160. Rosenberg S.A., Yang J.C. \& Restifo N.P. (2004) Cancer immunotherapy: moving beyond curtent vaccines. Nature Medicine 10, 909.915 .

101. Dirkx A.E.M., oude Egbrink M.G.A., Castermans K., Thijssen V...J.L., Van der Schaft D.W.I., Kwee L., Mayo K.H., Wagstaff I., Bouma-ter Steege J.C., Criffioen A.W. (2005) Anthangiogenesis therapy can overcome endothelial cell anergy and promote leukocyeendohelum interactions and infiltration in tumors. AASEB /. fin pressi.

162. Eubank T.D., Gålloway M., Monague C.M., Waldman WI., \& Marsh C.B. (2003) M.CSg Induces vascular endothelial growth factor production and angiogenic activity from human monocytes. $/ .1$ mmunol. 171, 2637 . 2643. 


\section{Chapter 6}

\section{General Discussion}

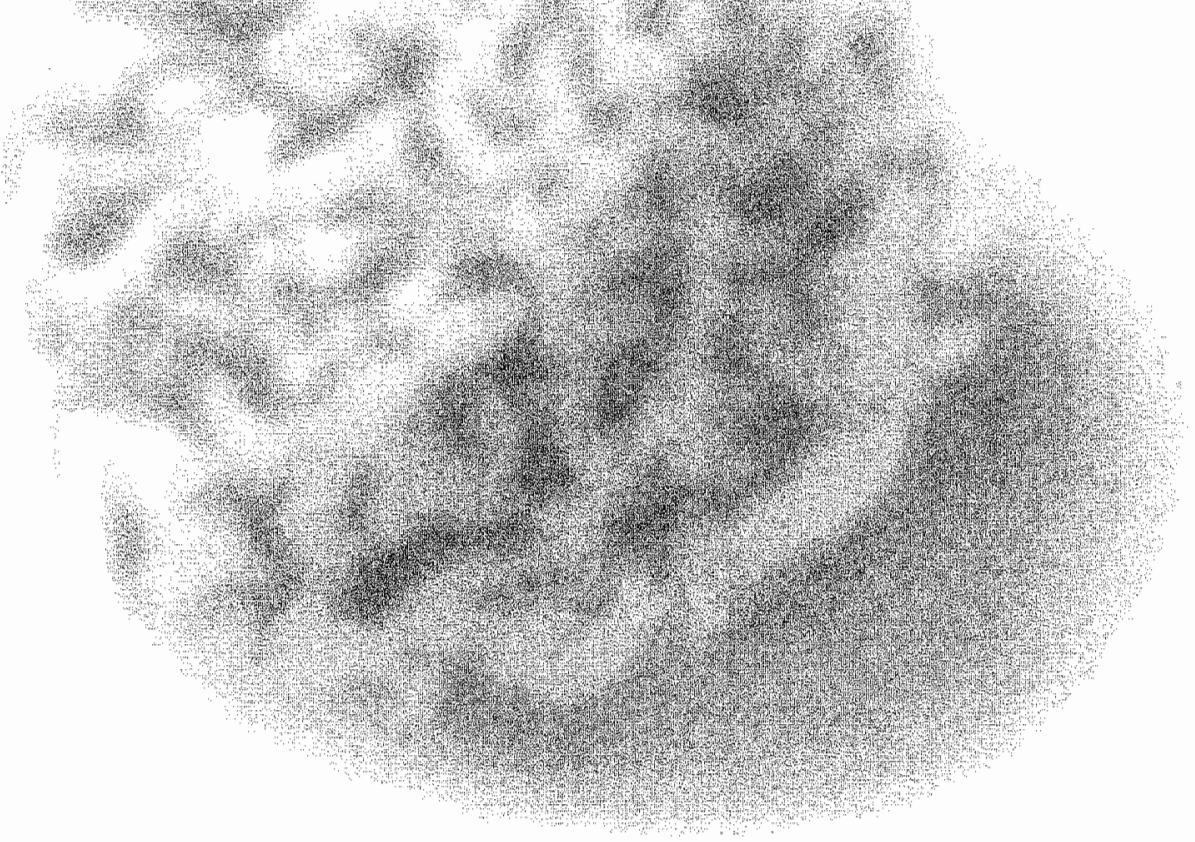




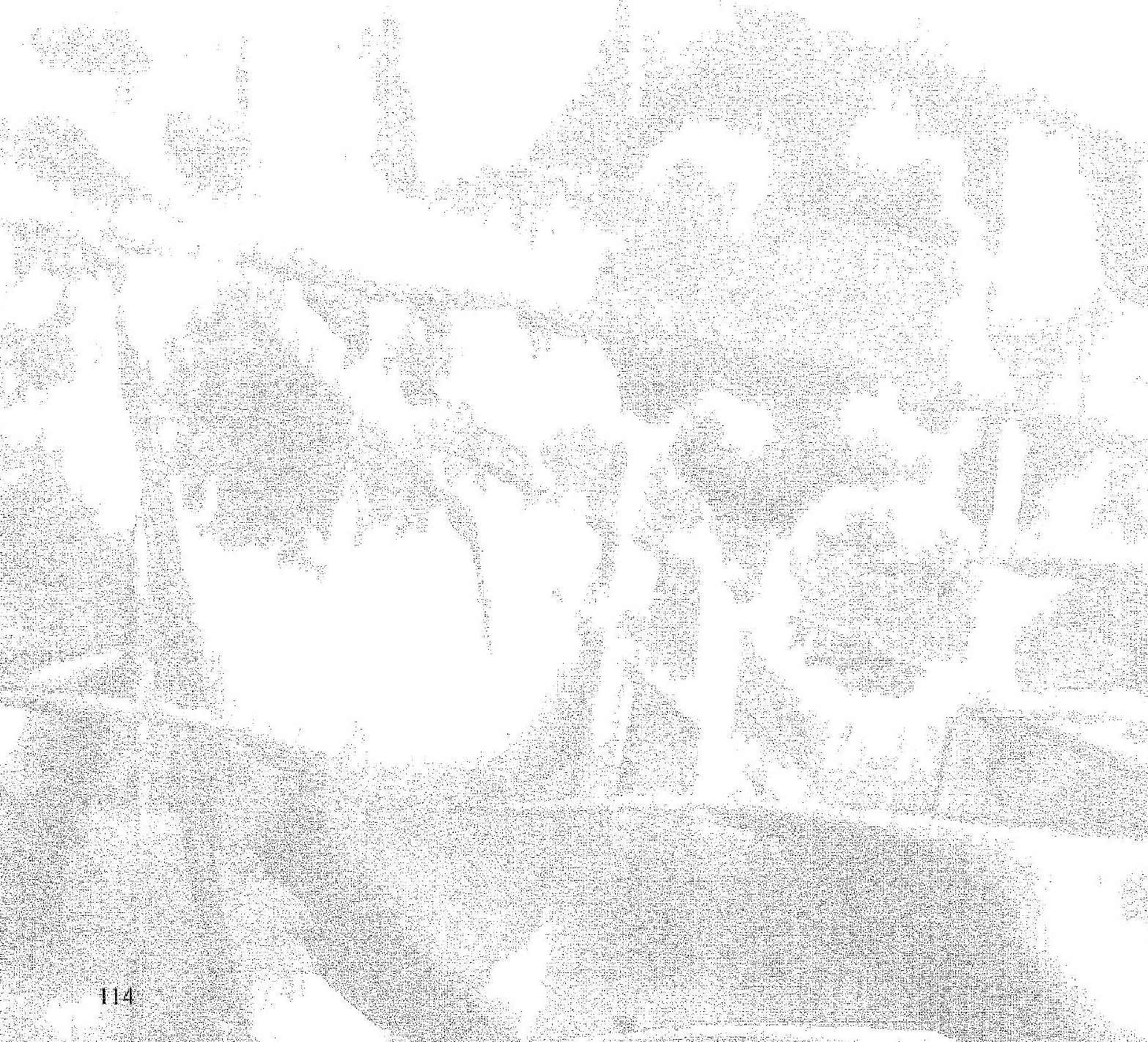




\section{General Discussion}

In European and American countries, cancer is one of the most important causes of death and despite persisting efforts, progress in improving cancer therapy has been modest. Cancer cells are heterogeneous in origin and are genetically unstable, which makes it difficult to develop anti-cancer strategies. Angiogenesis, the formation of new blood vessels out of pre-existing ones, plays a prominent role in tumor development. In 1971, Folkman and colleagues proposed that, because tumor growth and metastasis are dependent on angiogenesis, blocking angiogenesis could be a strategy to arrest tumor proliferation ${ }^{2}$. In addition to its effect on tumor development, the process of tumor angiogenesis appears to have an inhibiting effect on the function of the immune system ${ }^{3.7}$. Therefore, inhibition of tumor angiogenesis may result in tumor starvation as well as an improved anti-tumor immune response. For the development of improved anti-cancer strategies and cancer treatment it is necessary to understand the process of angiogenesis and its effects on the immune system.

To develop anti-angiogenesis based cancer therapies, various in vitro and in vivo assays are being used to investigate blood vessel formation and leukocyte-vessel wall interactions. These assays all have their own advantages and limitations. Generally, in vitro tests (like cell proliferation assays, migration assays and flow chamber experiments) are cheaper, faster and have fewer variables to be controlled by the researcher. However, the major disadvantage of such in vitro experiments is that the data obtained cannot be extrapolated to the in vivo situation straight away. When carried out carefully, in vivo assays generally provide more accurate information on the processes studied; they are the best and only basis for pre-clinical drug testing. In vivo angiogenesis assays include microcirculatory tissue preparations (like the dorsal skin fold chamber ${ }^{8}$, skin flaps ${ }^{9}$ and the chick chorio allantoic membrane (CAM) assay ${ }^{10}$ ) and implantations of biocompatible polymer matrig (like the sponge models ${ }^{11}$ and Matrigel-plug assays ${ }^{12}$ ), in which compounds of interest can be directly injected. The matrix implantation assays can be used to rapidly screen factors that either stimulate or inhibit angiogenesis. They are, however, expensive and animals have to be sacrificed before analysis can take place" ${ }^{\prime \prime}$. Only microcirculatory tissue preparations can be used to study leukocytevessel wall interactions in angiogenic vessels. These animal models are relatively time consuming, carry a high risk of failure and may induce an inflammatory reaction by surgical procedures at the site of interest. In the present study we have developed a new and simple mouse model in which both angiogenesis and leukocyte-vessel wall interactions in and outside a tumor can be quantified non-invasively, allowing Iongitudinal analysis during tumor development and/or in the course of anticancer treatment.

In the first experimental chapter (chapter 3$)^{3}$ we demonstrate, in two separate mouse models, that leukocyte-vessel wall interactions are suppressed in the angiogenic environment of a tumor. We hypothesized that this escape of the tumor from immune surveillance is due to the production of growth factors by tumor cells. Tumors secrete high levels of anglogenic factors such as vascular endothelial cell growth factors (VEGFs) and fibroblast growth factors (FGFs). Previously, we have shown that these factors are responsible for downregulating endothelial. adhesion molecules such as intercellular adhesion molecule-1/2 (1CAM-1/-2), CD3413,14, vascular cell adhesion molecule-1 (VCAM-1) and E-selectin ${ }^{15,16}$. In addition, it has been established both in vitro ${ }^{17}$ and in vivo ${ }^{18}$ that suppressed adhesion molecule expression by angiogenic factors results in diminished leukocyte-vessel wall interactions. In the present study we demonstrate that when mice bearing a small ear tumorare treated with a humanized anti-VEGF antibody, the downregulation of leukocyte-vessel wall interactions inside the tumor is prevented (chapter 3$)^{3}$, which is in support of our hypothesis. Interestingly, the present study also shows that a large tumor has a systemic effect: leukocyte vessel wall interactions appear to be downregulated in ear microvessels of mice bearing a large tumor on 
their flank (chapter 3$)^{3}$. Apparently, a large tumor can produce such large quantities of angiogenic factors that their plasma concentration gets high enough to decrease endothelial adhesion molecule expression systemically. This hypothesis is supported by the observation that the systemic leukocyte count in TNFo treated mice bearing a large flank tumor is higher than in TNFo treated control mice (chapter 3$)^{3}$, also suggesting a systemic effect of the tumor. Altogether, we have demonstrated that tumors have the capacity to prevent the formation of a proper anti-tumor immune response by the downregulation of endothelial adhesion molecules that are necessary for leukocyte-vessel wall interactions. These results are consistent with those described by other research groups ${ }^{6,19,20}$. This downregulation of leukocyte-vessel wall interactions, that potentially leads to escape from immune survelllance and progression of the tumor, was found to be mediated by the production of angiogenic growth factors ${ }^{13,15}$. A recent study in a large population of ovarian carcinoma patients elegantly demonstrated that the expression of VEGF in tumor tissue is negatively correlated with the presence of infiltrating $T$ lymphocytes. Interestingly, the latter was found to be the strongest prognostic factor in ovarian carcinoma ${ }^{21}$.

Once a tumor is vascularized it can be infiltrated by leukocytes, which are indeed found in several solid cancers. The presence of these leukocytes is often the consequence of a specific immune reaction to the tumor itself, since the immune system is known to recognize tumor-associated antigens ${ }^{22}$. In cancer patients, specific cytotoxic T-lymphocytes recognizing tumor antigens have been reported and the presence of these cells is related to a better prognosis ${ }^{23}$. In addition, antibodies to tumor-associated antigens produced by B-cells may also play a role in limiting tumor growth ${ }^{24,25}$. We hypothesized that when angiogenesis downregulates the infiltration of leukocytes, inhibition of angiogenesis would potentially overcome endothelial cell anergy and lead to increased leukocyte infiltration in tumors. From in vitro experiments performed in our laboratory we know that the angiogenesis inhibitors platelet factor-4 (PF4) and thrombospondin-1 prevent the downregulation of adhesion molecules by angiogenic stimulation of cultured human umbilical vein derived endothelial cells ${ }^{26}$. Similarly, angiostatin was found to enhance the expression of E-selectin ${ }^{27}$, while the synthetic angiogenesis inhibitor SU5416 reversed the BFGF-mediated downregulation of ICAM-1, VCAM-1 and E-selectin ${ }^{20}$. In chapter $4^{28}$, we demonstrate that this phenomenon is shared by more angiogenesis inhibitors and that it has impact on in vivo leukocyte-vessel wall interactions and the subsequent formation of an immune infiltrate in a tumor. We found that the angiogenic inhibitors anginex, endostatin and anglostatin, and also the chemotherapeutic agent paclitaxell significantly stimulate leukocyte-vessel wall interactions by circumvention of $\mathrm{EC}$ anergy in tumor vessels in vivo. This was confirmed by in vitro studies on the expression of ICAM-1 and VCAM-1 on cultured endothelial cells at the protein and mRNA level. However, not all angiogenesis inhibitors tested showed the sarme inflammatory response. For treatment of cancer, the preferred agent should combine the strongest angiostatic activity with the most potent inflammatory effect. Apparently, these properties are not interdependent; e.g. TNP-470 and anginex differ largely in modulating immune property, while they equally inhibit angiogenesis and tumor growth ${ }^{28}$, suggesting that the mechanisms of these effects are different. Anginex increased the expression of endothelial adhesion molecules on tumor endothelial cells both at mRNA and protein level, while TNP-470 had no such effect. Of the angiogenesis inhibitors used, anginex had the strongest inflammatory effect. It significantly increased leukocyte-vessel wall interactions in tumor vessels to levels found in healthy control animals. This, in turn, led to increased infiltration of leukocytes into the tumor in spite of the simultaneously occurring decrease in microvessel density. Interestingly, the inflammatory activity of the angiostatic compounds is shared with certain chemotherapeutic agents. It has been observed previously that chemotherapeutic compounds such as cyclophosphamide and paclitaxel can induce 
leukocyte infiltration in tumors ${ }^{29}$. The presently shown effecis of paclitaxel on adhesion molecule regulation and leukocyte-vessel wall interactions (chapter 4$)^{28}$ suipports the theory that certain chemotherapeutics are angiostatic and may be used at ultra low dosages for prolonged periods of time for the treatment of cancer. Except for cancer therapy, angiogenesis inhibition is also suggested to be a promising approach for the treatment of diseases with a chronic inflammatory component, such as rheumatoid arthritis and psoriasis ${ }^{28}$, in which pro-inflammatory activity is undesirable. It is tempting to speculate that the good results with TNP-470 in arthritis models are due to its lack of pro-inflammatory activity.

The mechanisms by which angiogenesis inhibitors influence tumor angiogenesis on the one hand and the endothelial expression of adhesion molecules on the other remain unclear. Many research institutions perform mechanistic studies on angiogenesis inhibitors, but little is known about the endothelial cell components with which the inhibitors interact. The mechanisms underlying the suppression of angiogenesis appear to be complex and require several players ${ }^{30}$. Several angiostatic compounds induce anoikis - or detachment of endothelial cells from the extracellular matrix through blocking of adhesion ${ }^{31,32}$ or interference in cell cycle $e^{33,34}$. In many of these examples exposure to the compound aiso forces EC to undergo apoptosis ${ }^{35}$. Similarly, it is largely unknown how angiogenesis inhibitors can induce adhesion molecules. Although the molecular mechanisms are unknown as yet, it is suggested that growth signals to endothellal cells de-differentiate cells into a phenotype that is suited for proliferation and migration. In such a state leukocyte adhesion would not be a priority of endothelium.

The results described in chapter $4^{28}$ of the present thesis are not in agreement with the recent observation by Chavakis and colleagues that angiostatin is a potent anti-inflammatory and antiadhesive substance by interacting directly with leukocyte B1- and B2-integrins ${ }^{36}$. Angiostatin was shown to inhibit leukocyte adhesion and transmigration in vitro and peritonitis-induced neutrophil emigration in wivo. This study was performed in the absence of a tumor, and in the in vivo experiments only one bolus injection of angiostatin was given 4.5 hours before measurement ${ }^{30}$. In our mouse model, in which angiostatin was continuously administered via minipumps for 7 days, angiostatin did not influence leukocyte-vessel wall interactions outside the tumor or in the absence of a tumor. In addition, we found no effects of angiostatin on leukocyte adhesion molecule expression. Interestingly, Chavakis and colleagues noted that angiostatin containing kringle domains 1-4 (K1-4) or kringle 4 domain (K4) alone, but not kringles 1-3 [KI-3), binds to $\mathrm{Mac}-1$ (a $\mathrm{B} 2$ integrin binding to ICAM-1) on leukocytes. Neither type of angiostatin was shown to bind to another known ICAM1 receptor, LFA $-1^{36}$. These results indicate that $\mathrm{K} 1.3$, the type of angiostatin used in our experiments, has a lower anti-adhesive effect on leukocytes than K1-4. Another recent paper by Yu and colleague $^{37}$ describes that E-selectin, one of the adhesion molecules that are upregulated by anginex, is required for the angiostatic activity of endostatin. In a corneal micropocket assay they showed that endostatin does not inhibit angiogenesis in E-selectin deficient mice, while control mice showed $40 \%$ reduction in bFGF-induced vessel area upon treatment with endostatin. Interestingly, endostatin was not found to block E-selectin mediated leukocyte adhesion, suggesting that it does not interfere with E-selectin binding to its leukocyte ligands.

Although leukocyte infiltration in tumors is often associated with better prognosis and overall survival, it has now been shown by us and others ${ }^{3.7}$ that tumors have developed mechanisms to escape immune surveillance and frequently show only limited leukocyte infiltration ${ }^{38}$. As a consequence, tumor immune responses are often not able to effectively destroy the tumor ${ }^{22}$. Leukocytes that do reach the tumor often remain localized in the tumor periphery or stroma and are often not able to exert strong antitumor effects ${ }^{39}$. Moreover, it is known that infiltrated leukocytes 
Show mpared maturation due to exposure to the tumor microenvironment ${ }^{22,40}$. By contrast, some leukocyte subsets have been described to promote proliferation and metastasis and, hence, tumor development. Tumor associated macrophages (TAM), for example, can exert protumor effects through the secretion of immunosuppressiwe cytokines, the release of free radicals like nitric oxide (NO) and hydrogen peroxide (rendering inmune cells hyporesponsive on even apoptotic) and, last but not least; the secretion of anglogenic cytokines and endymes (chapter 6$)^{41}$. Therefore, when performing general immunotherapy, one has to keep in mind which leukocyte subsets are being recruited to the tumor and which subsets are desired at this location.

Beside tumor cells, endothelial cells and leukocytes, other cells may be involved in tumor development as well. $A$ few years ago Pinedo and colleagues proposed the hypothesis that blood platelets are involved in tumor angiogenesi. ${ }^{42}$. Ouantitative and qualitative abnormalities of platelets are often found in cancer patients, due to increased or reduced thrombocytosis, spontaneous platelet aggregation or impaired adhesion ${ }^{43}$. in vitro studies revealed that platelets are able to stimulate endothelial cell proliferation and tube formation on Matrige ${ }^{44}$. Many types of tumor cells are capable of platelet activation in a process termed tumor cell induced platelet aggregation ${ }^{45}$ and activated piatelets were shown to be present within the tumor vasculature of human sarcoma patients ${ }^{40}$. Upon activation, platelets are known to release angiogenic factors like VEGF, bFGF and PDGF platelet derived growth factor; for a recent review on this topic the reader is referred to the paper by Sierko and colleagues) ${ }^{4}$. In several types of cancer, the systemic platelet count was found to significantly correlate with serum VEGF concentrations, whereas it did not correlate with plasma VEGF concentrations, indicating that platelets are an important source of VEGF ${ }^{47}$. bFGF, like VEGF a constituent of platelet $\alpha$-granules, is an important angiogenic factor inducing EC migration, proliferation and maturation. PDGF stimulates VEGF expression by endothelial cells and it is involved in vessel maturation by recruitment of pericytes ${ }^{47}$. In addition, platelets have been shown to modulate degradation and further remodeling of basement membrane and extracellular matrix components, an essential step in the process of vessel formation ${ }^{47}$. On the contrary, platelets also contain platelet factor $4^{47}$ and thrombospondin- $1^{48}$, which are both endogenous inhibitors of angiogenesis. These findings illustrate that multiple cell types are involved in the process of new vessel formation, all of which have to be taken into account when studying tumor angiogenesis.

In AIDS-associated Kaposi's Sarcoma lesions, an angio-proliferative tumor, the level of leukocytevessel wall interactions appears to be high with prominent infiltration of monocytes and T-cellis ${ }^{40}$. This is in contrast to the situation in other tumors, where immune surveillance is low (see above). In one of our studies (chapter 5$)^{50}$, we show that the HIV-tat protein (a regulatory protein of HIV. I released by infected cells) and the cytokine TNF $\alpha$ synergistically increase leukocyte-vessel. wal! interactions in vitro and in wivo. This, in turn, induces increased leukocyte adhesion (chapter 5$)^{50}$. The HIVtat protein affects the interaction between monocytes and endothelial cells by upregulating the expression of 132 -integrin adhesion molecules and MMP9 in monocytes ${ }^{51}$. As a consequence, it is observed in vitro that adhesion of monocytes is increased, monocyte dependent damage of endothelial cell monolawers is enhanced, and invasive behavior of monocytes is promoted ${ }^{52.54}$. Our finding that HIV-tat and TNFo synergistically increase leukocyte adhesion to the endothelium in wo may be explained by increased B2-integrin expression on monocytes and T-cells by HIV-tat., and upregulation of ICAM-1. VCAM-1 and E-selectin on endothelial cells by both HIV-tat and TNFa (chapter 5) so $^{50}$ It remains unclear why HIV-tat preferentiaily influences monocytes and T-cells, since B2-integrins are expressed uniformly by leukocytes. Indeed, immunohistochemical studies of ADSassociated Kaposi's Sarcoma lesions indicate infiltration of monocyte-macrophages together with CD4+ and CD8 + T-cells, whereas B-cells are rare or absent 55.60 . The co-operative activity of HIV. 
tat and TNFa may explain the 20.000-fold increased incidence of Kaposi's Sarcoma in ADDS ${ }^{61}$; it may also contribute to other vascular defects in AIDS that are associated with increased leukocyte adhesion and extravasation into tissues, including cardiovascular diseases and artherosclerosis.

\section{Future Directions}

Angiogenesis inhibition is now considered to be a promising therapeutic approach for cancer. Approximately 40 angiostatic compounds are currently being tested in trials for human cancer therapy and the search for novel inhibitors is still ongoing ${ }^{62,03}$. In chapter 4 we have tested some angiostatic compounds in our newly developed tumor model. It will be interesting to test some of the more recently developed angiostatic substances, such as Avastin and the SU- and ZD-compounds (like SU5416 (Semaxinib), SU6668 and SU1 1248 (all developed by Sugen), ZD4190 and ZD6474 (both developed Astrazeneca) and PTK787 (developed by Novartis)], for their action on leukocytevessel wall interactions in tumors.

As discussed in chapter 6 , the role of a tumor immune infitrate in cancer development has been debated frequently. Although often associated with improved prognosis and enhanced survival of cancer patients, several types of inflammatory cells have also been described to assist the tumor's capabilities to proliferate and metastasize. Therefore, it will be of great interest to investigate which leukocyte subsets are stimulated to interact with the vessel wall by angiostatic factors. To this purpose, leukocyte subsets can be isolated and labeled with a fluorescent probe ex vivo, and injected back into the mouse. Another interesting model to study leukocyte subsets is developed by von Andrian and colleagues ${ }^{64}$. In order to track individuall $\mathrm{T}$-cells, this group has generated transgenic mice which express green fluorescent protein (GFP) uniformly in CD4+ and CD8+T-cells. Since these mice were created on a $\mathrm{C} 57 \mathrm{Bl} / 6$ background, we could use our $\mathrm{B} 16 \mathrm{Fl} 10$ tumor model to study leukocyte trafficking to define whether CD $4+$ and CD8 + T-cells are stimulated to interact with the tumor vessel wall by angiostatic factors. Last but not least, cytotoxic Tlymphocytes (CTI.s) specifically directed to the Bl6F10 tumor have been created by Melief and colleagues ${ }^{55}$. It would be interesting to study homing of these CTLs in our B16F10 tumor model, with or without the use of angiostatic compounds.

For leukocyte-vessel wall interactions to occur, the expression and upregulation of endothelial adhesion molecules is necessary. In order to investigate which adhesion molecules are mainly affected and upregulated by angiostatic therapy, it will be interesting to label adhesion molecules such as ICAM-1, VCAM-I or E-selectin in wivo and study their expression patterns, both in and outside a tumor, using fluorescence intravital and/or multiphoton laser scanning microscopy. Another possibility to study the effects of angiostatic therapy on adhesion molecules and leukocyte-vessel wall interactions in tumors is by the use of selectin or ICAM-1 knockout mice.

\section{CONCLUSION}

Inhibition of angiogenesis is a promising approach for treatment of cancer and various other diseases like diabetes, rheumatoid arthritis, and cardiovascular diseases. Angiostatic factors not only inhibit tumor vessel formation, inducing tumor starvation, but they also modulate leukocyte-vessel wall interactions, making the tumor more vulnerable to the immune system. A combination of angiostatic treatment with conventional immunotherapy strategies represents a promising way to improve cancer therapy. 
chapter 0 


\section{REFERENCES}

1. Nair S., Bockowsk D., Moeller B., Dewhirst M.; Vieweg I. \& Gilboa E. 2003) Synergy beween tumal immunotherapy and antiangiogenic therapy. Blood 102, 964.971.

2. Carmeliel: P. \& Jain R.K. (2000) Angiogenesis in cancer and other diseases. Nature 407, 249.257.

3. Dirkx A.E.M., Oude Egbrink M.G., Kuijpers M., van der Niet S.T., Heinnen V.V., Bouma-ter Steege I.C., Wagstaff I., \& Griffioen A.W. (2003) Jumor angiogenesis modulates leukocyte-vessel wall interactions in viwo by reducing endothelial adhesion molecule expression. Cancer Res. 63,23222329 .

4. Grifioen A.W. \& Molema G. (2000) Angogenesis: potentials for pharmacologic intervention in the treatment of cancer, cardiovascullar diseases and chronic inflammation. Pharmacol.Rev. 52, 237.208.

5. Pawelec G., Heinzel S., Kiessling R., Muller L., Owyang Q., \& Zeuthen J. 2000 I Escape nechanisms in tumor immunity: a year 2000 update. Crit RevOncog. 11, $97-133$.

6. Melder R.)., Koenig G.C., Witwer B.P., Safabakhsh N., Munn L.L., Jain R.K. (1996) During angiogenesis, vascular endothelial growth factor and basic fibroblast growth factor regulate natural killer cell adhesson to tumor endothelium. Nature Med. 2, 992.997.

7. Zhang H. \& Issekutz A.C. (2001) Growth factor regulation of neutrophllendothelial cell interactions. J.Leukoc.Biol. 70, $225-232$.

8. Algire G.H. (1943) An adaptation of the transparant chamber technique to the mouse. J. Nat. Cancer Inst. 4, $1 \%$.

9. Yang M., Baranov E., Wang J.W., Jiang P., Wang X., Sun F.X, Bouvet M., Moossa A. R., Penman S., \& Hofmaln R.M. (2002) Direct external Imaging of nascent cancer, tumor progression, angiogenesis, and metastasis on internal organs in the fluorescent orthotopic model. Proc.NatLAcad.Sci.U.S.A 99, 3824-3829.

10. Nguyen $M$., Shing Y., \& Folkman J. (1994) Quantitation of angiogenesis and antiangiogenesis in the chick embryo chorioallantoic membrane. Microvasc Res. $47,31-40$.

11. Hasan J., Shnyder S.D., Bibby M., Double J.A., Bicknel R., \& Jayson G.C. (2004) Quantitative angiogenesis assays in viwo-a review. Anglogenesis. 7, 1-10.

12. Passaniti A., Taylor R.M., Pili R., Guo Y, Long P.V., Haney J.A., Pauly R.R., Grant D.S. \& Martin G.R. (1992) A simple, quantitative method for assessing angiogenesis and antiangiogenic agents using reconstituted basement membrane, heparin, and fibroblast growtin factor. Lab Invest 67, 519-528.

13. Griffioen A.W. Damen C.A., Martinotti S., Biiham G.H., \& Groenewegen G. \1996) Endothelia! ICAM-I expression is suppressed in human malignancies; role of angiogenic factors. Cancer Res. 56, 1111.1117.

14. Helwig S.M.M., Damen C.A., Van Adrichem N.P.H., Groenewegen G., Blifhan G.H., \& Grfioen A.W. (1097) Endothelial CD34 is suppressed in human malignancies; role of angiogenic factors. Cancer Letters 120,203. 211

15. Griffioen A.W., Damen C.A., Bliham G.H. \& Groenewegen G. 11906$)$ Tumor angiogenesis is accompanied by a decreased inflammatory response of tumor associated endothelum. Blood. 88, 667-673.

16. Griffoen A.W., Tromp S.C., H Hillen H.F.P. 19981 Angiogenesis modulates the tumor immune regponse. Int. Exp. Pathol. 79, 363.368.

17. Griffion A.W., Relou I.A.M, Gallardo Torres H.I., Damen C.A., Martinotti S., De Graaf J.C., Zwaginga J.J., \& Groenewegen G. (1099) Tumor angiogenesis impairs leukocyte adhesion and roling under flow conditions. Angiogenesis 2, 45.50.

18. Tromp S.C., oude Egbrink M.G.A., Dings R.P.M., Van Veizen S., Slaaf D.W., Hillen H.F.P., Tangelder G.I., Reneman R.S., \& Grifioen A.W. 2000) Tumor angiogenesis factors reduce leukocyte adhesion in vivo. Int.lmmunot 12,671676.

19. Madhavan M., Srinivas. P., Abraham E., Ahmed 1., Viayalekshmi N.R., \& Balaram P. (2002) Down regulation of endothelial adhesion molecules in node positive breast cancer: possible faillure of hosi defence mechanism. Pathol. OncolRes. $8,125 \cdot 128$. 
20. Zhang H.\& Iscewiz A.C. (2002) Down-modulation of monocyte urnsendothelial migration and endothelial adheston molecule expression by fbroblast growth factor: reversal by the anti-angiogenic agent SU6668. Am. Patiol 160, 22102230 .

21. Zhang L., Conejo Garcia J.R, Katcaros D., Cimotty P.A., Massobrio M., Regnani G., Makrigianakis A., Gray H, Schlenger K. Liebinan M.N, Rubin S.C., \& Coukos G. (2003) Intratumoral T cells, recurrence, and survivat in epthellal ovartan cancer. N.Engl/Med 348, 203213.

22. Brigati $C$. Noonan D.M. Abini A. , Benell R. (2002) Tumors and inflammatory infiltrates: friends or foes? Clin. Exp.Metastasis 19, 247-258.

23. Wada $\mathrm{Y}$, Nakashma O, Kutam R., Yamamoto O., \& Kojiro M. 119981 Clinicopathological study on hepatocelluar carcinoma with Jymphocytic infituation. Hepatology 27, 407-414.

24. Scanlan M.J., Gout 1., Cordon C.M., Wulamson B., Stockert E., Gure A.O., Jager D., Chen Y.T., Mackay A., O'Hare M.J., \& Old L.J. (2001) Humoral immunity to human breast cancerm antigen definition and quantitative analysis of mRNA expression. Cancer Immun. 1, 4.

25. Vaughan H.A., St Clair F, Scanlan M.I., Chen Y.T., Maraskovsky E., Sizeland A., Old I.J., \& Cebon I. (2004) The humoral immune response to head and neck cancer antigens as defined by the serological analysis of tumor antigens by recombinant cDNA expression cloning. Cancer Immun. 4, 5 .

20. Grifioen A.W., Damen C.A., Mayo K., BarendszJanson A.F, Martinotti S., Bliham G.H., \& Groenewegen C. (1999) Anglogenesis inhibitors overcotme tumor induced endothelial cell anergy. Intemational foumal of Cancer $80,315-319$.

27. Luo J., Lin J., Paranya $\mathrm{G}_{.}$\& Bischoff J. (1998) Angiostatin upregulates Esselectin in proliferating endothelial cells. Biochem. Biophys. Res. Commun. 245, 906911.

28. Dirkx A.E.M., oude Egbrink M.G.A., Castermans K., Thijssen V.L.J.L., Van der Schaft D.W.J., Kwee L., Mayo K.H., Wagsiaff J., Bouma-ter Steege J.C. \& Grifioen A.W. (2005) Anti-angiogenesis therapy can overcome endothelial cell anergy and promote leukocyte-endothelium interactions and infiltration in tumors. FASEB J. (in press).

29. Demaria S., Volm M.D., Shapiro R.L., Yee H.T., Oratz R., Formenti S.C., Muggia F., \& Symmans W.F. (2001) Development of tumorinfiltrating lymphocytes in breast cancer after neoaduvant pacilitaxel chemotherapy. Clinical Cancer Research 7, 3025-3030.

30. Cao Y. \& Xue L. (2004) Angiostatin. Semin. Thromb. Hemost. 30, 83-93.

31. wan der Schaft D.W., Dings R.P., de Lussanet O.G., van Eijk L.I., Nap A.W., Beets Tan R.G., Bouma-ter Steege J.C. Wagstaff J., Mayo K.H., \& Griftioen A.W. (2002) The destgner anti-angiogenic peptide anginex targets lunor endothelial cells and inhibis tumor growth in animal models. FASEB J. 16, 1991.1993.

32. Brooks P.C., Montgomery A.M.P., Rocenfeld M., Reisfeld R.A., Hu T., Klier G., \& Cheresh D.A. (1904) Integrin alphav beta-3 antagonists promote tumor regression by inducing apoptosis of angiogenic blood vessels. Cell $79,1157 \cdot 1164$.

33. Ahmed B., van Eijk L.I., Boumater Steege J.C, van der Schaft D.W., Van Esch A.M., Joosten-Achjanie S.R., Lambin $P_{\text {. }}$ Landuyt $W_{*, 4}$ \& Grifloen A.W. [2003) Vascular targeting effect of combretastatin A.4 phosphate dominates the inherent angiogenesis inhibitory activity. International Jounat of Cancer 105, 20-25.

34. Gupta S.K. \& Singh I.P. (1994) Inthibition of endothelial cell proliferation by platelet factor- 4 involves a unique action on S phase progression. 1.Cell Biol. 127, 1121.1127.

35. Claesson W.L., Welsh M., Ito N., Anand A.B., Soker S., Zetter B., O'Reilly M., \& Folkman J. (1998) Angiostatin induces endothelial cell apoptosis and activation of focal adhesion kinase independenty of the integrin-binding motif RCD. Proc.Nati.Acad.SciU.S.A 95, 5579-5583.

36. Chavakis T., Athanasopoulos A., Rhee J.S., Orlova V., Schmidt-Woll T., Bierhaus A., May A.E., Celik I., Nawroth P.P. \& Preissner K.T. 20051 Angiostatin is a novel anti-inflammatory factor by inhibiting leukocyte recruitment. Blood 105, 1036-1043. 
37. Yu Y, Mouton K.S., Khan M.K., Vineberg S, Boye E, Davis VM., O'Donnell P.E., Bischoff J., Mistone D.S. (2004) Eselectin is required for the antiangiogenic activity of endostatin. Proc.Nat.Acad SciU.S.A 101. 80058010 .

38. Chen O., Wang W.C., \& Evans S.S. (2003) Tumor microvasculature as a barrier to antitumor immunity. Cancer Immunolmmunother 52, 670-679.

39. Dvorak H.F. [1986] Tumors: wounds that do not heal. Similarities between wumor stroma generation and wound healing. N.Engl.J.Med. 315, 1650-1659.

40: Inoshima N., Nakanishi Y., Minami T, Izumi M., Takayama K., Yoshino I., \& Hara N. (2002) The influence of dendritic cell infiltration and vascular endothelial growth factor expression on the prognosis of nonsmall cell lung cancer. Clin. Cancer Res 8, 3480-3486.

41. Dirkx A.E.M., oude Egbrink M.O., \& Griffioen A.W. (2005) Monocyte/macrophage infilttation in tumors: modulators of angiogenesis. J.Leukoc. Biollaccepted por publication

42. Pinecio H.M., Verheul H.M. D"Amato R.J., \& Folkman J. (1998j Involvement of platelets in tumour angiogenesis? LANCET 352, $1775-1777$.

43. Wojtukiewicz M.Z, Sierko E., \& Rak J. (2004) Contribution of the hemostatic system to angiogenesis in cances: Semin. Thromb. Hemost. 30, 5.20.

44. Pipili-Synetos E., Papadimitriou E., \& Maragoudakis M.E. (1998) Evidence that platelets promote tube formaton by endothelial cells on matrigel. Br.J.Phamacol. 125, 1252-1257.

45. Wojtukiewicz M.2., Sierko E., \& Rak J. (2004) Contribution of the hemostatic system to angiogenesis in cance: Semin. Thromb. Hemost. 30, 5-20.

46. Verheul H.M., Hoekman K., Lupu F, Broxterman H.J., van d., V, Kakkar A.K., \& Pinedo H.M. (2000) Platelet and coagulation activation with vascular endothelial growth factor generation in soft tissue sarcomas. Clin. Cancer Res 6, 160-17\%.

47. Sierko E. \& Wojtukiewicz M.Z. (2004) Platelets and angiogenesis in malignancy. Semin Thomb.Hemost 30, 95.108.

48. Good D.). Polverini P.J., Rastinejud F, Le Beau M.M., Lemons R.S., Frazier WA., \& Bouck N.P. (1990h A tumor suppressordependent in bibitor of angiogenesis is immunologically and functionally indistinguishable from a fragment of thrombospondin. Proc.NatLAcad.Sci.U.S.A 87, 6024-6628.

49. Sturz M., Zietz C., Monini P., \& Ensoli B. (2001) Human herpesvirus-8 and Kaposi's sarcoma: relationship with the multistep concept of tumorigenesis. Adu Cancer Res $81,125.159$.

50. Matzen K., Dirkx A.E., Oude Egbrink M.G., Speth C., Gotte M., Ascherl G., Grimm T., Griffioen A.W., \& Sturzl M. (2004) HV. Tat increases the adhesion of monocytes and T.cells to the endothalium in wito and in vivo: implications for AIDS-associated vasculopathy. Virus Res 104, 145-155.

51. Lafrenie R.M., Wahl L.M., Epstein 1.S., Hewlet I.K., Yamada K.M., \& Dhawan S. 19901 HIV I Tat modulates the functon of monocytes and alters their interactions with microvessel endothelial cells. A mechanism of HV pathogenesis. Journal of Immunology 156, 1638-1045.

52. Latrenie R.M., Wahl L.M. Epstein I.S., Hewlet I.K., Yamada K.M. Dhawan S. (1996) HV I Tat modulates the function of monocytes and alters their interactions with microvesset endothelial cells. A mechanism of HIV pathogenesis. J./mmunol. 156, 1638-1645.

53. Latrenie R.M., Wahl L.M., Epstein JS., Hewlett J.K., Yamada K.M., \& Dhawan S. (1906) HIV 1.Tat protein promotes chemotaxis and invasive behavior by monocytes. J.Jmmunol 157, 974.977.

54. Lafrenie R.M., Wah L.M. Epstein IS., Yamada K.M., D Dhawan \$. 11997 . Activation of monocytes by HV. Tat treatment is mediated by cytokine expression. I.Immunol $159,4077-4083$.

55. Fionell V, Gendelman R., Simanni M.C. Chang H.K., Colombini S, Markham P.D. Monini P., Sonnabend J., Pintus A., Gallo R.C., \& Ensoli B. 119981 gamma-Interferon produced by CDB+ T cells infiltrating Kaposits sarcoma induces spindle cells with angiogeric phenotype and synergy with human immunodeficiency virus-1 Tat protein: an immune response to fumarn herpesvirus-8 infection? Blood 91,956967 . 
50. MacPhal LA, Dekker N.E., Regezi J.A.1996/ Macrophages and vascular adhesion molecules in oral Kaposi"s satconta. J. Cutan Pathol. 23, 464-472.

57. Nickoloff B.]. \& Griffiths C.E. "1989] The spindleshaped cells in cutaneous Kaposi's sarcoma. Histologic simulators include factor Xilla dermal dendrocytes. Am. Pathol 135, 793-800.

58. Regezl J.A., MacPhal L.A., Daniels T.E. DeSouza H.G., Greenspan IS., \& Greenspan D. (1993) Human immunodeficiency virus associaled oral Kaposi's sarcoma. A heterogeneous cell population doninated by spindleshaped endothelial cells. Anuf Pathol $143,240249$.

59. Tabala M., Langford A., Becker J., \& Reichart P.A. (1993) Distribution of immunocompetent cells in oral Kaposi's sarcoma (AlDS). Eur. Cancer B Oral Oncol 20B, 209-213.

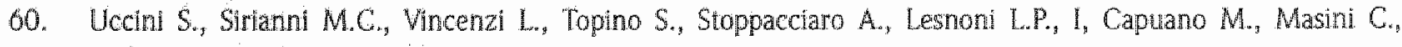
Cerimele D., Cella M, Lamzavecchia A., Alavena P., Mantovani A., Baroni C.D., \& Ruco L.P. (1997) Kaposi's sarcoma cells express the macrophage-associated antigen mannose receptor and dewelop in peripheral blood cultures of Kaposi's sarcoma patients. Am.J.Pathol 150,920.938.

61. Beral V., Peteman T.A., Berkelman R.L., \&affe H.W. (1990) Kaposi's sarcoma among persons with AIDS: a sexually transmitted infection? Lancet $335,123-128$.

62. Ferrara N., Hillan K..., Gerber H.P., \& Novotny W. [2004) Discovery and development of bevacizumab, an anti-VEGF antibody for treating cancer. Nat.Rew Drug Discov. 3, 391-400.

63. Augustin H.G. (2003) Translating angiogenesis research into the clinic: the challenges ahead. Br/.Radiol. 76 Spec No 1, S3-10.

04. Manjunath N., Shankar P., Stockton B., Dubey P.D., Lieberman J., \& Von Andrian U.H. (1999) A transgenic mouse model to analyze CD8[+] effector T cell differentiation in vivo. Proc.Nat.Acad.Sci.U.5.A 96, 13932 13937.

65. Sutmuller R.P., van Duivenvoorde L.M., van Elsas A., Schumacher T.N., Wildenberg M.E., Alison J.P., Toes R.E., Offinga R., \& Melief C.J. (2001) Synergism of cytotoxic T lymphocyte-associated antigen 4 blockade and depletion of CD25(-) regulatory T cells in antitumor therapy reveals alternative pathways for suppression of autoreactive cytotoxic T Iymphocyte responses. Joumal of Experimental Medicine 1.94, 823-832. 


\section{Chapter 7}

\section{Summary}

\section{Samenvatting}

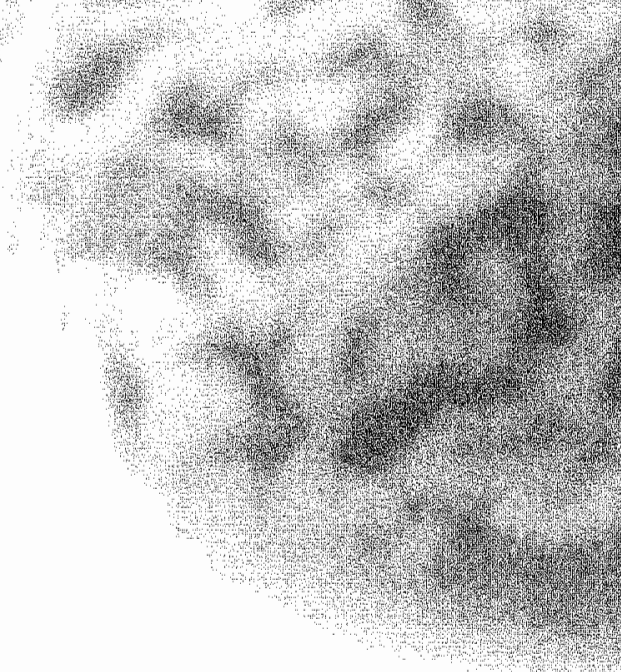


chapter 7 


\section{SUMMARY}

This thesis describes the interplay between tumor angiogenesis and the immune system, with special emphasis on leukocyte-vessel wall interactions inside the tumor. In Europe and Anerica, cancer is one of the most important causes of death. For the development of novel treatment strategies for cancer, it is necessary to fundamentally understand the process of tumor inititition, progression and metastasis. Angiogenesis is an important part of the last two. Besides allowing the tumor to grow and providing a route for metastasis, the presence of blood vessels in a tumor also enables various immune cells to enter the tumor and perform their particular immune function. As a result, the tumor can be infiltrated by leukocytes, a phenomenon observed in most solid cancers. Although frequently associated with better prognosis, these immune responses are often weak and not able to completely destroy a tumor, suggesting that tumors have developed mechanisms to escape immune surveillance. The aim of the present study was to investigate the relationship between angiogenesis and immunity in tumors and to explore ways of modulating this relationship in order to improve the prognosis of patients enhancing the activity of novel anti-cancer therapies.

Chapter 1 provides background information on several topics described in this thesis. First, an overview is given of both the angiogenic cascade and the process of leukocyte-vessel wall interactions. Subsequently, present knowledge on the influence of tumor angiogenesis on leukocytevessel wall interactions is discussed. Although angiogenesis enhances the possibilities for leukocytes to interact with the vessel wall inside a tumor, it has been shown before that exposure of endothelial cells to angiogenic factors (produced by tumor cells, such as VEGF and bFGF downregulates adhesion molecule expression and, hence, leukocyte-vessel wall interactions in vitro and also in vivo. Moreover, an angiogenic environment hampers the upregulation of adhesion molecule expression by proinflammatory cytokines, a phenomenon called endothelial cell anergy. These tumor regulated mechanisms are thought to help the tumor to escape immune surveillance. Finally, this chapter provides an introduction to the contents of the thesis.

For the studies presented in chapters 2 and 3 , we have developed a new mouse model in which angiogenesis and leukocyte-vessel wall interactions can be quantified non-invasively both in and outside a tumor, allowing longitudinal analysis during tumor development and/or in the course of anticancer treatment. A small tumor was grown in the ear, and intravital microscopy was used to quantify in wivo the effects of the tumor on leukocyte-vessel wall interactions and on fluid dynamic conditions in microvessels in and outside the tumor. In the study described in chapter 2 , we demonstrated in both a syngeneic mouse model (C57Bl/ 0 mice bearing murine B16F10 melanomas) and an aljogeneic mouse model (nude mice bearing small human LS174T colon carcinomas) that leukocyte-vessel wall interactions are suppressed in microvessels within a small tumor, but not in healthy vessels outside the tumor. The reduction in leukocyte-vessel wall interactions in tumor vessels appeared to be caused by a decreased expression of adhesion molecules on endothelial cells, and not by suppression of adhesion molecules on leukocytes. FACS-analysis showed that isolated tumor endothelial cells have suppressed levels of ICAM-1 as compared to endothellal cells from normal mouse tissues. The study described in this chapter was the first to show a systemic effect of a large tumor: leukocyte-vessel wall interactions appeared to be downlegulated in ear microvessels of mice bearing a large tumor on their flank. This systemic effect was less pronounced as compared to the situation within a tumor; leukocyte adhesion was only partially down regulated, while inside a tumor the level of adhesion was reduced to undetectable levels. Summarizing, the results described in this chapter show that tumors have evolved mechanisms to escape from immune surveillance.

In chapter 3 we hypothesized that inhibition of angiogenesis would overcome this tumor escape from immunity. This was investigated both in vivo and ex vivo in our mouse models, applying 
intravital microscopy, immunohistochemistry and qRT-PCR, and in witro on cultured endothelial cells by means of FACS-analysis and qRT.PCR. The angiogenesis inhibitors anginex, endostatin and angiostatin, and also the chemotherapeutic agent paclitaxel were found to significantly stimulate leukocytevessel wall interactions by circumvention of endothelial cell anergy in vivo, i.e. by upregulation of endothelial adhesion molecules in tumor vessels. This was confirmed by in vitro studies on cultured endothelial cells at the protein and mRNA levels. The new angiostatic designer peptide anginex was most potent at overcoming endothelial cell anergy. The enhanced leukocytevessel interactions led to an increase in the numbers of tumor infiltrating leukocytes. While anginex inhibited tumor growth and microvessel density (MVD) significantly, the amount of infiltrating leukocytes (CD45), as well as the number of infiltrated CD8+ cytotoxic T-lymphocytes, was enhanced markedly. The results described in this chapter indicate that not all angiogenesis inhibitors tested showed the same inflammatory response. The angiogenesis inhibitor TNP-470 was not able to increase leukocyte-vessel wall interactions in tumor vessels. Treatment of mice with the chemotherapeutic agent cyclophosphamide did induce an increase in leukocyte-vessel wall interactions in tumor vessels, but this effect did not reach the level of significance. The results presented in this chapter suggest that immunotherapy strategies can be improved by combination with anti-angiogenic and chemotherapeutic agents.

In AIDS-associated Kaposi's sarcoma lesions, an angio-proliferative tumor, the levell of leukocytevessel wall interactions appears to be high with prominent infiltration of monocytes and T-cells. This is in contrast to the situation in other tumors, where immune surveillance is low (see above). In the study described in chapter 4, we show that the HIV-1 Tat protein la regulatory protein of HIV1 released by infected cells) and TNF $\alpha$ (a cytokine increased in sera and tissues of HIV-1-infected patients\} synergistically stimulate the adhesion of leukocytes to endothelial cells in vitro as well as in viva. This effect is selectively mediated by HIV-1 Tat, since HIV-1 Nef, another HIV-1 regulatory protein, and the HIV-1 envelope protein gp 41 , had no effect. In vitro adhesion assays with peripheral blood mononuclear cells (PBMC) and quantitative cell type analysis of adherent cells by FACS demonstrated that HIV-I Tat selectively activates the adhesion of T-cells and monocytes, but not of B-cells. Intravital microscopic studies in mice confirmed the synergistic activity of HIV-1 Tat and TNFo on leukocyte adhesion to the endothelium in vivo. These data indicate that HIV-1 Tat in combination with TNFo may contribute to the vascular damage and cardiovascular diseases observed in AIDS patients, and also to the prominent extravasation of T-cells and monocytes which is a key process in the formation and progression of Kaposi's sarcoma lesions.

The role of a tumor immune infiltrate in cancer progression and metastasis has frequently been debated. Although often considered to be associated with improved prognosis and leading to enhanced survival of cancer patients, inflammatory cells have also been described to assist the capability of the tumor to progress, proliferate and metastasize. Tumor associated macrophages (TAMs), for example, have been show to be symbiotically related to tumor cells. Turnor cells recruit TAMs and provide them with survival factors, while TAMs in turn produce a variety of angiogenic factors in response to the tumor microenvironment. Chapter 5 reviews the research on the composition of immune infiltrates in tumors, and on the angiogenic and angiostatic properties of the infiirated immune cells. Special emphasis is on the angiogenesis-associated activities of TAMs. Although little is known on the angiostatic properties of TAMs, they are reported to produce several anglostatic compounds, such as IL-12, IL-18 and matrix metalloproteinase-12 (MMP-12). In contrast, more research has focused on their angiogenic properties (a.o. production of IL-1, VEGF, IL-8, bFGF, TNF $\alpha$ and MMP-9], which will hopefully raise new opportunities to counteract these activities in order to treat cancer. The development of immune and gene therapies using TAMs to mediate tumor 
cytotoxicity or to deliver gene constructs is also discussed. The ability of macrophages to infitrate tumors can be used to develop immunotherapeutic approaches for cancer treatment. Since immunotherapy has so far not been as effective as anticipated, a combination therapy in which angiostatic agents are used as well is put forward as a novel strategy to treat cancer.

In conclusion, inhibition of angiogenesis is a promising approach for treatment of cancer and various other diseases like diabetes, rheumatoid arthritis, and cardiovascular diseases. Angiostatic factors not only inhibit tumor vessel formation, inducing tumor starvation, but they also modulate leukocyte-vesse] wall interactions, making the tumor more vulnerable to immune attack. A combination of angiostatic treatment with conventional immunotherapy strategies represents a promising way to improve cancer therapy. 


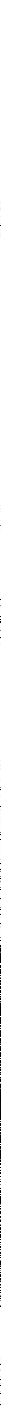


Samenwatting

\section{SAMENVATTING}

In dit proefschrift wordt de wisselwerking tussen tumor angiogenese en het immuunsysteen beschreven. De nadruk ligt hierbij op de interacties die leukocyten (witte bloedcellen) aangaan met de bioedvat wand. In de westerse wereld is kanker één van de voornaamste doodsoorzaken. Daarom is het belangrijk om de verschillende processen die betrokken zijn bij het ontstaan van een tumor zo goed mogelijk te begrijpen, en deze kennis te gebruiken voor het ontwikkelen van nieuwe therapieën tegen deze ziekte. De vorming van nieuwe bloedvaten die een tumor van bloed gaan voorzien (angiogenese) is noodzakelijk voor de groei van de tumor en maakt tevens metastasering van de tumor mogelijk. Daartegenover staat dat de aanwezigheid van bloedvaten in een tumor er ook toe leidt dat cellen uit het immuunsysteem in de tumor kunnen doordringen. Veel tumoren zijn dan ook geïnfiltreerd met leukocyten. Echter, de immuunrespons van deze leukocyten tegen de tumor blijkt vaak erg zwak te zijn en niet in staat om de tumor te vernietigen. Dit suggereert dat tumoren mechanismen hebben ontwikkeld om te ontsnappen aan het immuunsysteem. Het doel van de studies die in dit proefschrift zijn beschreven was dan ook om de relatie te onderzoeken die bestaat tussen tumor angiogenese en de werking van het immuunsysteem in tumoren, om via deze weg bij te dragen aan de ontwikkeling van een nieuwe behandelmethode tegen kanker.

Het eerste hoofdstuk verschaft achtergrondinformatie omtrent de verschillende onderwerpen die in dit proefschrift aan bod komen. Allereerst wordt er een averzicht gegeven van de angiogenese cascade en het proces van leukocyt-vaatwand interacties. Hoewel tumor angiogenese in principe de mogelijkheid voor leukocyten om een interactie aan te gaan met de vaatwand binnen de tunor vergroot, is ook bekend dat de blootstelling van endotheelcellen aan angiogene factoren (geproduceerd door tumorcellen, zoals VEGF en bFGF) de expressie van adhesiemoleculen op het endotheel verlaagt en daarmee zowell in vitro als in vivo leidt tot een daling in leukocyt-vaatwand interacties. Bovendien blijkt de opregulatie van endotheliale adhesiemoleculen door proinflammatoire cytokinen geremd te worden in een angiogeen milieu look wel endotheelcel anergie genoemd). Bovenstaande mechanismen spelen waarschijnlijk een rol bij thet ontsnappen van een tumor aan het immuunsysteem. Het eerste hoofdstuk wordt afgesloten met een overzicht van de inhoud van het proefschrift.

Voor de experimenten die beschreven staan in hoofdstukken 2 en 3 hebben we een nieuw muismodel ontwikkeld, waarin angiogenese en leukocyt-vaatwand interacties op een niet-invasieve wijze bestudeerd kunnen worden, zowel binnen als buiten een tumor. Met behulp van intravitaal microscopie zijn leukocyt-vaatwand interacties in vivo in venulen in de huid van een muizenoor bestudeerd, zowel in nieuw-gevormde vaten in de tumor als in gezonde vaten buiten de tumor. In het tweede hoofdstuk worden experimenten beschreven die zijn uitgevoerd in een syngeen muls model (C57Bl/6 muizen met een B16Fl0 melanoom) en in een allogeen muismodel (Swiss/nude muizen met een humaan LS174T colon carcinoom). De bevindingen tonen aan dat het niveau van leukocyt-vaatwand interacties in tumorvaten significant lager is dan in gezonde vaten buiten de tumor. De verminderde leukocyt-vaatwand interacties in tumor vaten bleken veroorzaakt te worden door een verlaagde expressie van adhesiemoleculen op de endotheelcellen, en niet op de leukocyten zelf. Analyse met behulp van FACS liet namelijk zien dat de ICAM-1 expressie op tumor endotheelcellen lager is dan op endotheelcellen verkregen uit gezond muizenweefsel. Daarnaast werd in deze studie voor de eerste keer aangetoond dat een grote tumor een systemisch effect heeft; in muizen met een grote tumor op de flank was het aantal leukocyt-vaatwand interacties in bloedvaten in de oorhuid lager dan in gezonde muizen. Dit systemisch effect was wel minder uitgesproken dan de situatie in de tumor zelf; de adhesie van leukocyten aan de vaatwand was slechts gedeeltelijk verlaagd, terwijl in tumor vaten het niveau van leukocyten adhesie bijna tot het 
nulpunt gedaald was. We concluderen wit deze resultaten dat tumoren mechanismen hebben ontwikkeld om te ontsnappen an het mmutnsysteem.

Indien de tumor angiogenese mede verantwoordelik is voor het feit dat tumoren het immuunsysteem ontwiken, dan kan remming van die angiogenese er wellicht voor zorgen dat tumoren weer detecteerbaar worden voor het immunsysteem. Dit is dan ook de hypothese warmee we tijdens de experimenten die beschreven staan in hoofdstuk 3 hebben gewerkt. Zowel in wio als ex vivo (intravitaal microscopie, immunohistochemie en GRT-PCR) en in vitro (FACS analyses en qRT.PCR) is gekeken naar de effecten van angiogenese remming op leukocyt-vaatwand interacties en de expressie van adhesiemoleculen in tumor bloedvaten. De angiogeneseremmers anginex, endostatine en angiostatine, maar ook het chemotherapeuticum paclitaxel stimuleerden op significante wijze de leukocyt-vaatwand interacties in tumor vaten door middel van opregulatie van de adhesiemolecuul expressie op endotheelcellen. Dit werd bevestigd door in vitro experimenten met gekweekte endotheelcellen, zowel op eiwit als mRNA niveau. De nieuwe angiogeneseremmer anginex was het beste in staat de endotheelcel anergie op te heffen, wat resulteerde in een toegenomen infiltratie wan leukocyten (CD45) en CD8+ cytotoxische T-cellen in behandelde tumoren. De resultaten laten ook zien, dat niet jedere angiogeneseremmer in staat is leukocytvaatwand interacties in tumoren te doen toenemen (zoals geldt voor TNP-470). Ook het chemotherapeuticum cyclophosphamide slaagde er niet in de leukocyt-vaatwand interacties in tumoren significant te verhogen. De resultaten beschreven in dit hoofdstuk laten echter wel zien dat immuuntheraple tegen kanker wellicht verbeterd kan worden door te combineren met remming van angiogenese.

In Kaposi's Sarcoma, een worm van kanker die vaak wordt gezien in AlDS-patiënten, is het niveau van leukocyt-vaatwand interacties hoog en wordt veelal een grote infiltratie gezien van monocyten en T-cellen, dit in tegenstelling tot de situatie in veel andere tumoren. In de experimenten beschreven in hel vierde hoofdstuk laten we zien dat het HIV-1. Tat proteine leen regulatoir eiwit van HIV-1, afgegeven door geinfecteerde cellen) en TNFo (een inflammatoir cytokine dat verhoogd is in het serum en in de weefsels van HIV-1 geïfecteerde individuen) op synergistische wijze de adhesie van leukocyten aan het endotheel stimuleren, zowel in vitro als in vivo. Dit effect kan toegeschreven worden aan HIV-1 Tat, aangezien twee andere eiwitten, HIV-I Nef en HIV-1 gp 41 , geen effect op leukocyt-vaatwand interacties bleken te hebben. Met behulp van in vitro adhesie experimenten met mononucleaire perifere bloedcellen gevolgd door een FACS analyse, is aangetoond dat HIV-I Tat bovendien selectief de adhesie van T-cellen en monocyten stimuleert, maar niet van Bcellen. Intravitaal microscopie bevestigde de synergistische activiteit van HV-1 Tat en TNFa op leukocyt-vatwand interacties in vivo. Deze data laten zien dat HIV-1 Tat in combinatie met TNF $\alpha$ een bijdrage zou kunnen leveren aan de cardiovasculaire ziekten die vaak optreden in AIDS. patiënten, en daarnaast ook aan de extravasatie van T-cellen en monocyten die een belangrike rol speelt bij het ontstatin en de progressie van lesies behorend bij Kaposi's Sarcoma.

De rol van een immuuninfiltrat tijdens de progressie en metastasering van kanker wordt tot op de dag wan wandaag betwist. Vaak wordt de aanwezigheid van zo'n infiltrat geassocieerd met een verbeterde prognose en een verhoogde overlevingskans voor kanker patiënten. Echter immuncellen worden ook wel beschreven als cellen die de tumor assisteren met betrekking tot proliferatie en metastasering. Tumor geassocieerde macrofagen (TAMs) zin bijvoorbeeld op symbiotische wilze verbonden met tumorcellen; tumorcellen rekruteren TAMs en zorgen voor hun overleving, terwill TAMs op hun beurt diverse angiogene factoren produceren die de tumor helpen zich verden te ontwikkelen. Hoofdstuk 5 is een review van de huidige stand van zaken in het onderzoek naar de samenstelling van een immuminfiltraat in tumoren en naar de angiogene en 
anti-angiogene eigenschappen van geïfiltreerde immuuncellen. Speciale aandacht wordt besteed aan de met angiogenese geassocieerde activiteiten van TAMs. Er is weinig bekend over de antiangiogene eigenschappen van TAMs, maar we weten wel dat ze verschillende anti-angiogene factoren produceren, zoals IL-12, IL-18 en matrix metalloproteinase-12 (MMP-12). Er is meer bekend over: de angiogene eigenschappen van TAMs (zoals de productie van IL-1, VEGF, IL-8, bFGF, TNFa en MMP-9]. Dergelijke kennis zou bij kunnen dragen aan de ontwikkeling van nieuwe mogelijkheden om deze eigenschappen tegen te gaan en zo te komen tot een nieuwe methode om kanker te behandelen. De ontwikkeling van immuun- en gentherapieën waarbij gebruik wordt gemaakt van TAMs wordt ook in dit hoofdstuk beschreven. Het feit dat macrofagen in staat zijn tumoren te infiltreren zou gebruikt kunnen worden om nieuwe immuuntherapeutische benaderingen te ontwikkelen voor de behandeling van kanker. Echter, immuuntherapie is tot op heden niet zo effectief gebleken als tevoren gedacht; wellicht zou een gelijktijdige behandeling met angiogese remmers hier een oplossing kunnen bieden.

De remming van angiogenese is een veelbelovende manier om kanker te behandelen, maar zou ook toepasbaar kunnen zijn voor andere ziekten zoals diabetes, reumatoïde artritis en hart- en vaatziekten. In een tumor remmen anti-angiogene factoren niet alleen de vorming van nieuwe bloedvaten (om zodoende de tumor uit te hongeren), maar ze maken de tumor ook meer toegankelijk voor het immuunsysteem, aangezien ze een stimulerend effect hebben op leukocyt-vaatwand interacties. De combinatie van angiogeneseremmers en conventionele immuuntherapie is een veelbelovende manier om de effectiviteit van de behandeling van kanker te verhogen. 


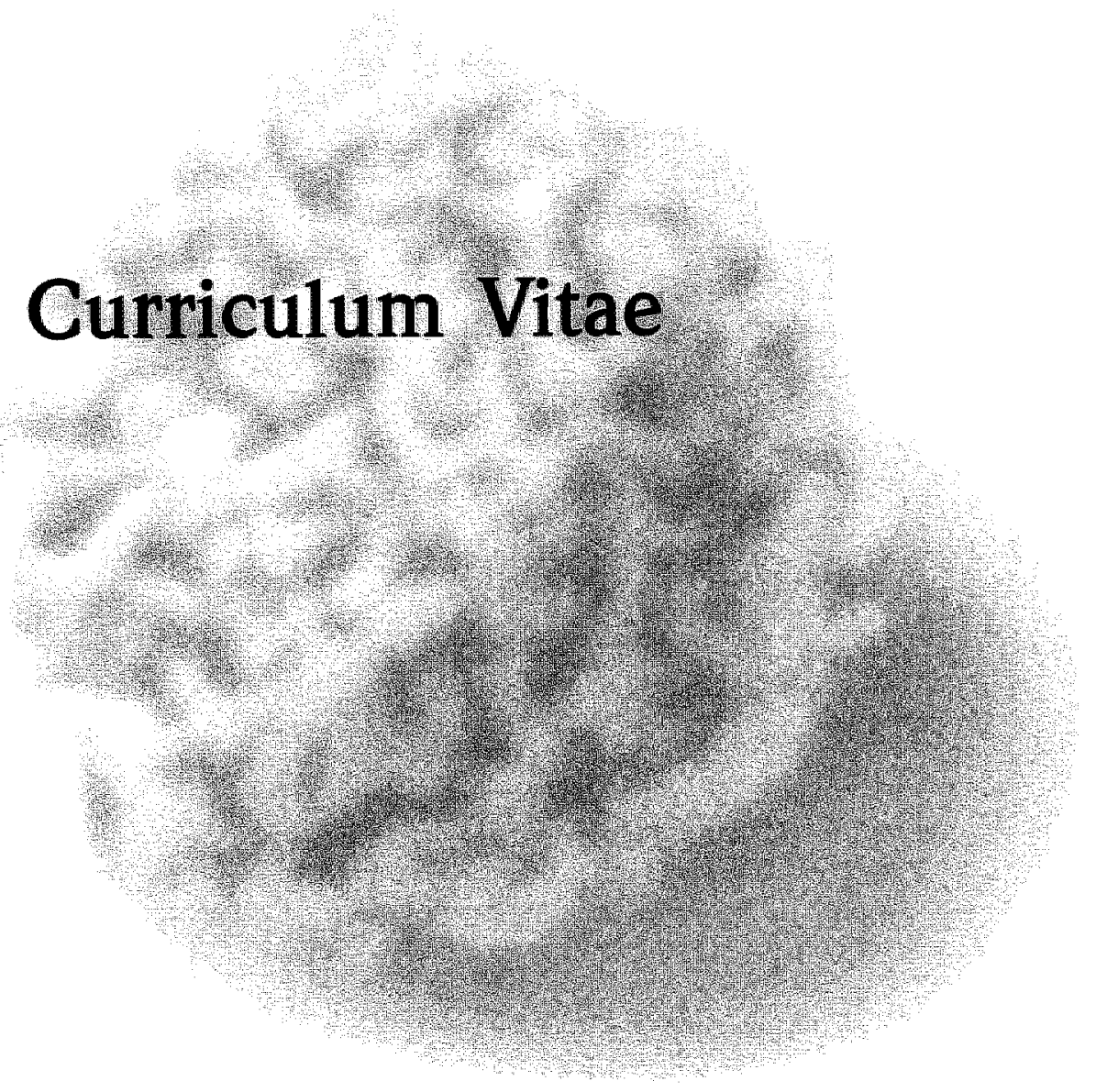


Curriculum Vitae 


\section{Curriculum Vitae}

Anita Elizabeth Maria Dirkx was born on February 8th 1976 in Eindhoven, the Netherlands. She completed her secondary education at the van Maerlantlyceum in Eindhoven in 1994. In the same year, she started her academic education at Maastricht University, where she studied Health Sciences with Biological Sciences as specialization. She conducted her first internship at the department of Immunology at Maastricht University under supervision of Dr. A. Duijvestijn. During this 9 month period she studied the role of brain endothelial cells in the induction of T-cell proliferation. In September 1999 she left Maastricht for her second internship at Organon N.V. in Oss, where she was supervised by Dr. M. Boots and Dr. J. Dulos. She investigated the effects of DHEA (dehydroepiandrosteron) on the progression of rheumatoid arthritis. In November 2000 she obtained her MSc degree and from February 2000 until February 2005 she was appointed as a PhD student at the faculty of Medicine at the University Hospital Maastricht. Under supervision of Prof. Dr. A.W. Griffioen, Dr. M.G.A. oude Egbrink and Prof. Dr. J. Wagstaff she worked at the departments of Internal Medicine, Pathology and Physiology to investigate leukocyte-vessel wall interactions in tumors. On February 1st 2005 she has joined the clinical documentation group at Organon N.V., to continue her career as Medical Writer. 



\section{Dankwoord
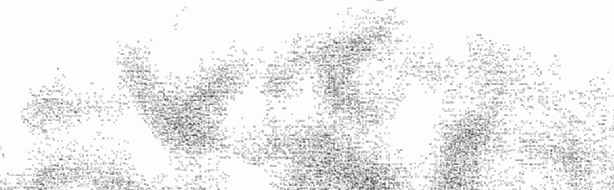

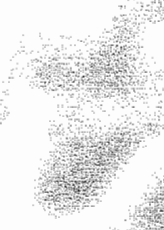




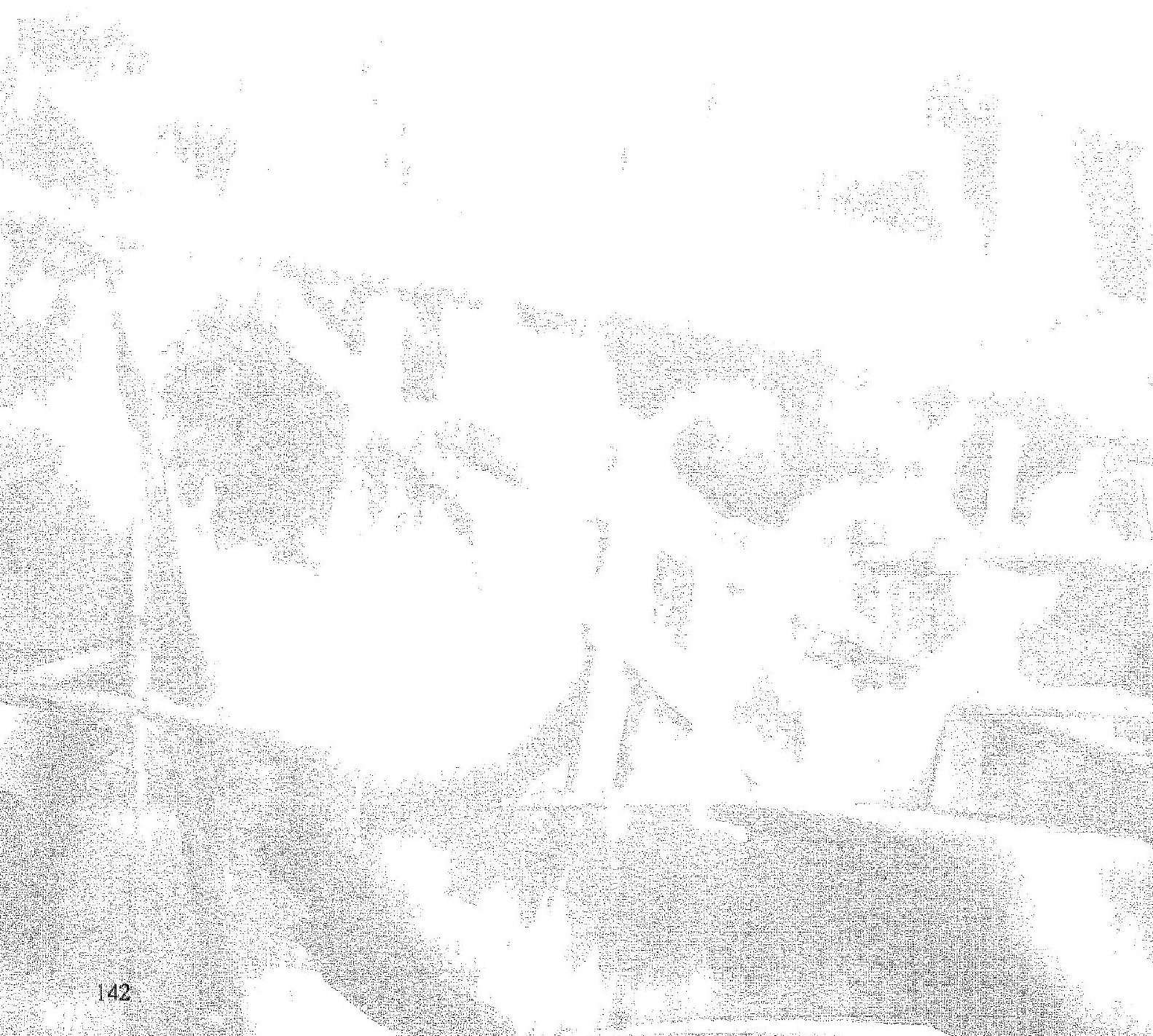




\section{....ik moet er niet aan denken dat ik dàt allemaal alleen had moeten doen... (Herman Finkers, ' $k$ Jan Klaasen')}

\section{DANKWOORD}

Gelukkig. Gelukkig is het proefschrift af en gelukkig heb ik het niet allemaal alleen hoeven te doen. Er zijn vele mensen die mil op diverse manieren geholpen en gesteund hebben, zowel inhoudelijk als mentaal, om deze klus te klaren.

Veel werk is uiteraard verzet door mijn promotieteam, bestaande uit twee promotores, Prof. Dr. Arjan W. Griffioen en Prof. Dr. I. Wagstaff en co-promotor Dr. Mirjam oude Egbrink.

Beste Arjan, ik will je allereerst bedanken voor de mogelijkheid om mijn promotieonderzoek onder jouw leiding uit te kunnen voeren. Je deskundigheid en toewijding voor het onderzoek zijn onmiskenbaar; je benoeming tot hoogleraar komt voor mij dan ook niet als een verrassing. Van harte proficiat hiermee.

Prof. Dr. J. Wagstaff, I would like to thank you for your scientifical and clinical input in my thesis.

Beste Mirjam, je wist me altijd weer te stimuleren en te motiveren om door te gaan, ook als ik het niet meer zag zitten. Wanneer ik bij je binnen liep met een vraag stond je direct klaar; ik heb dit altijd erg gewaardeerd. Bedankt voor je enthousiasme en je betrokkenheid.

En dan zijn er natuurlijk mijn twee lieve paranimfen, Inge en Miriam.

Lieve Inge, met zijn tweetjes hebben we al heel wat doorstaan: van samen trekken door Zuid-Afrika in de 'Beetle' tot samen moeder worden met alle ingewikkelde gevoelens die hierbij komen kijken. Ik wil je heel erg bedanken voor je vriendschap en je steun gedurende de afgelopen jaren. Baie liefies, Beppie!

Lieve Miriam, we begonnen als kamergenootjes en zijn nu goede vriendinnen. Heel wat (AIO) hief en leed is door ons gedeeld, en heel wat data is door ons gelijktijdig geanalyseerd (dit leverde in beginsel wel de nodige problemen op maar, al doende leert men... J. Jij bent mij, met jouw promotie, al voorgegaan en ik ben dan ook erg bij dat ik een ervaringsdeskundige aan mijn zijde heb staan!

Veel leuke en minder leuke ervaringen heb ik de afgelopen jaren gedeeld met mijn kamergenoten. Allereerst was dat natuurlijk Daisy, bedankt voor je begeleiding tijdens mijn eerste stapjes als AIO! Daarna kwamen Miriam, Veerle en Susan, we konden altijd bij elkaar terecht en we hebben ook een geweldige tijd gehad samen, met als hoogtepunt natuurlijk ons kameruitje naar de Efteling. Veerle ik wil je erg veel geluk toewensen met je nieuwe baan, proficiat! Susan, bedankt voor de Kolonisten-avondjes en heel veel succes in Brussel. Alex en Blanca ik wil jullie veel succes wensen met jullie verdere loopbaan. Jacqueline, last but not least, bedankt voor al onze leuke gesprekken. IK wens je erg veel succes met de laatste loodjes van je eigen proelschrift!

Natuurlijk gaat er ook een woord van dank uit naar de mensen van het Microcirculatie lab met wie ik de afgelopen jaren samen heb gewerkt. Lieve Geertje, bedankt voor al die fijne gesprekken die we tot nu toe samen hebben gehad. Je adviezen heb ik altijd erg ter harte genomen: "wacht 
maar..." was een opmerking die vaak uit jouw mond kwam wanneer ik weer eens in een opvoedkundig dilemma beland was. Viviane, jij hebt me de beginselen van het werken met muizen bijgebracht. En als de microscoop even nèt niet deed wat ik wilde, bracht het 'Viviane-knopje" vaak uitkomst... Prof. Dr. D.W. Slaaf, beste Dick, bedankt voor je kritische bilik op mijn proefschrift; bedankt ook dat je zitting wilde nemen in mijn beoordelingscommissie. Lieve Marc (Eline, Rosa en Myrthe), bedanki woor je vriendschap en de vrolike noot die je aan mijn tijd in Maastricht hebt gegeven. Ik hoop dat we nog erg vaak met zijn achten op vakantie gaan! Sietze, Remco en Kim, nog veel succes met jullie eigen promotie, natuurlik onder Marc zijn bezielende leiding. Wim, als computer-leek kon ik altijd bij je terecht; bedankt! Marijke en Imke, jullie sprankelende aarwezigheid was als een frisse wind door het lab, bedankt hiervoor en succes met jullie eigen promotie! Andries, Pascal, Ward, Birgit en Richard bedankt voor alle gezellige momenten.

Ik heb, vooral tijdens de eerste jaren van mijn promotieonderzoek, ook de nodige tijd doorgebracht op het Angiogenese lab. Loes, bedankt voor onze gesprekken en je interesse in mijn onderzoek. Sandra, je hebt me heel wat werk uit handen genomen, bedankt hiervoor. $\mathrm{lk}$ wens je veel succes met je verdere carrière. Lucy, ik vond het erg leuk dat ik je mocht begeleiden tijdens je afstudeerstage. Het was een leerzame tijd; veel sterkte met je eigen promotie en we houden contact! Karolien, ik wens je veel succes en plezier toe met de 'rollende bollen' op de IVM! Jessica, Coen, Judy, Ricardo, Edith, Sietske, Victor, Debby, Femke, Veerle en Nicole bedankt voor jullie interesse en de gezelligheid.

Beste Sander en Petra, onze Kolonistenavondjes zijn onvergetelijk en hebben gezorgd voor de broodnodige ontspanning in de (soms nachtelijke) uurtjes...

Beste Daniëlle, onze lunches waren een welkome afwisseling toen ik druk aan het schrijven was. Ik wens jou en Maurice veel geluk met jullie kleine Danique.

Lieve Marieke, we zijn al vriendinnen sinds het gymnasium. Ik ben heel erg blij dat jij en Erik nu dicht bij ons wonen en we weer 'ouderwets' naar de film kunnen gaan. Bedankt dat je zo'n lieve vriendin bent en dat je gedeeld hebt in mijn promotiestress. De oerknal houden we erin en mijn appel vergeet ik niet meer...

Rob loom Roel, Mark, Grace, Marcel, en Miriar, Guido en Rian, Rielette en Martijn, Laurine en Jaap, Mart en Jolanda, Marc en Eline, Inge en Frank: als vrienden hebben fullie allemaal op fullie eigen manier gezorgd voor ontspanning en plezier, naast het werken aan mijn proefschrift. Bedankt. hiervoor! En Frank, veel succes met je eigen promotie, het gaat je echt lakken hoor!

Graag wil ik alle mensen van het CPV van de Universiteit Maastricht bedanken voor de goede zorg voor mijn muizen. Dit wormt natuurlifk de basis van alle experimentele data die in dit boekje vermeld staan!

John en Eric, bedankt voor alle creatieve energie die jullie in dit proefschrift hebben gestopt en voon het prachtige onslagontwerp.

Dr. A.M. Duijvestijn, beste Ad, bedankt dat je me hebt gestimuleerd om na mijn afstudeerstage eerst nog eens in een andere keulken te kijken alvorens op de universiteit een AlO-baan te zoeken. Mijn tijd bij de vakgroep Immunologie was erg leerzaam, mede ook door de goede zorgen van Maria. Bedankt allebe!: 
Min familie Erwin en Karen, Henk en Doortje, Petra en Hans (en Joost), Eddy en Simone (en Rick) bedankt woor alte interesse die jullie de afgelopen jaren hebben getoond in de vorderingen die ik maakte ten aanzien van miln proefschrift.

Lieve pap en mam, dit boekje is niet woor niets aan julle opgedragen. Dit proefschift ligt nu woor Sullie door jullie onwoorwaardelikke steun aan mij. Jullie bleven in mij geloven en hebben me het doorzettingsvermogen gegeven om dit project tat een goed einde te brengen. $\mathrm{k}$ hoop dat $\mathrm{k}$ voor mijn eigen kinderen altijd net zo klaar zal kunnen staan zoals jullie voor mil) hebben gedaan (en nog steeds doen].

Mijn allerliefste mannetjes Tycho en Jesse, fullie zinn nu nog te kiein om te begrijpen waarom mama ai die tijd op zolder achter de computer zat. Maar hoe klein jullie ook zinn, door julle komst heb ik leren relativeren en te beseffen welke dingen mu eigenlijk ècht belangrijk zijn in het leven. Ik blị̂f iedere dag wan jullie genieten.

Leve Michel, dit boekje draag ik aan jou op ondat je er altijd voor me bent en voor alle nachtelijke gesprekken die we samen hebben gevoerd als ik weer een dipje had. Wat ik ook besioot, ik wist dat ij onvoorwaardelijk achter me stond en die wetenschap heeft ervoor gezorgd dat ik de energie heb gevonden dit boek te schrijven. Je bent mijn beste vriend, dank je wel dat ik alles met jou mag delen.

Anita 
maar...' was een opmerking die vaak uit jouw mond kwam wanneer ik weet eens in een opvoedkundig ditemma beland was. Viviane, jij hebt me de beginselen van het werken met muizen bigebracht. En als de microscoop even net niet deed wat ik wilde, bracht het 'Viviane-knopje' vaak uitkomst... Prof. Dr. D.W. Slaaf, beste Dick, bedankt voor je kritische blik op mijn proefschrift; bedankt ook dat je zitting wilde nemen in min beoordelingscommissie. Lieve Marc (Eline, Rosa en Myrthel, bedankt voor je vriendschap en de vrolike noot die je aan mijn tijd in Maastricht hebt gegeven. Ik hoop dat we nog erg vaak met zin achten op wakantie gaan! Sietze, Remco en Kim, nog veel succes met jullie eigen promotie, natuurlik onder Marc zin bezielende leiding. Wim, als computer-leek kon ik altijd bij je terecht; bedankt! Marike en Imke, jullie sprankelende aanwezigheïd was als een frisse wind door het lab, bedankt hiervoor en succes met jullie eigen promotie! Andries, Pascial, Ward, Birgit en Richard bedankt voor alle gezellige momenten.

Ik heb, vooral tijdens de eerste jaren vam mijn promotieonderzoek, ook de nodige tijd doorgebracht op het Angiogenese lab. Loes, bedankt voor onze gesprekken en je interesse in mijn onderzoek. Sandra, je hebt me heel wat werk uit handen genomen, bedankt hiervoor. Ik wens je veel succes met je verdere carliere. Lucy, ik vond het erg leuk dat ik je mocht begeleiden tijdens je afstudeerstage. Het was een leerzame tijd; veel sterkte met je eiger promotie en we houden contact! Karolien, ik wens le veel succes en plezier toe met de 'rollende bollen' op de IVM! Jessica, Coen, Judy, Ricardo, Edith, Sietske, Victor, Debby, Femke, Veerle en Nicole bedankt voor jullie interesse en de gezelligheid.

Beste Sander en Petra, onze Kolonistenavondjes zin onvergetelik en hebben gezorgd voor de broodnodige ontspanning in de (soms nachtelijke) uurtjes...

Beste Daniëlle, onze lunches waren een welkome alwisseling toen ik druk aan het schrijven was. Ilk wens jou en Maurice veel geluk met jullie kleine Danique.

Lieve Marieke, we zijn al vriendinnen sinds het gymnasium. Ik ben heel erg blij dat jij en Erik nu dicht bij ons wonen en we weer "ouderwets" naar de film kunnen gaan. Bedankt dat je zo"n lieve vriendin bent en dat je gedeeld hebt in mijn promotiestress. De oerknal houden we erin en mijn appel vergeet ik nlet meer...

Rob (oom Roel), Mark, Grace, Marcel en Miriam, Guido en Rian, Rielette en Martin, Laurine en Jaap, Mant en Jolanda, Marc en Lline, Inge en Frank: als mienden hebben jullie allemaal op jullie elgen manier gezorgd voor ontspanning en plezier, naast het werken aan mijn proefschrift Bedamkt Hiervoon! En Tiank veel succes met je elgen promotie, het gat je echt lakken hoor!

Grag wil ik alle mensen van het CPV van de Universiteit Maastricht bedanken voor de goede zorg voor mila muizen. Dit vormt natuurlijk de basis van alle experimentele data die in dit boekje vermeld stakan!

John en Eric, bedankt voor alle creatieve energle die jullie in dit proefschrift hebben gestopt en voor het prachige omslagontwerp.

Dr. A.M. Duivestijn, beste Ad, bedankt dat je me hebt gestimuleerd om na mijn afstudeerstage eenst nog eens in een andere keuken te kijken alvorens op de universiteit een AlO baan te zoeken. Min tijd bil de vakgroep Immunologle was erg leerzaam, mede ook door de goede zorgen wan Maria, Bedankt allebe! 
Mijn familie Erwin en Karen, Henk en Doortje, Petra en Hans (en Joost), Eddy en Simone (en Rick) bedankt voor alle interesse die jullie de afgelopen jaren hebben getoond in de vorderingen die ik maakte ten aanzien van mijn proefschrift.

Lieve pap en mam, dit boekje is niet voor niets aan jullie opgedragen. Dit proefschrift ligt nu voor jullie door jullie onvoorwaardelijke steun aan mij. Jullie bleven in mij geloven en hebben me het doorzettingsvermogen gegeven om dit project tot een goed einde te brengen. $\mathbb{k}$ hoop dat ik voor mijn eigen kinderen altijd net zo klaar zal kunnen staan zoals jullie voor mij hebben gedaan (en nog steeds doenl.

Mijn allerliefste manneties Tycho en Jesse, jullie zijn nu nog te klein om te begrijpen waarom mama al die tijd op zolder achter de computer zat. Maar hoe klein jullie ook zijn, door jullie komst heb ik leren relativeren en te beseffen welke dingen nu eigenlijk ècht belangrijk zijn in het leven. Ik blijf iedere dag wan jullie genieten.

Lieve Michel, dit boekje draag ik aan jou op omdat je er altijd voor me bent en voor alle nachtelijke gesprekken die we samen hebben gevoerd als ik weer een dipje had. Wat ik ook besloot, ik wist dat jij onvoorwaardelijk achter me stond en die wetenschap heeft ervoon gezorgd dat ik de energie heb gevonden dit boek te schrijven. Je bent mijn beste vriend, dank je wel dat ik alles met jou mag delen.

Anita 


\section{List of Publications}

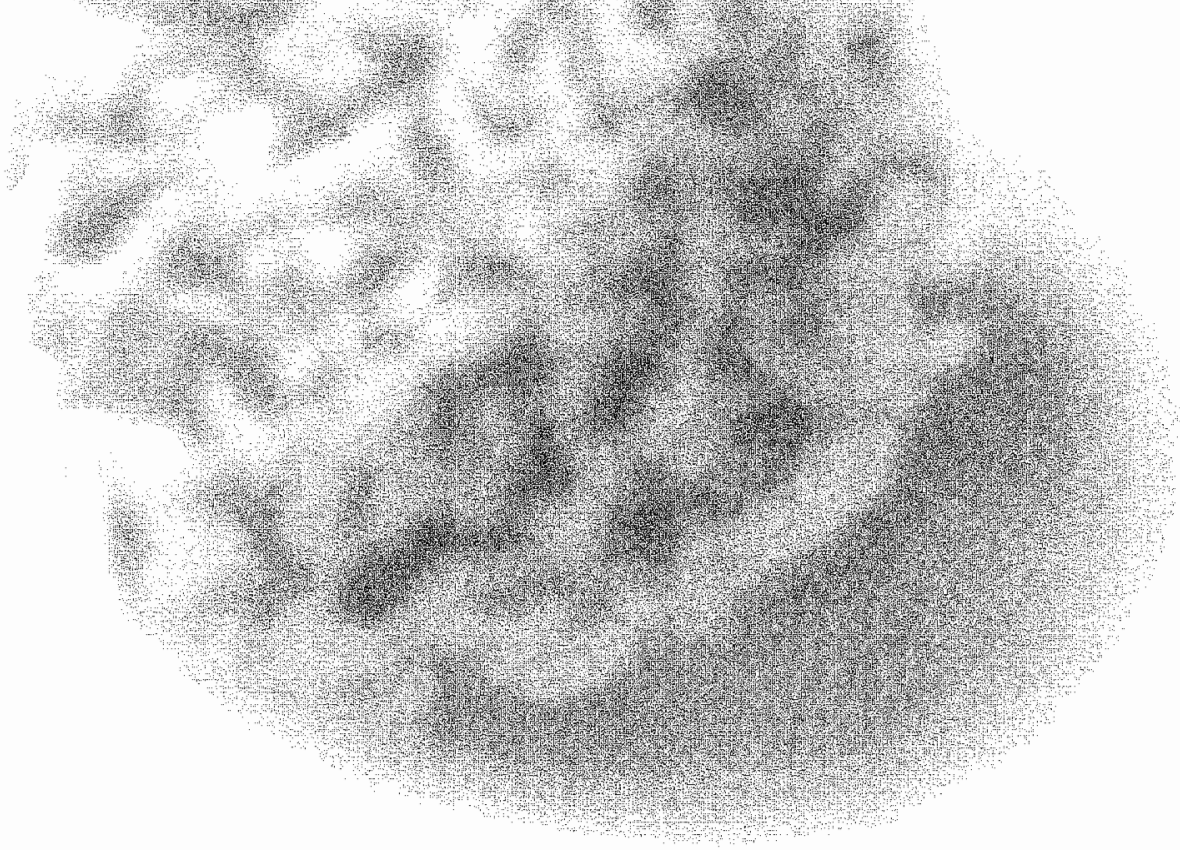




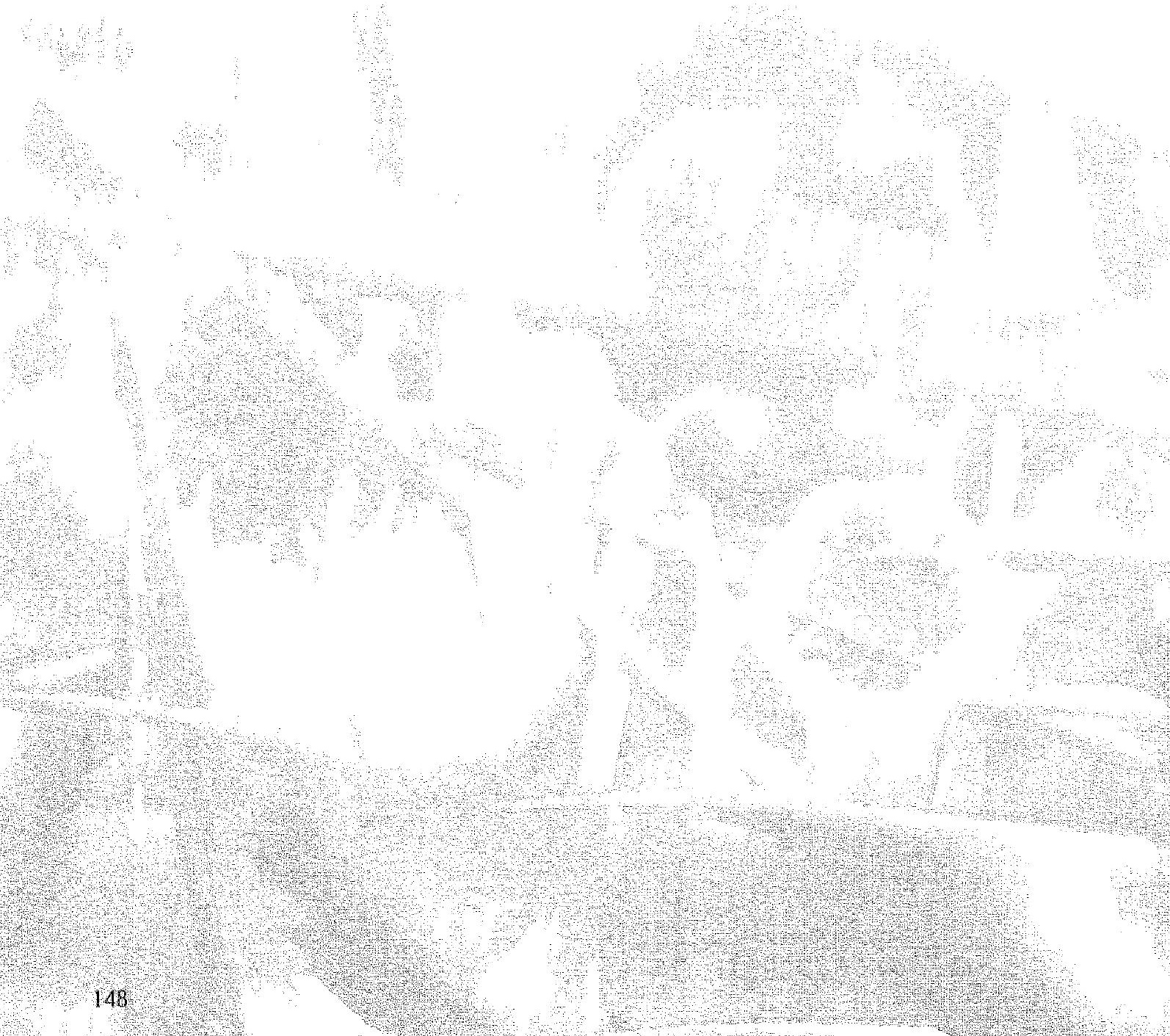




\section{LIST OF PUBLICATIONS}

\section{Full papers}

1 Dirkx AEM, oude Egbrink MGA, Wagstaff J, Griffioen AW. Monocyte/macrophage intutration in tumors: modulators of angiogenesis. 7 . Leukocyte Biol 2000 [accepted].

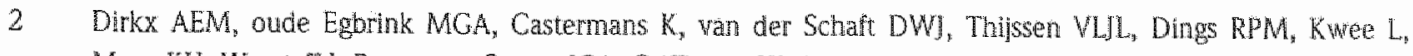
Mayo KH, Wagstaff I, Boumater Steege JCA, Griffoen AW. Amti-anglogenesis therapy can overcome endothelia! cell anergy and promote leukocyte-endothelim interactions and infiltration in tumors. FASEB I. 2000 (accepted).

3 Matzen K, Dirkx AEM, oude Egbrink MGA, Speth C, Götte M, Aschen G, Griffioen AW, Sturzl M. HIV. T. Tat increases the adhesion of monocytes and T.cells to the endothelum in vitro and in vivo: implications for AIDS. associated vasculopathy. Virus Research, 2004;104 (2): 145-155.

Dirkx AEM, oude Egbrink MGA, Kuijpers MJE, wan der Niet ST, Heijnen VTh, Boumater Steege JCA, Wagstaff I, Griffioen AW. Tumor angiogenesis modulates leukocyte-vessel wall interactions in vivo by reducing endothelial adhesion molecule expression. Cancer Research, 2003,63 101, 232222329.

\section{Abstracts and oral presentations}

5 Dirkx AEM, oude Egbrink MGA, Castermans K, Thijssen VLIL, van der Schaft DW, Kwee L, Bouma-ter Steege JCA, Griffioen AW. Anti-angiogenesis therapy can overome endothelial cell anergy and promote leukocyte-vessel wall interactions and inflitration in tumors. First European Conference on Tumor Angiogenesis and Antianglogenic Theory. Angiogenesis 2004,7 (S1), 1-53.

6 Ditkx AEM, oude Egorink MGA, Castermans K, Thijsen VUL, van der Schaft DWI, Kwee L., Boumater Steege JCA, Griffoen AW. Ant-angiogenesis therapy can overcome endothelal call anergy and promote leurocyte endothelium interactions in tumors. The Netherlands Society for Microcirculaton and Vascutar Biology (MWAB 2004 (oral presentation).

Dirkx AEM, oude Egorink MGA, Castermans $K$, Thissen WLL, wan der Schaft DW, Kwee L, Bouma ICA and Grifioen AW. Antiangogenests therpy can overcome endothelat cell anergy and pronote leukocytevessel wall interactions and influtation hamors. I VaSC Res 41/52/:22, 2004.

Dirk. AEM, oude Egbrink MGA, Kujpers ME, van der Net ST, Heinen VTh, Botmater Stege JCA, Wagstalf J. Gitfoen AW. Tumor angogenesis nodulates leukocytevessel wall interactions in retation to tumor size. of Euregtonal Oncology Meeting 2002 foral presentationi.

9 Dirkx AEM, oude Egbrink MGA, Kuipers MIE, wan der Nie ST, Heinen WTh, Bouma-ter Steege JCA, Wagktaft 1. Griffoen AW. Tumor angogenesis modulates leukochte-vessel wall interactions in relation to tumon size. The Dutch Society for Whochoulation and Vascular Bology fMTAB) 2002 loral presentation. 
10 Dinx AEM, oude Eghrink MGA, Kujpers ME, van der Net ST, Heinen VTh, Bouma-ter Steege ICA, Wagtauf 1. Grifficen AW. Turnor angogenesis modulates leukocyte-vessel wall interactions in relation to tumor size. 13 Endothelial Celf Research Symposium 200 l loral presentationj.

11 Dirkx AEM, oude Egbrink MGA, Kuipers MIE, Tromp SC, van der Niet ST, Wagstaff J, Griffioen AW. Tumour anglogenesis modulates leukocyle-vessel wall interactons. Benelux \& Dutch Soctety for Microcirculation 2001 foraf presentation.

12 AEM Dirkx, MGA oude Eghrink, ME Kuipers, ST van der Niet, I Wagstaff and AW Griffioen. Reduced leukocyte adhesion in vivo in the presence of a tumor. Proceedings of the $7^{\text {th }}$ World Congress for Microcilculation, Sydney, 2001. 


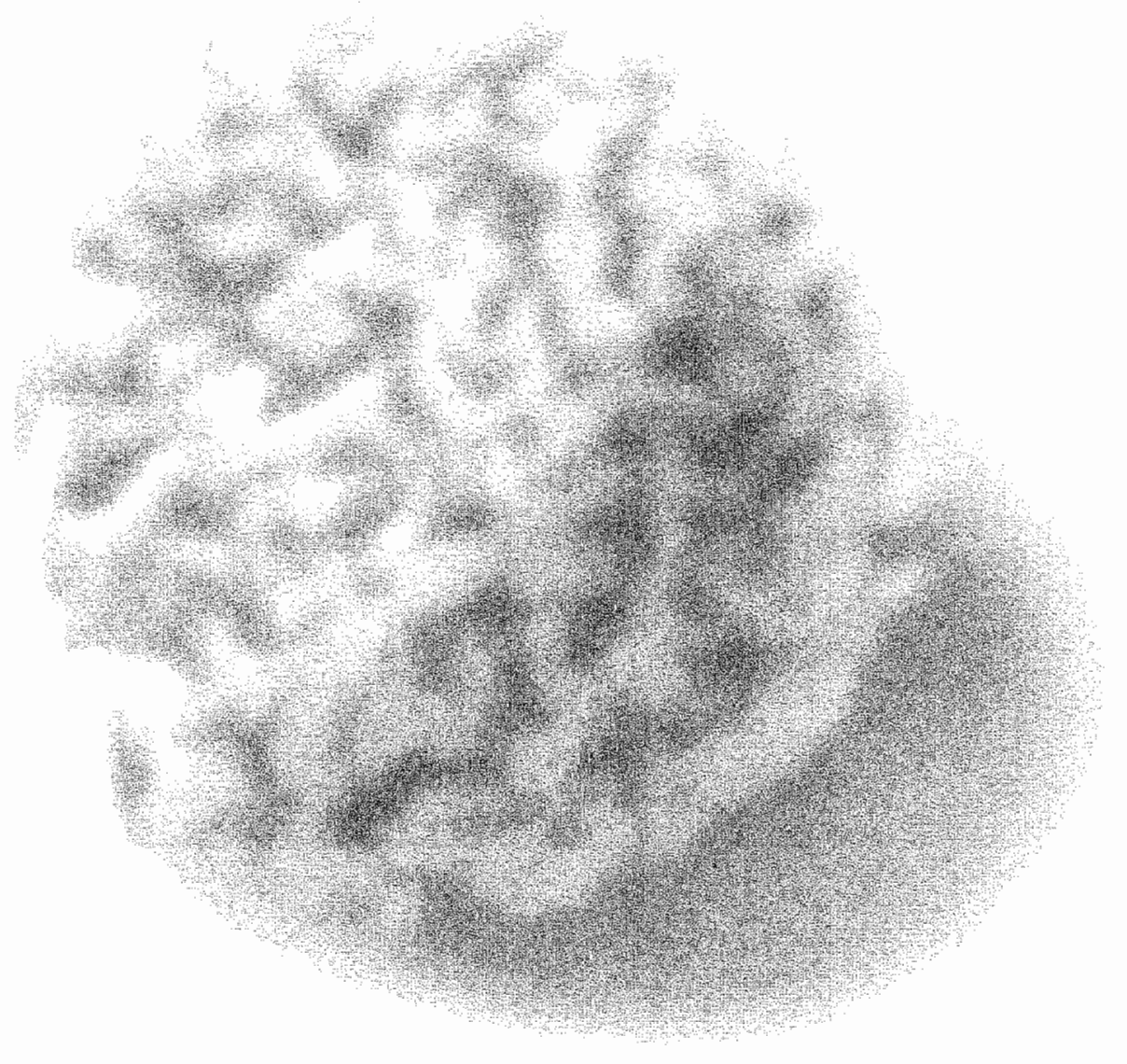

